\title{
Diversity and composition of tree communities in the mosaic landscape of north-eastern Madagascar
}

\author{
Dissertation \\ to attain the doctoral degree \\ Doctor rerum naturalium „Dr. rer. nat.“ \\ of the faculty of Forest Science and Forest Ecology \\ at the Georg-August-University Göttingen
}

Submitted by

Kristina Anna Charlotte Osen (M.Sc.)

Born on 15.06.1987 in Offenburg (Ortenaukreis)

Göttingen, September 2021 


\section{Thesis committee}

Prof. Dr. Dirk Hölscher

Prof. Dr. Holger Kreft

Prof. Dr. Teja Tscharntke

Prof. Dr. Ingo Grass
Tropical Silviculture and Forest Ecology, University of Goettingen, Germany Biodiversity, Macroecology and Biogeography, University of Goettingen, Germany Agroecology, Department of Crop Sciences, University of Goettingen, Germany Department of Ecology of Tropical Agricultural Systems, Institute of Agricultural Sciences in the Tropics, University of Hohenheim, Germany

\section{Examination board}

1. Referee:

2. Referee:

Additional members of the examination board:
Prof. Dr. Dirk Hölscher

Prof. Dr. Holger Kreft

Prof. Dr. Teja Tscharntke;

Prof. Dr. Ingo Grass

Date of oral examination: $15^{\text {th }}$ November 2021 


\section{Summary}

In Madagascar, a large percentage of the rural human population faces multifaceted poverty and depends on agriculture and natural resources as main livelihood sources. Consequently, the country's biodiverse natural ecosystems experience high land-use pressure. Especially the north-eastern rainforests comprise a remarkable diversity of trees species with high endemism rates but face rapid transformation into a human-modified mosaic landscape. This human-modified mosaic landscape in north-eastern Madagascar still contains a small share of protected old-growth forest and is otherwise composed of smallholder agricultural land, forest fragments, and smallholder agroforests to cultivate Madagascar's major export product vanilla. In these agroforests, trees are permanently integrated into the crop cultivation system either as shade trees or as support trees for the climbing vanilla orchid (Vanilla planifolia). Vanilla agroforests cover a wide range of structural and compositional characteristics and might offer promising land use options to reconcile biodiversity conservation with production goals in north-eastern Madagascar. Since evidence on the social and environmental benefits and tradeoffs of vanilla agroforestry has been scarce so far, the research project "Diversity Turn in Land Use Science" addresses this research gap. Within the frame of the Diversity Turn project, this thesis addresses the conservation value of agroforests by examining the diversity, stand structure, and composition of tree communities in vanilla agroforests and contrasting them to other tree-based land-use types in the mosaic landscape of northeastern Madagascar. To do so, this thesis first establishes a conceptual framework on agroforestry systems and then works through the individual aspects of this framework, using case studies on species diversity and stand structure, species composition, support tree diversity, and aboveground carbon stocks. The case studies build on tree inventory data from vanilla agroforests of contrasting land-use history, old-growth forests, forest fragments, and woody fallows after slash-and-burn shifting cultivation, which all contribute to the smallholder mosaic landscape of north-eastern Madagascar.

The conceptual study (chapter 1) elaborates that tropical agroforests differ in land-use history and may be either established inside a forest or on open land but this difference is often neglected in agroforestry research and policy. Based on literature data and an example from own tree inventories, the study shows that agroforests of contrasting land-use history differ in biodiversity, ecosystem functions, and services. The study suggests that the differentiation based on land-use history might be applicable in various regions and agroforestry systems, to better align landscape management with conservation goals. 
Chapter 2 analyses the stand structure and species diversity of trees in the different land-use types of the smallholder mosaic landscape. Therein, the study puts a special focus on how land-use history affects stand structure and species diversity in vanilla agroforests and demonstrates that forest-derived agroforests are important for maintaining habitat structure and tree diversity, whereas fallow-derived agroforests offer tree cover rehabilitation opportunities on open but formerly forested land.

Chapter 3 quantifies the variation of tree species communities within and among different land-use types in the mosaic landscape. The study uses beta-diversity metrics that reflect changes in both species composition and abundance in these different land-use types and demonstrates that (thus far) many tree species can persist in this mosaic landscape. However, turnover rates are high within and between tree communities in the land-use types, indicating that tree communities are transforming both in identity and abundance. The study endorses the implementation of conservation and restoration activities to maintain the unique tree species assemblages in the human-modified mosaic landscape and suggests the establishment of agroforests on formerly forested degraded land as an entry point. However, the study emphasizes considering the high turnover rates of tree species communities in the planning of such activities.

Chapter 4 focuses on the diversity and composition of agroforest-support trees, which have received little scientific attention so far. The study builds on support tree inventory data and farmer interviews from vanilla agroforests of contrasting land-use history. The study analyses the species diversity, composition, and geographic origin of support trees in these vanilla agroforests and shows that support trees substantially contribute to the tree diversity in these agroforests, but show clear differences based on land-use history: support trees in forest-derived agroforests encompass many native and endemic species richness and have four times higher species richness compared to fallow-derived agroforests, which harbor a high share of introduced species. Since fallow-derived vanilla agroforests can play an important role in restoration and rehabilitation, the study suggests a stronger consideration of native or endemic tree species in new to establish vanilla agroforests.

Chapter 5 estimates aboveground carbon stocks across stem diameters and geographic origin of tree species in the different land-use types of the smallholder mosaic landscape. Therein, the study particularly analyses how land-use history influences aboveground carbon stocks in agroforestry systems. The study demonstrates that agroforests can act as carbon reservoirs in a multifunctional landscape, but considering their land-use history and management is important to maximize their benefits: forest-derived agroforests support higher aboveground carbon stocks than fallow-derived agroforests and have the 
potential to maintain a forest-like structure with native and endemic trees in the landscape, whereas fallow-derived agroforests take land out of the slash-and-burn cycle by converting it into permanent treedominated land-use systems.

In conclusion, the studies within this thesis contribute to refining the conservation evaluation of tropical agroforests and provide data-based evidence to assess the conservation value of vanilla agroforests in the mosaic landscape of north-eastern Madagascar. The thesis sheds light on the diversity, composition, and stand structure of tree communities in the mosaic landscape of north-eastern Madagascar and thereby provides vital information to quantify and understand the consequences of land-use change in this tropical landscape. Such understanding is essential to develop land-use management schemes and conservation measures that aim to maintain species diversity, ecosystem functions, and services and is thus important for research and applied conservation alike. 


\section{Zusammenfassung}

In Madagaskar ist ein Großteil der ländlichen Bevölkerung von Armut betroffen und ist damit auf kleinbäuerliche Landwirtschaft und die Nutzung natürlicher Ressourcen zur Grundversorgung angewiesen. Folglich sind die natürlichen und artenreichen Ökosysteme des Landes einem hohen Landnutzungsdruck ausgesetzt. Vor allem die Regenwälder im Nordosten des Landes weisen eine bemerkenswerte Vielfalt an Baumarten und eine hohe Endemismusrate auf, sind jedoch von einer raschen Umwandlung in eine von Menschen veränderte Mosaiklandschaft bedroht. In dieser Mosaiklandschaft im Nordosten Madagaskars findet sich noch ein kleiner Anteil geschützter alter Wälder, ansonsten setzt sich die Landschaft aus einem Mosaik landwirtschaftlicher Flächen, Waldfragmente und Agroforste zusammen. Diese Agroforste dienen dem kleinbäuerlichen Anbau von Gewürzvanille, die Madagaskars wichtigstes Exportprodukt darstellt. In diesen Agroforsten spielen Bäume eine entscheidende Rolle. Sie werden entweder als Schattenbäume oder als Stützbäume für die kletternde Vanille-Orchidee (Vanilla planifolia) dauerhaft in das Anbausystem integriert. Vanille-Agroforste decken bezüglich ihrer Struktur und ihrer Artenzusammensetzung ein breites Spektrum ab. Somit weisen sie vielversprechende Landnutzungsoptionen auf, um die Erhaltung der biologischen Vielfalt mit den Produktionszielen im Nordosten Madagaskars in Einklang zu bringen. Da es bisher nur wenige Belege gibt, die eine soziale und ökologische Bewertung der Vanille-Agroforstwirtschaft erlauben, befasst sich das Forschungsprojekt "Diversity Turn in Land Use Science" mit dieser Forschungslücke. Im Rahmen des Diversity Turn-Projekts befasst sich die vorliegende Doktorarbeit mit dem Naturschutzwert von Agroforsten, indem sie die Vielfalt, Bestandsstruktur und Zusammensetzung von Baumgemeinschaften in Vanille-Agroforsten untersucht und sie mit anderen baumbasierten Landnutzungstypen in der Mosaiklandschaft im Nordosten Madagaskars vergleicht. Um dies zu erreichen, entwickelt die vorliegende Doktorarbeit zunächst einen konzeptionellen Rahmen, der eine Naturschutzbewertung von Agroforstsystemen erleichtert. Anschließend werden einzelne Aspekte dieses konzeptionellen Rahmens anhand von Fallstudien untersucht. Die Fallstudien setzen unterschiedliche Schwerpunkte und decken damit ein umfassendes Spektrum ab, das von der Baumartenvielfalt und Bestandsstruktur, über die Baumartenzusammensetzung, die Vielfalt der Agroforst-Stützbäume bis zur Erfassung des oberirdischen Kohlenstoffbestands reicht. Die Fallstudien stützen sich auf Bauminventurdaten, die in VanilleAgroforsten mit unterschiedlicher Landnutzungsgeschichte erhoben wurden, sowie in weitgehend ungestörten Wäldern, Waldfragmenten und holzigen Brachflächen, die alle Teil der kleinbäuerlichen Mosaiklandschaft im Nordosten Madagaskars sind. 
In der konzeptionellen Studie (Kapitel 1) wird zunächst dargelegt, dass sich tropische Agroforste in ihrer Landnutzungsgeschichte unterscheiden: sie können entweder im Wald oder auf Brachland angelegt werden. Jedoch wird dieser Unterschied in der Agroforstforschung und -politik bisher kaum beachtet. Auf der Grundlage von Literaturdaten und einem Beispiel aus eigenen Bauminventurdaten zeigt die Studie, dass sich Agroforste mit unterschiedlicher Landnutzungsgeschichte in Bezug auf biologische Vielfalt, Ökosystemfunktionen und Ökosystemdienstleistungen unterscheiden. Die Studie legt nahe, dass die Unterscheidung basierend auf der Landnutzungsgeschichte in verschiedenen Regionen und Agroforstsystemen anwendbar sein könnte, um lokale Naturschutzziele und Landschaftsmanagement besser aufeinander abzustimmen.

Kapitel 2 analysiert die Bestandsstruktur und die Artenvielfalt von Bäumen in den verschiedenen Landnutzungstypen der kleinbäuerlichen Mosaiklandschaft. Dabei steht insbesondere im Fokus, wie sich die Landnutzungsgeschichte in Vanille-Agroforsten auf deren Bestandsstruktur und die Baumartenvielfalt auswirkt: die Studie zeigt, dass Agroforste, die im Wald etabliert wurden, wichtig für die Erhaltung der Lebensraumstruktur und der Baumvielfalt sind, während Agroforste, die auf Brachland etabliert wurden, eine Möglichkeit zur Wiederherstellung der Baumbestände auf diesen ehemals bewaldeten Brachflächen bieten.

Kapitel 3 quantifiziert die Vielfältigkeit und Zusammensetzung der Baumartengemeinschaften innerhalb und zwischen verschiedenen Landnutzungstypen in der Mosaiklandschaft. Die Studie verwendet BetaDiversitätsmaße, die Veränderungen in der Baumartenzusammensetzung und -häufigkeit in diesen verschiedenen Landnutzungstypen widerspiegeln, und zeigt, dass (bis jetzt) viele Baumarten in dieser Mosaiklandschaft überleben können. Allerdings sind die Fluktuationsraten innerhalb und zwischen den Baumgemeinschaften in den verschiedenen Landnutzungstypen hoch, was darauf hindeutet, dass sich die Baumgemeinschaften sowohl in ihrer Identität als auch in ihrem Abundanz verändern. Die Studie befürwortet die Durchführung von Maßnahmen zur Aufforstung und Renaturierung ehemals bewaldeten Brachlands, um die einzigartigen Baumartengemeinschaften in der vom Menschen veränderten Mosaiklandschaft zu erhalten, und schlägt als Einstieg die Etablierung von Agroforsten auf ehemals bewaldeten Brachflächen vor. Die Studie betont jedoch, dass die hohe Fluktuationsrate von Baumartengemeinschaften bei der Planung solcher Aktivitäten zu berücksichtigen ist.

Kapitel 4 befasst sich mit der Vielfalt und Zusammensetzung von Agroforst-Stützbäumen, denen bisher wenig wissenschaftliche Aufmerksam zukam. Die Studie stützt sich auf Daten aus der Bestandsaufnahme von Agroforst-Stützbäumen in Vanille-Agroforsten mit unterschiedlicher Landnutzungsgeschichte, sowie 
auf Befragungen der Besitzer:innen der jeweiligen Vanille-Agroforste. Die Studie analysiert die Artenvielfalt, die Zusammensetzung und die geographische Herkunft der Stützbäume in diesen VanilleAgroforsten und zeigt, dass Stützbäume wesentlich zur Baumvielfalt dieser Agroforste beitragen, aber abhängig von der Landnutzungsgeschichte werden deutliche Unterschiede zwischen StützbaumBeständen sichtbar: Stützbäume in Agroforsten, die im Wald etabliert wurden, umfassen viele einheimische und endemische Stützbaumarten und weisen einen viermal höheren Artenreichtum auf als Agroforste, die auf Brachland etabliert wurden und einen hohen Anteil an eingeführten Stützbaumarten beherbergen. Da auf Brachland etablierte Vanille-Agroforste eine wichtige Rolle bei der Aufforstung und Renaturierung ehemals bewaldeten Brachlands spielen können, empfiehlt die Studie bei deren Etablierung verstärkt auf einheimische oder endemische Baumarten als Stützbäume zurück zu greifen.

Kapitel 5 quantifiziert die oberirdischen Kohlenstoffvorräte in den verschiedenen Landnutzungstypen der kleinbäuerlichen Mosaiklandschaft. Dabei wird insbesondere analysiert, wie die Landnutzungsgeschichte die oberirdischen Kohlenstoffvorräte in Agroforstsystemen beeinflusst. Die Studie zeigt, dass Agroforste als Kohlenstoffspeicher in einer multifunktionalen Landschaft fungieren können, dass es aber wichtig ist, ihre Landnutzungsgeschichte und ihre Bewirtschaftung zu berücksichtigen, um ihren Naturschutzwert zu maximieren: Agroforste, die im Wald etabliert wurden, weisen größere oberirdischen Kohlenstoffvorräten auf und haben das Potenzial, eine waldähnliche Struktur mit einheimischen und endemischen Bäumen in der Landschaft zu erhalten, während Agroforste, die auf Brachland etabliert wurden, dieses ehemalig bewaldete Brachland in dauerhaft baumdominierte Landnutzungssysteme zurückführen.

Zusammenfassend tragen die Studien im Rahmen dieser Doktorarbeit dazu bei, die ökologische Bewertung tropischer Agroforste zu verbessern. Die Studien liefern datengestützte Erkenntnisse aus Fallstudien in der Mosaiklandschaft im Nordosten Madagaskars, welche die ökologische Bewertung der Vanille-Agroforstwirtschaft in dieser Region ermöglichen. Die vorliegende Doktorarbeit beleuchtet die Vielfalt, die Zusammensetzung und die Bestandsstruktur von Baumgemeinschaften in der Mosaiklandschaft im Nordosten Madagaskars und liefert damit wichtige Informationen, um die Folgen von Landnutzungsänderungen in dieser tropischen Landschaft zu quantifizieren und zu verstehen. Ein solches Verständnis ist unerlässlich für die Entwicklung von regional angepassten Landnutzungsplänen und Schutzmaßnahmen, die darauf abzielen, die Artenvielfalt, Ökosystemfunktionen und Ökosystemdienstleistungen zu erhalten, und ist somit sowohl für die Forschung als auch für den angewandten Naturschutz von hohem Wert. 


\section{Chapter overview}

The core of this thesis is composed of five manuscripts (chapter 1-5). The author of this thesis, Kristina Osen (KO), was either leading the preparation of these manuscripts or substantially supported their preparation on several stages.

Chapter 1: $\quad$ Conceptual paper

\section{Land-use history determines ecosystem services and conservation value in tropical agroforestry}

Dominic A. Martin, Kristina Osen, Ingo Grass, Dirk Hölscher, Teja Tscharntke, Annemarie Wurz, Holger Kreft

Manuscript status: Published in Conservation Letters; https://doi.org/10.1111/conl.12740

Permission to reuse this published article: This is an open access article distributed under the terms of the Creative Commons CC BY license, which permits unrestricted use, distribution, and reproduction in any medium, provided the original work is properly cited.

Contribution: KO essentially contributed to the conceptualization, visualization and writing of this manuscript

Chapter 2: $\quad$ Case study

Land-use history determines stand structure and tree diversity in vanilla agroforests of northeastern Madagascar

Kristina Osen; Marie Rolande Soazafy; Dominic A. Martin; Annemarie Wurz; Adriane März; Hery Lisy Tiana Ranarijaona, Dirk Hölscher

Manuscript status: Published in Applied Vegetation Science; https://doi.org/10.1111/avsc.12563

Permission to reuse this published article: This is an open access article distributed under the terms of the Creative Commons CC BY license, which permits unrestricted use, distribution, and reproduction in any medium, provided the original work is properly cited.

Contribution: KO conceptualized the study, collected, cleaned, analyzed and visualized the data and was the lead author of this manuscript 
Chapter 3: $\quad$ Case study

High species turnover in tree communities in the mosaic landscape of northeastern Madagascar

Kristina Osen; Marie Rolande Soazafy; Dominic A. Martin; Annemarie Wurz; Patrice Antilahimena; Hery Lisy Tiana Ranarijaona, Dirk Hölscher

Manuscript status: Advanced draft

Contribution: KO conceptualized the study, collected, cleaned, analyzed and visualized the data and was the lead author of this manuscript.

Chapter 4: $\quad$ Case study

Support trees in vanilla agroforests of Madagascar: diversity, composition and origin Johannes Osewold; Yevgeniya Korol; Kristina Osen; Marie Rolande Soazafy; Thorien Rabemanantsoa; Dominic A. Martin; Annemarie Wurz; Dirk Hölscher Manuscript status: author-submitted article (in peer-review) Contribution: KO essentially contributed to the conceptualization, data collection and writing of this manuscript.

Chapter 5: Case study

Aboveground carbon stocks in Madagascar's vanilla production landscape - exploring rehabilitation by agroforestry in the light of land-use history

Marie Rolande Soazafy \& Kristina Osen; Annemarie Wurz; Estelle Raveloaritiana; Dominic A. Martin; Hery Lisy Tiana Ranarijaona, Dirk Hölscher

Manuscript status: Published in Global Ecology and Conservation;

https://doi.org/10.1016/j.gecco.2021.e01853

Permission to reuse this published article: This is an open access article distributed under the terms of the Creative Commons CC BY license, which permits unrestricted use, distribution, and reproduction in any medium, provided the original work is properly cited. 
Contribution: $\mathrm{KO}$ and Marie Rolande Soazafy contributed equally to this manuscript and share first-authorship. KO essentially contributed to the conceptualization of the study, and to collect, clean, analyze and visualize the data and led the writing of this manuscript. 


\section{Table of Contents}

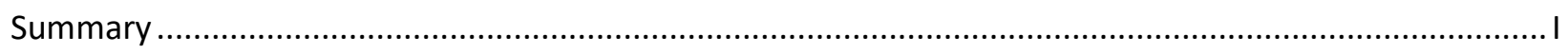

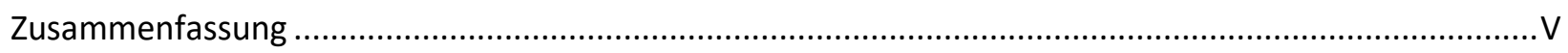

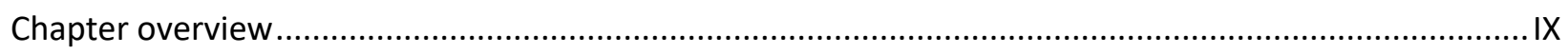

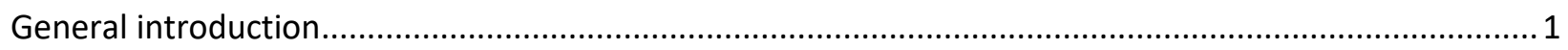

Chapter 1: Conceptual study: Land-use history in tropical agroforestry ............................................ 5

Chapter 2: Case study: Tree diversity and stand structure in the mosaic landscape .............................21

Chapter 3: Case study: Tree composition in the mosaic landscape .................................................. 43

Chapter 4: Case study: Support tree diversity in vanilla agroforests ...............................................67

Chapter 5: Case study: Aboveground carbon stocks in Madagascar's vanilla production landscape .........83

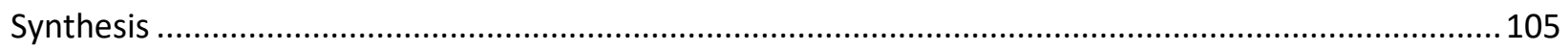

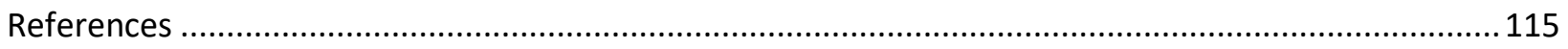

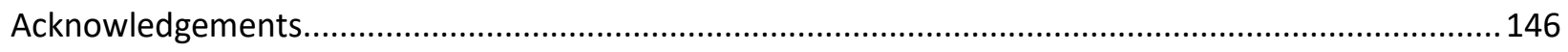

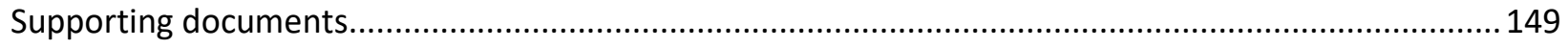





\section{General introduction}

Tropical forests hold a large share of the global terrestrial biodiversity and provide essential services to society (Corlett \& Primack, 2008; Gibson et al., 2011; Watson et al., 2018); yet, these forests are subject to interacting stressors such as deforestation and climate change (Barlow et al., 2018). Growing demand for land, food, fiber, timber, and other ecosystem goods is driving deforestation and agricultural expansion and transforming natural landscapes into human-modified landscapes (Foley et al., 2005; Green et al., 2005; Ramankutty et al., 2018; Winkler et al., 2021). This transformation involves habitat replacements and habitat losses that strongly affect biodiversity (Arroyo-Rodríguez et al., 2017; Barnes et al., 2014; IPBES, 2019; Newbold et al., 2020). This calls for land-use management schemes and conservation measures that slow down, halt or reverse such dynamics, to maintain species diversity, ecosystem functions, and services without risking food security (Foley et al., 2005; Grass et al., 2019; IPBES, 2019; Melo et al., 2013; Tscharntke et al., 2012). In this context, smallholder agroforests are promising candidates for such sustainable land-use options, as they permanently integrate trees into agricultural land while generating revenues for smallholder farmers (Bhagwat et al., 2008; Schroth, 2004; Waldron et al., 2017). However, the ecological integrity of agroforests is strongly influenced by the diversity and abundance of trees, as trees represent key structural and functional elements of tree-based ecosystems and directly or indirectly connect many ecosystem functions and species groups (Manning et al., 2006; Schuldt et al., 2018). Therefore, the ecological integrity of agroforests is highest if their stand structure resembles the stand structure and species composition of neighbouring natural forests (Barrios et al., 2018; Moguel \& Toledo, 1999). Thus, trees are key structural and functional elements of tree-based ecosystems and therefore play a central ecological and socio-economic role (Gibbons et al., 2008; Manning et al., 2006; Reed et al., 2017; Tscharntke et al., 2011). Additionally, trees provide many ecosystem services such as carbon storage and sequestration (Albrecht \& Kandji, 2003; De Beenhouwer et al., 2016), the improvement of soil health erosion control, or water infiltration (Castle et al., 2021). However, trade-offs may exist, such as a reduction in the area of crop production, yield losses or competition for water and nutrients (Blaser et al., 2018; Castle et al., 2021). Thus, it is important to adapt the choice of trees and management schemes to the local context, in order to minimize trade-offs, and maximize synergies (Barrios et al., 2018).

Madagascar is home to more than 2900 endemic tree species which are defined by having a narrow distribution limited to a single country. As such, the tree endemicity rate of $93 \%$ is very high, but at the same time, an alarming share of $63 \%$ of these endemic species is currently listed as threatened, following 
the IUCN criteria (Beech, Rivers, et al., 2021; BGCl, 2021). Within Madagascar, the tree species are not equally distributed, and almost half of the country's tree diversity occurs in the forests and humanmodified landscapes of the Northeast (Beech, Rivers, et al., 2021). Therein, protected areas play an important role to conserve the Malagasy tree species diversity, but many threatened endemic species occur entirely outside the protected area network (Beech, Rivers, et al., 2021). The north-eastern landscape is therefore an area of high conservation value and requires a particular need to apply and expand tree conservation efforts to avoid species loss, which will also benefit livelihoods (Beech, Rivers, et al., 2021).

To date, north-eastern Madagascar still holds the highest percentage of forest cover compared to the rest of the island, but deforestation rates are constantly high (Vieilledent et al., 2018) and the remaining forests face rapid transformation into a human-modified mosaic landscape, driven by a combination of agricultural practices and a diverse range of political, economic, cultural, demographic, and environmental factors (Scales, 2014). This intensifies the call for land-use options that maintain as much natural forest cover as possible without jeopardizing food safety and human wellbeing (Jones et al., 2019). In this context, smallholder agroforests to cultivate the spice vanilla are promising candidates for such sustainable land-use options in north-eastern Madagascar: vanilla agroforests are composed of a variety of tall trees that form the canopy above the vanilla orchid (Vanilla planifolia) and small-statured trees that support the vanilla vines as a climbing structure (Havkin-Frenkel \& Belanger, 2018; Osterhoudt, 2017). At the same time, vanilla is Madagascar's major export product (OEC, 2021), so these agroforests can generate significant revenues for smallholder farmers and more than $80 \%$ of rural households in the study region engage in vanilla farming (Hänke et al., 2018).

Consequently, vanilla agroforests might offer promising land use options to reconcile biodiversity conservation with production goals in north-eastern Madagascar, but evidence on the social and environmental benefits and tradeoffs of vanilla agroforestry has been scarce so far. For this reason, the research project "Diversity Turn in Land Use Science" started off in 2016 to address this research gap from different angles. The "Diversity Turn" project initially followed an inter- and transdisciplinary research approach, closely associated with a circle of local stakeholders composed of NGOs, researchers, vanilla farmers, intermediaries, and exporters in north-eastern Madagascar. This knowledge exchange provided valuable context and served as a basis to develop the respective disciplinary research questions. The mixed team of German and Malagasy researchers from different disciplines then used economic, agronomic, sociologic, and ecologic approaches to study the cultivation, preparation, trade, and the 
environmental performance of vanilla as a cash crop, in comparison to alternative subsistence agricultural land-use options such as paddy rice or hill rice. Within this project scope, the team of ecologists conducted a standardized large-scale multi-taxa survey to evaluate the potential of vanilla agroforests for maintaining native and endemic biodiversity. Therefore, the ecologist team established research plots in vanilla agroforests, old-growth forests, forest fragments, woody fallows and herbaceous fallows after slash-and-burn shifting cultivation, and rain-fed rice paddies that all form part of the human-modified mosaic landscape. On these plots, the team jointly assessed the diversity of trees, herbaceous plants, reptiles, amphibians, birds, butterflies, and ants, to detect and quantify diversity patterns.

Within this ecological framework, this thesis focuses specifically on trees and the individual studies in this thesis build exclusively on data from the tree-dominated land-use types: vanilla agroforests, old-growth forests, forest fragments and woody fallows after slash-and-burn shifting cultivation. Thereby, this thesis addresses the conservation value of agroforests by examining the diversity, stand structure, and composition of tree communities in vanilla agroforests and contrasting them to other tree-based landuse types in the mosaic landscape. To do so, this thesis first establishes a conceptual framework on agroforestry systems and then works through the individual aspects of this framework, using case studies on tree alpha-diversity, tree beta-diversity, support-tree diversity, and aboveground carbon stocks.

Lastly, the synthesis chapter of this thesis connects all study results and integrates them into the larger conservation context. This knowledge can ultimately feed into the development of biodiversity-friendly land-use practices and management plans, that benefit biodiversity conservation, rural livelihoods and climate change mitigation and adaptation and hence contribute to the long-term sustainability of the mosaic landscape. 


\section{Chapter 1: Conceptual study: Land-use history in tropical agroforestry}

Manuscript title: Land-use history determines ecosystem services and conservation value in tropical agroforestry

Authors: Dominic A. Martin, Kristina Osen, Ingo Grass, Dirk Hölscher, Teja Tscharntke, Annemarie Wurz, Holger Kreft

Manuscript status: Published in Conservation Letters; https://doi.org/10.1111/conl.12740

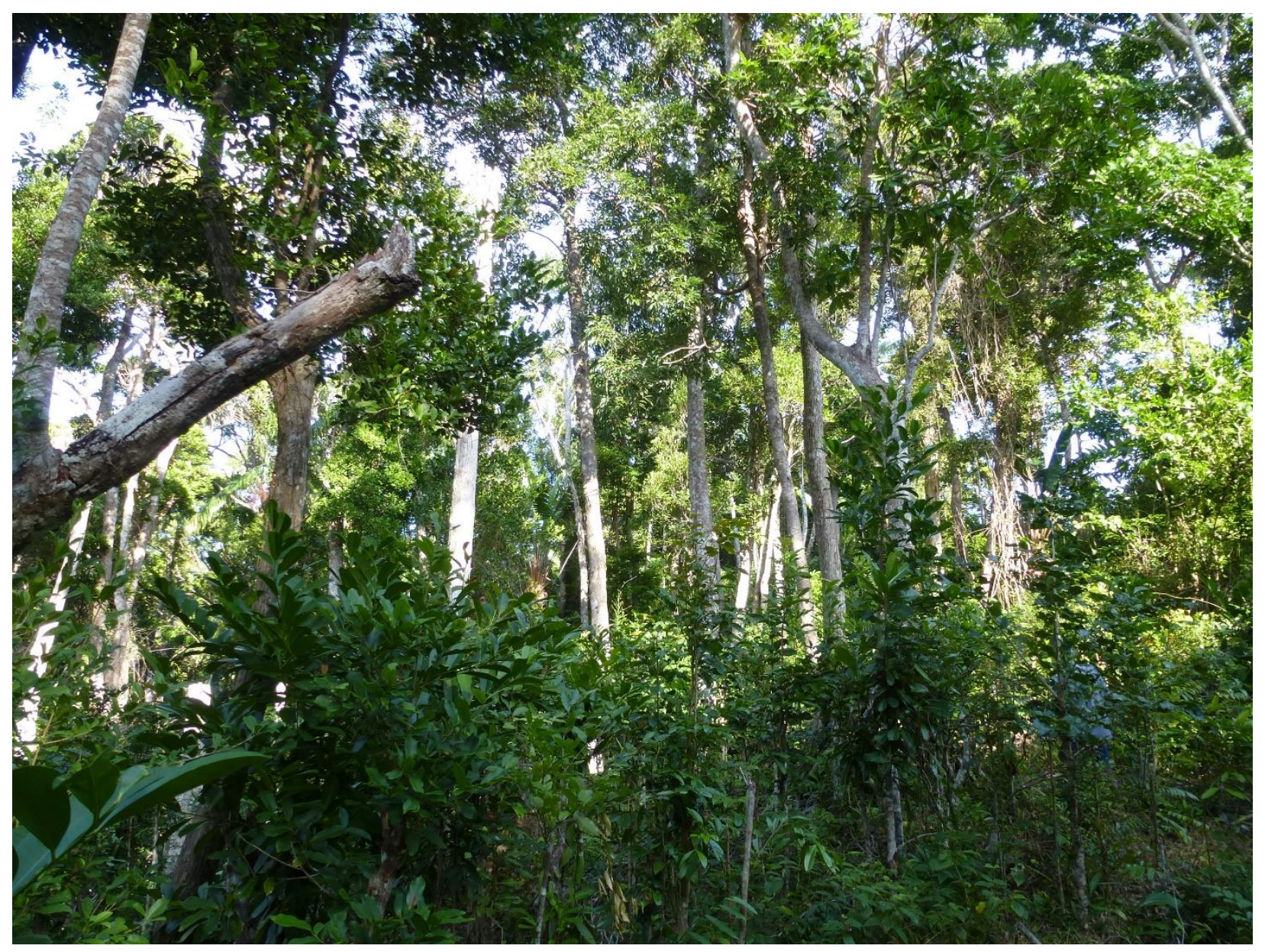




\begin{abstract}
Agroforestry is widely promoted as a potential solution to address multiple UN Sustainable Development Goals, including zero hunger, responsible consumption and production, climate action and life on land. Nonetheless, agroforests in the tropics often result from direct forest conversions, displacing rapidly vanishing and highly biodiverse forests with large carbon stocks, causing undesirable trade-offs. Scientists thus debate whether the promotion of agroforestry in tropical landscapes is a sensible policy. So far, this debate typically fails to consider land-use history, that is, whether an agroforest is derived from forest or from open land. Indeed, $57 \%$ of papers that we systematically reviewed did not describe the land-use history of focal agroforestry systems. We further find that forest-derived agroforestry supports higher biodiversity than open-land-derived agroforestry but essentially represents a degradation of forest, whereas open-land-derived agroforestry rehabilitates formerly forested open land. Based on a conceptual framework, we recommend to 1) promote agroforestry on suitable open land, 2) maintain tree cover in existing forest-derived agroforests and 3) conserve remaining forests. Land-use history should be incorporated into land-use policy to avoid incentivizing forest degradation and to harness the potential of agroforestry for ecosystem services and biodiversity.
\end{abstract}

Keywords: biodiversity, cacao, carbon stocks, coffee, ecosystem services, forest-derived agroforestry, land-use history, open-land-derived agroforestry, rehabilitation, restoration

\title{
Introduction
}

Agroforestry is often promoted in global initiatives as a way to simultaneously address multiple UN Sustainable Development Goals (van Noordwijk et al., 2018). Among them Zero Hunger (Goal 2), Responsible Consumption and Production (Goal 12), Climate Action (Goal 13), and Life on Land (Goal 15). Embedded in this context, the UN Decade on Ecosystem Restoration (2021-2030) emphasizes the opportunity to plant trees in agroforestry systems as a way to reverse land degradation and restore ecosystems, thereby contributing to climate change mitigation. However, the concept of agroforestry as an association of trees with crops or livestock on the same land (FAO, 2017) embraces a broad range of systems under different management schemes: Many important perennial agroforestry crops, such as cacao or coffee, can be farmed underneath shade trees. Such agroforests may be established on open land or inside forest (Moguel \& Toledo, 1999), but in the latter case, they may contribute to the loss of 
highly diverse forests (Lewis et al., 2015; Schroth, 2004). This drawback stimulates debate over the conservation value of tropical agroforests and whether their promotion is indeed a sensible policy (Philpott \& Dietsch, 2003; Tejeda-Cruz et al., 2010).

Surprisingly, tropical agroforestry research has made few attempts to investigate how ecosystem functions and services, as well as biodiversity, differ among agroforests of contrasting land-use history, i.e. between forest- and open-land-derived agroforests. Instead, researchers have commonly compared structurally simple with structurally diverse agroforests (Moguel \& Toledo, 1999) and have found biodiversity and non-yield ecosystem services to generally increase with structural complexity (De Beenhouwer et al., 2013).

Here, we collate published information on socio-economic implications as well as ecosystem services and biodiversity in forest- and open-land-derived agroforestry and identify knowledge gaps. We find that forest-derived agroforests can be best described as a form of forest degradation while open-land-derived agroforests rehabilitate formerly forested open land (sensu Chazdon et al., 2016). We then argue that emphasizing land-use history in tropical agroforestry research and policy may foster biodiversity conservation and contribute to the safeguarding of ecosystem functions and services in tropical landscapes. 
a) Conversion from forest to forest-derived agroforestry

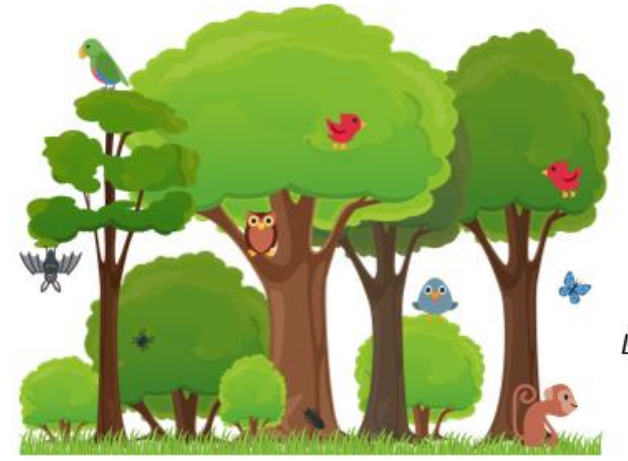

Tropical forest

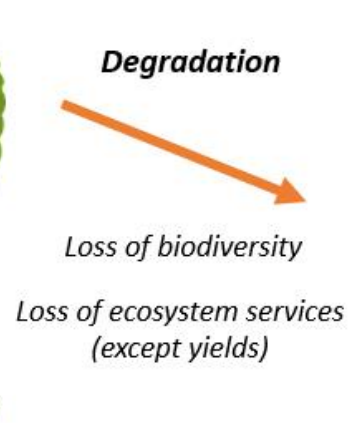

Forest-derived agroforestry

b) Conversion from open land to open-land-derived agroforestry

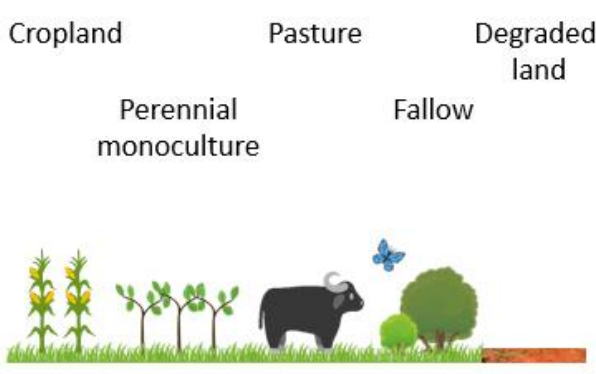

Open land
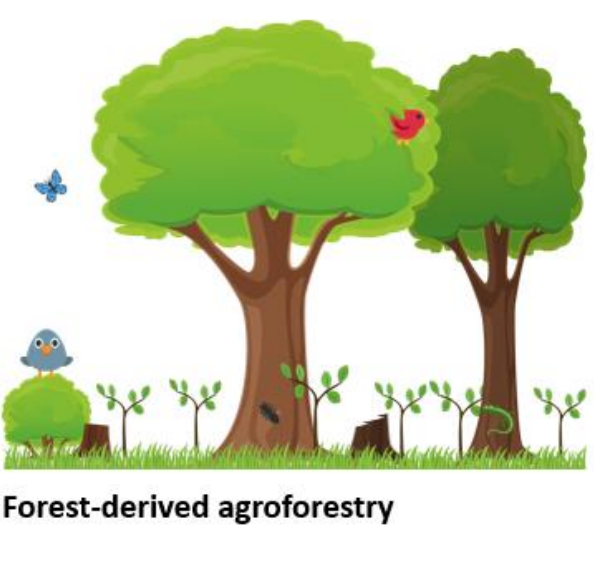

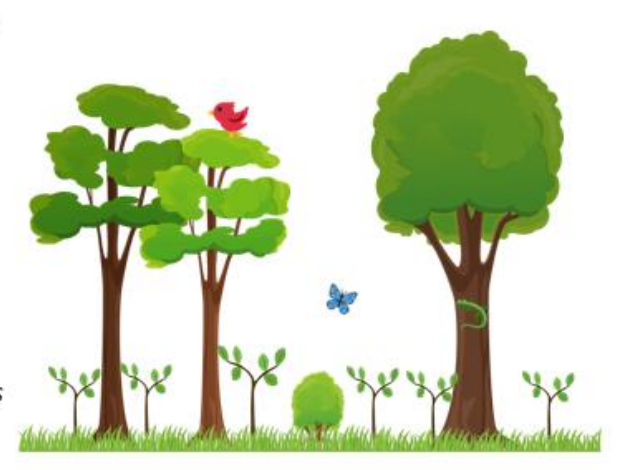

Open-land-derived agroforestry

Fig. 1.1: Concept of land-use history in agroforestry. a) Forest-derived agroforests are established by thinning the forest and replacing the understory with shade-tolerant agroforestry crops such as coffee, cacao, rubber, or vanilla, thereby representing a degradation of forest with overall losses of biodiversity and ecosystem services (except for yields). b) Open-land-derived agroforests are established by planting agroforestry crops alongside planted or naturally regenerating shade trees on suitable open land. Open-land-derived agroforestry consequently has the potential to rehabilitate cropland, perennial monocultures, pastures, fallow or degraded land, leading to gains in biodiversity and ecosystem services.

\section{Systematic review method}

We relied upon a recently published evidence and gap map (Miller et al., 2020), which systematically assessed the available literature on the impacts of agroforestry on agricultural productivity, ecosystem services, and human well-being. We used their data extraction record (sup-0001 from Miller et al., 2020) and filtered the results for the practice type 'Trees integrated with plantation crops' and 'Tropical' OR 'Multiple' ecoregions to match the scope of our paper. We subsequently excluded 23 studies that were either not in English (1 study), unavailable ( 2 studies), situated outside the tropics (5 studies), or that investigated combinations of trees with annual crops (15 studies). We then systematically reviewed the 
remaining 98 papers and assessed whether authors had 1) described land-use history of all agroforestry types studied, 2) directly compared between forest- and open-land-derived agroforests, 3) directly compared agroforests and their former land-use (forest/open land), and 4) discussed the topic. We provide a table with extracted data as Supporting Information (Appendix S1.1).

\section{The importance of land-use history in tropical agroforestry}

Relatively few crops are shade-tolerant and may be planted directly inside forests (Fig. 1.1). These crops include coffee, cacao, pepper, rubber or vanilla - all crops that can also be planted on open land, but that may partly require specific varieties or temporary artificial or natural shade. In our systematic review, $57 \%$ of studies did not describe the land-use history of focal agroforests and only $5 \%$ directly compared agroforests of contrasting land-use history. Of those studies which described land-use history, 50\% investigated forest-derived agroforests, while 38\% investigated open-land-derived agroforests and $12 \%$ compared the two, emphasizing the importance of both kinds. Forest- and open-land-derived agroforests are commonly found alongside each other in mosaic landscapes across the tropics. In Sulawesi, Indonesia, $50 \%$ of cacao plantations are forest-derived while the other half was established on open land (Rice \& Greenberg, 2000). In north-eastern Madagascar, 70\% of vanilla agroforests are open-land-derived, while 30\% are forest-derived (Hänke et al., 2018; more on vanilla agroforests in Box). The possibility to plant the same crops inside forest and on open land highlights the relevance of land-use history when studying such agroforestry systems. Furthermore, these crops are frequently farmed within forest landscapes in tropical biodiversity hotspots, accentuating the importance of biodiversity-friendly farming practices.

\section{Suitability of open vs. forest land for agroforest establishment}

Land accessibility and availability influence whether agroforests are established inside forests or on open land (Meyfroidt et al., 2014, Table 1.1). Establishing forest-derived agroforests is only possible where forests are available, typically at deforestation frontiers or where forest fragments are scattered in a landscape. As forests are vanishing across the tropics (Lewis et al., 2015), many farmers live far away from available forests, making open-land-derived agroforestry the only option.

Other factors are also shaping agroforestry expansion (Table 1.1). For example, planting crops inside forest may represent a form of land claim (Meyfroidt et al., 2014), incentivizing forest-derived agroforestry. On open-land, land tenure must already be secured, given the significant investments needed to establish an agroforest (Ruf, 2001). Opportunity costs may apply in either case: For forests, those are likely limited to the loss of forest-specific ecosystem functions and services, while on open land, 
the costs for losing perennial monocultures, arable crop land or pastures will be considerable. Fallows may offer an opportunity for open-land-derived agroforestry, given their abundance in many tropical regions (Chazdon et al., 2009). Degraded land, typically of low value to people and nature (Lamb et al., 2005), could also be suitable for open-land-derived agroforestry, but only if costs, for example associated with management of invasive species or erosion control, are manageable. The price tag might also be a more general disadvantage of open-land-derived agroforestry; cacao production costs are for instance 30 - 50\% higher in open-land-derived agroforests compared to forest-derived agroforests due to costs for fertilizers and maintenance (Ruf, 2001). Additionally, planting trees on open-land may be expensive (Ruf, 2001), while making space for forest-derived agroforestry may be attractive in itself if felled forest trees can be used or sold (Tscharntke et al., 2011). 
Table 1.1: Characteristics of forest-derived and open-land-derived agroforests with a comparison between the two. Characteristics are separated into suitability of land for agroforest establishment, ecosystem functions and services, and vegetation structure and biodiversity. References are reviews where available. If no studies were available, we formulated hypothesis that are formatted in italics.

\begin{tabular}{|c|c|c|c|c|c|}
\hline \multicolumn{2}{|c|}{ Characteristic } & $\begin{array}{l}\text { Characteristics of forest-derived } \\
\text { agroforests }\end{array}$ & $\begin{array}{l}\text { Characteristics of open-land-derived } \\
\text { agroforests }\end{array}$ & $\begin{array}{l}\text { Comparison between forest-derived } \\
\text { and open-land-derived agroforests }\end{array}$ & References \\
\hline \multicolumn{6}{|c|}{ Suitability of land for agroforest establishment } \\
\hline \multicolumn{2}{|c|}{ Land availability } & $\begin{array}{l}\text { Forest land may be the only land available } \\
\text { to farmers, particularly if their means to } \\
\text { purchase land are limited. }\end{array}$ & $\begin{array}{l}\text { Open land may be the only land } \\
\text { available at places without forest or } \\
\text { where remaining forests are protected } \\
\text { or otherwise inaccessible. }\end{array}$ & $\begin{array}{l}\text { Advantages and disadvantages of } \\
\text { either type depend on local and } \\
\text { individual context. }\end{array}$ & $\begin{array}{l}\text { Meyfroidt et al., } \\
\text { 2014; Ruf, } 2001\end{array}$ \\
\hline \multicolumn{2}{|c|}{ Land tenure \& rights } & $\begin{array}{l}\text { Agroforest establishment inside forest } \\
\text { may represent a land claim. Land rights } \\
\text { determine land availability. Forests may be } \\
\text { protected, preventing forest-derived } \\
\text { agroforestry. }\end{array}$ & $\begin{array}{l}\text { Land must already be claimed before } \\
\text { agroforest establishment. Land tenure } \\
\text { insecurity discourages agroforestry } \\
\text { establishment. }\end{array}$ & $\begin{array}{l}\text { No direct comparison available, strong } \\
\text { land rights will facilitate open-land- } \\
\text { derived agroforestry whereas strict } \\
\text { forest protection may hamper forest- } \\
\text { derived agroforestry. }\end{array}$ & $\begin{array}{l}\text { Meyfroidt et al., } \\
\text { 2014; Ruf, } 2001\end{array}$ \\
\hline \multicolumn{2}{|c|}{$\begin{array}{l}\text { Competition with } \\
\text { previous land use }\end{array}$} & $\begin{array}{l}\text { Direct land-use competition limited, but } \\
\text { loss of forest-generated ecosystem } \\
\text { functions and services. }\end{array}$ & $\begin{array}{l}\text { Competition with services and yields } \\
\text { derived from cropland, perennial } \\
\text { monoculture, pasture or fallow. Less } \\
\text { problematic on degraded land. }\end{array}$ & $\begin{array}{l}\text { No direct comparison available, trade- } \\
\text { offs exist for both types. Advantages } \\
\text { and disadvantages depend on local } \\
\text { context. }\end{array}$ & $\begin{array}{l}\text { Meyfroidt et al., } \\
2014\end{array}$ \\
\hline \multicolumn{2}{|c|}{ Production costs } & NA & NA & $\begin{array}{l}\text { Production costs are higher in open- } \\
\text { land-derived agroforestry compared to } \\
\text { forest-derived agroforestry. }\end{array}$ & Ruf, 2001 \\
\hline \multicolumn{6}{|c|}{ Ecosystem functions and services } \\
\hline \multirow[b]{2}{*}{ 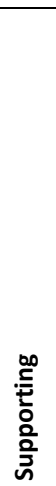 } & Soil fertility & $\begin{array}{l}\text { Nutrient acquisition incl. } \mathrm{N} \text { fixation } \\
\text { through forest remnant or planted } \\
\text { (legume) trees; litter fall maintains soil } \\
\text { fertility. }\end{array}$ & $\begin{array}{l}\text { Nutrient acquisition incl. N fixation } \\
\text { through planted (legume) trees; } \\
\text { particularly useful if resource needs of } \\
\text { chosen trees and agroforestry crop are } \\
\text { complementary. May also depend on } \\
\text { former use of open land. }\end{array}$ & $\begin{array}{l}\text { No direct comparison available, } \\
\text { possibly higher soil fertility in forest- } \\
\text { derived agroforestry but potential for } \\
\text { carry-over effects from previous land- } \\
\text { use in open-land-derived agroforestry. } \\
\text { May change over time. }\end{array}$ & $\begin{array}{l}\text { Cannell et al., } \\
\text { 1996; Tscharntke } \\
\text { et al., } 2011\end{array}$ \\
\hline & $\begin{array}{l}\text { Water } \\
\text { regulation \& } \\
\text { supply }\end{array}$ & $\begin{array}{l}\text { Integrity of water cycle with high } \\
\text { evapotranspiration and low surface run-off } \\
\text { may be retained. }\end{array}$ & $\begin{array}{l}\text { Improved integrity of the water cycle } \\
\text { with enhanced evapotranspiration and } \\
\text { reduced surface run-off. }\end{array}$ & $\begin{array}{l}\text { No direct comparison available, } \\
\text { possibly higher integrity of water cycle } \\
\text { in forest-derived agroforestry. }\end{array}$ & $\begin{array}{l}\text { Abdulai et al., } \\
\text { 2018; Blaser et } \\
\text { al., 2018; } \\
\text { Wanger et al., } \\
2018\end{array}$ \\
\hline
\end{tabular}




\begin{tabular}{|c|c|c|c|c|c|}
\hline \multicolumn{2}{|c|}{ Characteristic } & \multirow{2}{*}{$\begin{array}{l}\text { Characteristics of forest-derived } \\
\text { agroforests } \\
\text { Above-ground carbon stocks are lower } \\
\text { than in forests. Within forest-derived } \\
\text { agroforests, biomass is often times } \\
\text { reduced over time as trees are cut. Soil } \\
\text { organic carbon can be maintained if trees } \\
\text { are kept. }\end{array}$} & \multirow{2}{*}{$\begin{array}{l}\text { Characteristics of open-land-derived } \\
\text { agroforests } \\
\text { Above-ground carbon stocks are } \\
\text { initially low, but can be elevated to } \\
\text { medium levels with time. Soil organic } \\
\text { carbon is initially low but may rebound } \\
\text { over time. }\end{array}$} & \multirow{2}{*}{$\begin{array}{l}\text { Comparison between forest-derived } \\
\text { and open-land-derived agroforests } \\
\text { No direct comparison available, open- } \\
\text { land-derived agroforestry typically } \\
\text { have lower carbon stocks compared to } \\
\text { forest-derived agroforestry. }\end{array}$} & \multirow{2}{*}{$\begin{array}{l}\text { References } \\
\text { De Beenhouwer } \\
\text { et al., 2016; } \\
\text { Hombegowda et } \\
\text { al., 2016; Nair et } \\
\text { al., 2009 }\end{array}$} \\
\hline \multirow[b]{4}{*}{ 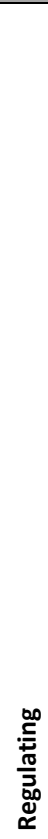 } & $\begin{array}{l}\text { Climate } \\
\text { regulation }\end{array}$ & & & & \\
\hline & $\begin{array}{l}\text { Climate change } \\
\text { adaptation }\end{array}$ & $\begin{array}{l}\text { Possibly dependent on tree cover; studies } \\
\text { report mixed results about the direction of } \\
\text { the effect for cacao. }\end{array}$ & $\begin{array}{l}\text { Possibly dependent on tree cover; } \\
\text { given that trees are often actively } \\
\text { planted, tree species adapted to } \\
\text { climate change could be chosen. }\end{array}$ & $\begin{array}{l}\text { No direct comparison available, more } \\
\text { active choice of tree species in open- } \\
\text { land-derived agroforests could be an } \\
\text { opportunity for climate change } \\
\text { adaptation. }\end{array}$ & $\begin{array}{l}\text { Abdulai et al., } \\
\text { 2018; Blaser et } \\
\text { al., 2018; } \\
\text { Wanger et al., } \\
2018\end{array}$ \\
\hline & $\begin{array}{l}\text { Erosion } \\
\text { prevention }\end{array}$ & $\begin{array}{l}\text { Little change compared to forest if trees } \\
\text { are maintained. }\end{array}$ & Improvement over open land. & $\begin{array}{l}\text { No direct comparison available, } \\
\text { possibly better in forest-derived } \\
\text { agroforests which have not } \\
\text { experienced clear cuts or fire. }\end{array}$ & $\begin{array}{l}\text { Labrière et al., } \\
2015\end{array}$ \\
\hline & $\begin{array}{l}\text { Biological } \\
\text { control }\end{array}$ & $\begin{array}{l}\text { Pest control services and disease } \\
\text { prevalence (in coffee and cacao) both } \\
\text { increase with tree cover, leading to } \\
\text { potential trade-offs between the two. }\end{array}$ & $\begin{array}{l}\text { Pest control services and disease } \\
\text { prevalence may increase with tree } \\
\text { cover recovery. }\end{array}$ & $\begin{array}{l}\text { No direct comparison available, pests } \\
\text { and disease may differentially affect } \\
\text { forest-and open-land-derived } \\
\text { agroforests. }\end{array}$ & $\begin{array}{l}\text { Blaser et al., } \\
\text { 2018; Clough et } \\
\text { al., } 2009\end{array}$ \\
\hline & $\begin{array}{l}\text { Primary crop } \\
\text { yield }\end{array}$ & $\begin{array}{l}\text { Yield gains in coffee and cacao are } \\
\text { common when shade tree cover is } \\
\text { reduced from high to medium shade, but } \\
\text { long-term yields may suffer under low } \\
\text { shade conditions. }\end{array}$ & $\begin{array}{l}\text { Possible yield reduction in coffee and } \\
\text { cacao agroforests where shade tree } \\
\text { regeneration leads to higher canopy } \\
\text { cover. }\end{array}$ & $\begin{array}{l}\text { No difference in cacao yield between } \\
\text { forest- and open-land-derived } \\
\text { agroforestry (but only one study } \\
\text { available). }\end{array}$ & $\begin{array}{l}\text { Clough et al., } \\
\text { 2009; Nijmeijer } \\
\text { et al., } 2019\end{array}$ \\
\hline 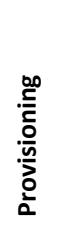 & $\begin{array}{l}\text { Secondary crop } \\
\text { yield \& raw } \\
\text { materials }\end{array}$ & $\begin{array}{l}\text { Products may be harvested if useful plants } \\
\text { and trees are kept, promoted or planted. } \\
\text { Trees can be cut and used. }\end{array}$ & $\begin{array}{l}\text { Useful plants/trees can be planted } \\
\text { during agroforest establishment but } \\
\text { might take time until first harvest; } \\
\text { dependent on product. }\end{array}$ & $\begin{array}{l}\text { No direct comparison available, the } \\
\text { more active choice of tree species in } \\
\text { open-land-derived agroforestry } \\
\text { predicts higher secondary crop yields in } \\
\text { such systems. }\end{array}$ & $\begin{array}{l}\text { Tscharntke et al., } \\
2011\end{array}$ \\
\hline \multicolumn{6}{|c|}{ Vegetation structure and biodiversity } \\
\hline & $\begin{array}{l}\text { cover \& } \\
\text { ture }\end{array}$ & $\begin{array}{l}\text { Initially high tree cover and structure may } \\
\text { be reduced with time if trees are } \\
\text { extracted. }\end{array}$ & $\begin{array}{l}\text { Initially low tree cover and structure, } \\
\text { may be elevated to medium levels with } \\
\text { time through tree growth. }\end{array}$ & $\begin{array}{l}\text { Typically lower tree cover and } \\
\text { simplified structure in open-land- } \\
\text { derived agroforestry than in forest- } \\
\text { derived agroforestry (See also Box). }\end{array}$ & $\begin{array}{l}\text { Nijmeijer et al., } \\
\text { 2019; Ruf, 2001; } \\
\text { Tscharntke et al., } \\
2011\end{array}$ \\
\hline
\end{tabular}




\begin{tabular}{|c|c|c|c|c|}
\hline Characteristic & $\begin{array}{l}\text { Characteristics of forest-derived } \\
\text { agroforests }\end{array}$ & $\begin{array}{l}\text { Characteristics of open-land-derived } \\
\text { agroforests }\end{array}$ & $\begin{array}{l}\text { Comparison between forest-derived } \\
\text { and open-land-derived agroforests }\end{array}$ & References \\
\hline Tree diversity & $\begin{array}{l}\text { Selective cutting of trees reduces diversity } \\
\text { compared to forest. More useful trees (see } \\
\text { above) are more likely to be kept. }\end{array}$ & $\begin{array}{l}\text { Diversity is highly managed as trees are } \\
\text { planted or selected by farmers. Species } \\
\text { are typically chosen based on their } \\
\text { usefulness, suitability and availability. }\end{array}$ & $\begin{array}{l}\text { Normally lower in open-land-derived } \\
\text { agroforestry than in forest-derived } \\
\text { agroforestry. }\end{array}$ & $\begin{array}{l}\text { Nijmeijer et al., } \\
\text { 2019; Tscharntke } \\
\text { et al., 2011; } \\
\text { Valencia et al., } \\
2016\end{array}$ \\
\hline Biodiversity & $\begin{array}{l}\text { Generally lower than in forest. May be } \\
\text { taxon-specific and/or on the level of } \\
\text { species composition rather than species } \\
\text { richness. Effects will be strongest for } \\
\text { forest-dependent species. }\end{array}$ & $\begin{array}{l}\text { Generally higher than in open land. } \\
\text { Effects may be taxon specific and/or on } \\
\text { the level of species composition rather } \\
\text { than species richness. Open-land } \\
\text { species may decrease following } \\
\text { agroforest establishment. }\end{array}$ & $\begin{array}{l}\text { Overall lower in open-land-derived } \\
\text { agroforestry than in forest-derived } \\
\text { agroforests, but open-land and } \\
\text { generalist species may be more } \\
\text { common in open-land-derived } \\
\text { agroforests. }\end{array}$ & $\begin{array}{l}\text { De Beenhouwer } \\
\text { et al., 2013; } \\
\text { Hoehn et al., } \\
\text { 2010; Perfecto et } \\
\text { al., 1996; } \\
\text { Philpott et al., } \\
2008\end{array}$ \\
\hline Legacy effects & $\begin{array}{l}\text { Extinction debts are likely to exist, } \\
\text { suggesting a loss in species over time even } \\
\text { under stable tree cover. }\end{array}$ & $\begin{array}{l}\text { Immigration credit is likely to exist, } \\
\text { suggesting a gain in species over time } \\
\text { under stable management regime. }\end{array}$ & $\begin{array}{l}\text { No direct comparison available, } \\
\text { realizing legacy effects would lead to } \\
\text { reduced differences between forest- } \\
\text { and open-land-derived agroforests in } \\
\text { terms of biodiversity. }\end{array}$ & $\begin{array}{l}\text { Hylander \& } \\
\text { Nemomissa, } \\
\text { 2017; Jackson \& } \\
\text { Sax, 2010; Shumi } \\
\text { et al., 2018 }\end{array}$ \\
\hline
\end{tabular}




\section{Land-use history affects ecosystem functions and services}

Establishing an agroforest on open land that was formerly forested can be regarded as a form of rehabilitation (Chazdon et al., 2016), leading to an overall increase of tree cover and associated ecosystem functions and services (Table 1.1). Tropical open-land-derived agroforests thus have a large carbon sequestration potential (Hombegowda et al., 2016; Nair et al., 2009; Nijmeijer et al., 2019). Forest-derived agroforests, on the other hand, typically store less carbon than forests (De Beenhouwer et al., 2016; Nair et al., 2009). For example, forest-derived coffee agroforests in Ethiopia lose $47 \%$ of their carbon stocks along an intensification gradient compared to forests (De Beenhouwer et al., 2016). For tree basal area, we find the same pattern in vanilla agroforests, where open-land-derived agroforests have three times more basal area than open fallow land. Forest-derived vanilla agroforests, on the other hand, have 59\% less basal area than forest (Box).

Whether forest- and open-land-derived agroforestry differ in yields remains poorly understood. A single study in cacao shows no differences (Nijmeijer et al., 2019), but research has mainly focused on how tree cover is correlated with yields. In coffee, yields are typically higher under low- or medium-shade conditions (Perfecto et al., 1996). In cacao, yields generally increase when shade is reduced (Blaser et al., 2018), but low-shade systems may fail to maintain yields in the long run (Clough et al., 2009). Yields may also be influenced by pest control services in agroforestry systems, but whether land-use history per se influences pest control is unknown. Similarly, it remains unclear whether land-use history affects how agroforests cope with elevated temperatures and droughts. Elucidating the interplay between land-use history, tree cover, pest control and yields under climate change will thus help to improve agroforest management to the benefit of farmers as well as ecosystem services and biodiversity.

\section{BOX: The case of vanilla agroforestry in Madagascar}

Vanilla agroforests along with hill- and paddy rice, fallows and forest fragments form a mosaic landscape in north-eastern Madagascar which arose through rainforest conversion. High vanilla prices have led to an expansion of vanilla agroforestry at the cost of both forest and open land. Forest-derived vanilla agroforests, which make up around $30 \%$ of all vanilla agroforests (Hänke et al., 2018), are established by understory clearance and tree thinning. This conversion maintains some tree cover but basal area in forest-derived vanilla agroforests is less than half compared to forest (Fig. 1.2). In contrast, $70 \%$ of vanilla agroforests originate from abundant open land that lays fallow as part of the slash-and-burn hill rice cultivation cycle (Hänke et al., 2018). The cessation of fire, that comes with the establishment of 
permanent open-land-derived vanilla agroforests, enables tree recovery, resulting in a threefold higher basal area compared to open land (Fig. 1.2). When compared directly, forest-derived vanilla agroforests have almost twice the basal area of open-land-derived vanilla agroforests. This highlights the role of agroforests of contrasting land-use history for maintaining trees and their associated functions and services.
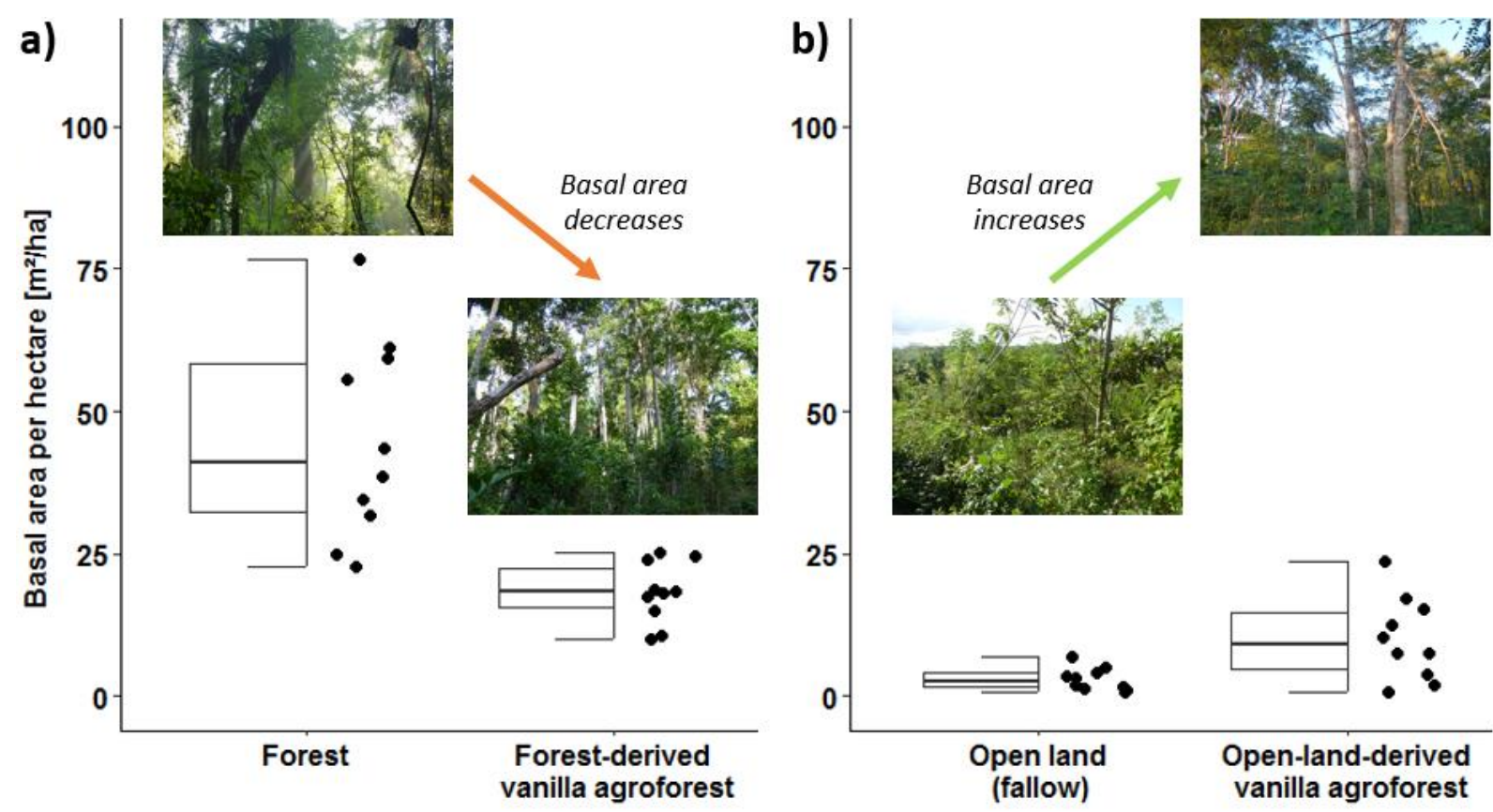

Fig. 1.2: Basal area $\left[\mathrm{m}^{2} / \mathrm{ha}\right.$ ] in 40 circular study plots of $1963.5 \mathrm{~m}^{2}$. Measurements include all living trees, palms and herbs with a diameter at breast height $\geq 8 \mathrm{~cm}$. a) Basal area in forest-derived vanilla agroforests is $59 \%$ lower than in forests $(p<0.001)$. b) Basal area in open-land-derived vanilla agroforests is three times higher than in open lands ( $238 \%$ increase; $p=0.011$ ). Open-land-derived vanilla agroforests have $45 \%$ less $(p=0.009)$ basal area than forestderived vanilla agroforests. Test results are based on Wilcoxon signed-rank tests.

\section{Land-use history shapes vegetation structure and biodiversity}

Planting crops inside forest and the accompanying simplification of vegetation structure leads to a loss of biodiversity (De Beenhouwer et al., 2013; Tscharntke et al., 2011). While immigrating generalist or openland specialist species may compensate for some of the losses in species richness, forest specialists (De Beenhouwer et al., 2013; Perfecto et al., 1996) and threatened species (Schroth, 2004) are particularly affected. This species turnover exacerbates conservation concerns of forest-derived agroforestry. Nevertheless, forest-derived agroforests surpass alternative forms of forest conversion, such as slash-andburn practices (Perfecto et al., 1996; Schroth, 2004). Planting agroforests on open land should, in contrast, 
enhance structural complexity and increase resource diversity, thereby bolstering biodiversity of forestassociated taxa (Fig. 1.1). However, few studies compare open-land-derived agroforests with their respective baselines (Rice \& Greenberg, 2000). This is also reflected in our systematic review, where only two studies compared biodiversity of open-land-derived agroforestry with open land while 14 studies compared forest-derived agroforestry with forest (see also Table 1.1 and Appendix S1.1). Direct comparisons between forest-derived and open-land-derived agroforests are scarce, but published studies show a more forest-like species composition (Hoehn et al., 2010; Valencia et al., 2016) fewer invasive species (Bos et al., 2008), and higher species diversity (Nijmeijer et al., 2019; Siebert, 2002) in forestderived agroforests.

However, the differences between agroforests of contrasting land-use history might diminish over time. Oftentimes, forest-derived agroforests lose tree cover due to logging of existing trees, natural mortality, and limited recruitment (De Beenhouwer et al., 2016; Shumi et al., 2018; Valencia et al., 2016), typically resulting in a reduction of biodiversity (Philpott et al., 2008; Tscharntke et al., 2011). Contrastingly, openland-derived agroforests gain tree cover over time and could thereby enter into a positive biodiversity trajectory (Perfecto et al., 1996). In this context, contrasting trajectories in forest- and open-land-derived cacao agroforests in Cameroon have equalized tree diversity after 25 years (Nijmeijer et al., 2019).

Furthermore, legacy effects could reduce the gap in biodiversity between forest- and open-land-derived agroforests over time. Extinction debts suggest a continuing loss of biodiversity as populations that are not viable under new conditions go extinct (Jackson \& Sax, 2010).

Evidence for extinction debts comes from forest-derived agroforests in Ethiopia, where epiphytes are less likely to occur in long-converted agroforests further away from the historic forest edge (Hylander \& Nemomissa, 2017). Conversely, open-land-derived agroforests may enjoy an immigration credit (Jackson \& Sax, 2010; Shumi et al., 2018), implying that species have not yet immigrated into newly established agroforests, despite suitable habitat. "Paying out" extinction debts and immigration credits would thus reduce differences in species richness between forest- and open-land-derived agroforests.

\section{Discussion}

Agroforestry is often seen as an economically viable land-use option that benefits people and nature alike (Schroth, 2004), thereby contributing to reaching the UN Sustainable Development Goals. To what extent will depend on whether an agroforest is established on open land or at the cost of biodiverse tropical forest. Nonetheless, forest-derived agroforestry represents a limited loss of ecosystem functions and 
biodiversity compared to more destructive conversion methods such as slash-and-burn or a combination of intensive logging and grazing (Fig. 1.3). Conversely, agroforestry on formerly forested open land will typically have a positive effect on ecosystem services and biodiversity: The land gains vertical habitat complexity through the restoration of shade trees and crops on open land, which in turn increases biodiversity and ecosystem functions and services. In short, open-land-derived agroforestry will often perform worse than forest-derived agroforestry in absolute terms but forest-derived agroforestry degrades forest whereas open-land-derived agroforestry rehabilitates open land that was once forested (Box; Fig. 1.3).

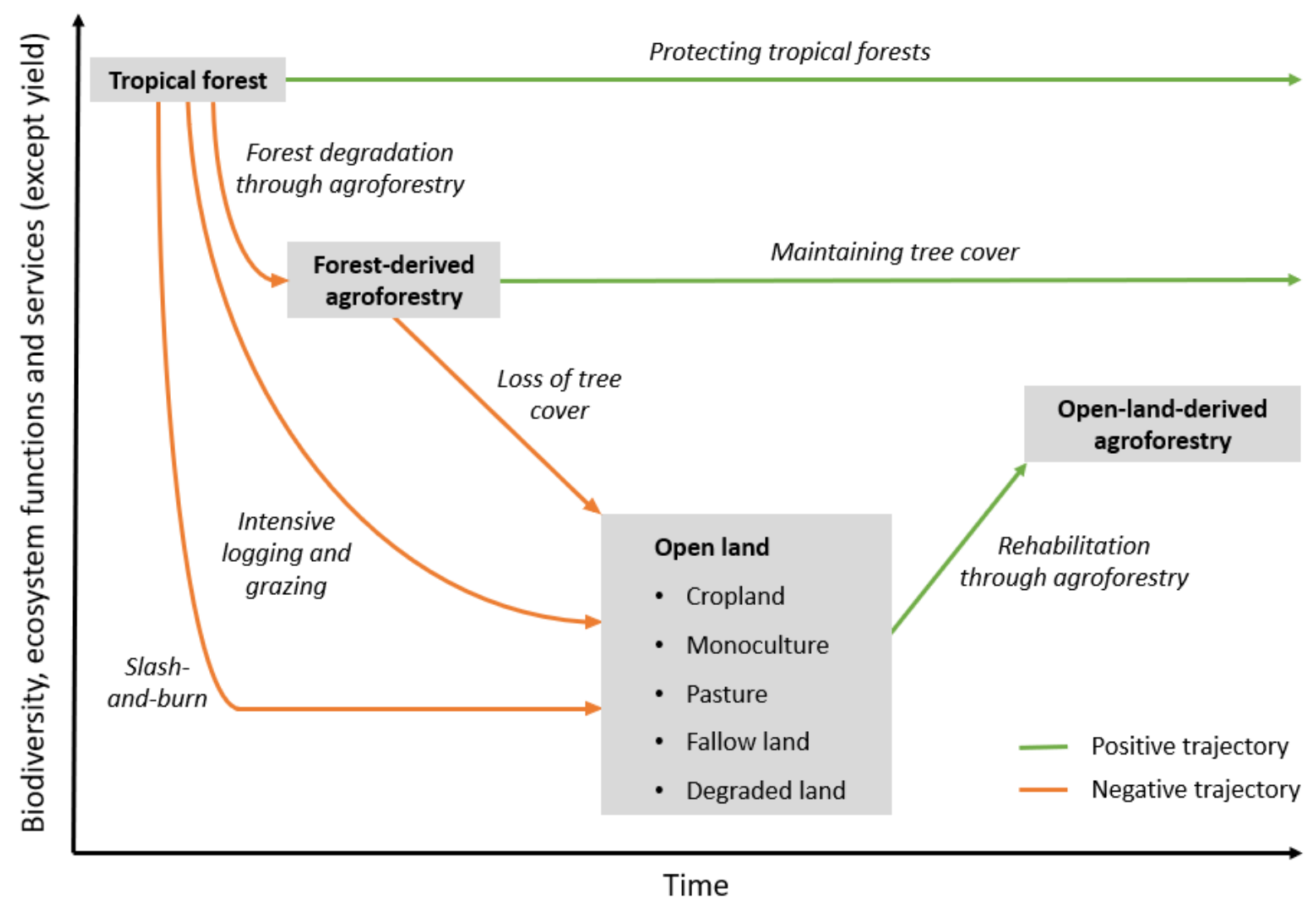

Fig. 1.3: Conceptual framework of land-use history for tropical agroforests including possible transformation pathways. Forest-derived agroforestry represents a decline of biodiversity, ecosystem functions and services compared to forest (except crop yields). Conversely, open-land-derived agroforestry represents an improvement over previous land use. In direct comparison, forest-derived agroforestry outperforms open-land-derived agroforestry if tree cover is maintained. Importantly, the framework only applies to formerly forested land in the tropics and is not applicable to naturally open land, such as savannahs. Note that both axes are not absolute, i.e. processes may happen faster or slower ( $x$-axis) and losses and gains could be stronger or weaker ( $y$-axis), depending on environmental and socio-economic context. 


\section{Incentivising positive land-use trajectories}

Maintaining tree cover in forest-derived agroforestry (Fig. 1.3) might be associated with lower yields (Blaser et al., 2018; Perfecto et al., 1996) and establishing open-land-derived agroforests instead of forestderived ones might come at extra direct costs (Ruf, 2001; Tscharntke et al., 2011). Incentives such as sustainability certification schemes could, however, make both economically viable (Philpott \& Dietsch, 2003; Tscharntke et al., 2015). Analogously, farmers could profit from payments for ecosystem services aimed at carbon sequestration in their open-land-derived agroforests (Salzman et al., 2018). Interestingly, many sustainability standards prohibit "forest conversion into production land" (e.g. Rainforest Alliance, Organic, Fair Trade (International Trade Centre, 2019)), effectively excluding forest-derived agroforests. But in practice, many certified agroforests are forest-derived (e.g. vanilla: (Hänke et al., 2018); coffee: Philpott \& Dietsch, 2003). This is not per se problematic if sustainability certification ensures that ecosystem functions and services, as well as biodiversity, are maintained in long-established agroforests (Tscharntke et al., 2015). To avoid incentivizing forest degradation, the certification of recently converted forest-derived agroforests should nonetheless be avoided. On the other hand, open-land-derived agroforests might struggle to meet certification criteria, despite the improvement over previous land use. For instance, Rainforest Alliance requires "diverse native shade canopies for shade-tolerant crops" (International Trade Centre, 2019)- a criterion that will typically be harder to meet in open-land-derived agroforestry (Rice \& Greenberg, 2000). In this case, rules could be adapted so that open-land-derived agroforests with a lower proportion of native trees still qualify for sustainability standards. In sum, sustainability standards and payments for ecosystem services should be sensitive to land-use history in order to avoid adverse outcomes.

\section{Key research questions on land-use history of tropical agroforests}

First, we encourage studies that investigate the time scale of described processes. In forest-derived agroforestry, we hypothesize a rapid loss of biodiversity and ecosystem functions and services during the initial transformation from forest and a somewhat slower decline thereafter. In open-land-derived agroforestry, recovery time will again depend on the focal variable but may be only a few years for certain ecosystem functions (Nijmeijer et al., 2019). In this context, time series will be particularly interesting. Second, research quantifying the extent of biodiversity and ecosystem functioning gain and loss during transformation is equally important. Third, elucidating how forest- and open-land-derived agroforestry could be utilized to restore land-sharing/sparing connectivity landscapes would be highly interesting (Grass et al., 2019). For example, one could imagine landscapes with forest-derived agroforests as buffers 
around protected areas and corridors of open-land-derived agroforestry connecting forest fragments thereby reaping the advantages of both types.

\section{Policy implications}

Agroforestry is widely promoted to address multiple UN Sustainable Development Goals, but policy often does not distinguish between forest- and open-land-derived agroforests. Here, we find that ecosystem functions and services, as well as biodiversity, are strongly influenced by land-use history in agroforests; suggesting a high relevance of land-use history for policy. Policies aiming to conserve biodiversity and ecosystem services should 1) prioritize forest protection over forest-derived agroforestry, 2) promote forest-derived agroforestry as an alternative to deforestation, 3) incentivise tree cover maintenance in existing forest-derived agroforests, 4) encourage open-land-derived agroforestry on suitable open land, particularly on fallow and degraded land, and 5) stimulate applied research on land-use history.

Our framework is relevant to numerous policy tools. Those include payments for ecosystem services and sustainability certification but can be extended to agricultural subsidy schemes, zero-deforestation commitments and governmental land-use policy, among others. Notably, all approaches will need to be highly adapted to local context as environmental and socio-economic factors influence whether and where the promotion of forest- respectively open-land-derived agroforestry is a sensible policy.

\section{Author contribution}

All authors conceived ideas and planned the paper; DAM conducted the systematic review, produced Fig. 1.1 and Fig. 1.3, and led the writing of the manuscript; KO collected basal area data and created Fig. 1.2. All authors contributed to the writing and gave final approval.

\section{Acknowledgments and data}

We thank the 'Diversity Turn in Land Use Science' team for inspiring discussions. We are grateful to Marie Rolande Soazafy and research assistants who contributed to basal area data. We thank two anonymous reviewers and the editor for their helpful feedback. This study was financially supported by the Niedersächsisches Vorab of Volkswagen Foundation (Grant number 11-76251-99-35/13 (ZN3119)). Basal area data is available upon request. 


\section{Chapter 2: Case study: Tree diversity and stand structure in the mosaic landscape}

Manuscript title: Land-use history determines stand structure and tree diversity in vanilla agroforests of northeastern Madagascar

Authors: Kristina Osen; Marie Rolande Soazafy; Dominic A. Martin; Annemarie Wurz; Adriane März; Hery Lisy Tiana Ranarijaona, Dirk Hölscher

Manuscript status: Published in Applied Vegetation Science; $\quad$ https://doi.org/10.1111/avsc.12563

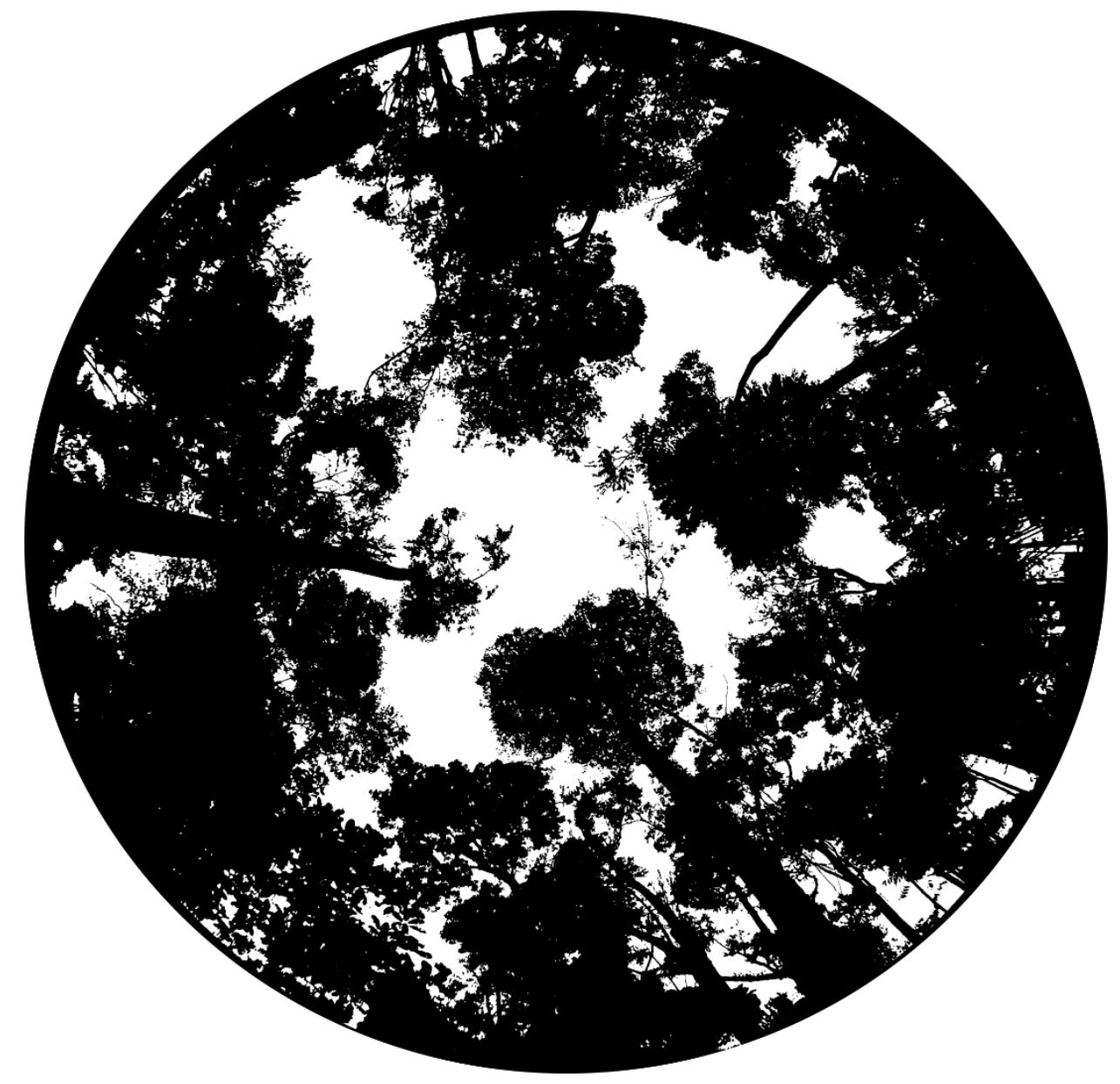




\section{Abstract}

\section{Question}

In human-modified tropical landscapes, agroforestry is considered a promising land use to reconcile biodiversity conservation with production goals. The role of agroforests with regard to conservation may strongly be influenced by land-use history, however, few studies have explicitly investigated this. We thus tested the importance of land-use history for habitat structure and tree diversity in vanilla agroforests situated in a human-modified tropical landscape.

\section{Location}

Smallholder mosaic landscape of north-eastern Madagascar.

\section{Methods}

We studied tree stand structure, diversity and composition in vanilla agroforests of contrasting land-use history, old-growth forests, forest fragments and woody fallows after slash-and-burn agriculture, which all contribute to the smallholder mosaic landscape of north-eastern Madagascar. The vanilla agroforests were either derived directly from forest, or otherwise from woody fallows after slash-and-burn agriculture.

\section{Results}

Land-use history strongly influenced tree species diversity and composition in vanilla agroforests and also affected stand structure. Forest-derived agroforests maintained high levels of tree species diversity and differed in community composition compared to fallow-derived agroforests, which had relatively low levels of tree diversity. Additionally, forest-derived vanilla agroforests harboured a significantly higher percentage of endemic species than fallow-derived agroforests, and forest-derived agroforests also shared many species with old-growth forests and forest fragments. Fallow-derived vanilla agroforests harboured a lower percentage of endemic species than woody fallows.

\section{Conclusion}

Considering the land-use history of agroforests is important to unfold their full potential as elements in a multifunctional human-modified landscape. Forest-derived agroforests are an alternative to forest conversion through slash-and-burn agriculture and have the potential to sustain high levels of species diversity and important habitat structures. In contrast, fallow-derived agroforests regain stand structure 
on degraded historically forested land, and thereby have the potential to increase canopy cover and connectivity at the landscape scale.

Keywords: Land-use history; conservation; old-growth forest; human-modified landscape; endemism; forest fragments; Madagascar; vanilla agroforestry; stand structure; tree diversity

\section{Introduction}

Tropical biodiversity is threatened by past and ongoing forest loss, driven by a growing demand for land and resources (Defries et al., 2004). Sustainable land-use options are therefore needed to maintain high levels of species diversity and habitat structure while ensuring food security (Foley et al., 2005; Godfray et al., 2010; Tscharntke et al., 2012). Particularly in tropical human-modified landscapes, agroforestry is considered a promising land-use option to meet production goals while maintaining forest stand structures, tree species diversity and associated life-forms across biological kingdoms (Bhagwat et al., 2008; Schroth, 2004). However, agroforestry is multi-facetted: on one hand, it may drive further forest conversion, thereby accelerating species loss and stand structure simplification (Rappole et al., 2003). On the other hand, agroforestry may restore tree cover and associated biodiversity, and ecosystem functions and services on historically forested and degraded lands (Martin et al., 2020) and might therefore provide an attractive restoration practice (Brancalion et al., 2018; Giudice Badari et al., 2020).

Evaluating the conservation potential of tropical cash crop agroforestry systems such as coffee or cacao is often based on the comparison of structurally simple and structurally diverse agroforests (Moguel \& Toledo, 1999; Rappole et al., 2003). However, agroforests have contrasting land-use histories and can be either forest- or open-land-derived (Martin et al., 2020). In a conceptual study, Martin et al. (2020) suggest that forest-derived agroforestry supports higher biodiversity than open-land derived agroforestry but essentially represents a degradation of forest, whereas open-land derived agroforestry rehabilitates historically forested open land. Yet, 57\% of the systematically reviewed studies did not describe the landuse history of focal agroforestry systems at all, and only very few made land-use history a central point of analysis (Martin et al., 2020).

The important role of agroforestry in balancing conservation goals and economic development is very apparent in Madagascar (Jones et al., 2019). Madagascar is classified as a biodiversity hotspot (Buerki et al., 2013; Ganzhorn et al., 2001; Myers et al., 2000), and especially the eastern rainforests represent 
centres of endemism for plants and other taxa (Goodman \& Benstead, 2005; Schatz, 2005; Willis, 2017). Yet, the eastern rainforests have been suffering from forest cover losses in recent years and evidence of natural forest regeneration is limited (Harper et al., 2007; Irwin et al., 2010). To date, north-eastern Madagascar still holds the highest percentage of forest cover compared to the rest of the island, yet deforestation rates are constantly high (Vieilledent et al., 2018). This intensifies the call for land-use options that contribute to rural development while maintaining as much natural forest cover as possible (Jones et al., 2019). In this context, the cultivation of the orchid Vanilla planifolia in agroforests constitutes an important feature within the human-modified landscape of north-eastern Madagascar (Osterhoudt, 2017). Vanilla is an important cash crop, considering both its share in the country's export earnings and its importance for livelihoods (Hänke et al., 2018). Rising global demand for vanilla in recent years, therefore, lead to a rapid expansion of vanilla agroforests in north-eastern Madagascar (Llopis et al., 2019). Within vanilla agroforests, smallholders use small-statured trees as a support for the climbing orchid, while a variety of taller trees form the canopy above (Havkin-Frenkel \& Belanger, 2018). Hence, vanilla agroforests comprise a wide range of tree densities and tree canopy cover (Hending et al., 2020). Furthermore, household surveys in north-eastern Madagascar found that vanilla agroforests particularly differ in their land-use history: around 30\% of agroforests are forest-derived, established by cleaning the understorey, thinning the forest, and planting vanilla under the canopy of the already established trees (Hänke et al., 2018). Roughly $70 \%$ of agroforests originate from fallow land that had formerly burned within the slash-and-burn cycle for hill rice cultivation (locally known as tavy (Styger et al., 2007)) before tree structures re-established and vanilla was planted (Hänke et al., 2018). Independent of their land-use history, all vanilla farming systems can be characterized as agroforests, since they permanently integrate trees and other large woody perennials into the crop cultivation system. This definition embraces a broad range of different management schemes with trees and large woody perennials that already existed prior to the agroforest establishment, but also encompasses spontaneous regrowth or actively planted trees or other tall woody plants (Bhagwat et al., 2008; Schroth, 2004). Recent studies show that vanilla agroforests can provide habitat for native wildlife (Hending et al., 2018, 2020; Martin, Andriafanomezantsoa, et al., 2021), but it remains unclear to which extent the habitat structure and tree diversity are determined by land-use history. Furthermore, it is unclear how agroforest tree species communities are composed in these different agroforest types, and whether vanilla agroforests can provide suitable habitat for forestdependent species, as many tropical species strongly depend on forest and do not occur in humanmodified landscapes (Rembold et al., 2017). 
In our study, we conducted inventories in forest-derived and fallow-derived vanilla agroforests, oldgrowth forests, forest fragments and woody fallow sites resulting from slash-and-burn agriculture, which represent the common tree-dominated land-use types of north-eastern Madagascar. We used trees as a study group, given their importance as structure-providing elements (McElhinny et al., 2005) and their high diversity in north-eastern Madagascar (Callmander et al., 2011; Schatz, 2005). We examined how land-use history affects tree diversity and community composition within vanilla agroforests in this biodiversity hotspot in north-eastern Madagascar. Specifically, we asked: (a) how do stand structure, tree diversity and community composition vary among vanilla agroforests of contrasting land-use history? (b) how does land-use history influence total and endemic tree species diversity and species composition among vanilla agroforests? (c) how do stand structure, tree diversity and community composition vary between vanilla agroforests of contrasting land-use history compared to other tree-dominated land-use types? (d) can vanilla agroforests of contrasting land-use history provide suitable habitat for forestdependent tree species?

\section{Methods}

\section{Study area}

We conducted fieldwork in the SAVA region of north-eastern Madagascar (Fig. 2.1a-c). The climate is tropical-humid with a mean annual temperature of $23.9^{\circ} \mathrm{C}$ and $2258 \mathrm{~mm}$ of rainfall per year (means across 58 plots, based on CHELSA (Karger et al., 2017)). Topographically, the region is characterized by coastal lowlands, merging into hills and mountains. The landscape was formerly covered with humid evergreen forest harbouring a high floristic diversity and high levels of endemism (Callmander et al., 2011). However, remnant areas of relatively undisturbed continuous old-growth forest only remain in protected areas (Schüßler et al., 2020). Outside of these, the landscape comprises a mosaic of land uses consisting of vanilla and paddy rice cultivation and different stages of slash-and-burn agriculture for hill rice and vegetable production interspersed with forest fragments. Slash-and-burn agriculture for hill rice production (Malagasy: tavy) is a major subsistence practice but also a driver of deforestation (Styger et al., 2007). Vanilla agroforests differ in land-use history and can either be derived from formerly burned fallow land with natural or planted woody regrowth, or from unburned thinned forest fragments

(Fig. 2.1d). Technically, vanilla agroforests could also be established directly in old-growth forest, but the legal establishment of forest-derived agroforests in the study region can nowadays exclusively take place in forest fragments, since old-growth forest in our study region is legally protected (Schüßler et al., 2020). 


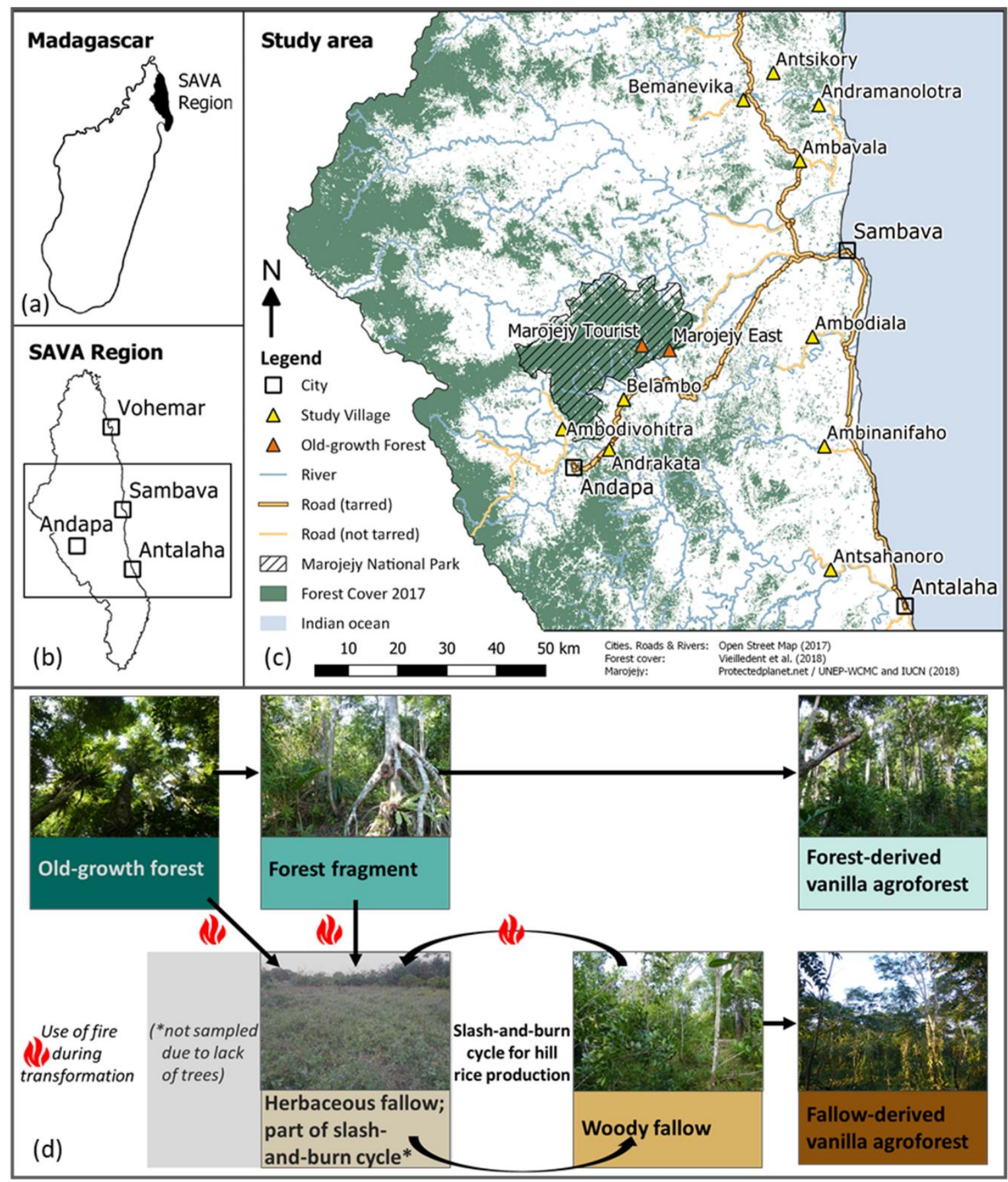

Fig. 2.1: Study area map and study design overview: (a) the island of Madagascar with the SAVA region; (b) SAVA region with four main cities; (c) study area with 2017 forest cover (Vieilledent et al., 2018), 10 study villages, and the two sampling sites in Marojejy National Park; (d) a schematic concept of typical transformation pathways from oldgrowth forest into different land-use types highlighting the different land-use history pathways of vanilla agroforests. The fire icon symbolizes the use of fire during land-use transformation. 


\section{Study design and sampled land-use types}

The five selected land-use types (forest- and fallow-derived vanilla agroforest, woody fallow, forest fragment and old-growth forest) represent the most common woody land cover types in the study region. Around each of the ten study villages (Fig. 2.1c), we selected three vanilla agroforests, one forest fragment, and one naturally regenerating woody fallow part of the slash-and-burn cycle (Fig. 2.1d). Vanilla agroforests were characterized by a variety of taller trees and small-statured support trees carrying the vanilla vines. Within the 30 chosen vanilla agroforests, 20 agroforests were derived from fallow land, and 10 agroforests were derived from forest fragments, as indicated by the landowners. On two fallowderived agroforests, the landowners withdrew from the study, leaving us with 28 vanilla agroforests. The 10 naturally regenerating woody fallows (Malagasy: savoka) in our study had last burned 5 - 17 years prior to data collection and were characterized by a mix of herbaceous plants, shrubs, small trees and occasionally bamboos. The 10 chosen forest fragments were not impacted by fire, but showed signs of regular human disturbance for the extraction of timber, firewood and other products. In comparison to that, the old-growth forest plots were situated in the Marojejy National Park, where extraction of timber, firewood and other products is not allowed. The park has been protected since 1952 (Goodman, 2000; Goodman et al., 2018) and nowadays represents the largest remnant of relatively undisturbed lowaltitude rainforest in the study region (see Fig. $2.1 \mathrm{b \& c}$ for map of study region). Within the Marojejy National Park, we chose 10 plots at two locations that showed least indication of recent human disturbance (5 plots at each location) at elevations < 700 m.a.s.I. (Appendix S2.1).

Overall, we worked on 58 plots (Appendix S2.2) and collected data between September 2018 and January 2019. The minimum distance to the nearest neighbouring plot spanned from 260 to $2555 \mathrm{~m}$ (mean $827 \mathrm{~m}$, SD $539 \mathrm{~m}$ ). Plot elevation spanned from 20 to 819 m.a.s.l. (mean 208 m, SD 213 m); plot slopes spanned from $1.6^{\circ}$ to $27.4^{\circ}$ (mean $9.8^{\circ}$, SD $5.8^{\circ}$ ). We estimated slope and elevation values using the plugin "Raster Terrain Analysis" in QGIS (QGIS Development Team, 2016), based on the 30 m-resolution digital surface model "ALOS World 3D" by the Japan Aerospace Exploration Agency (JAXA) and applied slope correction.

\section{Stand structure}

We collected all data within circular plots (Paul et al., 2019) of 25 m-radius. On each study plot we inventoried all plant species with free-standing stems with $\geq 8 \mathrm{~cm}$ of diameter at breast height (DBH), hereafter 'trees', also including arborescent palms, herbs and tree ferns but excluding lianas. Schatz (2005) suggested to use a DBH cut-off of $5 \mathrm{~cm}$ but this might include sterile saplings, without clear identification features. Additionally, a DBH cut-off of $5 \mathrm{~cm}$ would have increased our sample size and time 
investment per plot considerably. Thus, we chose a DBH cut-off of $8 \mathrm{~cm}$ to increase identification accuracy and economize time. For each plant, we measured the DBH at $1.3 \mathrm{~m}$ or immediately above the tallest buttress or stilt root, whenever this exceeded $1.3 \mathrm{~m}$, following a standardized protocol (Condit, 2008). Based on the DBH measurements we calculated the basal area per tree, summed up basal area of all trees per plot and extrapolated it to $\mathrm{m}^{2} /$ ha.

Furthermore, we estimated the percentage of canopy closure per plot, derived from digital hemispherical photographs (Jonckheere et al., 2004). We used a Nikon D5100 camera equipped with a Sigma Circular

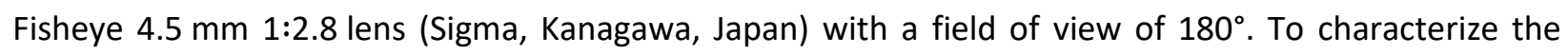
canopy above the vanilla support trees and understory vegetation, we mounted the camera on a tripod at $2.4 \mathrm{~m}$ height. On each plot, we shot a series of photographs with different exposure values and manually selected the photographs showing the best contrast between sky and vegetation, following the protocol of Beckschäfer et al. (2013). We further processed the photographs to create a binary image representing sky and vegetation by using the software "ImageJ" (Rasband, 2014) and applied an automated thresholding technique following the protocol of Beckschäfer (2015). We derived gap fraction values and converted them to canopy closure values, to finally calculate the mean canopy closure percentage per plot (Appendix S2.3).

Additionally, we estimated the leaf area index (LAI) defined as the amount of leaf area in a canopy per unit ground area (Asner et al., 2003). We retrieved LAI values with a LI-COR LAI-2200C Plant Canopy Analyzer (LI-COR, Lincoln, USA). Using two sensors with $90^{\circ}$ view caps, we collected below-canopy records on the plot and above-canopy records in nearby gaps, following the LI-COR Instruction Manual (LI-COR Biosciences, 2019). We mounted the sensors on a tripod at $2.4 \mathrm{~m}$ height to characterize the canopy above the vanilla support trees and understory vegetation, and recorded a total of 100 readings per plot. Finally, we processed the readings using the "FV 2200" software (LI-COR Biosciences, 2019) and derived one mean LAl value with $\mathrm{m}^{2}$ leaf area $/ \mathrm{m}^{2}$ ground per plot (Appendix S2.3).

\section{Tree species diversity}

We identified all living tree individuals with local and scientific names according to the Tropicos Madagascar Catalogue (http://www.tropicos.org/Project/Madagascar_with the help of one local expert and one taxonomic expert from Missouri Botanical Garden in Antananarivo. We collected samples for further comparison with herbarium specimens; voucher specimens are kept at the National Herbarium Tsimbazaza, Antananarivo and the herbarium of the University of Mahajanga. Information on origin and 
endemism for each species was derived from the Catalogue of the Plants of Madagascar (Tropicos (2020); accessed January 2020; Appendix S2.4).

The taxonomy of the highly diverse Malagasy tree flora is a dynamic field of research and species identification is a challenging task (Callmander et al., 2011). Tree identification is often based on reproductive features, so sterile tree individuals represent an additional challenge. However, we could minimize these cases by sampling during the main flowering season. Nonetheless, we used a conservative identification approach and acknowledge that our tree species diversity assessment might underestimate the actual tree species diversity, especially for rare species, due to taxonomic uncertainties.

To assess and compare species diversities between land-use types, we used the Hill number framework, which transforms common diversity measures such as Shannon entropy or Gini-Simpson index into effective numbers of species (Jost, 2006). This conversion unifies the different measures to the same unit (number of species), which allows for easier interpretation and comparison of the different diversity indices (Chao et al., 2014). We focussed on the three most common Hill number orders of species richness $(q=0)$, Shannon diversity $(q=1)$ and Simpson diversity $(q=2)$. Species richness $(q=0)$ is not sensitive to species frequency within the sample, so rare species are as important as common species. Shannon $(q=1)$ and Simpson diversity $(q=2)$ are frequency-based indices: Shannon diversity weights each species exactly by its frequency in the sample, without favouring neither rare nor common species disproportionately (Jost, 2007). Simpson diversity emphasizes the more common species whereas uncommon species hardly contribute to the value (Jost, 2007). Jointly, these three diversity measures provide insight into community diversity and evenness (Jost, 2007).

To compare the magnitude of species diversity differences across all plots and land-use types, we further integrated the Hill number framework into the sample-sized- and coverage-based rarefaction and extrapolation (R/E) approach (Chao et al., 2014). In this approach, all samples are standardized to an equal size, thus providing a fair comparison among incomplete samples (Chao et al., 2014).

\section{Data analysis}

We compared the stand structure of all land-use types in terms of stem density (individuals/ha), basal area $\left(\mathrm{m}^{2} / \mathrm{ha}\right)$, canopy closure (\%) and LAI ( $\mathrm{m}^{2}$ leaf area $/ \mathrm{m}^{2}$ ground). Therefore, we tested if assumptions for normality and homogeneity of variances were met. If the residuals were homoscedastic, we tested for differences between the groups using analyses of variance (ANOVA) and Tukey's post-hoc test. If the residuals were heteroscedastic, we used the non-parametric Kruskal-Wallis test, followed by Dunn's posthoc test (Ruxton \& Beauchamp, 2008). For the diversity analysis, we calculated Hill number diversities for 
$q=0,1$ and 2 and computed sample-size and coverage-based R/E sampling curves based on abundance data using the R-package iNEXT (Hsieh et al., 2016).

To display the numbers of shared and specialized tree species per land-use type, we used the R-package VennDiagram (Chen, 2018). To assess differences in tree species composition between land-use types, we generated an abundance-based Bray-Curtis dissimilarity matrix with two dimensions, as Bray-Curtis dissimilarity focuses on compositional changes in species' identities (Anderson \& Walsh, 2013). Based on this matrix, we applied a dispersion test using the betadisper function of the R-package vegan (Oksanen et al., 2019), followed by a permutation test (999 permutations) to identify differences in dispersion among groups, using the permutest function. To test for differences in tree species composition between land-use types, we used a pairwise permutational multivariate analysis of variance (PERMANOVA, 999 permutations; (Anderson \& Walsh, 2013)) with a Bonferroni correction, using the pairwise.adonis function in the R-package pairwiseAdonis (Martinez Arbizu, 2019). Finally, we performed non-metric multidimensional scaling (NMDS), using the metaMDS function of vegan. We performed all analyses in $\mathrm{R}$ 3.6.3 (R Core Team, 2019) and used the R-package ggplot2 (Wickham, 2011) for data visualization.

\section{Results}

\section{Stand structure}

We recorded a total of 5980 living stems belonging to 5484 single or multi-stemmed trees. Stem density per hectare varied between the land-use types and reached from a median of 1182 stems per hectare in old-growth forests to 177 stems per hectare in woody fallows (Fig. 2.2a). Forest fragments had a median stem density of 607 stems, forest-derived agroforests of 494 stems and fallow-derived agroforests of 331 stems per hectare (Fig. 2.2a, Appendix S2.5). Basal area per hectare also varied between the land-use types and spanned form a median of $41 \mathrm{~m}^{2} /$ ha in old-growth forests to a median of $3 \mathrm{~m}^{2} / \mathrm{ha}$ in woody fallows (Fig. 2.2b). Forest-derived agroforests had a median basal area of $18 \mathrm{~m}^{2} /$ ha comparable to forest fragments $\left(20 \mathrm{~m}^{2} / \mathrm{ha}\right)$ and fallow-derived agroforests had a median basal area of $8 \mathrm{~m}^{2} / \mathrm{ha}$ (Fig. 2.2b; Appendix S2.6). 
(a)

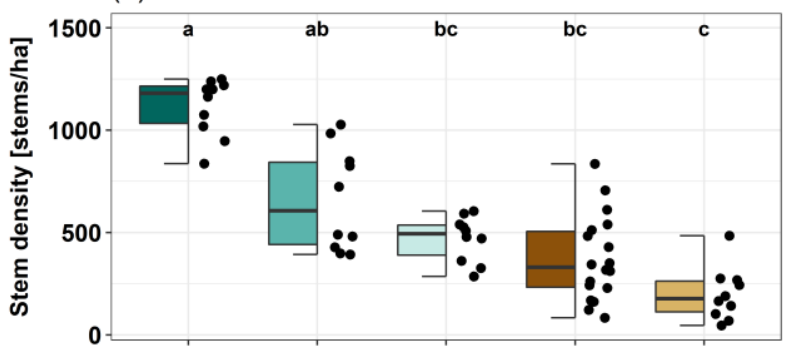

(c)

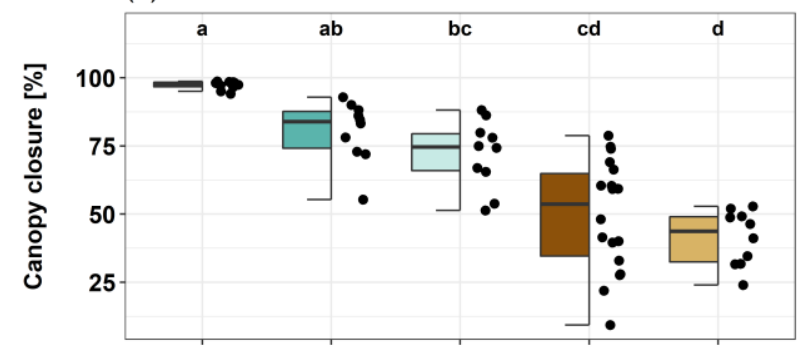

(e)

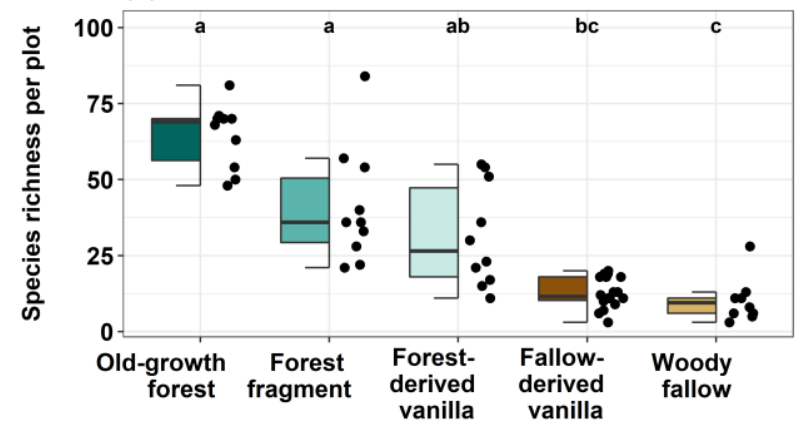

(b)

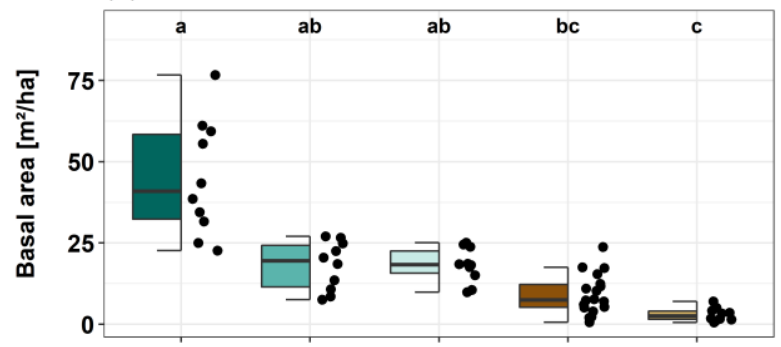

(d)

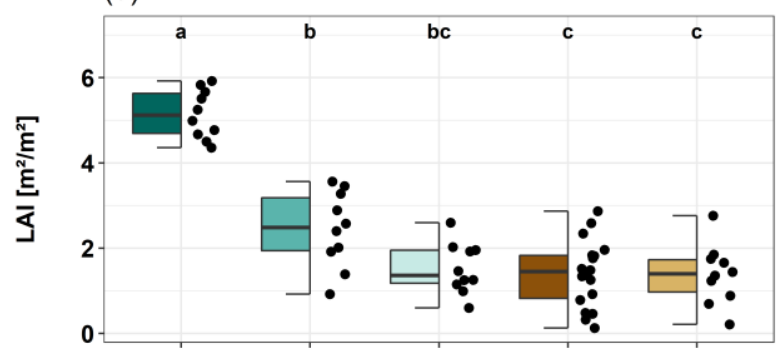

$(f)$

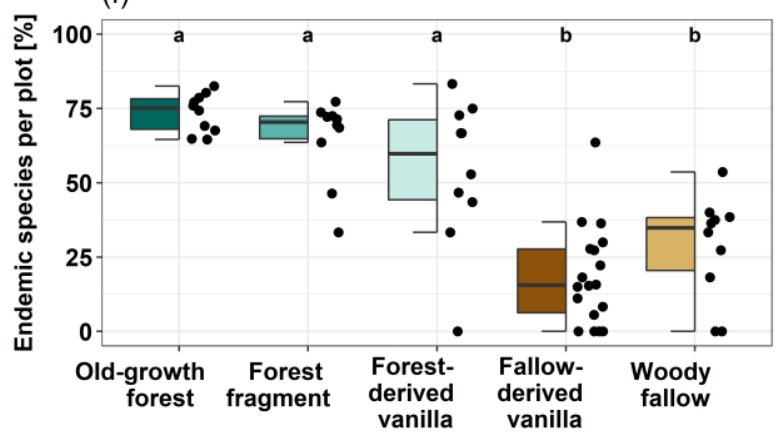

Fig. 2.2: Stand structure and tree diversity on the five studied land-use types (a) stem density [stems/ha]; (b) basal

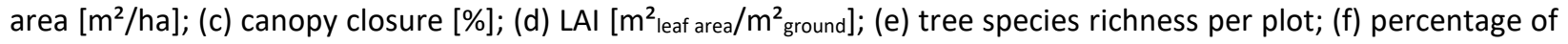
endemic species per plot. The black horizontal lines represent the median for each land-use type. The lower and upper hinges of each box correspond to the first and third quartiles. The upper whiskers extend to the largest value whereas the lower whiskers extend to the smallest value, no further than 1.5 times the inter-quartile range from the hinges of the box, respectively. Letters indicate significant differences between land-use types. For panels (a), (b), (c) \& (e), results are based on Kruskal-Wallis rank sum test $(p<0.05)$ and Dunn's post-hoc test. For panels $(d) \&(f)$, results are based on ANOVA and a Tukey's HSD post-hoc test (Appendix S2.5 - S2.10).

Canopy closure and LAI were significantly higher in old-growth forests than in both types of vanilla agroforests and woody fallows (Fig. 2.2c \& d; Appendix S2.7 \& S2.8). Old-growth forests had a canopy closure median of $98 \%$ and an LAI median of 5.1, which was significantly higher than the LAI median in forest fragments (2.5). Within vanilla agroforests, forest-derived agroforests had a canopy closure median 
of $75 \%$ and an LAI median of 1.4, whereas fallow-derived agroforests had a canopy closure median of $54 \%$ and an LAI median of 1.5.

\section{Tree species diversity}

Of the recorded 5484 individuals, 90\% were classified as trees (sensu stricto with woody stems, see Schatz (2005), $2 \%$ as palms, $1 \%$ as tree ferns and $7 \%$ as arborescent herbs. Overall, we identified 455 species and morphospecies belonging to 195 genera and 71 families. The most species-rich families were Rubiaceae (34 species), Lauraceae (28 species), Fabaceae and Moraceae (both 25 species; Appendix S2.11).

Species richness per plot varied between land-use types and spanned from a median of 69 species in oldgrowth forests to a median of 10 species in woody fallows (Fig. 2.2e). Forest-derived agroforests had a median of 27 species and fallow-derived agroforests of 12 species. Forest fragments had a median of 36 species (Fig. 2.2e; Appendix S2.9).

Furthermore, forest-derived and fallow-derived agroforests differed significantly in both species richness $(q=0)$ and community evenness (Shannon diversity $q=1$ and Simpson diversity $q=2$ ), as indicated by the rarefaction and extrapolation curves with non-overlapping 95\% confidence intervals (Fig. 2.3). Comparing species richness $(q=0)$ and community evenness $(q=1$ and $q=2)$ for all land-use types, rarefaction and extrapolation curves revealed a significant difference between the group of forest-derived agroforests, forest fragments and old-growth forests and the group of fallow-derived agroforests and woody fallows (Fig. 2.3). 


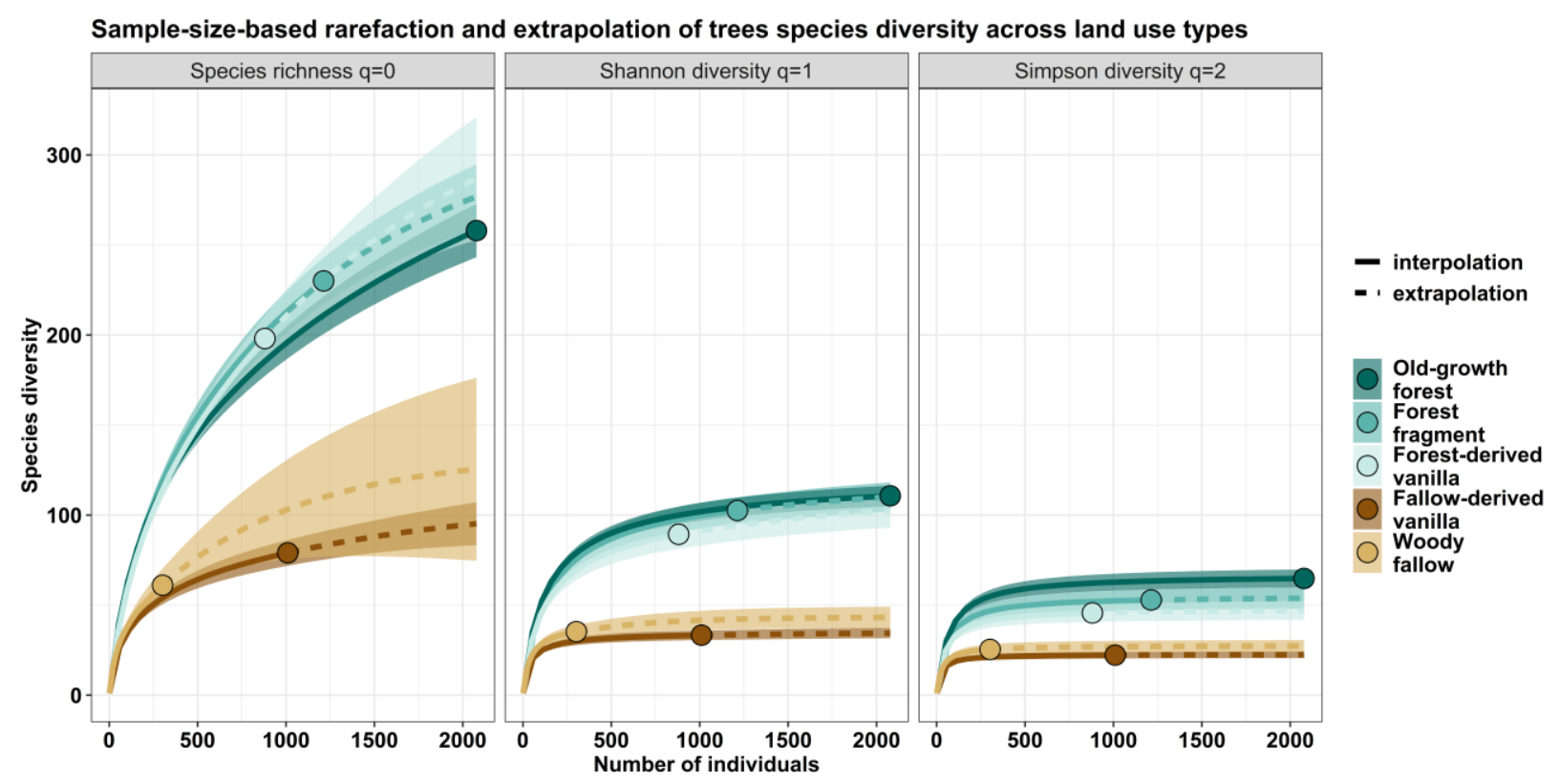

Fig. 2.3: Sampling curves of sample-size-based rarefaction (solid lines) and extrapolation (dashed curves), up to the base sample size of 2078 individuals (= the maximum reference sample size) of tree species diversity for Hill number orders $q=0, q=1$, and $q=2$ across land-use types. The $95 \%$ confidence intervals (shaded regions) were obtained by a bootstrap method based on 200 replications (Appendix S2.12). Colours represent land-use types and reference samples are denoted by solid dots.

The group of forest-derived agroforests, forest fragments and old-growth forests showed overlapping 95\% confidence intervals for species richness, indicating species pools of similar sizes (Fig. 2.3; Appendix S2.12). Confidence intervals of Shannon diversity curves for these three land-use types also overlapped. Confidence intervals of Simpson diversity curves only overlapped for forest-derived agroforests and forest fragments, whereas old-growth forests were higher and confidence intervals did not overlap with any other land-use type.

For the group of fallow-derived agroforests and woody fallows, rarefaction and extrapolation curves for species richness indicated similar-sized species pools, even though woody fallows showed a larger confidence interval than fallow-derived agroforests (Fig. 2.3). Additionally, both Shannon and Simpson diversity curves for these two land-use types overlapped, indicating similar community evenness (Fig. 2.3; Appendix S2.12).

\section{Tree species composition}

Of all 455 inventoried tree species, 229 species (50\%) occurred in the two vanilla agroforest types, among which 48 species occurred in both agroforest types and 150 only in forest-derived agroforests (Fig. 2.4). 
Old-growth forests, forest fragments and forest-derived agroforests shared 53 species (14\%) that did not occur in the fallow-derived agroforests or the woody fallows. The latter two shared 29 species (6\%), that did not occur in any of the old-growth forest, forest fragment or forest-derived agroforest plots (Fig. 2.4). Additionally, 221 species (47\%) occurred only in old-growth forests or forest fragments, among these 118 species (26\%) occurred exclusively in old-growth forest (Fig. 2.4).

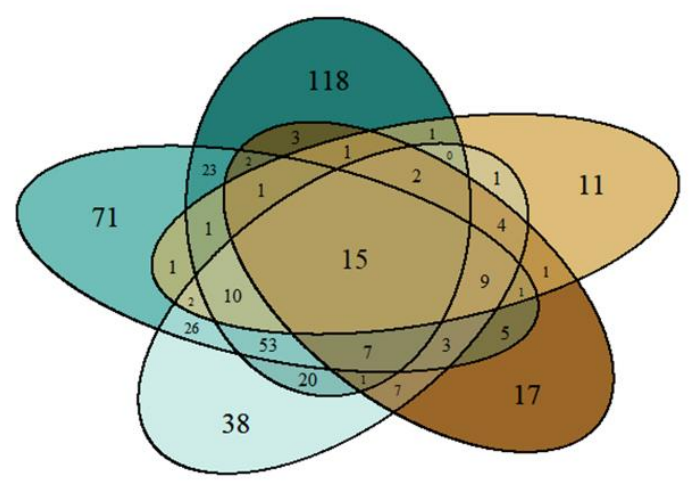

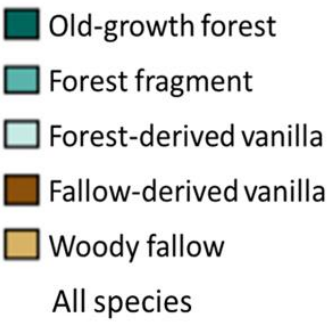

$$
\begin{aligned}
& n=258 \text { species } \\
& n=230 \text { species } \\
& n=198 \text { species } \\
& n=79 \text { species } \\
& n=61 \text { species } \\
& n=455 \text { species }
\end{aligned}
$$

Fig. 2.4: Shared and exclusive tree species occurrence of 455 species in the five studied land-use types.

From the 455 species in this inventory, 279 (61\%) were endemic, 114 (25\%) native but not endemic, 34 (8\%) introduced and 28 (6\%) of unknown origin. Endemic species proportions per plot varied between the land-use types and spanned form a median of $75 \%$ in old-growth forests to $16 \%$ in fallow-derived agroforests (Fig. 2.2f). In forest-derived agroforests, endemic species proportions had a median of 59\%, which was significantly higher compared to fallow-derived agroforests (16\%) and woody fallows (35\%) (Fig. 2.2f; Appendix S2.10).

Based on their proportional occurrence in each land-use type, the majority of the 279 endemic species were found in forest habitat: old-growth forests and forest fragments accounted for the largest share of endemic species and exclusively harboured 142 (51\%) of the inventoried endemic species whereas we recorded only 4 (2\%) endemic species exclusively in woody fallows or fallow-derived agroforests (Fig. 2.5a). Forest-derived agroforests harboured 125 (45\%), fallow-derived agroforests harboured 24 (9\%), and woody fallows harboured 25 (9\%) of the inventoried endemic species (Fig.2.5a). 
(a)

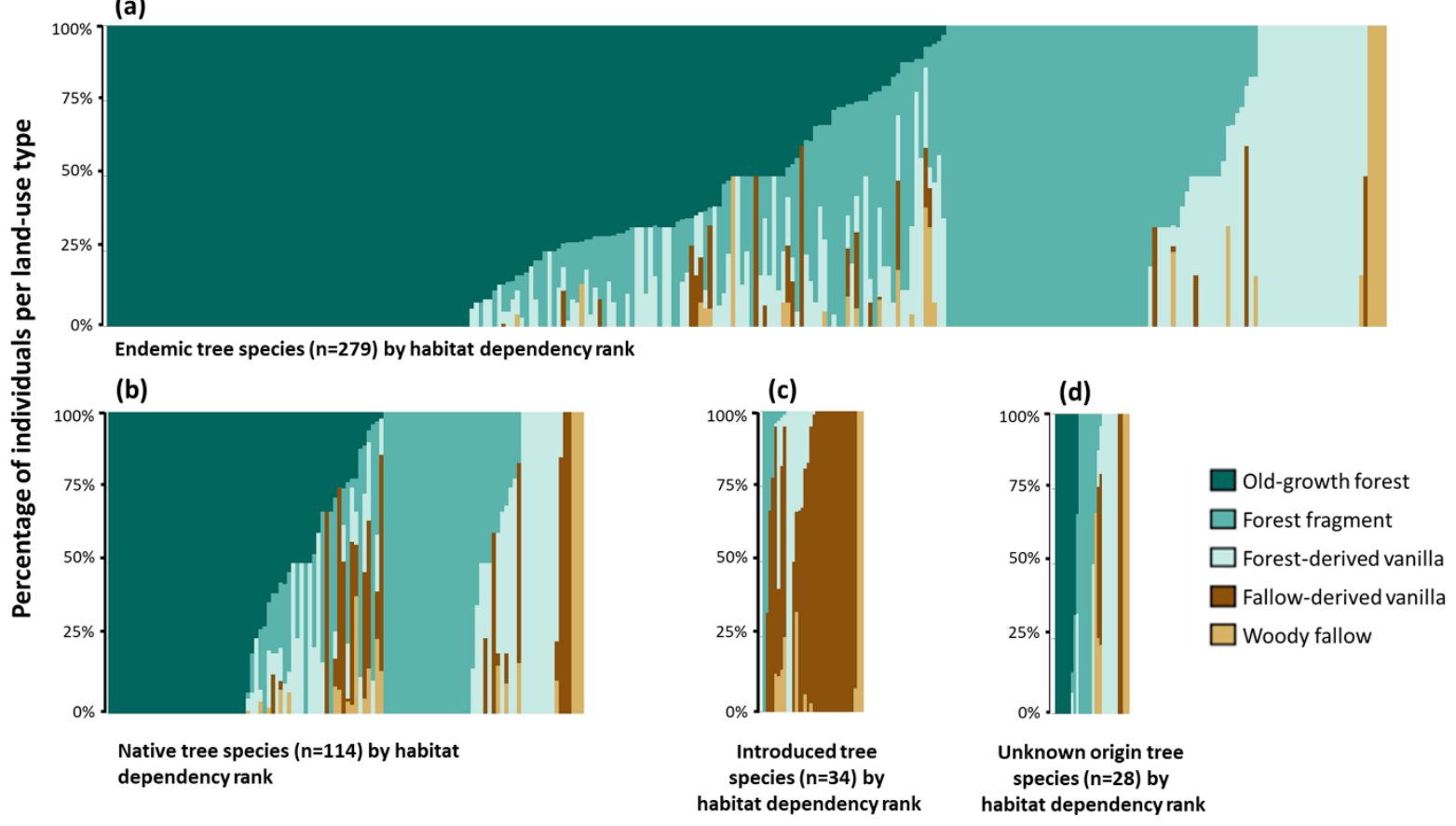

Fig. 2.5: Forest dependency of 455 tree species and 5484 tree individuals measured as proportion of individuals of each species in each of the five land-use types: (a) proportion of 279 endemic species; (b) proportion of 114 native but not endemic species; (c) proportion of 34 introduced species; (d) proportion of 28 species of unknown origin in each of the five land-use types.

The pattern was similar for the 114 native but not endemic species in our inventory. Old-growth forests and forest fragments accounted for the largest share of native species and exclusively harboured 57 (50\%) of the inventoried native species, whereas we recorded only 5 (4\%) native species exclusively on woody fallows or fallow-derived agroforests (Fig. 2.5b). Forest-derived agroforests harboured 48 (42\%), fallowderived agroforests harboured 22 (19\%), and woody fallows harboured 21 (18\%) of the inventoried native species (Fig. 2.5b).

Among the 34 introduced species, 29 (85\%) species occurred in fallow-derived agroforests (Fig. 2.5c) and $14(41 \%)$ species were also found in forest-derived agroforests. Additionally, 10 (29\%) species were recorded in woody fallows, $8(24 \%)$ species in forest fragments and no species in old-growth forests (Fig. 2.5c). From the 28 species of unknown origin in our inventory, 75\% were recorded only in forestderived agroforests, old-growth forests and forest fragments (Fig. $2.5 \mathrm{~d}$ ).

The land-use types differed in species composition, particularly between the group of forest-derived agroforests, forest fragments and old-growth forests and the group of fallow-derived agroforests and 
woody fallows, indicated by clear and tight clusters from the NMDS ordination (Fig. 2.6). Significant differences in dispersion occurred between old-growth forests and all other land-use types but were not significant between vanilla agroforests (Appendix S2.13). Furthermore, species composition in forest-and fallow-derived agroforests was significantly different, as revealed by PERMANOVA results (Appendix S2.14). Species composition in forest-derived agroforests was more similar to forest fragments than to fallow-derived agroforests. Additionally, species composition in fallow-derived agroforests was more similar to woody fallows than to forest-derived agroforests, forest fragments or old-growth forests. Species composition in old-growth forests was significantly different compared to all other land-use types, as revealed by PERMANOVA results (Appendix S2.14).

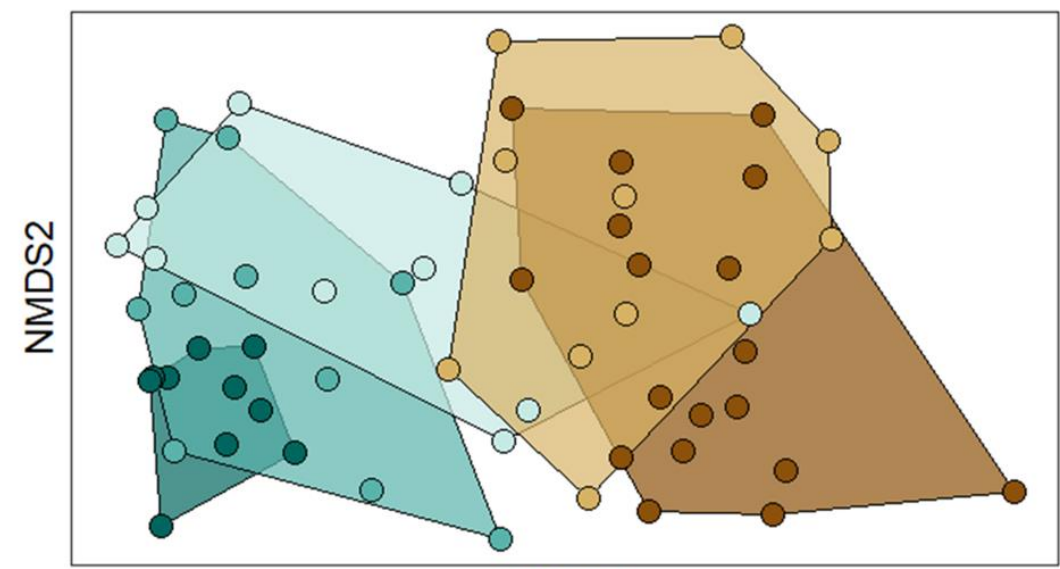

NMDS1

$\square$ old-growth forest

Forest fragment

Forest-derived vanilla

Fig. 2.6: Species composition of the five land-use types as revealed by non-metric multidimensional scaling (NMDS) based on Bray-Curtis dissimilarity ( $k=2$; stress level 0.19855). We tested for dispersion effects among groups (followed by a pairwise permutation test with 999 permutations) and identified dispersion differences between oldgrowth forest and all other land-use types (Appendix S2.13). Pairwise permutational multivariate analysis of variance (PERMANOVA, 999 permutations; with Bonferroni-correction) between land-use types revealed significant differences between old-growth forest and all other land-use types. Forest-derived and fallow-derived vanilla agroforests also showed significant differences in species composition; all other pairs were not significantly different from each other (Appendix S2.14). 


\section{Discussion}

The mosaic landscape of north-eastern Madagascar comprised a wide range of stand structure attributes and a high tree species diversity. We show that land-use history determined stand structure, tree diversity and community composition in vanilla agroforests. Forest-derived agroforest harboured a significantly higher tree diversity and a different community composition than fallow-derived agroforest with more endemic tree species in forest-derived agroforests compared to fallow-derived agroforests. Total and endemic tree species diversity in forest-derived agroforests was more similar to forest fragments and oldgrowth forests than to fallow-derived agroforests; the latter was more similar to woody fallows than to forest-derived agroforests. We thus demonstrate that forest-derived agroforests can play an important role in providing habitat for forest-dependent tree species, but it results from forest degradation. In contrast, fallow-derived agroforests play a marginal role for tree species diversity but contribute to the recovery of stand structure on historically forested degraded land.

\section{Stand structure}

Stem density, basal area, canopy closure and LAI were highest in old-growth forests. The median basal area in old-growth forests of $41 \mathrm{~m}^{2} /$ ha was similar to the median value of $39 \mathrm{~m}^{2} /$ ha for Malagasy lowland rainforests (Ibanez et al., 2019). Also, the LAI median of 5.1 in old-growth forests in our study was similar to the mean LAI of 4.8 in tropical evergreen humid forests (Asner et al., 2003), indicating a continuous and little disturbed canopy. The significant decline of LAI from old-growth forests to forest fragments, vanilla agroforests and woody fallows indicates a structural simplification along with changing light regimes, that may affect the growth and mortality of tree seedlings and saplings and influence tree species diversity and composition (Montgomery \& Chazdon, 2001; Rocha-Santos et al., 2016). The observed structural simplification is likely caused by different levels of human interference (Allnutt et al., 2013) or natural forces, e.g. cyclones (de Gouvenain \& Silander, 2003).

Within vanilla forests, we observed variability in stand structure characteristics, where forest-derived vanilla agroforests were more similar to forest fragments, and fallow-derived agroforests were more similar to woody fallows. This further suggests that past land-use is the main driver for stand structure dynamics and recovery opportunities in tropical tree-dominated habitats (Chazdon, 2003). Observations in other agroforestry systems also reported significant variations in stand structure characteristics within agroforests (e.g Hending et al., 2020; Moguel \& Toledo, 1999; Rappole et al., 2003) and even though these studies did not specifically address or report land-use history, the observed stand structure variation within these agroforests might also be influenced by land-use history differences. However, a case study 
from Cameroon reported that forest- and savannah-derived cacao agroforests exhibit an increasingly comparable stand structure within maturing agroforest (Nijmeijer et al., 2019). Also, a chronosequence from vanilla agroforests in Madagascar showed that canopy structures initially differ but fallow-derived agroforests increase canopy structures and become more similar to forest-derived agroforest canopy structures over time (Martin, Wurz, et al., 2021). This indicates that forest-derived agroforests initially exhibit higher canopy closure and basal area than fallow-derived agroforests but stand structure characteristics have the potential to become more similar over time.

Other species groups such as birds also respond to agroforest land-use history across the same plots: fallow-derived agroforests provide less valuable bird habitat but indirectly favor birds by contributing to recover stand structure on open historically forested land (Martin et al., 2020). In contrast, forest-derived agroforests provide more valuable bird habitat and avoid total loss of natural tree cover even though they result from forest degradation which affects birds negatively (Martin, Andriafanomezantsoa, et al., 2021). Yet, our results indicate that fallow-derived agroforests have the potential to recover stand structure characteristics and become structurally similar to forest-derived agroforests and this structural alignment becomes stronger over time (Martin, Wurz, et al., 2021).

\section{Tree species diversity}

Land-use history strongly determined tree species diversity in vanilla agroforests: vanilla agroforests harboured 229 species (50\%) of all inventoried tree species and tree species diversity in forest-derived agroforests was more than twice as high compared to fallow-derived agroforests. Overall, tree diversity in forest-derived agroforests was more similar to old-growth forests and forest fragments whereas tree diversity in fallow-derived agroforests was more similar to woody fallows. Therefore, we confirm that vanilla agroforests can play a substantial role to maintain high levels of tree diversity within the humanmodified landscape (Hending et al., 2020). In addition, we highlight that considering land-use history is pivotal to assess the conservation value of vanilla agroforests.

Additionally, tree species diversity in Madagascar is closely linked to the survival of other species groups such as lemurs (Ganzhorn et al., 1997). Given that many lemur species face extinction risk driven by habitat loss and human disturbance (Schwitzer et al., 2013, 2014), they critically depend on the structural and phenological variability of trees, that offer a broad range of microhabitats and food resources for lemurs (Ganzhorn et al., 1997). Besides its ecological importance, tree diversity is also of benefit to human-wellbeing by providing shade, fruits and a range of products, thereby reducing vulnerability to environmental, economic or social shocks (Reed et al., 2017). Especially in Madagascar, a high share of 
the country's population lives in rural areas with low infrastructure, therefore their livelihoods highly depend on natural resources and tree products for domestic use and off-farm income (Zaehringer et al., 2017). Additionally, maintaining tree diversity may also increase resilience in light of climate change (Isbell et al., 2011).

\section{Tree species composition}

Our results further show that land-use history strongly determined tree species composition in vanilla agroforests. In forest-derived agroforests, tree community composition partly overlapped with forest fragments, indicating that forest-derived agroforests provide the option to incorporate many forest trees into agricultural production systems, with only moderate compositional changes and species turnover compared to forest fragments. Especially if management practices allow for natural regeneration of native and endemic trees, these agroforests have the potential to contribute to long term tree conservation in the agricultural landscape, as shown for other tropical agroforestry systems (Valencia et al., 2016).

Fallow-derived agroforests harboured proportionally fewer endemic tree species than woody fallows, but the community composition in both land-use types still overlapped, indicating that the transition from woody fallows to fallow-derived agroforests might not result in strong tree species turnover. Additionally, natural forest regrowth on woody fallows in Madagascar after slash-and-burn agriculture seems to be slow and often dominated by a few fast-growing pioneer species, eventually leading to a complete loss of woody species after several cropping cycles (Manjaribe et al., 2013; Styger et al., 2007; Zwartendijk et al., 2017).

Tree species communities in both agroforest types also included introduced species. These non-native species can act as invaders and alter habitat dynamics (Bos et al., 2008). However, non-native tree species also contribute to increase canopy cover and basal area and can also ameliorate degraded soils and promote understorey growth (Bollen \& Donati, 2006). Furthermore, non-native trees can serve as important components in resilient smallholder farming landscapes and form fundamental pillars of the local economy and daily needs, such as for cash crop cultivation (e.g. clove) or fruit cultivation (Kull et al., 2014; Zaehringer et al., 2017).

Additionally, tree species community composition in old-growth forests was unique compared to all human-modified land-use types. Even though these differences might partly be driven by variances in group dispersion, as old-growth forests plots were spatially closer together than all other land-use type plots, the differences strongly indicate species turnover between old-growth forests and all other landuse types. Especially among endemics, $28 \%$ occurred exclusively in old-growth forests. Even though many 
endemics are rare and poorly studied, and there is limited understanding of individual species habitat requirements and dispersal syndromes (Buerki et al., 2013), more than $60 \%$ of the Malagasy endemic tree genera are known to be confined to humid forests for their survival (Schatz, 2005). Palms also exhibit a high diversity in Madagascar (Dransfield \& Beentje, 1995) and were most abundant and diverse in oldgrowth forests. Given that more than $83 \%$ of Malagasy palm species are ranked as threatened due to habitat loss (Rakotoarinivo et al., 2014), this further underlines the irreplaceable value of old-growth forests for biodiversity in Madagascar (K. A. Brown et al., 2015; Schatz, 2005) and elsewhere (Gibson et al., 2011).

A loss of tree species in general and endemic and forest-dependent species in particular might also have cascading effects on functionally linked species groups, which depend on trees as habitat-providing elements and food resources (Ganzhorn et al., 1997; Herrera, 2016; Irwin et al., 2010). Furthermore, tree species composition might be influenced by seed dispersers such as frugivorous lemurs (Martinez \& Razafindratsima, 2014). However, identifying and understanding the specific drivers of tree community change in agroforests, natural forest and fallow sites would strongly improve the development of management schemes to maintain tree species diversity in mosaic smallholder landscapes; however, this goes beyond the scope of this paper.

\section{Conservation implications}

Vanilla agroforests rarely undergo drastic clearing after their initial establishment (Martin, Wurz, et al., 2021) and if agroforest management interventions allow natural tree regeneration, the stand structure might recover at the plot level over time (Jagoret et al., 2018) and might even result in a canopy cover increase at the landscape scale (Martin, Wurz, et al., 2021). Additionally, the establishment of agroforests on historically forested open land prevents further degradation on lands under slash-and-burn cultivation (Styger et al., 2007). Depending on management activities such as tree planting, cutting and pruning, both agroforest types might contribute to maintain or restore stand structure and functional processes and also contribute to increase canopy cover on the plot- and landscape scale over time (Martin, Wurz, et al., 2021). This becomes specifically important, as forest fragments in agricultural landscapes are likely to disappear over time (Schüßler et al., 2020). Indeed, predictions show that Malagasy lowland-rainforest trees are vulnerable to both individual and combined effects of land-use and climate change (K. A. Brown et al., 2015). Similar scenarios are unfolding in other tropical countries resulting in a worrying decline of the pantropical forest cover, despite protected areas (Hansen et al., 2020). Consequently, agroforests can 
enhance connectivity, dispersal and movement within a landscape matrix, as the matrix becomes structurally more similar to the remnant patches (Driscoll et al., 2013).

We conclude that forest-derived agroforests represent an alternative to forest conversion by slash-andburn agriculture and have the potential to serve as habitat refugia and biodiversity reservoirs for forestdependent species. If diverse and dense canopies are maintained, forest-derived agroforests can sustain high levels of tree species diversity and important habitat structures, corroborating Martin et al. (2020). However, agroforests represent a degradation and a structural simplification in comparison to old-growth forests. If old-growth forests continue to decline, agroforests cannot replace these habitats. At the landscape scale, old-growth forest transformation may lead to habitat and species homogenization with negative and strong far-reaching impacts upon ecosystem stability and multifunctionality (De Beenhouwer et al., 2013; van der Plas et al., 2016). Therefore, we strongly argue against agroforest establishment in old-growth forests as it would decrease habitat complexity and impair native and endemic tree species and other forest-dependent species and is therefore not justifiable. Furthermore, if old-growth forest habitats are protected, the legal establishment of forest-derived agroforests can exclusively take place in forest fragments. However, forest fragments are important to maintain tree species diversity and habitat structures and should also be integrated into conservation schemes within multifunctional human-modified landscapes (Duriaux Chavarría et al., 2018).

Fallow-derived agroforests only have a limited contribution to maintaining tree diversity. However, fallowderived agroforests permanently integrate trees into agricultural production. They also regain stand structure on degraded historically forested land and this structural alignment becomes stronger over time, thereby contributing to an increase in canopy cover and connectivity at the landscape scale (Martin, Wurz, et al., 2021). This re-establishment of stand structure and vegetation on historically forested fallow land might also result in a quicker rehabilitation and built-up of soil nutrient stocks (Klanderud et al., 2010). Furthermore, fallow-derived agroforests can be integrated as a restoration approach into certification schemes to provide incentives to farmers to maintain or plant trees on historically forested open land (Giudice Badari et al., 2020). Especially since Madagascar is among the countries with highest mean restoration opportunity scores (Brancalion et al., 2019), fallow-derived vanilla agroforests could be integrated into the national restoration agenda.

Our findings show that agroforests should not be considered as a substitute but as an addition to forest conservation at the landscape level. Thus, agroforests can represent a means to retain or increase tree cover and connectivity in a multifunctional landscape, but it is key to consider their land-use history and 
management, to unfold their full conservation potential and to mitigate further degradation and species loss.

\section{Author contribution}

KO, DAM, AW, MRS, HLTR and DH conceived the ideas and designed methodology; KO and MRS collected tree inventory data; KO and AM collected canopy closure and LAI data; KO processed and analyzed the data; KO led the writing of the manuscript. All authors contributed to the manuscript and gave final approval for publication.

\section{Acknowledgments}

We thank all plot owners, all chef de fokontany and the village residents for their hospitality and for granting us access to information and sites. We are grateful to Thorien Rabemanantsoa, Jean Chrysostome Bevao and Patrice Antilahimena for their support during data collection. At the institutional basis, we acknowledge the support of MNP (Madagascar National Parcs) and Ministère de I' Environnement, de I' Écologie et des Forêts (MEEF).

To facilitate tree species identification, we collected samples of leaves, twigs, fruits and flowers based on research permits $\mathrm{N}^{\circ} 18 / 18 / \mathrm{MEEF} / \mathrm{SG} / \mathrm{DGF} / \mathrm{DSAP} / \mathrm{SCB} . \mathrm{Re}$ and $\mathrm{N}^{\circ} 254 / 18 / \mathrm{MEEF} / \mathrm{SG} / \mathrm{DGF} / \mathrm{DSAP} / \mathrm{SCB} . \mathrm{Re}$ ) issued by MEEF, Antananarivo, Madagascar. Tree species were identified with the help of Jean Chrysostome Bevao (local names) and Patrice Antilahimena from Missouri Botanical Garden at the family, genus-, and species level. 


\section{Chapter 3: Case study: Tree composition in the mosaic landscape}

Manuscript title: High species turnover in tree communities in the mosaic landscape of north-eastern Madagascar

Authors: Kristina Osen; Marie Rolande Soazafy; Dominic A. Martin; Annemarie Wurz; Patrice Antilahimena; Hery Lisy Tiana Ranarijaona, Dirk Hölscher

Manuscript status: $\quad$ Advanced draft

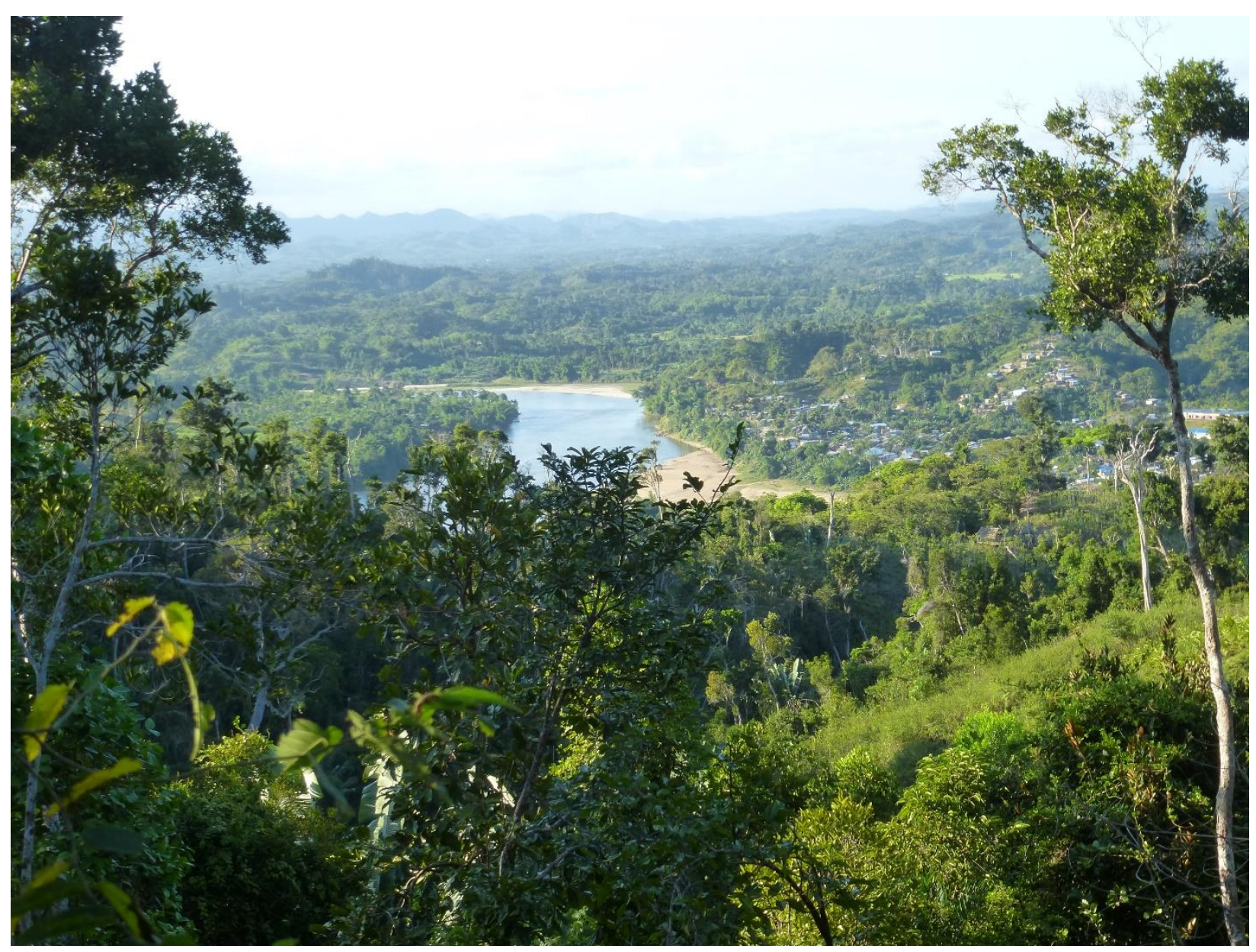




\section{Abstract}

Aim:

Tropical forests undergo transformations into human-modified landscapes with potentially severe consequences for species communities. We aimed to quantify and better understand the variation of tree species communities within and among different land-use types in a smallholder mosaic landscape.

\section{Location:}

Smallholder mosaic landscape in north-eastern Madagascar.

\section{Methods:}

We analysed the tree community composition using beta-diversity metrics that reflect changes in both species' composition and abundance. Tree inventories were conducted in old-growth forests, forest fragments, forest-derived vanilla agroforests, fallow-derived vanilla agroforests, and naturally regenerating woody fallow as part of the slash-and-burn agriculture cycle.

\section{Results:}

We found a high beta-diversity of tree species in all land-use types, even if their regional species pool was already impoverished. Changes in the tree community composition predominantly consisted of species turnover, whereas species nestedness accounted only for a small proportion of observed composition changes both within and among land-use types. Every land-use type was dominated by a set of tree species but the composition of these subsets of dominant species varied across land-use types.

\section{Main conclusions:}

Many tree species can (thus far) persist in this mosaic landscape but we identified high turnover rates within and between tree communities in different tree-based land-use types, indicating that tree communities are transforming both in identity and abundance. Thus, we suggest considering the high turnover rates of tree species communities in the planning of conservation and restoration projects, to maintain the unique tree species assemblages and the associated landscape gamma-diversity within the human-modified mosaic landscape.

Keywords: beta-diversity; endemism; community assembly; conservation; dominance; rarity; rehabilitation; restoration; species composition 


\section{Introduction}

Natural landscapes are being transformed into human-modified landscapes, with agricultural expansion playing a central role and contributing to biodiversity decline (Green et al., 2005; IPBES, 2019; Olden, 2006; Ramankutty et al., 2018). This calls for land-use management schemes and conservation measures that prevent, halt or reverse such dynamics, to maintain species diversity, ecosystem functions and services (Gann et al., 2019; Grass et al., 2019; IPBES, 2019; UN Decade on Ecosystem Restoration 20212030). As a first approximation, conservation measures commonly build on biodiversity assessments, using species richness as a standard evaluation tool (Hillebrand et al., 2018). Even though species richness measures provides valuable information, they highlight only one aspect of the multifaceted construct of biological diversity and neglect other aspects such as species turnover and dominance patterns (Hillebrand et al., 2018). Local species richness in human-dominated landscapes can be fairly high, yet their community composition might be altered compared to natural landscapes (Socolar et al., 2016; Solar et al., 2015). Thus, it is necessary to extend emphasis beyond species richness to capture and quantify non-random changes in species composition caused by humans and detect potential biotic homogenization which might even be decoupled from species richness (Hillebrand et al., 2018; Mori et al., 2018; Socolar et al., 2016).

Biotic homogenization in the broader sense refers to an ecological process that encompasses the loss of genetic and taxonomic distinctiveness and/or the replacement of many complex functional and ecological systems by fewer and simpler systems (McKinney \& Lockwood, 1999; Mori et al., 2018; Olden, 2006; Solar et al., 2015; Tabarelli et al., 2012). Yet, studying species composition change does not necessarily measure extinction but rather losses and gains of species identities and abundances (Hillebrand et al., 2018). However, in the case of endemic species, a local loss and replacement increases the risk of global extinction (Fordham \& Brook, 2010; Pimm et al., 2014).

Madagascar harbours a wealth of endemic species among which a high proportion has narrow range sizes, further classifying them as microendemics (Vences et al., 2009). This high concentration of biotic endemism arises not only at the species level but also at higher clades of genera and families (Vences et al., 2009). However, the country faces many challenges at the nexus of sustainable development, health, agricultural expansion and conservation (Herrera et al., 2021; Jones et al., 2019). Madagascar counts among the countries with highest levels of threatened trees (BGCl, 2021) and especially the eastern rainforests obtain a high biological distinctiveness and comprise a remarkable species diversity and high endemism rates for trees and other taxa (Goodman \& Benstead, 2005; Schatz, 2005; Vences et al., 2009; 
Willis, 2017). Yet, these forests experience high land-use pressure and undergo conversion into humanmodified landscapes (Vieilledent et al., 2018; Zaehringer et al., 2016). Currently, north-eastern Madagascar still holds the highest percentage of forest cover compared to the rest of the island, but deforestation rates are high (Vieilledent et al., 2018) and advance the potential homogenization of the landscape (Zaehringer et al., 2015). This urgently calls for land-use options that better align social and economic needs and interests with conservation goals to avoid land degradation and species loss (Jones et al., 2019). Previous research already highlighted that several land-use types in this landscape sustain high levels of tree species richness (Osen et al., 2021). However, questions of homogenization and heterogeneity among trees species assemblages within and among land-use types have not yet been assessed.

Biotic homogenization and heterogeneity among species assemblages can be quantified as beta-diversity, using a wide range of established metrics (Mori et al., 2018; Olden, 2006; Socolar et al., 2016). In this study, we build on the benchmark that biotic heterogeneity is linked to the classical multiplicative betadiversity sensu Whittaker (1960), in which beta-diversity is the ratio between gamma- and alpha-diversity and thus reflects the degree of compositional variability among sampling units (Baselga, 2013; Tuomisto, 2010; Whittaker, 1960). As such, beta-diversity is either calculated through pairwise dissimilarities or multiple-site dissimilarity measures to account for overall assemblage heterogeneity (Baselga, 2013, 2017). Depending on data availability and initial ecological questions, beta-diversity can be derived from incidence data or from abundance data. Generally, incidence-based measures account for all species identities equally, no matter how rare or common the species are. Abundance-based measures give less weight to rare species but capture abundance changes and dominance patterns. Thus, the combination of incidence-based metrics and abundance-based metrics allows to understand dissimilarity changes driven by compositional differences as well as by abundance differences (Baselga, 2017; Socolar et al., 2016).

Furthermore, beta-diversity can be partitioned into its components of turnover and nestedness. Turnover means that some species replace others, whereas nestedness occurs when the species composition in a site represents a subset of the more diverse species composition in another site (Anderson et al., 2011; Baselga, 2010). Thereby, this partition allows to differentiate between the complementarity and the loss of species and has strongly contributed to a more rigorous understanding of community organization (Baselga, 2017; Karp et al., 2012; Mori et al., 2018; Socolar et al., 2016). Additionally, turnover and nestedness have a high relevance to inform conservation practitioners: turnover among natural sites 
implies that conservation measures should target a variety of sites and species, while nestedness suggests that conservation measures should better concentrate on the richest sites and species assemblages to maximize regional species diversity (Socolar et al., 2016).

Most unmanaged forest tree communities are often composed of a few common species with high abundances and many rare species with low abundances (Drever et al., 2012; Enquist et al., 2019). Patterns of commonness and rarity based on abundance and range size commonly build up on local abundance, extent of the geographic range, and habitat specificity (Enquist et al., 2019). However, changes in species composition (loss/gain) are not random and might affect community composition and ecosystem functions in different ways: Endemic species classify to have a restricted geographical distribution (Fordham \& Brook, 2010) and rare species classify to occur in low abundances (Drever et al., 2012). Thus, endemic and rare species are disproportionately vulnerable to climate- and land-use change and habitat loss and are orders of magnitude more likely to go extinct (Enquist et al., 2019; Fordham \& Brook, 2010; Pimm, 2021; Pimm et al., 2014). In contrast, dominant species have a high local abundance and often broad spatial distribution. Both rare and dominant can serve as early indicators of future ecosystem changes or even indicate extinction risks and can therefore help to understand community composition and adapt conservation measures (Avolio et al., 2019).

We studied tree community compositions in the human-modified mosaic landscape of north-eastern Madagascar across different tree-based land-use types. The study comprises the land-use types forest fragments, woody fallows resulting from slash-and-burn shifting cultivation, forest- and fallow-derived vanilla agroforests, as well as one last remaining block of near-natural old-growth forest. Our main objectives were to quantify the variability of tree communities in terms of species identities and abundances and to differentiate between turnover and nestedness within and among land-use types. Relatedly, we further looked into patterns of species dominance and rarity. These results may inform conservation interventions to maintain tree diversity and enhance ecological integrity of tree-based ecosystems within the human-modified mosaic landscape.

\section{Methods}

\section{Study area}

We conducted our study in north-eastern Madagascar in the SAVA region (Fig. 3.1). This part of the country used to be covered with humid evergreen forest of exceptional floristic diversity and endemism levels (Callmander et al., 2011; Du Puy \& Moat, 1996; Goodman \& Benstead, 2005; Schatz, 2005) but 
agricultural expansion fuelled high deforestation rates (Vieilledent et al., 2018). Nowadays, remnants of continuous old-growth forest with little or no human disturbance only remain in protected areas (Schüßler et al., 2020). Outside of protected areas, the mosaic landscape consists of vanilla agroforests, paddy rice fields, and different stages of slash-and-burn shifting cultivation for hill rice production (Malagasy: tavy), interspersed with forest fragments. The climate of the study area is tropical-humid climate with a mean annual temperature of $23.9^{\circ} \mathrm{C}$ and $2258 \mathrm{~mm}$ of mean rainfall per year across 58 study plots (based on CHELSA (Karger et al., 2017)). The predominant land-use trajectory in north-eastern Madagascar involves the conversion of old-growth forest into human-modified land-use types (Fig. 3.1D). 


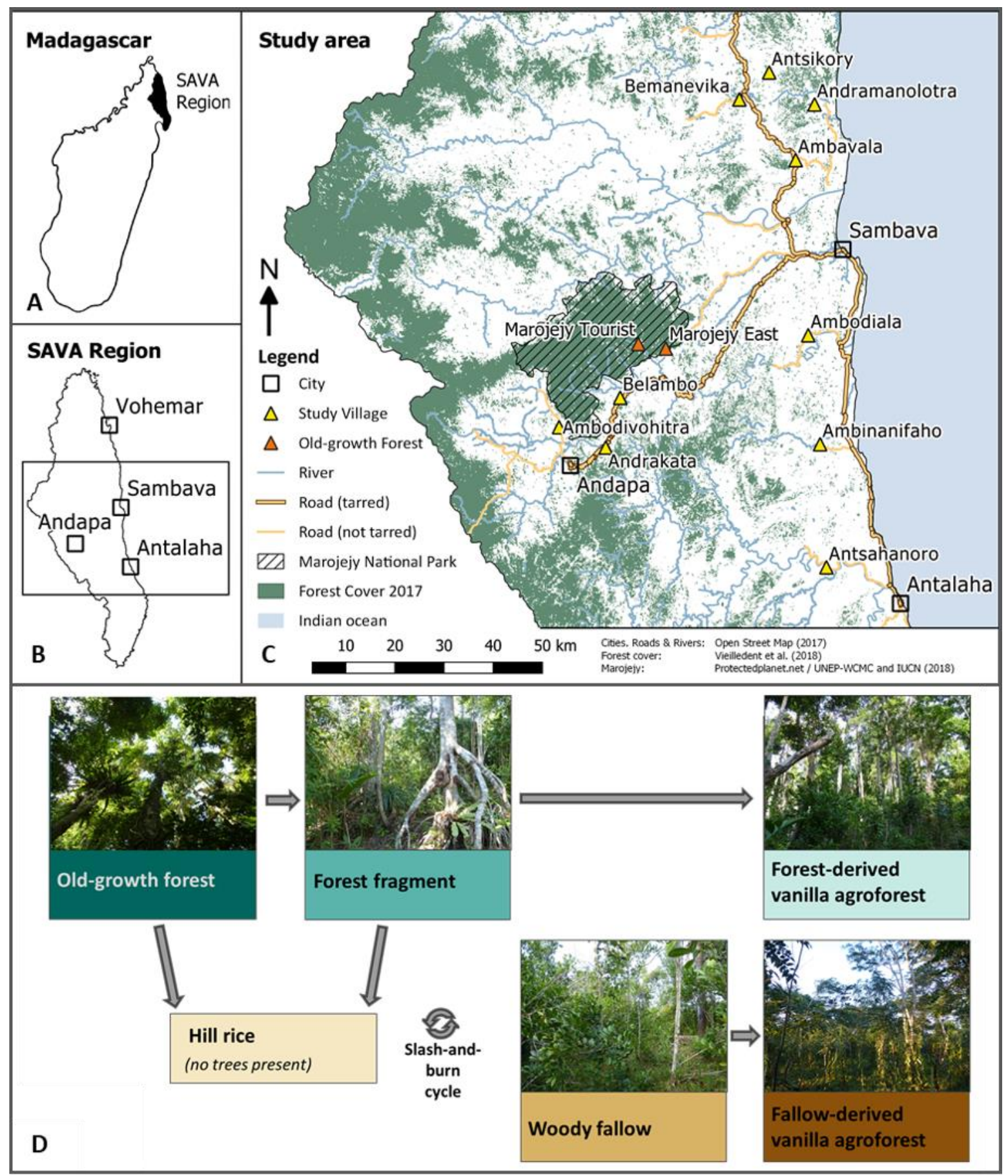

Fig. 3.1: Study area map and common land-use trajectories. Panel A: the island of Madagascar with the SAVA region located at the north-eastern coast; panel B: the SAVA region with four main cities Sambava, Andapa, Vohemar, and Antalaha.; panel C: the study area with 2017 forest cover (Vieilledent et al., 2018), 10 study villages, and the two sampling sites in the old-growth forest of Marojejy National Park; panel D: a schematic concept of the predominant land-use trajectory in the study area, depicting the conversion of old-growth forest into human-modified land-use types. 


\section{Study design}

We conducted tree inventories in the most common tree-based land-use types in the study region, which are vanilla agroforests, forest fragments, naturally regenerating woody fallow as part of the slash-andburn cycle and old-growth forests.

Overall, we worked on 58 plots between September 2018 and January 2019 in ten villages within the study region and in the Marojejy National Park (Fig. 3.1C). Around each village, we selected three vanilla agroforests, one forest fragment, and one naturally regenerating woody fallow (Fig. 3.1D). Out of 30 chosen vanilla agroforests in our study, 20 agroforests were fallow-derived, and 10 agroforests were forest-derived. Since two landowners withdrew from the study, we finally collected data on 28 vanilla agroforests: 10 forest-derived and 18 fallow-derived agroforests. The 10 forest fragments were either private or communal land that showed signs of regular extraction of timber, firewood, and other products but had not been burned in living memory. The 10 naturally regenerating woody fallows (Malagasy: savoka) had last burned 5 - 17 years before data collection and were characterized by a mix of herbaceous plants, shrubs and small trees. The 10 old-growth forest plots in Marojejy National Park were located at two sites (5 plots at each site), which showed the least indication of recent human disturbance at elevations $<700$ meter above sea level. Marojejy is the largest old-growth forest persisting in the study region and the collection of timber, firewood, and other products is prohibited (Goodman, 2000).

All study plots had a large spatial distribution across 10 villages in the study area (Fig. 3.1C), except of the old-growth forest plots, which were spatially relatively clustered within the Marojejy National Park. Given that patterns of community heterogeneity are sensitive to geographical distance and typically increase with distance (Antão et al., 2019; Nekola \& White, 1999; Soininen et al., 2007), the unequal spatial distribution of the plots in our study might influence the observed beta-diversity differences within landuse types. This difference in spatial distribution between old-growth forest and human-modified land-use types is unfortunate but unavoidable in our study landscape because Marojejy National Park is the only continuous low-elevation old-growth forest with comparatively lowest levels of human disturbance, that persist in our study area.

\section{Data collection and species identification}

We collected all data within circular plots of $25 \mathrm{~m}$ radius $\left(1962.5 \mathrm{~m}^{2}\right)$. On each of the 58 study plots, we recorded all woody plants with free-standing stems with $\geq 8 \mathrm{~cm}$ of diameter at breast height (DBH), including trees, arborescent herbs, palms, and tree ferns (but excluding lianas) and assigned local and scientific names with the help of one local expert. Since tree identification is often based on reproductive 
features, sterile tree individuals entail a taxonomic ambiguity, but we could reduce these cases by sampling during the main flowering season. We collected samples for further comparison with herbarium specimens; voucher specimens are deposited at the National Herbarium Tsimbazaza, Antananarivo and the herbarium of the University of Mahajanga. On this basis, we classified all morphospecies to the most accurate taxonomic level possible. Furthermore, we assigned all species to their geographic origin, based on information from the Catalogue of the Plants of Madagascar (Tropicos, 2020; accessed January 2020). We classified all species as "endemic", which occur exclusively in the country of Madagascar. We classified all species as "native", which occur naturally in the country of Madagascar but also outside the country. We further classified all species as "introduced", which are not native to Madagascar. We classified all species as "origin unknown", if their origin was not available in the Catalogue of the Plants of Madagascar (2020). For all species which could only be identified to genus or family level, we checked whether their specific genus or family was classified as exclusively endemic or native to Madagascar in the Catalogue of the Plants of Madagascar (2020) and listed them accordingly. Otherwise, we classified them as introduced or origin unknown, when applicable (see Appendix S3.1 \& S3.12).

\section{Data analysis}

To quantify beta-diversity, we used the Jaccard index for incidence-based data and the Bray-Curtis index for abundance-based data, which are both robust to errors of taxonomy or numerical undersampling (Schroeder \& Jenkins, 2018). First, we assessed variation in species composition within each land-use type separately by calculating multiple-site dissimilarity and the respective turnover and nestedness components (Baselga, 2017). To standardize sampling efforts, we used a resampling procedure: we randomly chose 5 out of 10 plots per land-use type (except for fallow-derived agroforest with 5 out of 18 plots) and repeated this procedure 500 times to obtain the mean and the standard deviation of betadiversity and its components for each land-use type (Baselga, 2017). To do so, we used the R-package 'betapart' (Baselga et al., 2021) and applied the function beta.sample for incidence data and beta.sample.abund for abundance data.

Additionally, we calculated the proportion of nestedness components to overall multiple-site dissimilarity to obtain the beta ratio $=\frac{\text { beta nestedness component }}{\text { overall multiple site dissimilarity }}$. Values of beta-ratio $<0.5$ indicate that betadiversity is mainly determined by species turnover, and beta-ratio values $>0.5$ indicate that beta-diversity is mainly determined by nestedness (Si et al., 2015). 
Next, we calculated null models that indicate how beta-diversity would look like with a completely random assembly process, while maintaining the alpha- and gamma-diversity as given in the data set (Catano et al., 2017; Chase et al., 2011; Ponisio et al., 2016). As such, null model analyses allow to compare patterns of beta-diversity among sites to differentiate between actual variation and variation based on stochasticity (Hillebrand et al., 2018; Tucker et al., 2016). Thus, we calculated null models for both incidence- and abundance data by sequentially reshuffling 1000 randomly sampled submatrices at constant row and column sums within each land-use type (Catano et al., 2017; Ponisio et al., 2016). To do so, we used the quasi-swap algorithm of the permatswap function in the R-package 'vegan' (Oksanen et al., 2019) and then calculated either the Jaccard-distance for each randomized matrix based on incidence data or respectively the Bray-Curtis-distance for each randomized matrix based on abundance data. Furthermore, we calculated z-scores to analyse whether observed beta-diversity was higher or lower than expected by chance. Z-scores are defined as: observed dissimilarity - $\frac{\text { mean(randomized dissimilarity) }}{\text { sd(randomized dissimilarity) }}$ (Karp et al., 2018; Ponisio et al., 2016).

To assess variation in species composition among land-use types, we tested whether overall Jaccard- and Bray-Curtis dissimilarities, as well as their turnover and nestedness components differed among land-use types. Thus, we calculated the multivariate dispersion of each beta-diversity component by calculating the distance from each plot to the centroid of all plots in the same land-use type using the betadisper function (Anderson et al., 2006) from the R-package 'vegan' (Oksanen et al., 2019). Then, we extracted the distances to the centroids and fitted linear mixed models, with land-use type as a fixed effect and study site as a random effect, using the Imer function in the R-package 'Ime4' (Bates et al., 2015) with maximum likelihood estimates. For each beta-diversity component, we compared the mixed model to a reduced model in which we dropped the effect of the land-use types and applied a likelihood ratio test to obtain a p-value. If the effect of land-use types was significant, we conducted a pairwise comparison of land-use types, using the function Ismeans in the R-package 'Ismeans' (Lenth, 2016).

To assess species dominance structures among land-use types, we calculated species-dominance-curves with the function rankabundance in the R-package 'BiodiversityR' (Kindt \& Coe, 2005). Furthermore, we identified potentially dominant species based on their abundance and frequency of occurrence by calculating the Dominance Candidate Index (DCi; sensu Arvolio et al. (2019)). We calculated the DCi as $\frac{\text { average relative abundance }+ \text { relative frequency }}{2}$ for each land-use type separately, to identify and quantify the upper quartile of dominant species within each land-use type. Lastly, we quantified rare species as the 
total number of singletons per land-use type and assessed their global conservation status using the IUCN Red List (IUCN, 2021) and The Red List of Trees of Madagascar (Beech, Rivers, et al., 2021).

\section{Results}

\section{Beta-diversity within land-use types}

Incidence-based overall multiple-site beta-diversity ranged from a mean of 0.85 (SD 0.01) within oldgrowth forest to a mean of 0.94 (SD 0.01) within forest-derived agroforests (Fig. 3.2; Appendix S3.2); the values for incidence-based turnover almost mirrored overall beta-diversity values within all land-use types. Nestedness was generally low within all land-use types and ranged from a mean of 0.02 (SD 0.01) within old-growth forests to a mean of 0.05 (SD 0.02) within woody fallows. The proportion of nestedness components to overall multiple-site beta-diversity was far below $<0.5$ in all land-use types (Appendix S3.2), indicating that multiple-site beta-diversity within each land-use type was almost exclusively caused by turnover (Fig. 3.2A; C; E, see Appendix S3.3 for numeric results). 
Incidence-based
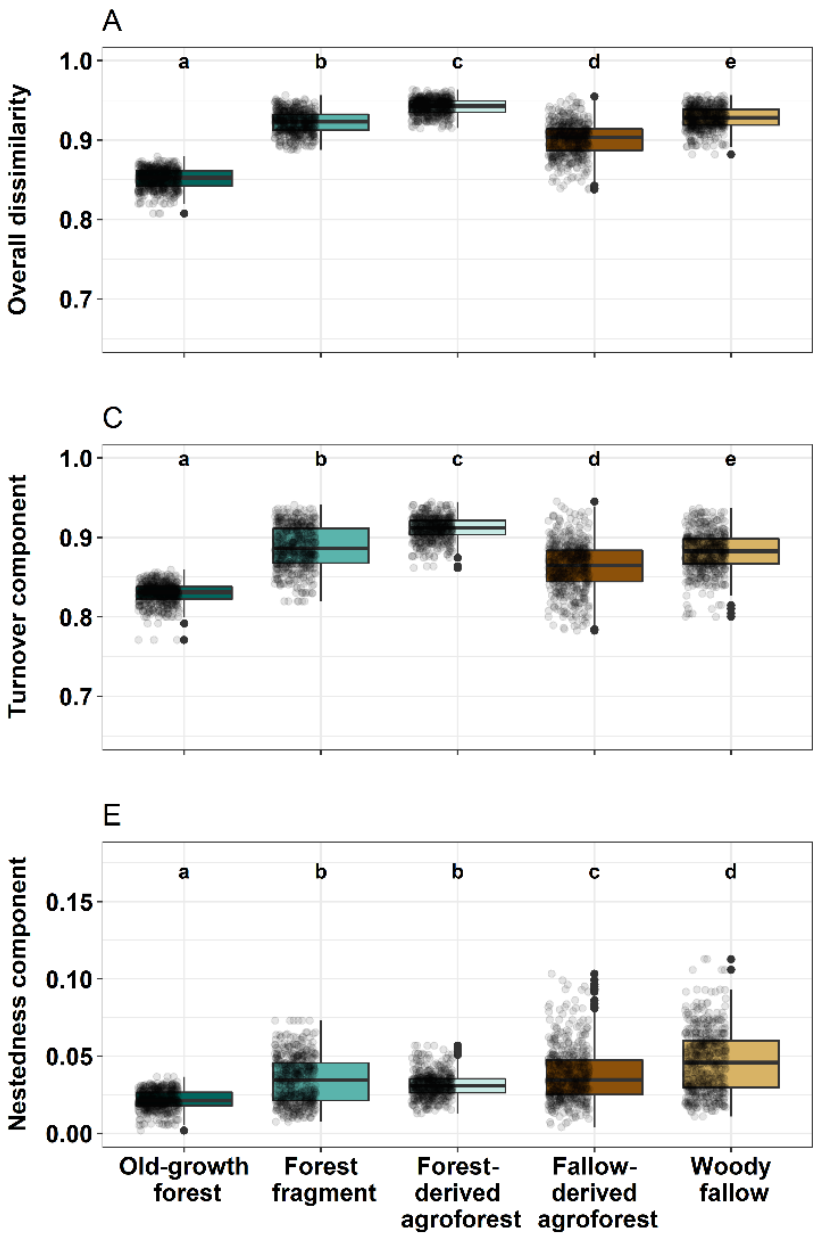

Abundance-based
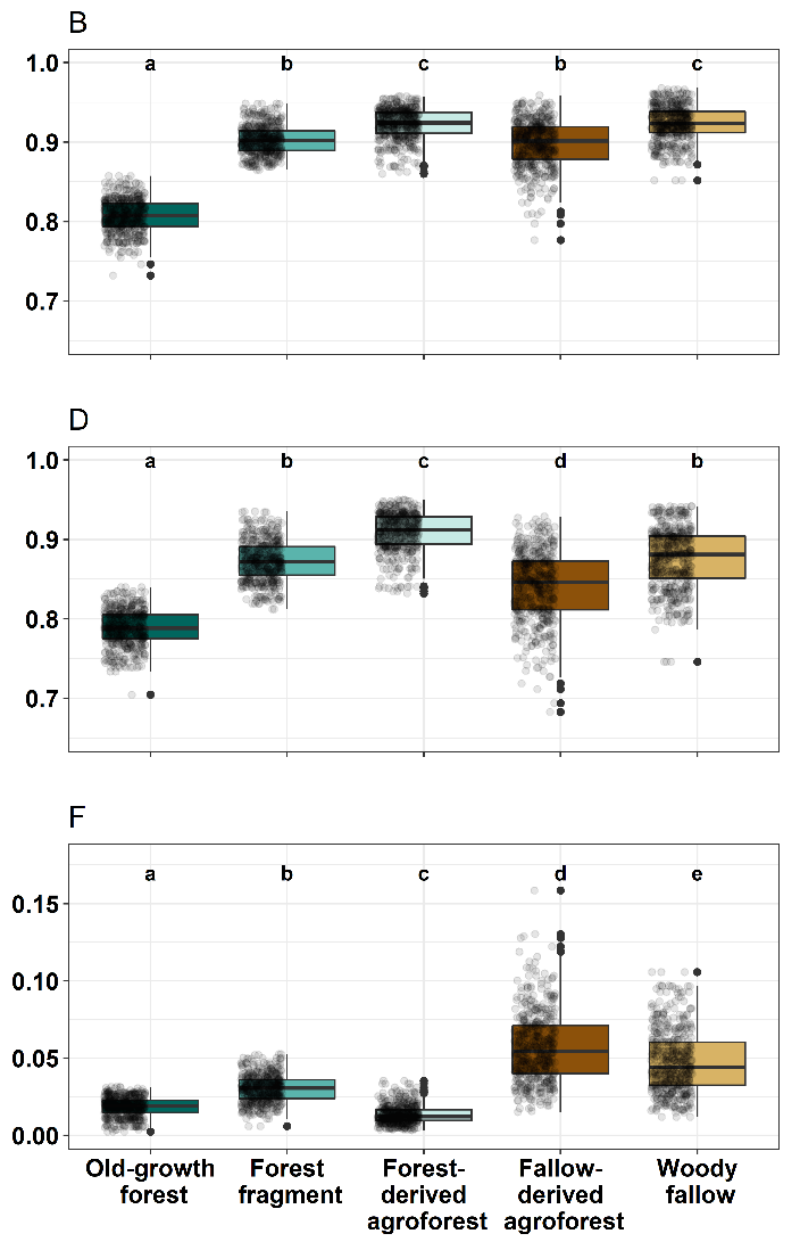

Fig. 3.2: Beta-diversity comparison within land-use types. Multiple-site dissimilarity based on the Jaccard index for incidence data (panel A, C; E) or the Bray-Curtis index for abundance data (panel B, D, F). The panels display overall beta-diversity (panel A \& B) as well as its components of turnover (panel C \& D) and nestedness (panel E \& F). To standardize sampling efforts, the distributions of multiple-site dissimilarity indices for each land-use type are based on a random subset of 5 out of 10 plots per land-use type (except for fallow-derived agroforest with 5 out of 18 plots) and repeated 500 times. Values range between 0 (species identities and abundances are equal) and 1 (no species is present in more than one site). The black horizontal lines represent the median for each land-use type. The lower and upper hinges of each box correspond to the first and third quartiles. The upper whiskers extend to the largest value whereas the lower whiskers extend to the smallest value, no further than 1.5 times the interquartile range from the hinges of the box, respectively. Letters indicate significant differences between land-use types based on Kruskal-Wallis rank sum test $(p<0.05)$ and Dunn's Post-hoc test with Holm-Bonferroni correction. Note the different scaling of the $y$-axis in panel $C$. 
For abundance-based data, multiple-site beta-diversity showed similar patterns and ranges as for incidence-based data (Fig. 3.2B; D; F). Overall beta-diversity and turnover were lowest within old-growth forests and highest within forest-derived agroforests. Abundance-based nestedness was generally low within all land-use types and ranged from a mean of 0.01 (SD 0.01) within forest-derived agroforests to a mean of 0.06 (SD 0.02) within fallow-derived agroforests.

Likewise, the abundance-based ratio of nestedness components to overall multiple-site beta-diversity was far below < 0.5 in all land-use types (Appendix S3.2), indicating that turnover almost exclusively accounted for multiple-site beta-diversity within each land-use type (Fig. 3.2B; D; F see Appendix S3.3 for numeric results). When comparing the beta-ratio between incidence-based and abundance-based data for each land-use type, old-growth forests, forests fragments and forest-derived vanilla agroforests showed higher ratio values for incidence-based data, whereas fallow-derived agroforests and woody fallows showed higher ratio values for abundance-based data (Appendix S3.2).

\section{Beta-diversity null model analysis within land-use types}

Null model z-scores for incidence data indicated that the observed beta-diversity within forest fragments was lower than expected by chance (Fig. 3.3A; Appendix S3.4). Within all other land-use types, the incidence-based z-scores were close to zero, indicating that the observed dissimilarity was neutral and did not differ from random assembly processes, given the respective alpha- and gamma-diversity within each land-use type. In comparison, null model results for abundance data showed different patterns (Fig. 3.3B; Appendix S3.4): within all land-use types except of woody fallows, the z-scores were positive and indicated higher observed beta-diversity levels than expected by chance. Within woody fallows, the z-scores were close to zero, indicating that the observed dissimilarity did not differ from random assembly processes. 

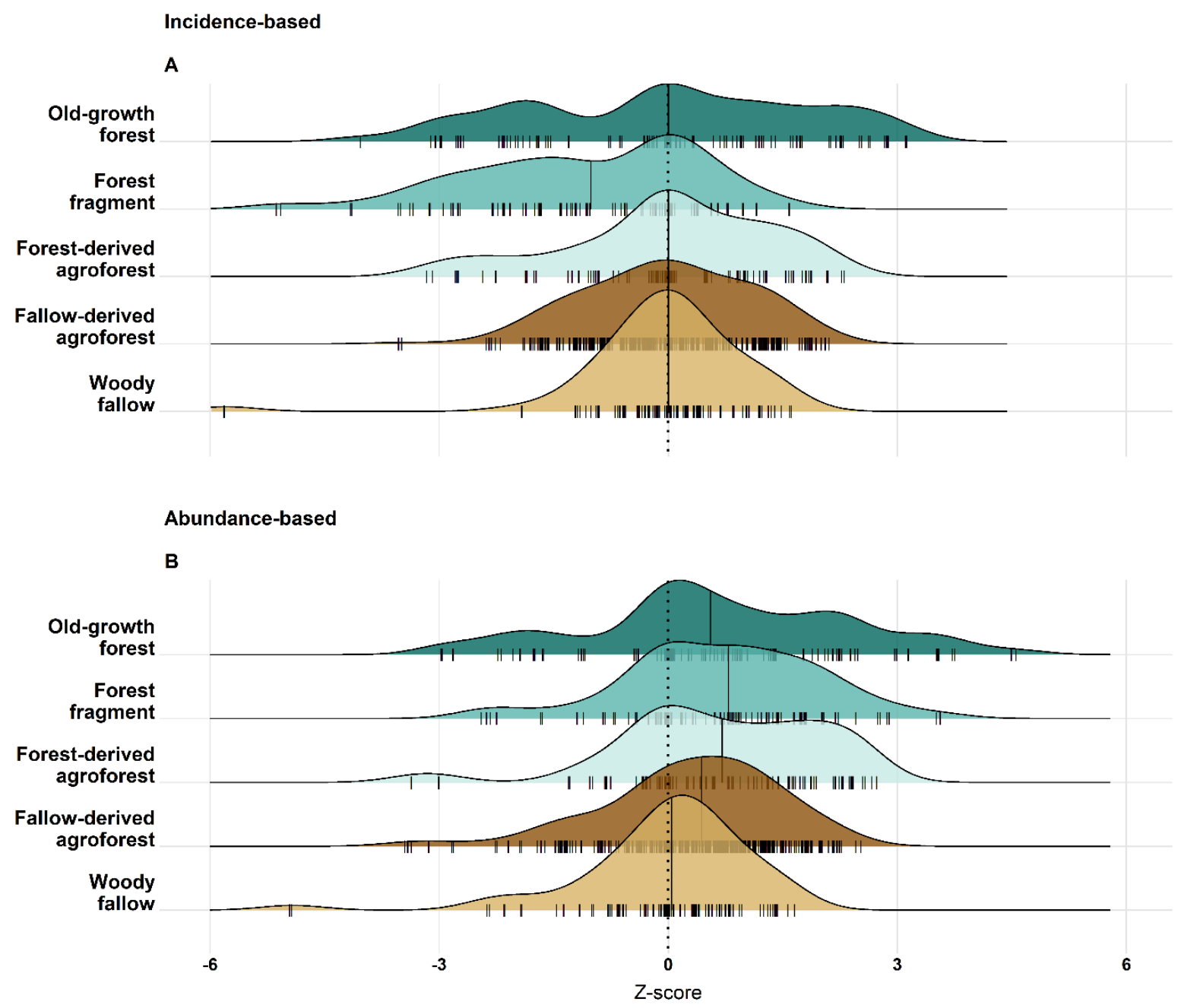

Fig. 3.3: Beta-diversity null model analysis within land-use types. Density distribution of z-scores from null model simulations based on incidence data (panel A) and abundance data (panel B). The z-scores represent the standardised difference between observed dissimilarity and null model simulated dissimilarity, divided by the standard deviation of null model simulated dissimilarity. Z-scores above 0 indicate that the observed beta-diversity was higher than expected by chance and z-scores below 0 indicate that the observed beta-diversity was lower than expected by chance. The marginal rug indicates the underlying data points, the solid vertical lines indicate the median per land-use type and the dotted vertical line indicates zero.

\section{Beta-diversity among land-use types}

The mixed-effect model for incidence-based beta-diversity revealed that all land-use types had a significant effect and a substantial power to explain the variance in overall Jaccard dissimilarity (marginal $\mathrm{R} 2$ of 0.47 ) and its turnover component (marginal R2 of 0.26 ) but had no significant effect to explain the nestedness-component (marginal R2 of 0.13 ) (Fig. 3.4). The pairwise comparison between land-use type 
effects on overall Jaccard dissimilarity revealed a significant difference for old-growth forests which was lower compared to all other land-use types. For the Jaccard-turnover component, only the pairwise comparison between old-growth forests and forest-derived agroforests was significant (Appendix S3.5 S3.7 for numeric results).
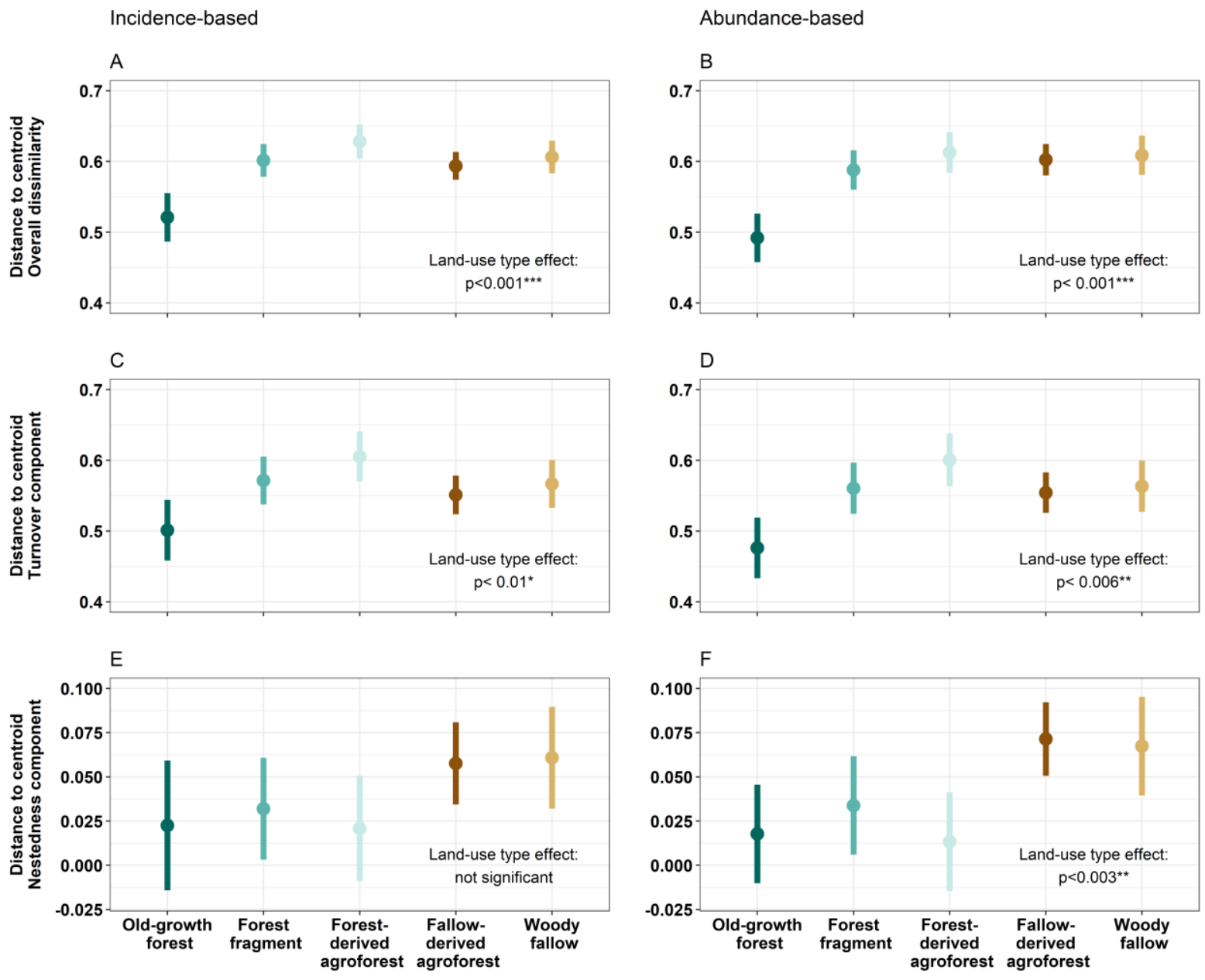

Fig. 3.4: Beta diversity comparison among land-use types measured as dispersion (distance to group centroid). The distance to the group centroid of each land-use type is based on the Jaccard index for incidence data (panel A, C; E) and the Bray-Curtis index for abundance data (panel B, D, F). Panels A \& B display overall beta-diversity, panel C \& D display the turnover and panel E \& F the nestedness components. The dots represent the fitted values of the mixed model and the lines indicate the upper and lower confidence intervals. The $p$-values are derived from the ANOVA between the mixed models and the respective reduced model in which the effect of the land-use types was dropped (Appendix S3.5 - S3.7 for numeric results).

The mixed-effect model for abundance-based beta-diversity metrics showed similar patterns: all land-use types had a significant effect and a substantial power to explain the variance in overall Bray-Curtis 
dissimilarity (marginal R2 of 0.49) and its turnover component (marginal R2 of 0.31). The explanatory power for the nestedness-component (marginal R2 of 0.25) was lower and only fallow-derived agroforests and woody fallows had a statistically significant effect and showed significant differences in the pairwise comparison (Fig. 3.4). Furthermore, the pairwise comparison between land-use types revealed that overall Bray-Curtis dissimilarity was significantly lower in old-growth forests compared to all other landuse types. For the Bray-Curtis-turnover component, only the pairwise comparison between old-growth forests and forest-derived agroforests yielded significant differences (Appendix S3.5 - S3.7 for numeric results).

\section{Dominance analysis}

Dominance patterns were similar for all land-use type communities, with a few highly abundant species and many more uncommon or rare species (Fig. 3.5). Within each land-use type, a share of $\sim 10 \%$ species represented $50 \%$ of tree individuals. Yet, the species numbers corresponding to these proportions varied largely, due to significant differences in the number of species and individuals. 

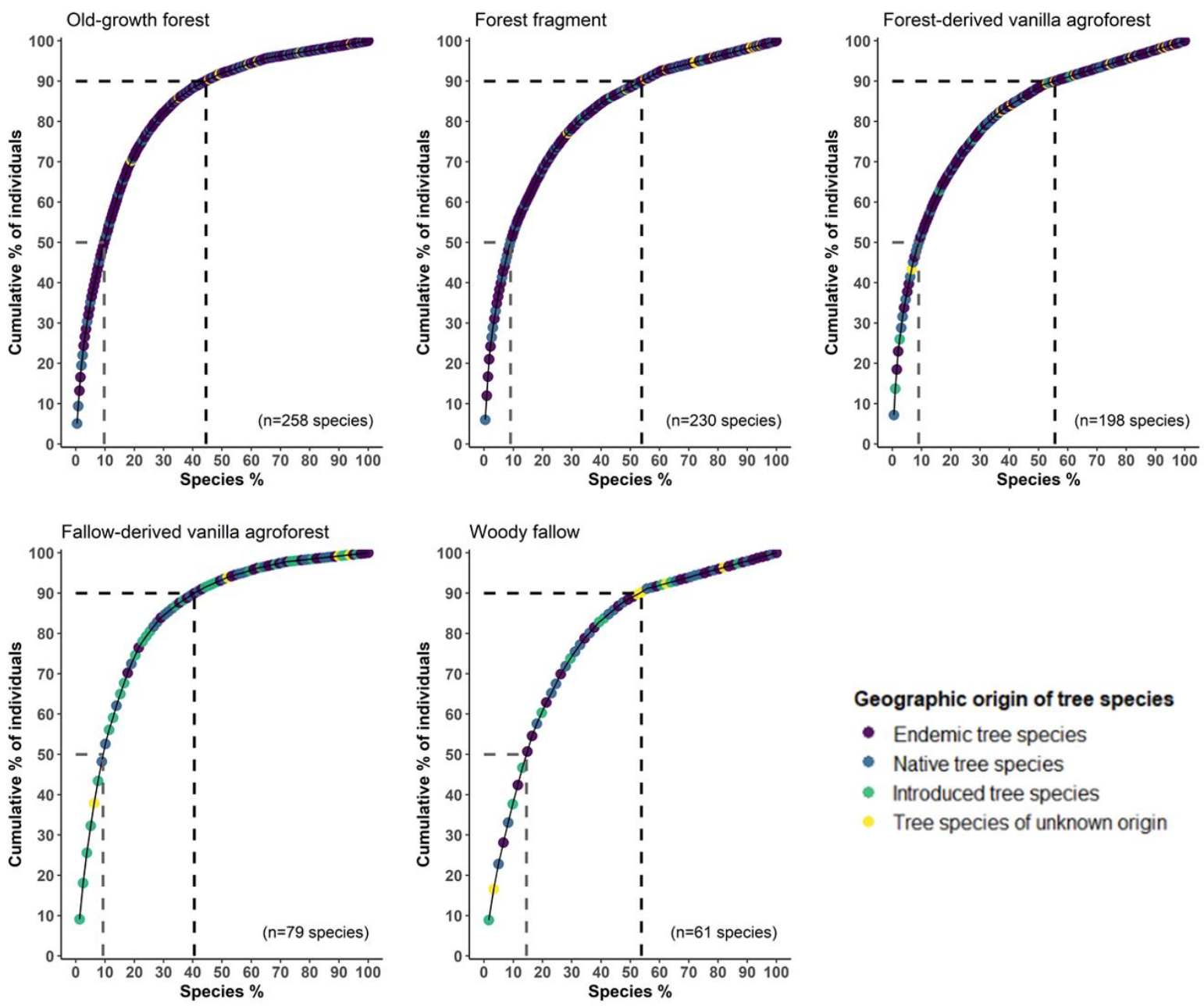

Geographic origin of tree species

- Endemic tree species

- Native tree species

- Introduced tree species

Tree species of unknown origin

Fig. 3.5: Species dominance structure among trees for each land-use type. In each panel, the light grey dashed line indicates the share of species representing $50 \%$ of all individuals; the black dashed line indicates the share of species representing $90 \%$ of all individuals in each land-use type. Each dot represents a tree species ranked by relative abundance and the colour of the dots indicates the geographic origin.

Additionally, we identified a subset of 15 common species (Appendix S3.9) which occurred on all land-use types. The upper quartile of dominant candidate tree species (sensu Arvelio et al 2019) was composed of 51 species, among which 57\% were endemic (Table 3.1; Appendix S3.11) and occurred almost exclusively in old-growth forests, forest fragments and forest-derived vanilla agroforests. Further $29 \%$ dominant candidate species were native and occurred mainly in old-growth forests, forest fragments and forestderived vanilla agroforests and only marginally in woody fallows or fallow-derived agroforests. Introduced dominant candidate species (12\%) occurred mainly in woody fallows or fallow-derived agroforests. 


\section{Beta-diversity patterns}

Overall multiple-site dissimilarity measures reached median values above 0.8 within all land-use types, which is relatively high, considering that the maximum achievable value is 1 (Baselga, 2017). Furthermore, both incidence-based metrics and abundance-based metrics lead to similar results, indicating that dissimilarity within land-use types was shaped as strongly by the influence of rare species (captured by the incidence-based metrics), as by the influence of species dominance patterns (captured by the abundance-based metrics) (Barwell et al., 2015; Baselga, 2017). These observations are in line with tree community analyses from western Amazonia, which also reported that beta-diversity patterns for incidence-based and abundance-based metrics yielded similar results (Draper et al., 2019). We can thus infer that tree communities in our study area were highly heterogenic within land-use types and the estimated dissimilarities were neither exclusively based on dominant species, nor on rare species.

By partitioning beta-diversity into its components, we found low beta-ratios (defined as the proportion of nestedness components to overall multiple-site dissimilarity), indicating that turnover was the dominant contributor to multiple-site dissimilarity whereas nestedness played a minor role and this pattern was constant within all land-use types. These observations compare with meta-analyses on larger scale across organisms and ecosystems (Antão et al., 2019; Soininen et al., 2018).

The high turnover values and the comparatively minor role of the nestedness within all land-use types in our study indicates that none of the land-use types suffered from substantial tree species losses because absent species were replaced by new species; this process is called additive heterogenization, in which new species establish (Socolar et al., 2016). High beta-diversity values can also originate from the process of subtractive heterogenization, in which many common species become rare, but few disappear (Socolar et al., 2016).

Since our land-use types differed significantly in species richness, the application of null models allowed us to examine if dissimilarity was lower or higher than expected by chance (Chase et al., 2011). Even though null models are criticized to suffer from internal constraints that induce Type II errors (Ulrich et al., 2017), they still represent the best available option to account for effects of the regional species pool size on beta-diversity patterns (Catano et al., 2017; Chase et al., 2011; Tucker et al., 2016).

For incidence-null model calculations, we found that the observed beta-diversity within forest fragments was lower than expected by chance. This indicates that tree communities in forest fragments might be niche-structured, meaning that demographic rates (such as reproduction, death, dispersal) differed between species due to external factors (Tucker et al., 2016). These external factors might be 
consequences of human activities, given that forest fragments in our study area were partly heavily disturbed due to timber extraction and charcoal production. Since incidence data is strongly influenced by rare species, our null model results indicate that forest fragment communities became more similar than expected to the detriment of rare species. This suggests that forest fragments underwent biotic homogenization in which rare and/or specialized tree species struggled to survive and reproduce, while generalist species coped well or even proliferated under altered environmental conditions (Filgueiras et al., 2021; McKinney \& Lockwood, 1999; Tabarelli et al., 2012). Within all other land-use types, observed beta-diversity did not deviate from the null model expectation, indicating that these communities were mainly structured by neutral assembly mechanisms (Tucker et al., 2016) meaning that biotic homogenization might play a less prominent role. However, Tucker et al. (2016) showed in a methodological approach that incidence-based null models were less robust than abundance-based null models, so our incidence-null models might underestimate the effect of human activities on tree species composition. Indeed, for abundance-null model calculations, we found higher observed beta-diversity levels than expected by chance within all land-use types, except woody fallows. This indicates that abundance-based beta-diversity within woody fallows could not clearly be distinguished from stochastic sampling effects (Tucker et al., 2016). Within all other land-use types, external factors lead to higher betadiversity than expected. Most likely, theses external factors are linked to land-use practices, given that species communities in tropical biomes (such as north-eastern Madagascar) show a particularly high sensitivity to land-use change (Newbold et al., 2020). The deviation between observed and expected values was highest in forest fragments and forest-derived agroforests, indicating that external factors were linked to habitat alterations that heterogenized the communities either by additive or subtractive heterogenization (sensu Socolar et al., 2016).

Land-use types had a significant effect and a substantial power to explain the variance in beta-diversity and its turnover component among land-use types for both incidence-based metrics and abundancebased metrics. This indicates that land-use types were linked to external factors such as human activities, which strongly influenced the compositional turnover between land-use types. These findings align with the global trend that synergistic effects between land-use and climate change drive plant species turnover and lead to profound changes in the structure of ecological assemblages and likely accelerate diversity declines over time (Di Marco et al., 2019; Newbold et al., 2016).

Nestedness values were generally low, indicating low species net loss. However, woody fallows and fallow-derived agroforests showed a comparatively higher abundance-derived nestedness variation than 
all other land-use types. Considering that these two land-use types harboured more introduced species but counted with significantly lower alpha diversity compared to all other land-use types (Fig. 3.5), these abundance-derived nestedness patterns could originate from the establishment of new and potentially introduced generalist species which gradually displaced less competitive species (Socolar et al., 2016).

\section{Dominance and rarity patterns}

Our findings revealed similar dominance patterns for all land-use type communities, with a few highly abundant species and many more uncommon or rare species, which is similar to dominance structure patterns found in other tropical tree communities (eg. Hazell et al., 2021). Targeting the many rare species, we quantified a share of $\sim 37 \%$ singletons across land-use types. This value is similar to global rarity estimations of land plants, which categorize $\sim 36 \%$ of vascular plant species as highly rare with very little distributional and/or botanical information available for each species (Enquist et al., 2019). In a global comparison, eastern Madagascar even classifies as a "hotspot of rarity" for plant species, showcasing high numbers of rare species (Enquist et al., 2019) with high levels of threatened species (Beech, Rivers, et al., 2021; BGCl, 2021). Generally, rarity builds on abundance but is defined in a wide variety of ways (Drever et al., 2012). In our study, we applied a very strict definition and only considered singletons as rare species, which might underestimate the number of rare species. Yet, it is important to recognize that potential sampling biases can influence the rarity attribution (Enquist et al., 2019; Oliveira et al., 2019). In our case, some small-statured species might hardly reach the sampling DBH threshold and therefore classify as rare in our dataset, even though they might be naturally small-structured common trees. Lastly, species' morphological plasticity, lack of clear identification features of sterile individuals and ongoing taxonomic reclassification can introduce certain taxonomic biases (Callmander et al., 2011; Enquist et al., 2019). Despite these ambiguities, our assessment represents an estimation of rarity among tree species across land-use types and can serve as a proxy and baseline for future studies or conservation interventions. Among these rare species, we identified one Critically Endangered species (Dombeya marojejyensis) and further 26 species categorized as either Endangered, Vulnerable or Near Threatened (Beech, Rivers, et al., 2021; IUCN, 2021). Almost 75\% of these species occurred either in old-growth forest, forest fragment or forest-derived agroforest. Moreover, tree species are long-lived organisms, and even if they temporally survive in altered habitats, disturbance-sensitive species might not be able to reproduce over time, leading to time-lagged extinction events (Flinn \& Vellend, 2005). This process is commonly known as extinction debt (Kuussaari et al., 2009) and might be specifically critical for the high share of rare and 
endemic tree species in old-growth forests, forest fragments and forest-derived agroforests in our study area, highlighting that these species face considerable extinction risk.

Additionally, we identified 15 common species that can potentially cope well with the given biotic and abiotic habitat conditions, because they occurred on all land-use types. We further identified 51 dominance candidate tree species (sensu Arvelio et al 2019; Appendix S3.11). Most dominant candidate species occurred in old-growth forests which aligns with findings from other tropical lowland forests in which a small number of dominant species accounts for a large share of individuals (Bastin et al., 2015; Draper et al., 2019; ter Steege et al., 2013). Due to their high proportional abundance, dominant tree species represent main structural elements and have a strong impact on biomass provision, and ecosystem functions and processes (Avolio et al., 2019; Bastin et al., 2015). Furthermore, research from Amazonian forests has shown that dominant tree species were representative of overall beta-diversity patterns and might serve as proxies for community composition patterns at the regional scale (Draper et al., 2019). Also, dominance is not static in the light of changing land-use dynamics, meaning that dominant species turnover and dominance identity may change, but the concept of dominance persists (Avolio et al., 2019). Thus, knowledge of dominant species and their successional dynamics should be integrated into restoration approaches to recover ecosystem functions and integrity.

\section{Conservation outlook}

Our results provide a deeper understanding of tree community structures in tree-based land-use types within the mosaic landscape of north-eastern Madagascar. This is of high ecological and conservation relevance since altered tree community changes also affect other species groups and multi-trophic networks, which are strongly associated with trees (Fornoff et al., 2019). If tree species decline or disappear, the resilience of associated trophic networks and ecosystem processes might erode cascadingly, eventually leading to network instability and permanent shifts in ecosystem functions (Fordham \& Brook, 2010; Pimm et al., 2014; White et al., 2020) with negative consequences for ecosystem services and the people who rely on them (Díaz et al., 2006). Thus, maintaining the unique and high tree diversity of north-eastern Madagascar is a key conservation goal. We show that old-growth forests harboured a high share of endemic and threatened tree species, which emphasizes that protected areas such as Marojejy National Park are irreplaceable to prevent further species loss and forest clearance. In addition, we also show that human-modified land-use types retained a share of endemic and endangered species and had high turnover rates, indicating that the floristic composition and species dominance patterns within each land-use type differed strongly from plot to plot. These high turnover rates outside 
of protected areas indicate that complementary conservation interventions are necessary to maintain the unique tree species assemblages and the associated landscape gamma-diversity within the humanmodified mosaic landscape. Therefore, ecological restoration and tree-based rehabilitation interventions could serve as complementary tools to secure overall net gains of biodiversity and a net-positive effect on environmental conditions and ecosystem services (Gann et al., 2019; UN Decade on Ecosystem Restoration 2021-2030). Additionally, the area adjacent to Marojejy National Park has been highlighted as a priority area for the conservation and restoration of endemic trees species in Madagascar (Carrasco et al., 2020). We fully endorse the call for restoration interventions based on stakeholder-defined objectives (Di Sacco et al., 2021). A suggested point of entry would be the establishment of agroforests on formerly forested degraded land, which could increase tree cover at the landscape scale (Martin, Wurz, et al., 2021), while generating revenues for smallholder farmers (Hänke et al., 2018). But even on woody fallows and fallow-derived agroforests, the tree communities had a high turnover between plots and woody fallows harbored a share of endemic and endangered species. Since tree-based ecosystem restoration should not be a driver of homogenization, we emphasize the importance to consider the high turnover rates of tree species communities and take this knowledge into account in the planning and implementation of restoration projects, to effectively protect the rich diversity of Malagasy trees in the mosaic landscape.

\section{Author contribution}

KO, MRS, DAM, AW, HLTR and DH conceived the ideas and designed methodology; KO, MRS and PA collected tree inventory data; PA identified the tree species; KO processed and analysed the data; KO led the writing of the manuscript. All authors contributed to the manuscript and gave final approval for publication.

\section{Acknowledgments}

We thank all plot owners, chef de fokontany, and village residents for their hospitality and for granting us access to information and sites. We are grateful to Thorien Rabemanantsoa and Jean Chrysostome Bevao for their support during data collection. At the institutional basis, we acknowledge the support of MNP (Madagascar National Parcs), Ministère de l'Environnement, de l'Écologie et des Forêts (MEEF), and Missouri Botanical Garden Antananarivo.

To facilitate tree species identification, we collected samples of leaves, twigs, fruits and flowers based on research permits $\mathrm{N}^{\circ} 18 / 18 / \mathrm{MEEF} / \mathrm{SG} / \mathrm{DGF} / \mathrm{DSAP} / \mathrm{SCB}$. Re and $\mathrm{N}^{\circ} 254 / 18 / \mathrm{MEEF} / \mathrm{SG} / \mathrm{DGF} / \mathrm{DSAP} / \mathrm{SCB} . \mathrm{Re}$ ) 
issued by MEEF, Antananarivo, Madagascar. Thanks to Carolina Ocampo Ariza and Gabriel Marcacci for helpful discussions and advice regarding the beta-diversity analysis and null model calculation. 


\section{Chapter 4: Case study: Support tree diversity in vanilla agroforests}

Manuscript title: Support trees in vanilla agroforests of Madagascar: diversity, composition and origin

Authors: Johannes Osewold; Yevgeniya Korol; Kristina Osen; Marie Rolande Soazafy; Thorien

Rabemanantsoa; Dominic A. Martin; Annemarie Wurz; Dirk Hölscher

Manuscript status: Submitted to Agroforestry Systems; author-submitted article

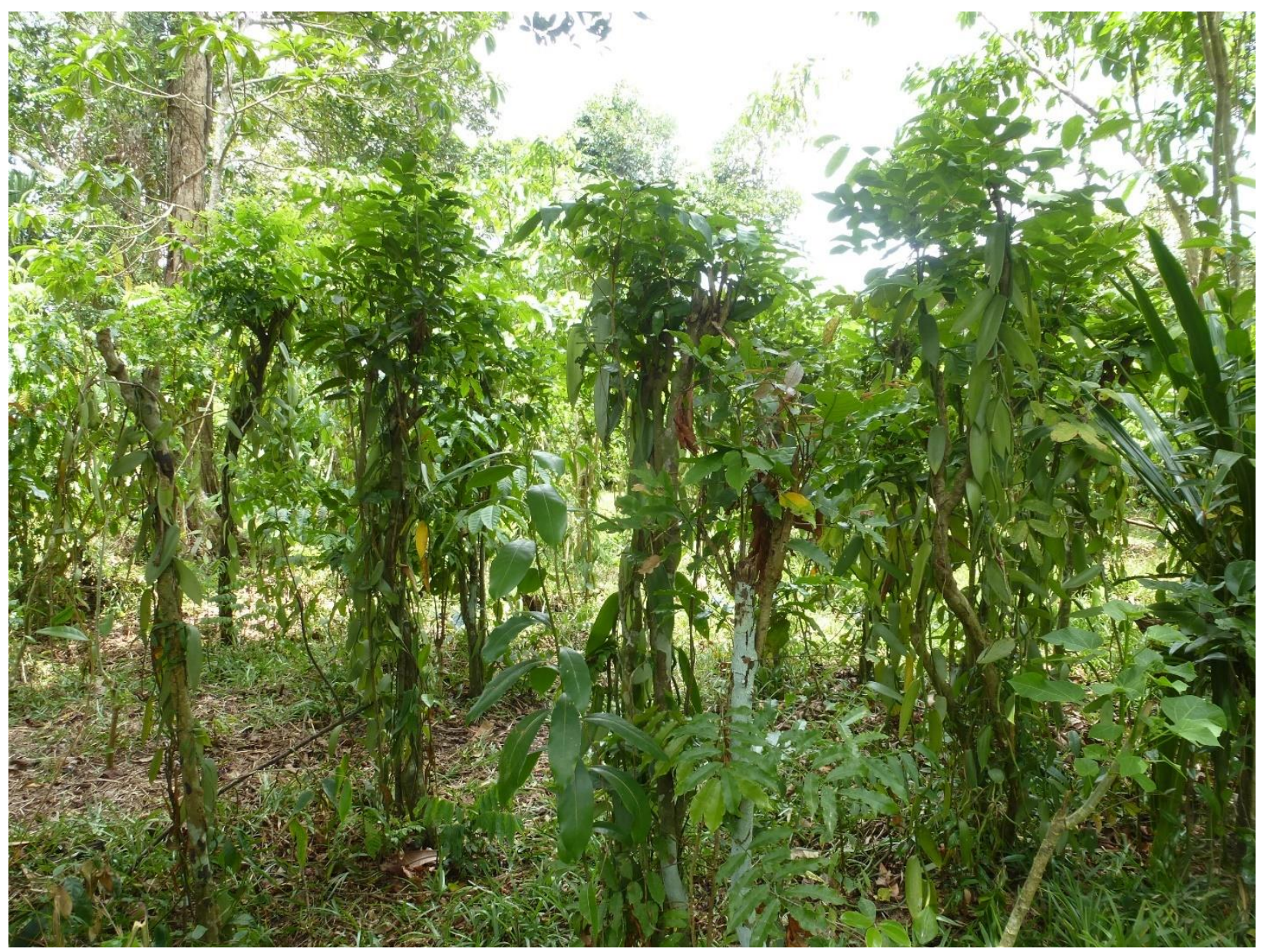




\begin{abstract}
Trees in agroforestry systems provide multiple ecological and economic functions. Smallholder vanilla agroforests include shade trees, common across agroforestry systems, and small-statured support trees carrying the vanilla vine. Support trees have received little scientific attention so far. The objectives of our study were to assess the diversity, composition and geographic origin of support trees in vanilla agroforestry systems of north-eastern Madagascar. The region is a global biodiversity hotspot, undergoes a rapid land-use change and produces a large share of the globally traded spice vanilla. The studied vanilla agroforests differed in land-use history being either forest-derived (established directly in a forest) or fallow-derived (established on land previously used for slash-and-burn agriculture). Among the support trees, we found 122 species of which $25 \%$ were endemic to Madagascar. The species richness per plot was four times higher in forest-derived than in fallow-derived vanilla agroforests. The species distribution was particularly uneven in fallow-derived vanilla agroforests with one species (Jatropha curcas) comprising $52 \%$ of all individuals. In forest-derived vanilla agroforests, $44 \%$ of all trees were native or endemic to Madagascar, whereas in fallow-derived vanilla agroforests only $11 \%$ were native or endemic. We conclude that there is a considerable diversity among support trees in Malagasy vanilla agroforestry. The support tree diversity is strongly affected by land-use history. Fallow-derived vanilla agroforests currently have a comparatively low species richness, yet they can play an important role in land rehabilitation, and more emphasis on growing native and endemic tree species would contribute to aligning land use with conservation goals.
\end{abstract}

Keywords: Biodiversity, endemism, land-use history, native trees, smallholder agroforestry, tutor trees

\title{
Introduction
}

Agroforestry systems host - by definition - trees and crops or livestock (FAO, 2015). Studies often investigate multiple ecological and economic functions of shade trees (Nesper et al., 2017; Tscharntke et al., 2011) or crop-bearing woody plants like apple, cherry, coffee etc. (Kay et al., 2020; Liu et al., 2020; Wu et al., 2016). However, vanilla agroforestry systems have a further category of trees: small-statured support trees (also called tutor trees) carrying the climbing vanilla plant (Vanilla planifolia, Orchidacea). Support trees (Fig. 4.1) are pruned to an accessible height to facilitate vanilla hand-pollination and vanilla 
harvesting. Support trees are also common in other agroforestry systems, e.g., black pepper (Piper nigrum), yams (Dioscorea spp.) or chayote (Sechium edule) (World Agroforestry Centre, 2009).
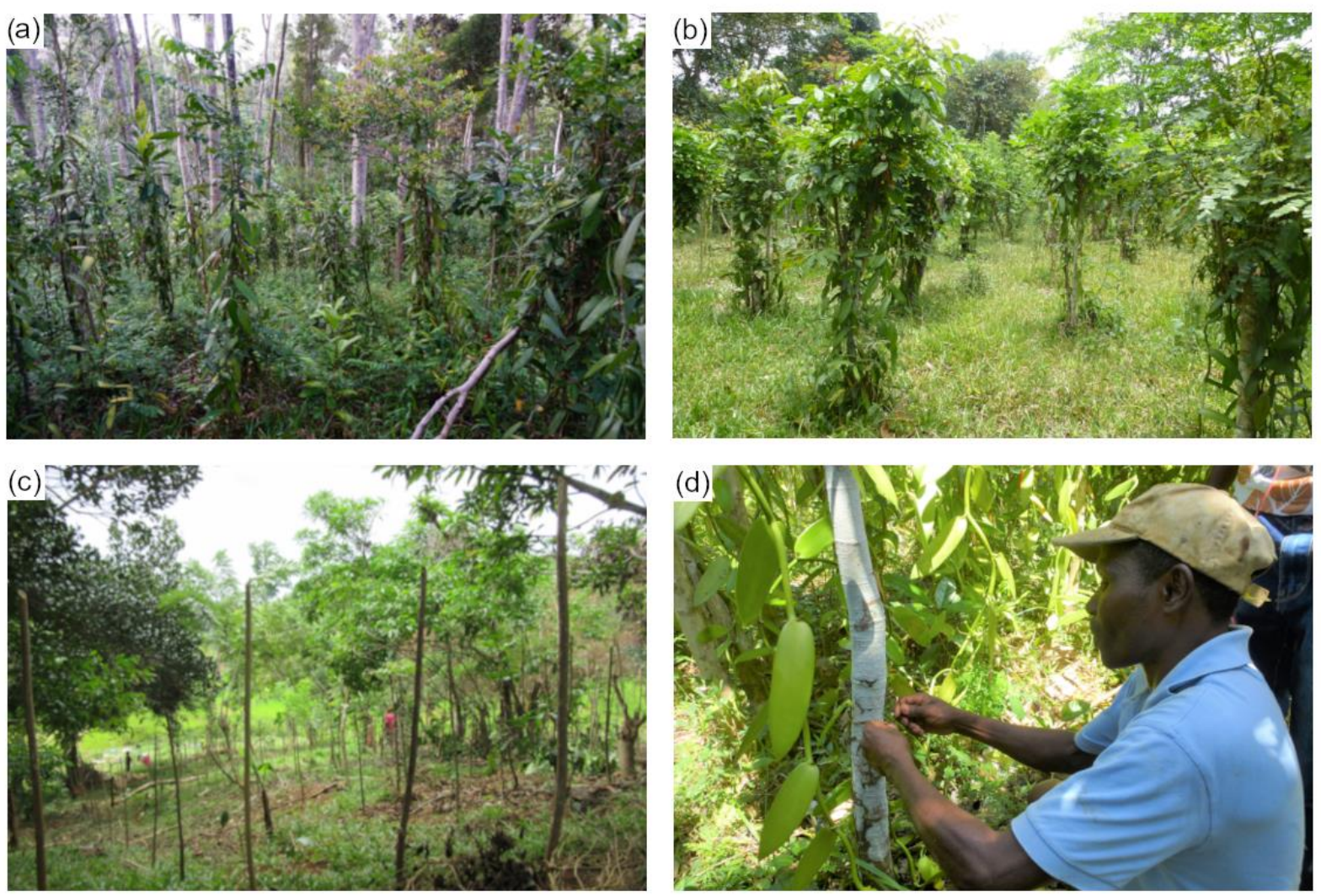

Fig. 4.1 Smallholder vanilla agroforests in Madagascar with support trees for carrying the vanilla plants. A forestderived vanilla agroforest (a); a fallow-derived vanilla agroforest (b); establishment of a new vanilla agroforest with freshly planted support trees (c); attaching a vanilla vine to a support tree (d).

Madagascar contributes about $40 \%$ of natural vanilla to the world market (FAO, 2020). The island is also a biodiversity hotspot with particularly high rates of endemism (Ganzhorn et al., 2014; Myers et al., 2000). Forests of Madagascar harbour the majority of endemic plants and animal species (Dufils, 2003), but large parts of natural forests have already been lost and deforestation rates are still high (Vieilledent et al., 2018). Even though some species can persist in human-modified landscapes (e.g., Raveloaritiana et al., 2021; Torppa et al., 2020)) and information of responses to habitat degradation is lacking for many taxa (Irwin et al., 2010), deforestation certainly threatens Madagascar's biodiversity (Ganzhorn et al., 2001; Rakotoarinivo et al., 2014). Slash-and-burn shifting cultivation is the main driver of deforestation in Madagascar (Yesuf et al., 2019; Zaehringer et al., 2015). 
Agroforests can contribute to biodiversity maintenance in deforested and degraded landscapes (Montagnini, 2020; Schroth et al., 2004). Vanilla agroforests in north-eastern Madagascar support native bird species (Martin, Andriafanomezantsoa, et al., 2021), several lemur species (Hending et al., 2018) and many plant species (Osen et al., 2021; Raveloaritiana et al., 2021). The shade trees in vanilla agroforests are highly diverse and include many endemic species (Osen et al., 2021). Additionally, vanilla agroforests with many shade trees and a dense understory can contribute to the conservation of predation as an important ecosystem function (Schwab et al., 2021).

The diversity of crops and associated trees as well as the structural complexity of an agroforestry system can evolve under climatic, social and economic pressure as shown, e.g., for Malagasy clove cultivation (Michel et al., 2021). For vanilla agroforests in north-eastern Madagascar, also the previous land-use history is important: if established by thinning and converting forests (forest-derived vanilla agroforests), they contribute to species preservation but are a degradation of a natural forest ecosystem; if established on open or fallow land previously used for slash-and-burn agriculture (fallow-derived vanilla agroforests), they may harbour less biodiversity but significantly contribute to ecosystem rehabilitation (Martin et al., 2020; Osen et al., 2021; Raveloaritiana et al., 2021). Nevertheless, both types of vanilla agroforests provide considerable income opportunities to farmers and are similar in vanilla yield which is not affected by the shade tree canopy cover (Martin, Wurz, et al., 2021).

According to our observations, living support trees are normally used as climbing structures in the vanilla agroforestry of north-eastern Madagascar. Both in Madagascar and worldwide, support trees have received little scientific attention so far. However, these trees are intensively managed by farmers and thus offer the opportunity to influence the diversity and structure of agroforests. Our objectives were to identify the species diversity, composition and geographic origin of the support trees in forest-derived and fallow-derived vanilla agroforests in north-eastern Madagascar. The results may inform approaches to creating a multifunctional landscape and contribute to maintaining or restoring tree diversity in agroforestry systems.

\section{Methods}

\section{Study region}

The study was conducted in north-eastern Madagascar (Fig. 4.2). The regional climate is tropical-humid with an annual mean temperature of $24.1^{\circ} \mathrm{C}$ and precipitation of $2157 \mathrm{~mm} \mathrm{y}^{-1}$ (means across study plots, based on CHELSA (Karger et al., 2017)). The topography consists of coastal lowlands, hills and mountains. 
The natural vegetation is tropical rainforest (Moat \& Smith, 2007), today mainly restricted to protected areas like Marojejy National Park. The landscape is characterized by a mosaic of land-use types where slash-and-burn agriculture, locally called tavy, and vanilla agroforestry prevail (Hänke et al., 2018; Llopis et al., 2019).

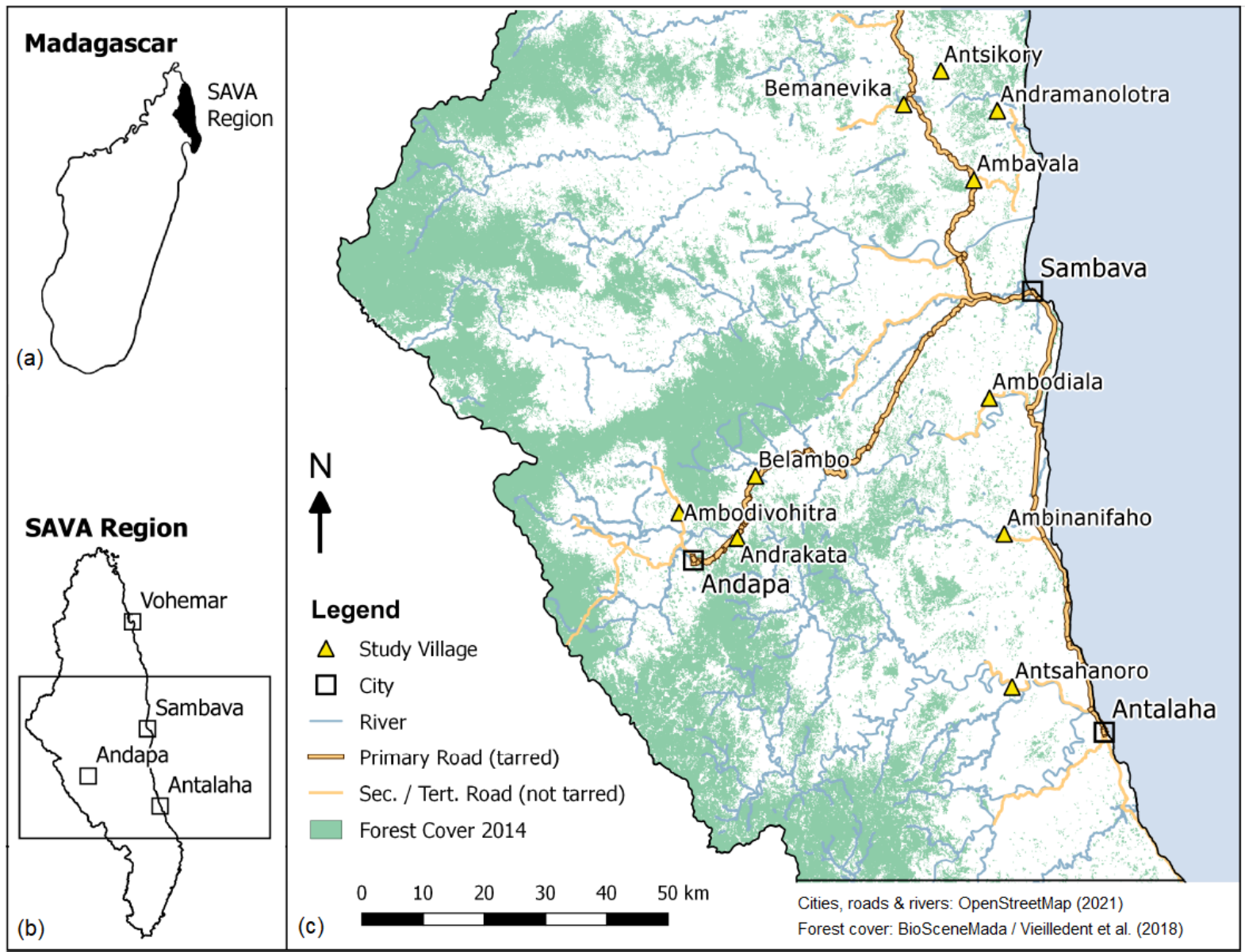

Fig. 4.2 Location of the SAVA region in Madagascar (a); location of our study region within the SAVA region (b); a close-up of the study region with the study villages (yellow triangles; $c$ ).

\section{Sampling design}

We worked in 10 villages across north-eastern Madagascar's SAVA region (Fig. 4.2). In each village, we studied three vanilla agroforests. Interviews with the farmers revealed that 10 out of 30 studied vanilla agroforests were forest-derived and 20 were fallow-derived. In every vanilla agroforest, we placed a circular study plot of $50 \mathrm{~m}$ in diameter $\left(1963 \mathrm{~m}^{2}\right)$. We put 36 markings in a fixed scheme (Fig. 4.3) inside the plots. At each marking, we sampled the support tree carrying a living vanilla plant that grew closest to the respective marking. On every study plot, our selection of 36 support trees represented a share of 
$3-11 \%$ of all support trees within the study plot, depending on the vanilla planting density. Overall, we sampled 1080 support trees consisting of 68 dead and 1012 living support trees. For our analysis, we only considered the 1012 living support trees.

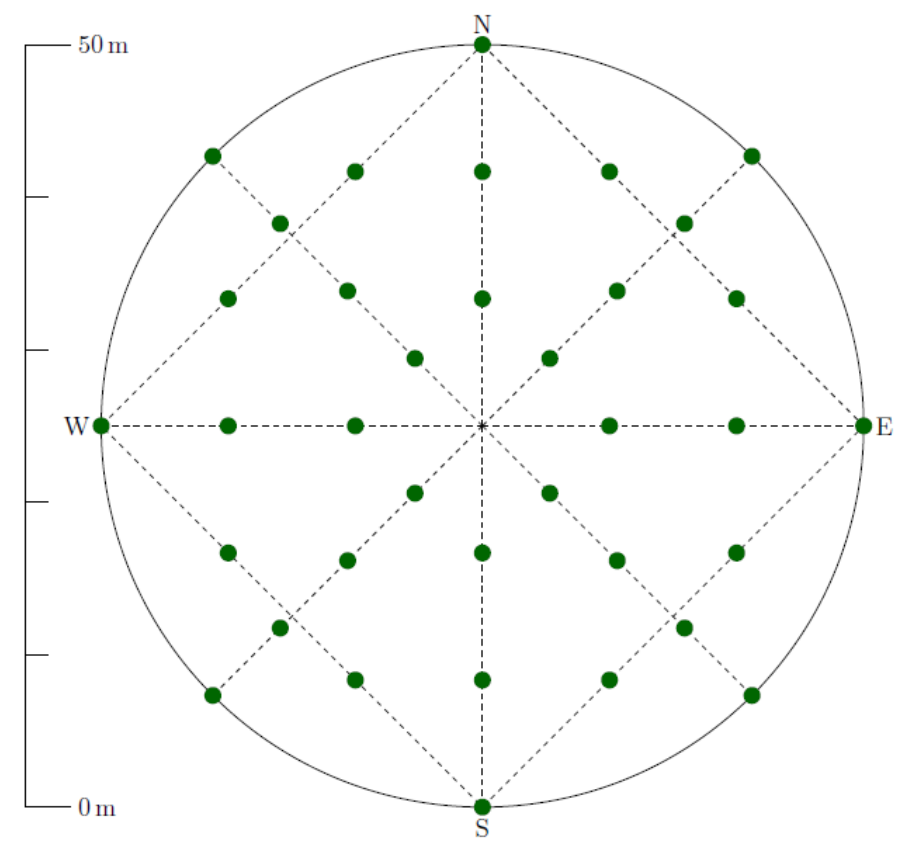

Fig. 4.3 Support tree sampling scheme within a circular study plot $(50 \mathrm{~m}$ diameter) in each of the 30 vanilla agroforests. The dashed lines represent the grid of ropes used to set the scheme. The green dots $(n=36)$ represent the markings along the ropes to select the closest growing support tree.

\section{Species identification}

In the field, we identified 960 of 1012 sampled living support trees to their vernacular names. We took samples and photos (mostly leaves, bark and branches, rarely flowers or fruits) and consulted a local tree expert to identify the remaining 52 support trees to their vernacular names. Thereafter, we used Schatz (2005) and assigned the vernacular names to the corresponding scientific names for 86 species making up 305 trees in our sample. Although Schatz (2005) only differentiates species to genus level, some genera are monotypic and thus a species name could be assigned. If a vernacular name corresponded to several genera, we requested support by the local tree expert to decide for one of them. In addition, we used a report on the floral inventory of the Antanetiambo Nature Reserve by Randrianavaio (2014) and an unpublished inventory list from 2001 provided by Marojejy National Park staff to get suggestions of scientific names matching the vernacular names. The suggestions were then validated by the descriptions of tree characteristics in Schatz (2005). In doubtful cases and the cases not covered by Schatz (2005), we used a species list by Osen et al. (2021) for verification (63 species, 223 trees in our sample). Finally, we 
could identify $41 \%$ of species in our sample ( $86 \%$ of all sampled tree individuals) to scientific species names; $51 \%$ species ( $11 \%$ of all individuals) to genus level and $8 \%$ of species ( $3 \%$ of all individuals) to their vernacular names. However, some uncertainties remain. These are partly due to the frequent taxonomic rearrangements of the diverse Malagasy tree flora (Callmander et al., 2011) which can be challenging to align with local vernacular naming systems. Additionally, tree identification is often based on reproductive features, so sterile and/or young tree individuals can hamper identification precision (Gomes et al., 2013). Therefore, we acknowledge that taxonomic uncertainties might underestimate the diversity of rare species in our support tree assessment.

\section{Species origin and diversity}

Using the Catalogue of the Plants of Madagascar (Tropicos, 2020) and GlobalTreeSearch (Beech, Hills, et al., 2021), we categorized the support tree species based on their origin into endemic (existing only in Madagascar), native (existing naturally in Madagascar but also in other places) or introduced (do not exist in Madagascar naturally). We could not categorize the trees identified only to genus level or vernacular names (130 from 1012 trees in the total sample). We further assessed the global conservation status of the species using the IUCN Red List (IUCN, 2021) and The Red List of Trees of Madagascar (Beech, Rivers, et al., 2021). Diversity was calculated as species richness (species per plot) and Shannon index (Shannon, 1949). We included all species and morphospecies (identification to genus level or vernacular names) in the diversity analysis.

\section{Interviews}

We conducted interviews to assess the share of planted support trees and to clarify what kind of secondary products support trees currently provide. For each vanilla agroforest, we interviewed the person directly involved in its management. We conducted the interview not for each support tree individual but asked each question once per agroforest and morphospecies. Answer categories were provided for each question as well as a possibility to give a free answer (answer category "other"). We conducted every interview only after explicit informed consent was given by each interviewee verbally. All interview participants were free to skip questions and had the right to stop the interview any time.

\section{Statistics}

To analyse the differences between forest-derived and fallow-derived vanilla agroforests in both the species richness per plot and Shannon index, we applied unpaired t-tests (Welch, 1947) after checking the normality of distribution with the Shapiro-Wilk test (Shapiro \& Wilk, 1965). We calculated the share of 
endemic, native and introduced species per plot and used the Mann-Whitney-U-Test (Mann \& Whitney, 1947) to test for significant differences between forest-derived and fallow-derived vanilla agroforests. We also used the Mann-Whitney-U-Test to test for the difference of the share of planted support trees between the forest- and follow-derived vanilla agroforests. Statistically significant difference was assumed at $p<0.05$. We performed the statistical analysis in R version 4.0.2 (R Core Team, 2019) and calculated the Shannon index with the R packages "vegan" (Oksanen et al., 2019). We also used packages "plotrix" (Lemon et al., 2021) and "VennDiagram" (Chen, 2018) for visualization purposes.

\section{Results}

\section{Species diversity and abundance}

In total, we found 122 support trees species belonging to 84 genera and 38 families. The number of species supported by forest-derived vanilla agroforests (115 species) was higher than in fallow-derived vanilla agroforests (31 species; Fig. 4.4). The species richness per plot was significantly higher in the forestderived vanilla agroforests (mean $=19.7, \mathrm{sd}=7.3$ ) than in the fallow-derived vanilla agroforests ( mean $=$ 4.4, $\mathrm{sd}=2.1$ ), (unpaired t-test, $\mathrm{t}=6.541, \mathrm{df}=9.7466, \mathrm{p}<0.001$ (Table 4.1)). The diversity of support trees indicated by the Shannon index was, again, significantly higher for forest-derived vanilla agroforests (mean $=2.6$, sd $=0.65)$ than for fallow-derived vanilla agroforests ( mean $=0.83$, sd $=0.56$ ), (unpaired ttest, $\mathrm{t}=7.318, \mathrm{df}=15.957, \mathrm{p}<0.001($ Table 4.1)). 


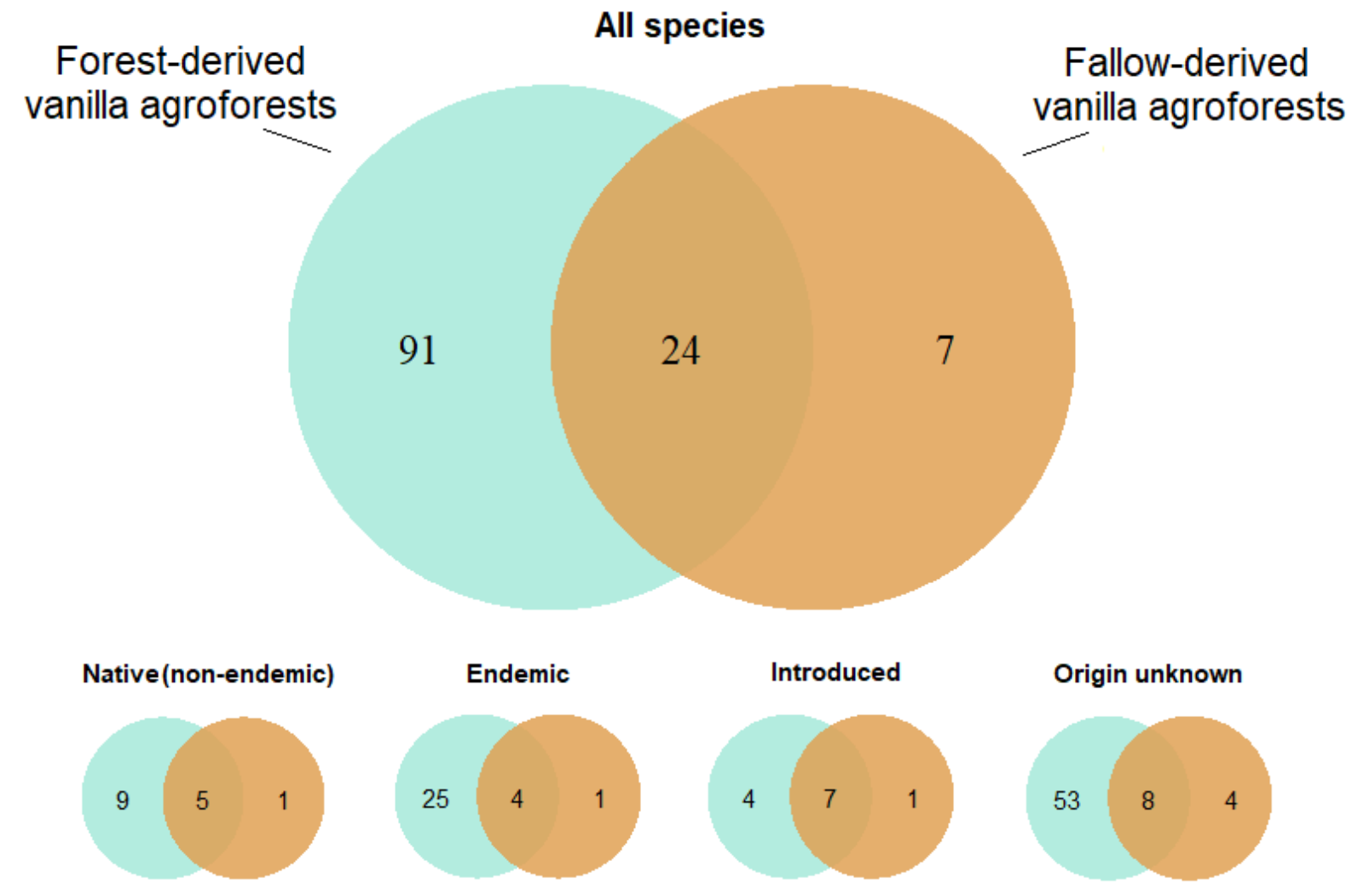

Fig. 4.4 Number of support tree species being different (circle margins) or common (circle intersections) for 10 forest-derived and 20 fallow-derived vanilla agroforests in the study region. The bottom part of the diagram displays the total numbers according to the origin (native, endemic and introduced) of the species. Origin of the species identified to genus or vernacular names only could not be specified (Origin unknown).

Table 4.1 Species diversity of support trees in forest-derived $(n=10)$ and fallow-derived $(n=20)$ vanilla agroforests in north-eastern Madagascar.

\section{All vanilla agroforests}

122

$$
9.5 \text { (8.6) }
$$$$
1-29
$$

\section{Forest-derived vanilla agroforests}

115
19.7 (7.3)

$6-29$
Fallow-derived vanilla agroforests
Species richness ( $\mathrm{n}$, total)

Species richness ( $\mathrm{n}$ per plot)

\section{Shannon index}

$$
\min -\max \text { (per plot) } \quad 0.00-3.34
$$
$2.6(0.65)$
$1.19-3.34$

4.4 (2.1)

$1-8$

$0.83(0.56)$

$0.00-1.84$ 
The three most abundant species comprising $53 \%$ of all sampled trees were Jatropha curcas, Clausena excavata, and Pachira glabra. In forest-derived vanilla agroforests, the most abundant $15 \%$ of species, i.e. 16 species, contributed $50 \%$ of all trees. Other $38 \%$ of species in our sample for forest-derived vanilla agroforests ( 355 trees) were represented by $2-4$ individuals and $47 \%$ by only 1 individual each. The tendency of some species being highly abundant and many being rare was even more pronounced in the fallow-derived vanilla agroforests where just one species (Jatropha curcas) accounted for $52 \%$ of all trees (Fig. 4.5).
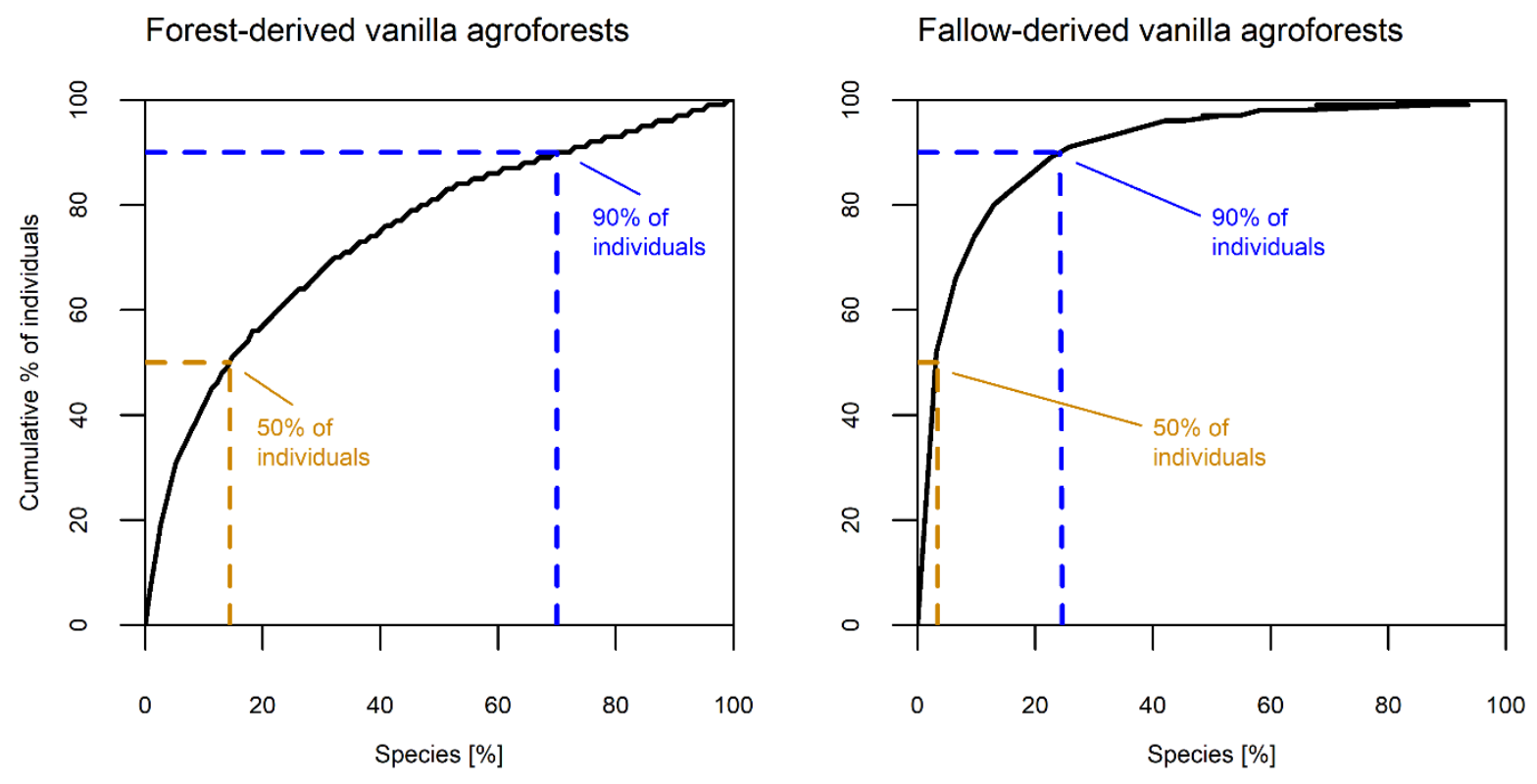

Fig. 4.5 Species dominance structure among support trees in forest-derived and fallow-derived vanilla agroforests. In forest-derived vanilla agroforests ( $n=10$ plots), we found 115 species among 335 individuals. In fallow-derived vanilla agroforests ( $n=20$ plots), there were 31 species among 677 individuals. The brown dashed line indicates the share of species contributing $50 \%$ of all individuals; the blue dashed line indicates the share of species contributing $90 \%$ of all individuals.

\section{Species origin and IUCN status}

We found 45 of 122 species to be native or endemic ( $12 \%$ of all species and $25 \%$ of all species respectively; see also Fig. 4.4) of which 11 were endemic at genus level. We observed 12 introduced species, which accounted for two-thirds of all sampled trees (Fig. 4.6). The summed share of native and endemic species among all found species was similar for the forest-derived and fallow-derived vanilla agroforests ( $37 \%$ and $35 \%$ of species, see also Fig. 4.4). Nevertheless, the situation differed when accounting for support trees abundances: $44 \%$ of all individuals in the forest-derived vanilla agroforests belonged to the native or 
endemic flora, whereas only $11 \%$ of the individuals were native or endemic in fallow-derived vanilla agroforests (Fig. 4.6).
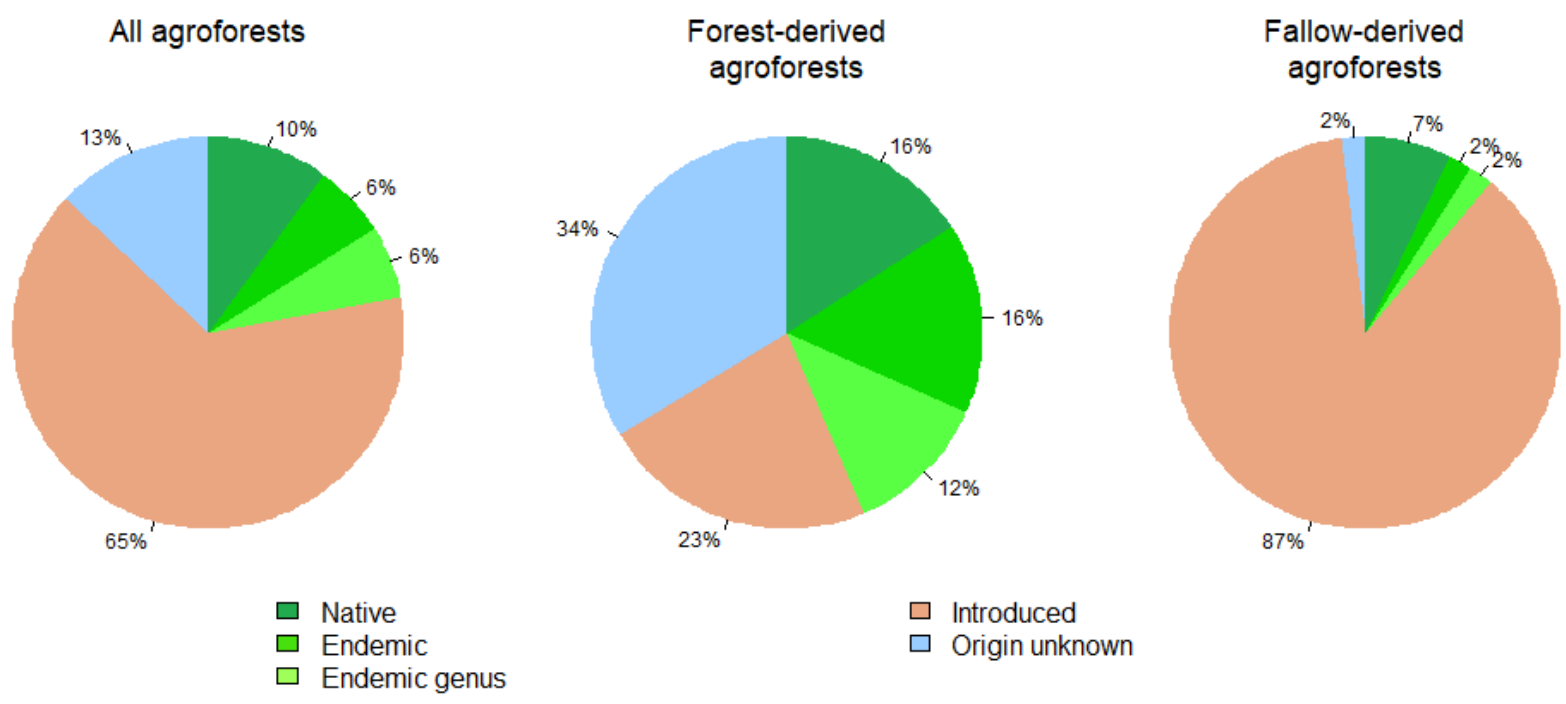

Fig. 4.6 Share of tree individuals belonging to native, endemic or introduced species across all vanilla agroforests ( $\mathrm{n}$ $=30$ ), in forest-derived ( $n=10$ plots) and in fallow-derived ( $n=20$ plots) vanilla agroforests. We could not specify the origin of the species defined to genus or vernacular names only (Origin unknown). The share of trees belonging to introduced species differed significantly between forest-derived (median $=6 \%, I Q R=37 \%$ ) and fallow-derived ( median $=93 \%, I Q R=11 \%$ ) vanilla agroforests (Mann-Whitney-U-Test, $U=183.5 ; p<0.001)$.

Among all 50 species that we could identify to species level, 82\% have been assessed in the IUCN Red List (2021). Most of the species had the status "LC - Least Concern". Intsia bijuga was listed as vulnerable, Dichaetanthera altissima as endangered. Both species formed $0.5 \%$ of the whole sample and were only encountered in the forest-derived vanilla agroforests.

\section{Planted support trees}

According to our farmer interviews, $21 \%$ of all support trees in forest-derived vanilla agroforests were planted $\left(\right.$ median $\left.=0 \%, I Q R=33 \%, n_{\text {plots }}=10\right)$. In contrast, $71 \%$ of all support trees in fallow-derived vanilla agroforests were planted (median $\left.=83 \%, I Q R=27 \%, n_{\text {plots }}=20\right)$. A Mann-Whitney-U-Test indicated a significant difference between both groups $(U=30, p=0.002)$. The support trees species whose individuals were mostly planted were Jatropha curcas (97\%, of all individuals planted), Pachira glabra, Gliricidia sepium, and Morus alba (each with 100\% individuals planted). Thus, planted trees were mostly introduced species. 


\section{Secondary use of support trees}

Secondary use could be confirmed for $32 \%$ of all support trees in our sample. Most common secondary uses of support trees included personal use as medicine (12\% of all individuals) and edible fruits for personal consumption or selling ( $6 \%$ of all individuals). Among the introduced species, the most used ones were Coffea canephora ( $81 \%$ of individuals for personal consumption as food; $54 \%$ for selling food; and $12 \%$ each for medicine and firewood), Jatropha curcas (20\% of individuals used for medicine) and Morus alba (92\% of all individuals used for medicine). Among native species, the mostly used one was Parinari curatellifolia ( $18 \%$ of individuals used for food and $18 \%$ for medicine). Another relatively frequently used native species was Sorindeia madagascariensis ( $28 \%$ of individuals used for personal food consumption).

\section{Discussion}

In vanilla agroforests of north-eastern Madagascar, we found 122 species of support trees used for carrying vanilla plants. Land-use history strongly influenced the species richness with higher diversity in forest-derived than in fallow-derived vanilla agroforests. Species abundance was highly uneven with few dominant and many rare species, especially in fallow-derived vanilla agroforests. Endemic species dominated the group of native species (30 of 45 native species). Together, native and endemic species comprised $44 \%$ of the support trees in forest-derived and $11 \%$ in fallow-derived vanilla agroforests. The most abundant support tree species was the introduced Jatropha curcas.

\section{Species richness of support trees compared with shade trees}

The total of 122 support tree species is lower than 229 species of shade trees encountered on the same plots (all sampled shade trees $>8 \mathrm{~cm}$ DBH; Osen et al., 2021). While most support tree species identified to the species level were also found among shade trees, $18 \%$ (i.e. 9 of 50) were not. Four of these (Hibiscus tiliaceus, Manihot esculenta, Psiadia altissima and Tambourissa thouvenotii) are shrubs or small trees and thus less likely to be accounted for in shade tree surveys. However, except M. esculenta, these species are native to Madagascar and two of them ( $P$. altissima and $T$. thouvenotii) belong to the endemic Malagasy flora. Overall, six of the support tree species without shade trees analogous have the status of endemics. We found seven of the support species without shade trees analogous exceptionally in the forest-derived vanilla agroforests and two other species ( $H$. tiliaceus and $P$. altissima) only in the fallowderived vanilla agroforests. The difference between support and shade tree species indicates that support trees enrich the overall native and endemic plant diversity in vanilla agroforests of the region. 


\section{Land-use history determines support tree diversity}

As for vanilla agroforests in north-eastern Madagascar, our data suggest that land-use history strongly influences species richness of support trees there. Forest-derived vanilla agroforests show a higher species richness (with a mean of 19.7 species per plot) than fallow-derived vanilla agroforests (with a mean of 4.4 species per plot). This corresponds to a similar trend in tree species diversity among shade trees (Osen et al., 2021). This is also in line with the analyses by Martin et al. (2020) emphasizing the importance of land-use history for biodiversity and ecosystem services in agroforestry systems. Overall, with 122 species of support trees and 229 species among shade trees (Osen et al., 2021), the vanilla agroforests in north-eastern Madagascar contribute to maintaining the unique tree diversity of the island.

\section{Support tree management results in strong unevenness in species abundances}

Our findings revealed a strong unevenness in the abundance of support tree species (Fig. 4.5): few species were highly abundant, and many species were rare. In fallow-derived vanilla agroforests, just one species (Jatropha curcas) accounted for $52 \%$ of all trees. J. curcas and other introduced species abundant in the fallow-derived vanilla agroforests like Gliricidia sepium, Pachira glabra and Morus alba were mostly planted. Planting G. sepium and J. curcas, farmers in north-eastern Madagascar possibly follow guidelines of a former extension and training project that recommended to use these species (J.-J. Tsialefitra, personal communication, 12.12.2016). Planting these introduced species may be motivated by their easy propagation by cuttings as well as soil-improving abilities (World Agroforestry Centre, 2009). J. curcas and G. sepium, both being native for Mesoamerica and Mexico, are known for these characteristics and used as support structures for vanilla in Africa, Asia and Oceania (Hernandez \& Lubinsky, 2011; Komarek, 2010; Minh et al., 2015; Van der Grijp, 1997). G. sepium is also used as support structure for other crops as black pepper and yam in West Africa and India (World Agroforestry Centre, 2009). Introduced trees can contribute to people's livelihood (Gérard et al., 2015; Kull et al., 2013), and the introduced J. curcas and M. alba were used for medicinal purposes in our study region. However, G. sepium and P. glabra, the two other frequently planted introduced species, had no such use. On the other hand, some native species like Parinari curatellifolia and Sorindeia madagascariensis were used for food and medicine at rates comparable with that of J. curcas.

\section{Promoting native and endemic support trees to foster ecosystem service provisioning}

In total, in our sampled vanilla agroforests, introduced species hold a low share of species (11\%) but a relatively high share of all individuals (65\%). One of them, J. curcas, was classified as invasive by Kull et al. (2012), but our impression is that this consideration would need further assessment in the mosaic 
landscape of north-eastern Madagascar. Furthermore, our data suggest that also many native or endemic species can be used as support tree species as particularly found in forest-derived vanilla agroforests. At least 45 encountered support tree species were native to Madagascar of which 30 were endemic including 11 being endemic at genus level. Here might be a potential for vanilla farming that favours native and endemic tree diversity. Promoting native and endemic support tree species can contribute to maintaining other native and endemic taxa as far as small-statured trees can also provide habitat and food for associated fauna in human-modified landscapes, especially if such trees are present in large quantities (Le Roux et al., 2015). Being a part of the understory, they could also help to support high predation rates as described by Schwab et al. (2021).

\section{Conclusion}

Overall, we conclude that vanilla agroforests in north-eastern Madagascar are rich in tree species, also among the support trees. Native and endemic tree species are being used for carrying the vanilla plants with particularly many native and endemic species observed in forest-derived vanilla agroforests. The relatively high number of native and endemic species in forest-derived vanilla agroforests as well as a high share of support tree individuals belonging to these species groups, imply a considerable conservation value of forest-derived vanilla agroforests. On the other hand, since fallow-derived vanilla agroforests can play an important role in restoration and rehabilitation but are today largely dominated by introduced species among support trees, we suggest a stronger consideration of native or even endemic tree species also in new to establish vanilla agroforests.

\section{Author contribution}

JO, KO, AW, DAM, MRS and DH conceived the ideas and designed methodology; JO and TR collected the data; JO processed and analysed the data; YK, JO \& DH led the writing of the manuscript. All authors contributed to the manuscript and gave final approval for publication.

\section{Acknowledgements}

We are thankful to agroforest owners, chef de fokontany and the village communities for receiving us and providing us access to their vanilla agroforests. Special thanks to the local tree specialist Jean Chrysostome Bevao from Madagascar National Parcs (MNP) and the tree expert Patrice Antilahimena from Missouri Botanical Garden Antananarivo, for supporting us with the tree species identification. 


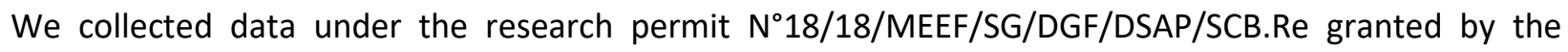
Ministry for Water, Ecology and Forest (MEEF), Antananarivo, Madagascar. We thank MNP and MEEF for the collaboration. Our work was financially supported by the 'Niedersächsisches Vorab' of 'Volkswagen Foundation' as part of the research project 'Diversity Turn in Land Use Science' (Grant number 11-7625199-35/13 (ZN3119)). MRS was supported by the German Academic Exchange Service (DAAD) within the 'Partnerships for Supporting Biodiversity in Developing Countries' initiative (Project Nr. 57449386).

\section{Data availability statement}

After acceptance for publication, the underlying tree data will be uploaded to the Open Science Framework (OSF) database.

\section{Consent to participate}

The owners of the studied agroforests provided us access to their land. They were free to deny the access and/or stop the process of sampling. Also, an interview with agroforest owners was a part of our study. Before the interview, interviewees gave they participation agreement verbally. They were free to refuse or withdraw their answers. They also were aware that it was possible to stop the interview any time.

\section{Consent for publication}

All agroforest owners and interview participants gave their verbal approval for the results of our study to be published. 


\section{Chapter 5: Case study: Aboveground carbon stocks in Madagascar's vanilla production landscape}

Manuscript title: Aboveground carbon stocks in Madagascar's vanilla production landscape - exploring rehabilitation by agroforestry in the light of land-use history

Authors: Marie Rolande Soazafy* \& Kristina Osen*; Annemarie Wurz; Estelle Raveloaritiana; Dominic A. Martin; Hery Lisy Tiana Ranarijaona, Dirk Hölscher (*shared first-authorship)

Manuscript status: Published in Global Ecology and Conservation; https://doi.org/10.1016/j.gecco.2021.e01853

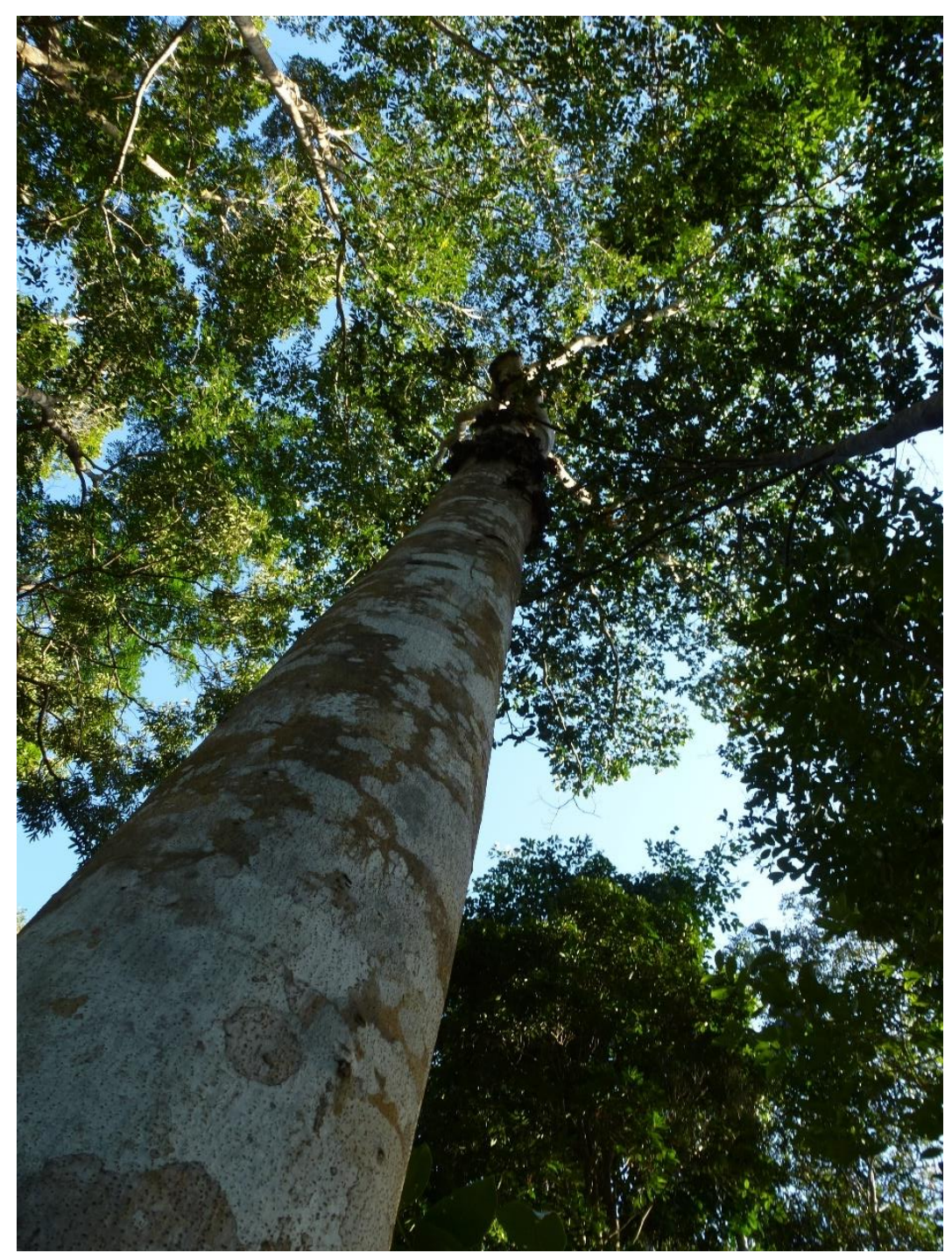




\section{Abstract}

Forests and tree-dominated land uses store large amounts of carbon stocks in plant biomass. However, anthropogenic changes in land use and land cover decrease tree cover and associated carbon stocks. Agroforestry has the potential to maintain or restore carbon in plant biomass but the amount will be influenced by various factors that may include land-use history and management practices. However, few studies explicitly address how these factors determine aboveground carbon stocks. Therefore, our study estimates aboveground carbon stocks in different land-use types, across stem diameters and geographic origin of tree species, and its structural controls. We particularly focus on the importance of land-use history in agroforestry systems. We conducted the study in the mosaic landscape of north-eastern Madagascar in old-growth forests, forest fragments, woody fallows, and vanilla agroforests. The agroforests differed in land-use history and were either directly derived from a forest or a woody fallow after slash-and-burn shifting cultivation. Aboveground carbon stocks were highest in old-growth forests and lowest in woody fallows. Within vanilla agroforests, aboveground carbon stocks were highly variable: forest-derived agroforests stored significantly higher carbon stocks that were mainly stored in native and endemic species, whereas fallow-derived agroforests stored lower carbon stocks that were mainly provided by introduced species. Furthermore, aboveground carbon stocks were mainly controlled by stem density and stem diameter. In conclusion, forest-derived agroforests have the potential to maintain relatively high carbon stocks and a forest-like structure in the landscape, whereas fallow-derived agroforests contribute to converting historically forested open land into permanent tree-dominated landuse systems, thereby restoring carbon stocks. Thus, considering the land-use history of agroforests is important for conservation and restoration agendas.

Keywords: Vanilla agroforestry; endemism; restoration; stand structure; human-modified landscape; tree-dominated land-use systems

\section{Introduction}

Tropical forests play a globally important role for biodiversity and provide essential services to society (Corlett \& Primack, 2008; Gibson et al., 2011; Watson et al., 2018). Furthermore, tropical forests have a strong influence on the global carbon cycle by storing up to $55 \%$ of global forest carbon stocks in plant biomass and soil (Pan et al., 2011). Consequently, the anthropogenic conversion of tropical forests has 
profound effects on many levels: forest conversion alters biodiversity and also impacts ecosystem functioning and ecosystem service provision of these forests (Brancalion et al., 2019; Isbell et al., 2011). Therefore, preventing tropical forest conversion is an important aspect of climate change mitigation and biodiversity conservation and represents a key goal in global international environmental agreements (Watson et al., 2018). Specifically, the strategies to reduce carbon emissions associated with deforestation and forest degradation are increasingly gaining attention by international policymakers (Brancalion \& Chazdon, 2017; Chazdon et al., 2017; Verdone \& Seidl, 2017). Additionally, international initiatives aim to mitigate climate change through carbon storage by restoring land and increasing tree cover in historically forested landscapes (Brancalion et al., 2019; Brancalion \& Holl, 2020; Lewis et al., 2019).

The largest share of aboveground carbon stocks (ACS) in tropical forests is contained in trees (Clark et al., 2001; Houghton, 2007). Therefore, the most common proxy to evaluate these ACS within landscapes is to estimate the aboveground biomass of living plants, especially trees (S. Brown \& Lugo, 1982; Chave et al., 2014), which can then be converted to estimate ACS. Specifically, in tropical human-modified landscapes, carbon storage is strongly influenced by land cover and land use (Houghton, 2007). Hence, carbon-based funding schemes often translate into action on the ground via land management practices, such as agroforestry (Bhagwat et al., 2008; Lewis et al., 2019; Zomer et al., 2016).

Agroforestry shapes human-modified landscape in many tropical countries by integrating trees into agricultural cropping systems for subsistence agriculture but also for cash-crop cultivation (Bhagwat et al., 2008; Zomer et al., 2016). Agroforestry has the potential to restore tree cover and associated carbon stocks (Albrecht \& Kandji, 2003; Schroth et al., 2015). However, agroforests have contrasting land-use histories and can be either forest- or open-land-derived (Martin et al., 2020), which might influence their role for carbon storage. Presumably, forest-derived agroforestry supports higher carbon stocks than openland derived agroforestry, but essentially represents a degradation of forest, whereas open-land derived agroforestry contributes to rehabilitating historically forested open land (Martin et al., 2020; Martin, Wurz, et al., 2021). Even though several studies assess the carbon storage potential of agroforests (De Beenhouwer et al., 2016), we are not aware of any study that directly compares carbon stocks of openland- and forest-derived agroforests, thereby accounting for land-use history.

In north-eastern Madagascar, smallholder agroforests are a common element of the tropical mosaic landscape (Osterhoudt, 2017). These agroforests are used to cultivate vanilla (Vanilla planifolia), which is Madagascar's major export product (OEC, 2021). Additionally, vanilla sales are important footholds of family livelihoods, as more than $80 \%$ of rural households in the study region engage in vanilla farming 
(Hänke et al., 2018). In these agroforests, small-statured trees provide support for the climbing vanilla orchid, and a variety of taller trees form the canopy and provide shade to the crop (Havkin-Frenkel \& Belanger, 2018). Household surveys from north-eastern Madagascar report that vanilla agroforests differ in land-use history: around $30 \%$ of vanilla agroforests are derived directly from the forest, whereas $70 \%$ of vanilla agroforests originate from fallow land that had formerly burned within the slash-and-burn cycle (Hänke et al., 2018). Global demand and high world market prices have led to an expansion of vanilla agroforests in recent years (Llopis et al., 2019). Throughout Madagascar, forest cover decreased in the last decades, driven by agricultural practices and a diverse range of political, economic, cultural, demographic, and environmental factors (Scales, 2014). However, evidence of natural forest regeneration is limited (Harper et al., 2007; Irwin et al., 2010; Schüßler et al., 2020). Thus, much of today's remaining forest cover in north-eastern Madagascar is highly degraded and only a small share of old-growth forest remains intact and natural forest cover has declined by around 20\% since 1990 (Schüßler et al., 2020). At the same time, Malagasy forests shelter a vast range of biodiversity with high endemism levels (Buerki et al., 2013; Callmander et al., 2011; Goodman \& Benstead, 2005; Schatz, 2005; Willis, 2017). More than 95\% of Malagasy trees and shrubs are endemic among which $>60 \%$ are confined to evergreen forest habitats (Schatz, 2005), making these forest landscapes a national and global priority for conservation and restoration efforts (Ganzhorn et al., 2001; Myers et al., 2000; Willis, 2017).

Vanilla agroforests cannot replace old-growth forests, but they can provide habitat for native wildlife (Fulgence et al., 2021; Hending et al., 2018, 2020; Martin, Andriafanomezantsoa, et al., 2021; Raveloaritiana et al., 2021) and represent a means to retain or increase tree diversity and tree cover (Osen et al., 2021), and probably connectivity in a multifunctional landscape. Yet, considering their land-use history and management is key to unfold their full potential in a conservation context (Osen et al., 2021). Therefore, we hypothesize that land-use history also plays a role in determining the aboveground carbon stocks (ACS) in vanilla agroforests. Understanding to which extent vanilla agroforests of contrasting landuse history act as ACS reservoirs and understanding the driving factors at the plot level is important to better integrate such agroforests into conservation and restoration agendas.

In this study, we examined the variation of ACS across tree-dominated land-use types in north-eastern Madagascar. Specifically, we asked: (a) how do ACS vary among vanilla agroforests of contrasting landuse history as well as in comparison to other tree-dominated land-use types? (b) how do stem diameter and geographical origin of tree species vary proportionally across land-use types and how do they contribute to ACS patterns? Furthermore, we focussed specifically on vanilla agroforests and asked: (c) 
how does land-use history influence the respective effects of allometric variables underlying the ACS estimations within vanilla agroforests?

\section{Methods}

\section{Study area}

We implemented our study in north-eastern Madagascar in the SAVA region (Fig. 5.1). The tropical-humid climate has a mean annual temperature of $23.9^{\circ} \mathrm{C}$ and $2258 \mathrm{~mm}$ of mean rainfall per year across 58 study plots (based on CHELSA; Karger et al., 2017). The landscape is characterized by coastal lowlands, merging into hills and mountains, and was historically covered with humid evergreen forest with a high floristic diversity and high levels of endemism (Callmander et al., 2011; Goodman \& Benstead, 2005; Schatz, 2005; Willis, 2017). Nowadays, the landscape comprises a mosaic of land uses consisting of vanilla agroforests, paddy rice fields, and different stages of slash-and-burn shifting cultivation for hill rice production (Malagasy: tavy), which is also a major driver of deforestation (Llopis et al., 2019). Additionally, the landscape is interspersed with forest fragments which are commonly used to harvest wood and other resources. Remnant areas of continuous old-growth forest with little or no human disturbance only remain in protected areas (Schüßler et al., 2020). The major cash crop in the study region is vanilla, which is cultivated in smallholder agroforests (Osterhoudt, 2017). 


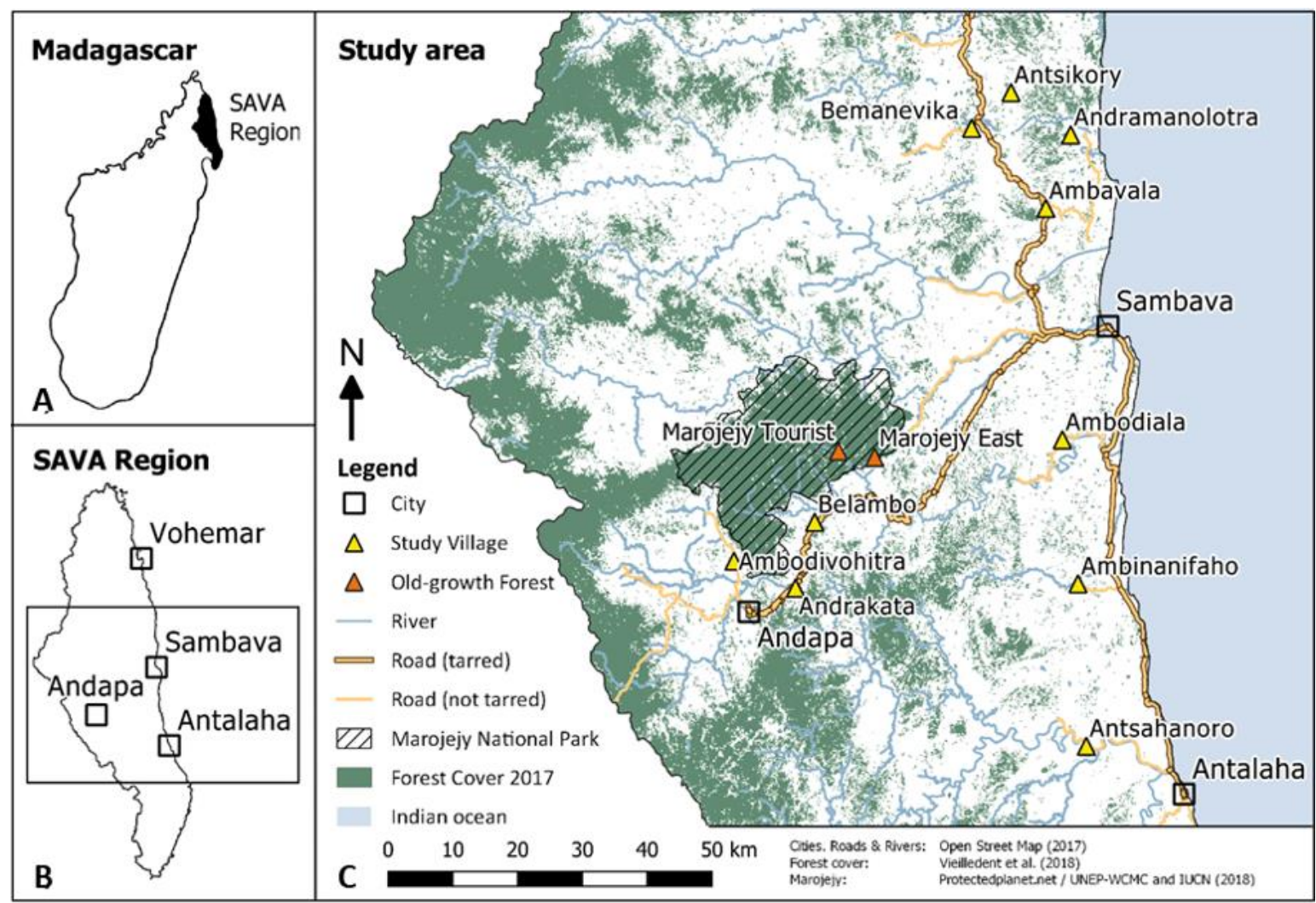

Fig. 5.1: Study area map. Panel A: the island of Madagascar with the SAVA region at the north-eastern coast; panel B: the SAVA region with four main cities Sambava, Andapa, Vohemar, and Antalaha.; panel C: the study area with 2017 forest cover (Vieilledent et al., 2018), 10 study villages, and the two sampling sites in the old-growth forest of Marojejy National Park.

\section{Study design and sampled land-use types}

We conducted tree inventories and assessed aboveground carbon stocks (ACS) in the most common treedominated land-use types in the study region, namely vanilla agroforests, old-growth forests, forest fragments and naturally regenerating woody fallow as part of the slash-and-burn cycle. Vanilla agroforests differ in land-use history and can either be forest-derived or fallow-derived. Forest-derived agroforests are established by thinning the forest, cleaning the understory, and planting vanilla under the canopy of the forest remnant trees. Fallow-derived agroforests originate from fallow land that had formerly burned within the slash-and-burn cycle before trees re-established and vanilla was planted (Fig. 5.2). We worked in ten villages within the study region (Fig. 5.1C). Around each village, we selected three vanilla agroforests, one forest fragment, and one naturally regenerating woody fallow (Fig. 5.2). Out of 30 chosen vanilla agroforests in our study, 20 agroforests were fallow-derived, and 10 agroforests were forestderived. Since two landowners withdrew from the study, we finally collected data on 28 vanilla 
agroforests: 10 forest-derived and 18 fallow-derived agroforests. The 10 naturally regenerating woody fallows (Malagasy: savoka) in our study were characterized by a mix of herbaceous plants, shrubs and small trees, and had last burned 5 - 17 years before data collection. All 10 chosen forest fragments were either private or communal land that had not been burned in living memory but showed signs of regular extraction of timber, firewood, and other products.

Additionally, we chose 10 old-growth forest plots within the Marojejy National Park. The park is the largest old-growth forest persisting in the study area and the extraction of timber, firewood, and other products is not allowed (Goodman, 2000). We chose 10 old-growth forest plots at two sites (5 plots at each), which showed the least indication of recent human disturbance at elevations below 700 meters above sea level (m.a.s.I.). Overall, we worked on 58 plots and collected data between September 2018 and January 2019.

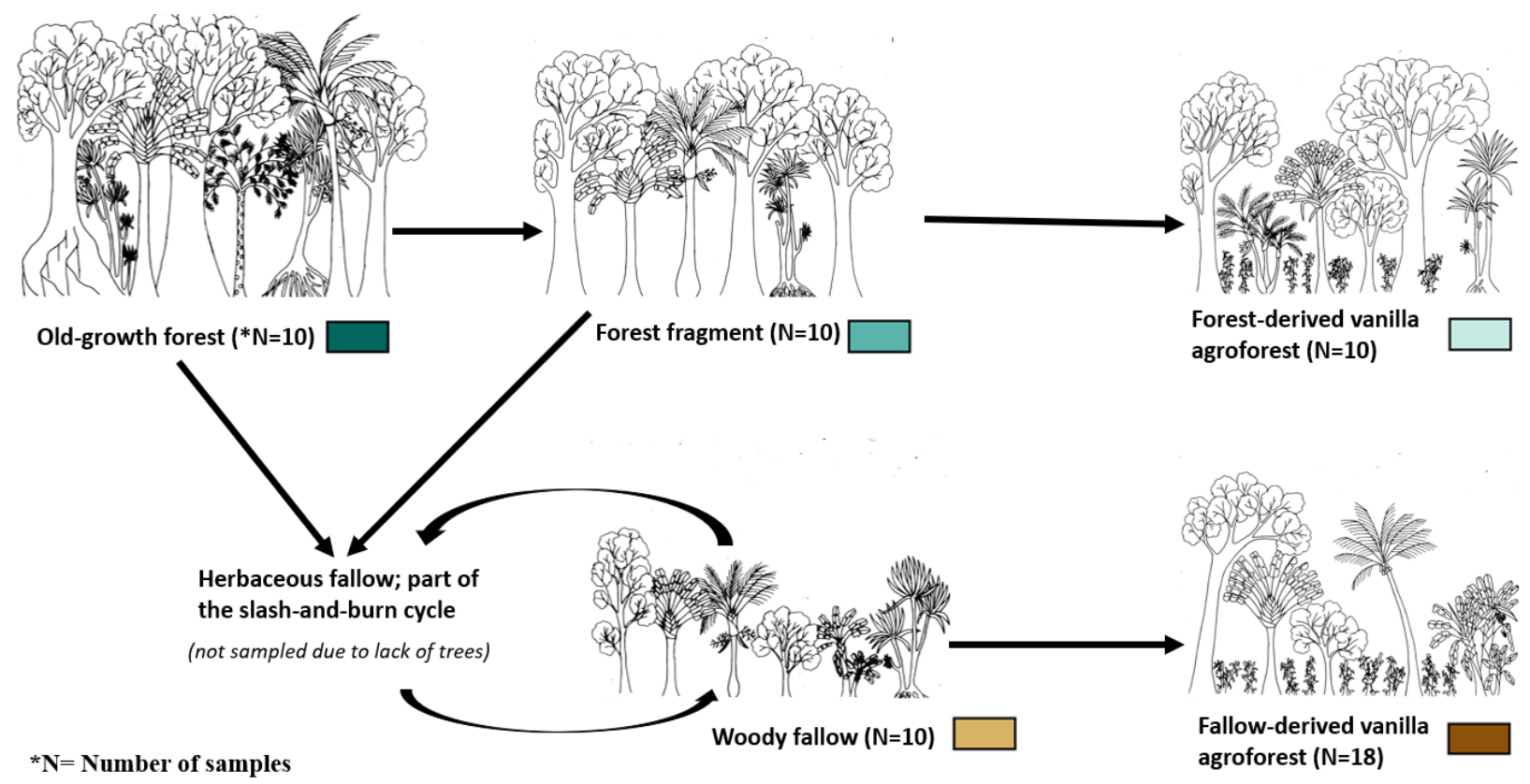

Fig. 5.2: Schematic concept of typical transformation pathways from the old-growth forest into different land-use types highlighting the different land-use history pathways of vanilla agroforests. Artwork: Marie Rolande Soazafy.

\section{Plot design}

We collected all data within circular plots of $25 \mathrm{~m}$ radius $\left(1962.5 \mathrm{~m}^{2}\right)$. We derived the mean slope and mean elevation of each study plot from the 30 m-resolution digital surface model "ALOS World 3D" by the Japan Aerospace Exploration Agency (JAXA) and applied slope correction. Across all 58 study plots, the mean minimum distance from one plot to the closest neighbouring plot was $827 \mathrm{~m}$, standard deviation 
(SD) $539 \mathrm{~m}$ with a minimum of $260 \mathrm{~m}$. Plot slopes spanned from $1.6^{\circ}$ to $27.4^{\circ}$ (mean $9.8^{\circ}, \mathrm{SD} 5.8^{\circ}$ ) and plot elevation spanned from 20 to 819 m.a.s.I (mean 208 m.a.s.I, SD 213 m.a.s.l.; Appendix S5.8).

\section{Aboveground plant biomass and carbon stocks assessment}

On each plot, we recorded all plants with free-standing stems with $\geq 8 \mathrm{~cm}$ of diameter at breast height (DBH), including trees, arborescent herbs, palms, and tree ferns (but excluding lianas). For each individual, we measured the $\mathrm{DBH}$ at $1.3 \mathrm{~m}$ or immediately above the tallest buttress or stilt root, whenever this exceeded $1.3 \mathrm{~m}$ (Osen et al., 2021). Additionally, we recorded the total height of each individual from the base of the trunk to the highest point of the crown, using a Vertex III height meter (Haglöf, Långsele, Sweden). In the case of palms, we defined height as the length from the base of the trunk to the base of the lowest living leaf (Condit, 2008).

We measured wood density for all tree species at breast height $(1.3 \mathrm{~m})$ using a Pilodyn $6 \mathrm{~J}$ wood tester (PROCEQ SA, Zurich, Switzerland). The Pilodyn wood tester measures the penetration depth of a metal pin into the stem wood of a tree and this value can be recalculated into wood density, using formula (1) following Kotowska et al. (2015), where $\mathrm{h}$ is the pin penetration [mm] and $\mathrm{s}$ is the wood density $[\mathrm{g} / \mathrm{cm} 3]$ :

$$
\ln (s)=0.8711-0.5763 * \ln (h)
$$

We pooled pilodyn pin penetration values per species and matched them to the dataset. We obtained pilodyn values for $93 \%$ of all tree individuals and converted them to wood density values. If pilodyn values were not available for a certain species, we retrieved wood density values from a Madagascar-specific database (Vieilledent et al., 2012). For the remaining species, we retrieved wood density values from the global wood density database (Chave et al., 2009; Zanne et al., 2009) using the function "getWoodDensity" from the R-package BIOMASS (Réjou-Méchain et al., 2017). This function provided wood density data at the species, genus, or family level, depending on data availability (for $6 \%$ of all tree individuals). For 18 trees ( $0.3 \%$ of all tree individuals), we had no field measurements and could not retrieve wood density data from Chave et al. (2009) and Zanne et al. (2009), so we assigned the respective genus mean wood density value derived from our dataset (for 3 individuals). If genus mean wood density values were not available (for 15 individuals), we assigned the respective plot mean wood density derived from our dataset (Appendix S5.7).

To estimate the aboveground plant biomass for trees (plants with woody stems, see Schatz (2005)), we used the pantropical allometric model by Chave et al. (2014) (Table 5.1). 
For other non-woody plants such as palms, tree ferns (Cyathea sp.), bananas (Musa sp.), or traveller palms (Ravenala madagascariensis), we used different allometric equations from the literature (Table 1). For the arborescent monocotyledonous plants Dracaena sp. and Pandanus sp. we are not aware of any published allometric equation, so we used the same equation as for palms due to their structural similarity.

We obtained aboveground carbon stocks (ACS) by multiplying the estimated aboveground plant biomass per plant by 0.5 , based on the assumption that plant biomass is $50 \%$ composed of carbon (S. Brown \& Lugo, 1982; Chave et al., 2005). Only for the arborescent herbs of Musa sp., we multiplied the estimated aboveground biomass per plant by 0.46 to obtain ACS, following the concept of Danarto and Hapsari (2015). Overall, we summed up values for every plant per plot to obtain stand-scale ACS.

Table 5.1: Allometric equations used to determine aboveground biomass (AGB) for different tree-like plant growth forms. AGB is the estimated aboveground biomass (in $\mathrm{kg}$ ), $\mathrm{D}$ the trunk $\mathrm{DBH}$ (DBH in $\mathrm{cm}$ ), $\mathrm{H}$ the total height (in $\mathrm{m}$ ), and rho the wood density (in $\mathrm{g} / \mathrm{cm}^{3}$ )

\begin{tabular}{|c|c|c|}
\hline $\begin{array}{l}\text { Aboveground biomass per } \\
\text { growth form }\end{array}$ & Allometric equations & Authors \\
\hline Trees & $A G B=0.0673 *\left(r h o^{*} D^{2 *} H\right)^{0.976}$ & Chave et al., 2014 \\
\hline Tree ferns (Cythea sp.) & $A G B=2.70 * 10^{-3 *}\left(D^{2 *} H\right)^{1.19}$ & Beets et al., 2012 \\
\hline Ravenala madagascariensis & $\ln (A G B)=-5.08+5.654 * \ln (H)-0.772 *(\ln (H))^{2}$ & $\begin{array}{l}\text { Randrianasolo et al., } \\
2019\end{array}$ \\
\hline Banana (Musa sp.) & $A G B=0.0303 * D^{2.1345}$ & $\begin{array}{l}\text { Danarto \& Hapsari, } \\
2015\end{array}$ \\
\hline Palms & $\mathrm{AGB}^{0.25}=0.55512 *\left(0.37 * \mathrm{D}^{2} * \mathrm{H}_{\text {stem }}\right)^{0.25}$ & Goodman et al., 2013 \\
\hline Dracaena sp. & $A G B^{0.25}=0.55512 *\left(0.37 * D^{2} * H_{\text {stem }}\right)^{0.25}$ & Goodman et al., 2013 \\
\hline Pandanus sp. & $A G B^{0.25}=0.55512 *\left(0.37 * D^{2} * H_{\text {stem }}\right)^{0.25}$ & Goodman et al., 2013 \\
\hline Species geographic origin & & \\
\hline
\end{tabular}


Antananarivo. Scientific names and information on the geographic origin of each identified species were based on data on the Catalogue of the Plants of Madagascar (Tropicos, 2020): we classified all species occurring exclusively in the country of Madagascar as endemic and those species occurring naturally in Madagascar and elsewhere as native. We further classified non-native species as introduced and if their origin was missing from the Catalogue of the Plants of Madagascar (Tropicos, 2020), we classified these species as origin unknown.

\section{Data analysis}

We performed all analyses in R 3.6.3 (R Core Team, 2019) and used the R-package ggplot2 (Wickham, 2011) for data visualization.

To assess differences of ACS between the land-use type, we first tested for normality and homogeneity of variances. To meet the ANOVA-specific assumptions of homogeneity of variance, we log-transformed the ACS values and therefore address proportional rather than absolute variation (Mascaro et al., 2011). Then, we conducted an analysis of variance (ANOVA), followed by a Tukey's posthoc test using the R-package multcompView (Graves et al., 2019).

To quantify the proportional contribution of stem diameter to stem density and ACS per land-use type, we assigned all stems to diameter classes: we classified plants with a DBH from $8-20 \mathrm{~cm}$ as small-sized stems; plants with a DBH from $>20-40 \mathrm{~cm}$ as medium-sized stems; and plants with a $\mathrm{DBH}>40 \mathrm{~cm}$ as largesized stems, in line with McNicol et al. (2018).

To disentangle how much of the variation in ACS within vanilla agroforests can be explained by which of the allometric variables that underlie the ACS estimations, we set up a Linear Mixed Model (LMM) using the R-package Ime4 (Bates et al., 2015). However, LMMs are impaired by collinearity (Zuur et al., 2010), so we first calculated a correlation matrix of all structural variables, to identify potential collinearity between variables, using the R-package corrplot (Wei et al., 2017). Since the mean DBH and mean height were highly correlated (Appendix S5.1), we only selected mean DBH for our model. For the first LMM, we selected mean $\mathrm{DBH}$, mean wood density and stem density as explanatory variables and scaled them to zero mean and unit variance, to facilitate effect size comparison. To test whether responses would differ between forest- and fallow-derived agroforests, we included interactions between land-use history (forest-derived vs. fallow-derived agroforest) and all explanatory variables. Furthermore, we included 'village' $(N=10)$ as a random effect to control for the nested structure of our sampling plots. Since the response variable ACS was not normally distributed, we applied a square root-transformation to the response variable (Mascaro et al., 2011). We checked model diagnostics for over- or underdispersion, 
outliers, and heteroscedasticity using the R-package DHARMa (Hartig, 2021) and found no model misspecification problems. We extracted model fit values using the R-package Effects (Fox \& Weisberg, 2018) and produced model outputs with the R-package report (Makowski et al., 2020).

\section{Results}

\section{Aboveground carbon stocks across land-use types}

Mean aboveground carbon stocks (ACS) ranged from 5 megagram/hectare ( $\mathrm{Mg} / \mathrm{ha})$ in woody fallows to $178 \mathrm{Mg} / \mathrm{ha}$ in old-growth forests. Forest fragments $(51 \mathrm{Mg} / \mathrm{ha})$ stored $71 \%$ less ACS than old-growth forests. Mean ACS between forest fragments and forest-derived agroforests (52 Mg/ha) was at par. Among vanilla agroforests, ACS differed significantly, based on land-use history: fallow-derived agroforests (16 Mg/ha) stored 69\% less ACS compared to forest-derived agroforests. However, fallowderived agroforests stored 220\% more ACS than woody fallows (Fig. 5.3; Appendix S5.2). 


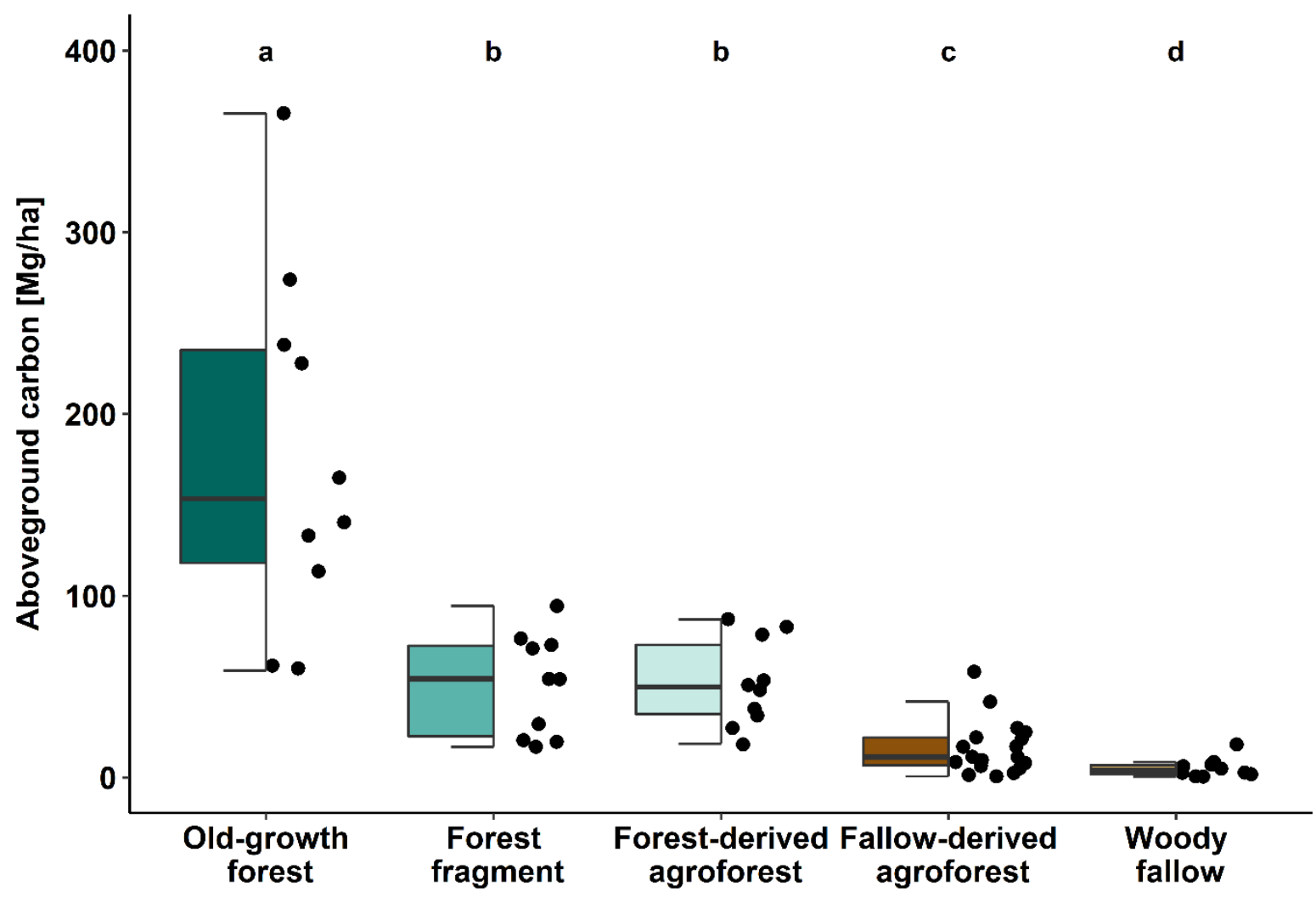

Fig. 5.3: Aboveground carbon stocks $[\mathrm{Mg} / \mathrm{ha}=$ megagram/hectare $]$ across the studied land-use types. Each point represents one study plot. The black horizontal lines within the boxplot represent the median of aboveground carbon for each land-use type. The lower and upper hinges of each box relate to the first quartile and the third quartile, respectively. The annotations (a-d) within the graph indicate significant differences between land-use types after running ANOVA and Tukey's HSD posthoc test. See Appendix S5.3 for numeric results.

\section{Contribution of stem diameter and geographic origin to total ACS}

Across all land-use types, large-sized stems (DBH $>40 \mathrm{~cm}$ ) were proportionally rare and represented only 1 - 5\% of all stems (Fig. 5.4A), yet they accounted for 21 - 42\% of ACS in human-modified land-use types and even $61 \%$ of ACS in old-growth forests (Fig. 5.4B). Within vanilla agroforests, small-sized stems (DBH $8-20 \mathrm{~cm}$ ) represented the largest proportion in fallow-derived agroforests ( $83 \%$ of stems) and forestderived agroforests (59\% of stems) but accounted only for $24 \%$ of ACS in fallow-derived and $16 \%$ of ACS in forest-derived agroforests. Medium-sized stems (DBH $>20^{\circ} \mathrm{cm}-40 \mathrm{~cm}$ ) represented $13 \%$ of stems in fallow-derived and $36 \%$ in forest-derived agroforests and accounted for $35 \%$ of ACS in fallow-derived and $55 \%$ of ACS in forest-derived agroforests. Large-sized stems (DBH $>40 \mathrm{~cm}$ ) represented only $3 \%$ of stems in fallow-derived and $5 \%$ in forest-derived agroforests, yet they accounted for $42 \%$ of ACS in fallowderived and $30 \%$ of ACS in forest-derived agroforests (Appendix S5.4) 
Old-growth forests and forest fragments harboured almost exclusively endemic and native stems (Fig. 5.4C). In forest-derived agroforests, $84 \%$ of stems were endemic or native while introduced stems represented $13 \%$ of stems and contributed only to $5 \%$ of AC (Fig. 5.4D). In contrast, fallow-derived agroforests were dominated by introduced stems (63\%) which contributed to $56 \%$ of ACS. Endemic and native stems represented $31 \%$ of stems in fallow-derived agroforests and contributed to $34 \%$ of ACS. Woody fallows had a higher share of endemic and native stems (62\%) with a higher contribution to ACS (75\%) compared to fallow-derived agroforests (Appendix S5.4). 

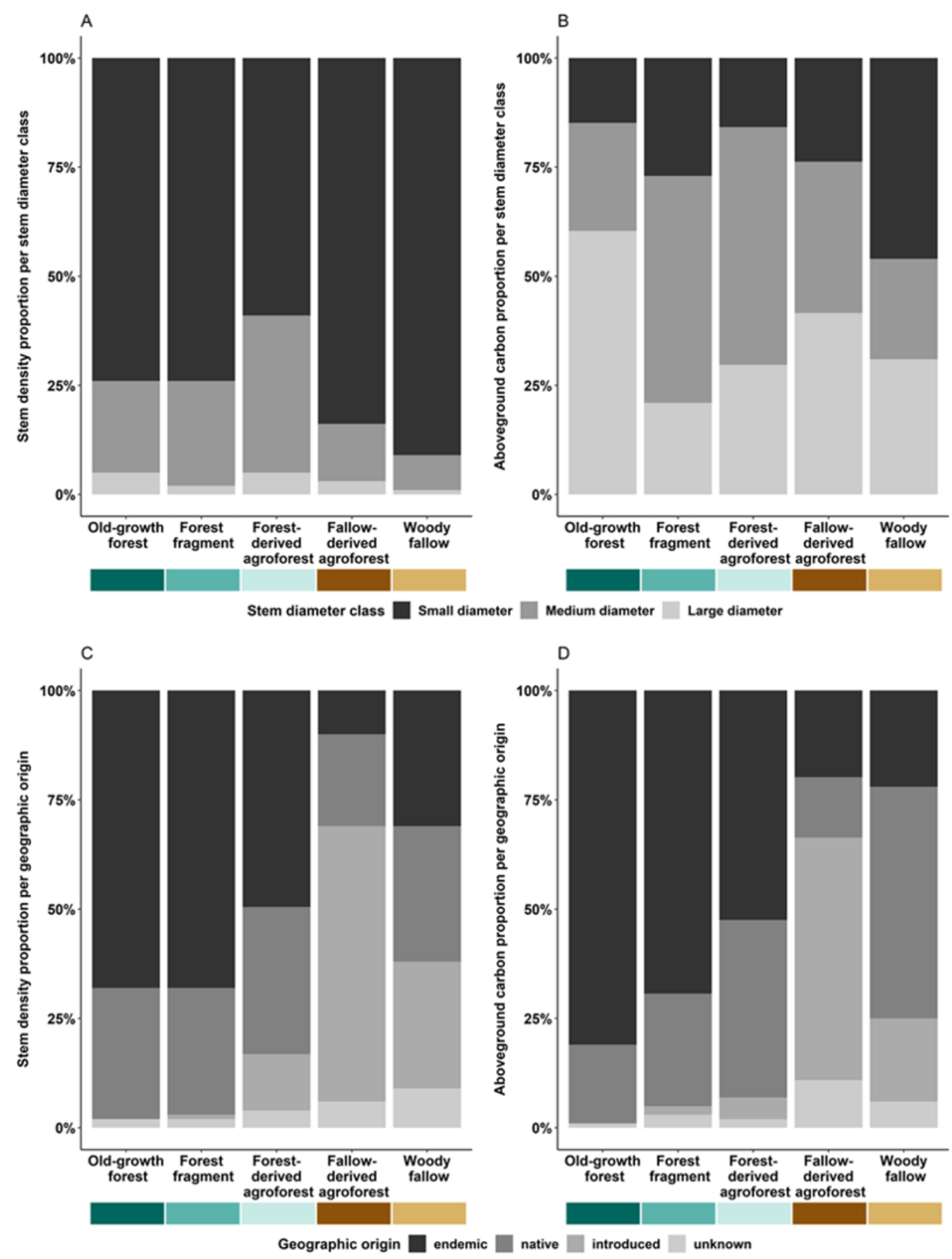

Fig. 5.4: Proportional contribution of stem diameter classes and species' geographic origin to stem density and aboveground carbon stocks (ACS) per land-use type. Panel A: contribution of stem diameter classes (small diameter ranges from $8-20 \mathrm{~cm}$, medium sized-diameter from $>20-40 \mathrm{~cm}$, and large trees with $\mathrm{DBH}>40 \mathrm{~cm}$ ) to stem density per land-use type; panel B: contribution of stem diameter classes to ACS per land-use type; panel C: contribution of species' geographic origin (endemic; native; introduced; unknown) to stem density per land-use type; panel D: contribution of species' geographic origin to ACS per land-use type. See Appendix S5.4 \& S5.5 for numeric summary. 


\section{Determinants of aboveground carbon stocks within vanilla agroforests}

The allometric variable model (Fig. 5.5; Appendix S5.6) revealed that ACS significantly increased with increasing mean stem diameter and stem density. Both stem density and stem diameter had comparable effects on ACS. Mean wood density showed a positive trend but no significant effect on ACS. Furthermore, land-use history showed no significant interactions either with mean diameter, stem density or mean wood density, showing that the effect of all three variables on ACS is the same in forest- and fallowderived agroforests. The model's explanatory power related to the fixed effects alone was high (marginal $R^{2}$ of 0.91$)$.

A

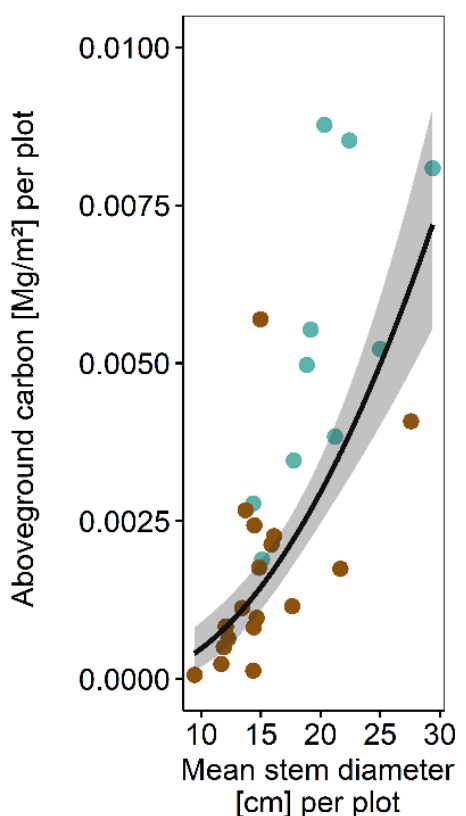

B

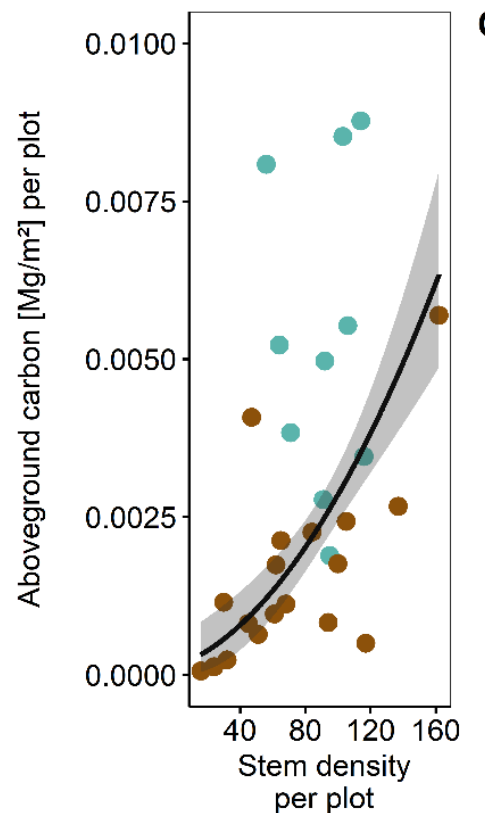

C

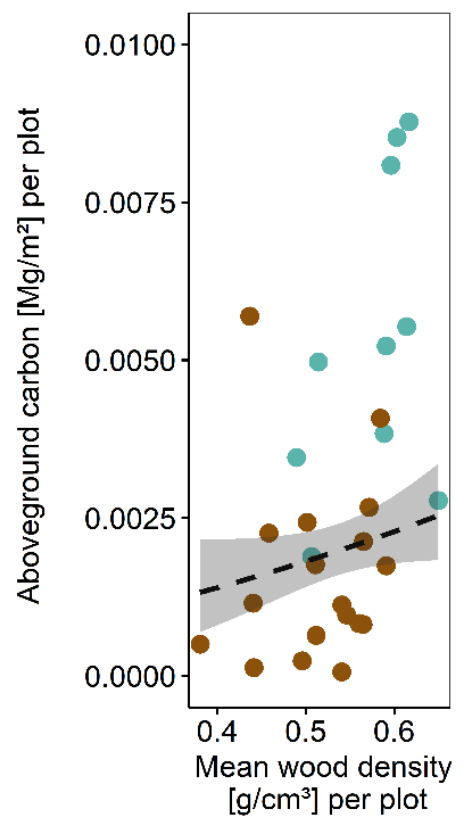

Vanilla agroforest - Forest-derived - Fallow-derived

Fig. 5.5: Effects of allometric variables on aboveground carbon stocks (ACS) across vanilla agroforests of different land-use history, based on a multiple linear mixed-effects model. Panel A: effects of mean DBH (diameter at breast height) on ACS across agroforests; panel B: effect of stem density on ACS across agroforests; panel C: effect of mean wood density on ACS across agroforests. Solid regression lines show significant model predictions ( $p$-value $<0.05)$. Dashed line shows the non-significant correlation. We included all allometric variables in interaction with land-use history (forest-derived vs fallow-derived vanilla agroforest) and added 'village' ( $N=10)$ as a random effect. See Appendix S5.6 for numeric model results.

\section{Discussion}

Based on plot inventory data, we demonstrate that old-growth forests provided the highest aboveground carbon stocks (ACS) in the mosaic landscape of north-eastern Madagascar, but other tree-dominated land- 
use types such as vanilla agroforests or forest fragments also contributed to ACS at moderate levels. Within vanilla agroforests, ACS were highly variable and strongly differed based on land-use history: mean ACS in fallow-derived agroforests were $68 \%$ lower than in forest-derived agroforests. Additionally, ACS in forest-derived agroforests were mainly provided by native and endemic trees, whereas ACS in fallowderived agroforests were mainly provided by introduced trees. Furthermore, we show that among the allometric variables which underlie the ACS estimations, stem diameter and stem density had comparable effects on ACS in agroforests, whereas wood density played a minor role, independent of land-use history. Overall, our findings emphasize the importance to consider land-use history when assessing the carbon storage potential of agroforests: forest-derived agroforests can play an important role to maintain ACS through large-statured native and endemic tree species, yet these agroforests result from forest degradation. In contrast, fallow-derived agroforests largely comprise introduced tree species but contribute to recovering ACS on historically forested fallow land, especially if trees are allowed to mature.

\section{Aboveground carbon stocks across land-use types}

The mean ACS of old-growth rainforest in our study (177 Mg/ha) was slightly lower compared to mean estimates of $209 \mathrm{Mg} / \mathrm{ha}$ recorded for tropical lowland rainforests in continental Africa (Slik et al., 2013). Other studies from Malagasy lowland rainforests also report mean ACS estimates of $150 \mathrm{Mg} / \mathrm{ha}$ (Vieilledent et al., 2016) and $99.5 \mathrm{Mg} / \mathrm{ha}$ (Asner et al., 2012), that lie below the mean of $209 \mathrm{Mg} / \mathrm{ha}$ for African lowland rainforests (Slik et al., 2013). This difference could trace back to the structural composition of Malagasy lowland forests with relatively low canopies and relatively high stem densities compared to other tropical forests in continental Africa (de Gouvenain \& Silander, 2003). These structural characteristics are likely independent of human influence but rather linked to cyclone dynamics (de Gouvenain \& Silander, 2003), which regularly lead to locally strong tree damages, especially along the eastern coast (Birkinshaw \& Randrianjanahary, 2007) where we conducted this study.

Large-sized trees with a DBH $>40 \mathrm{~cm}$ were rare in our study, yet they contributed disproportionately to ACS across all land-use types, representing a sizeable component of the landscape's carbon reservoir. Furthermore, large-sized trees are often old, prolonging the residence time of carbon within the wood (Chambers et al., 1998). Apart from their outstanding role for carbon stocks, large-sized trees within landscapes represent keystone structures and play unique ecological roles which cannot be fully compensated by younger and smaller trees, making the global decline of large-sized trees even more worrying (Lindenmayer et al., 2012). 
Old-growth forests harboured more large-sized trees and stored significantly more ACS than all humanmodified land-use types, corroborating that the density of large trees predominantly explains ACS variation in pantropical forests (Slik et al., 2013). Additionally, old-growth forests harboured almost exclusively endemic and native stems which further underlines the ecological importance of old-growth forests, making their protection the most effective strategy to maximize carbon storage as well as associated biodiversity and ecosystem services (Cook-Patton et al., 2020; Lewis et al., 2019). Yet, high land-use pressure often causes habitat fragmentation (Haddad et al., 2015), restricting continuous oldgrowth forests to protected areas (Morelli et al., 2020). Outside of protected areas, forests often undergo degradation to fragments or transformation to other land uses and the remaining Malagasy forest cover is highly fragmented (Vieilledent et al., 2018). The forest fragments in our study stored $71 \%$ less ACS than old-growth forests, likely due to the selective extraction of large-sized trees from forest fragments, as residents use these fragments to obtain timber and other forest products (Urech \& Zaehringer, 2015). Even though forest fragments undergo structural degradation, lose large-sized trees, and store less ACS than old-growth forests, they can still provide habitat for forest-dependent tree species (Osen et al., 2021), thus playing an important ecological role in the mosaic landscape. However, in a pantropical comparison, Madagascar counts among the countries with the highest forest fragment loss rates (Hansen et al., 2020) and studies predict that forest fragments in the agricultural landscapes are likely to disappear over time (Morelli et al., 2020; Schüßler et al., 2020).

In our study, forest-derived agroforests had a lower stem density than forest fragments but harboured proportionally more large-diameter trees (DBH $>40 \mathrm{~cm}$ ), which resulted in similar mean ACS for both landuse types. Considering the distribution of stems, more than $70 \%$ of stems in forest fragments had a small diameter (DBH $<20 \mathrm{~cm}$ ) and contributed proportionally little to ACS, whereas forest-derived agroforests had a higher share of large and medium-sized stems, with a proportionally high ACS contribution. Most likely, this is linked to farmer's agroforest management strategies to maintain few but large stems in their agroforests to provide shade for the vanilla vines. In this context, the felling of large trees would cause damage to nearby vanilla vines and ultimately reduce vanilla yields, thus farmers carefully consider the costs and benefits of felling large trees in their vanilla agroforests (personal communication with farmers). Similar management practices have been reported from coffee agroforests, where farmers retain large trees and remove smaller trees (Valencia et al., 2016).

Additionally, ACS in forest-derived agroforests was mainly stored in endemic or native stems, whereas introduced stems contributed only to $5 \%$ of ACS. This difference between agroforests of contrasting land- 
use history links to fallow-derived agroforests harbouring only a small share of endemic and native tree species diversity (Osen et al., 2021). In contrast, forest-derived agroforests retain high shares of native and endemic tree species (Osen et al., 2021) which also store the main share of ACS in these agroforests. The different shares of native and endemic species between agroforests of contrasting land-use history likely root in a combination of ecological and socioeconomic factors: Styger et al, (2009) studied the regeneration potential of trees on degraded land in eastern Madagascar and found that slash-and-burn practices strongly impaired natural regeneration dynamics and tree species were subsequently outcompeted and replaced by shrubs, ferns and finally grasses. Research from other tropical areas confirms that natural tree regeneration can take centuries to recover comparable pre-disturbance tree diversity levels, depending on the availability of propagule sources (Latawiec et al., 2016). Additionally, fallow-derived agroforests undergo land-management practices linked to planting (species selection, spatial organisation of species) which can either promote or impoverish the diversity and composition of native trees, based on farmer's preferences, perceptions, risk management strategies and constraints (Mariel et al., 2021). Thus, forest-derived agroforests can contribute to sustain endemic and native tree species and promote the longevity and stability of ACS within the mosaic landscape, as they rarely undergo drastic clearing after initial establishment (Martin, Wurz, et al., 2021).

Fallow-derived agroforests stored 68\% less ACS than forest-derived agroforests and were mainly dominated by small stems ( $\mathrm{DBH}<20 \mathrm{~cm}$ ) whereas large stems ( $\mathrm{DBH}>40 \mathrm{~cm}$ ) were rare. Additionally, ACS in fallow-derived agroforests was mainly stored in introduced stems. However, in comparison to woody fallows, fallow-derived agroforests had $67 \%$ more ACS. A rough estimation of carbon sequestration in the fallow-derived agroforests since establishment from woody fallows would base on the mean ACS of all woody fallows (5 Mg/ha) as a proxy for ACS at the time of the agroforest establishment, the age of the agroforests as reported by the landowners, and the observed ACS at the time of the study. This estimation results in an average $\mathrm{C}$ accumulation in aboveground biomass of $1.3 \mathrm{Mg}$ ha-1 year-1, which falls within the range obtained in a meta-analysis of carbon sequestration in agroforests ( 0.15 to $12.97 \mathrm{Mg}$ ha-1 year1; Feliciano et al., 2018). Our estimate strengthens the assumption that fallow-derived agroforests have a considerable potential to accumulate and store carbon in aboveground biomass since fallow-derived vanilla agroforests can become structurally similar to forest-derived agroforests over time (Martin, Wurz, et al., 2021).

However, when comparing fallow-derived agroforests with woody fallows, ACS in fallow-derived agroforests were mainly stored in introduced stems ( $63 \%$ of stems; $56 \%$ of ACS), whereas ACS in woody 
fallows were mainly stored in native and endemic trees (62\% of stems; $75 \%$ of ACS). This suggests that the transformation from woody fallows to fallow-derived agroforests might increase ACS at the expense of native tree species because farmers prefer the use of introduced tree species in fallow-derived agroforests. This has also been reported from cacao and coffee agroforests, where management practices on fallow-derived agroforests favoured introduced tree species (Anglaaere et al., 2011), or pioneer species with negative impacts on late-successional trees of conservation concern (Valencia et al., 2016).

\section{Disentangling effects of ACS variation within vanilla agroforests}

Looking at the allometric variables which underlie the ACS estimations in vanilla agroforests, our results show that variation in ACS was mainly influenced by mean stem diameter and stem density per plot, whereas mean wood density played only a minor role, and land-use history had no significant effect on ACS variation. Thus, agroforests with more and larger stems increase ACS, independent of land-use history. Consequently, maintaining large-diameter trees or promoting their growth would lead to ACS increases in both types of agroforests. This result is in line with findings from other tropical forest systems, which show that increases in the frequency and mean size of stems influence biomass accumulation (Bordin et al., 2021; Jucker et al., 2016; Slik et al., 2013) and ACS variation is largely driven by differences in stem density, light availability and structural complexity (van der Sande et al., 2017).

In our study, mean wood density showed a positive trend but had no significant effect on ACS variation agroforests, independent of land-use history. Usually, succession theory in wet tropical forests predicts that fast-growing tree species are soft-wooded and are initially abundant, but dense-wooded tree species replace them in the long term (Poorter et al., 2019). However, the effect of wood density on ACS in agroforests seems to be less relevant, as long as stand basal area remains high.

\section{Integrating vanilla agroforests of contrasting land-use history into conservation and restoration agendas}

Our results show that ACS in vanilla agroforests were extremely variable, but consistently much lower than in old-growth forests. Consequently, tree-dominated agriculture practices such as agroforestry cannot replace but complement old-growth forests to maintain carbon stocks in a human-modified landscape. Vanilla agroforests can act as permanent carbon stock reservoirs because once they are successfully established, vanilla sales provide considerable income, making it unprofitable to abandon or clear-cut the agroforests (Martin, Wurz, et al., 2021). Yet, agroforests show significant differences in species composition, diversity, and structure compared to the old-growth forest (Osen et al., 2021) and these differences also result in ACS differences. Furthermore, the contrasting land-use histories of 
agroforests require different approaches to unfold their full potential within national conservation and restoration agendas. We show that forest-derived agroforests stored significantly higher carbon stocks that were mainly stored in native and endemic species, whereas fallow-derived agroforests stored lower carbon stocks that were mainly provided by introduced species. Thus, a narrow focus on carbon may incentivize maintaining large-diameter stems while losing sight of many species with low carbon values but considerable local and biological importance (Ferreira et al., 2018). Due to the unique species assemblages in Malagasy lowland forests with large numbers of endemic species, human modifications could lead to local species loss, culminating in extinction. This might have severe consequences because even small threats to plant diversity can have direct effects on community diversity, structure, and function of mammals and birds (Park \& Razafindratsima, 2019). This calls for strategies that align both carbon stocks and biodiversity goals.

Our results further show that land-use history is intricately linked with land management interventions and affects the potential of vanilla agroforests to store ACS. Interventions to cut stems, add stems, or retain stems affect the stem density and diameter, which had the strongest influence on ACS. Changes in the basal area also influence the canopy structure (Midgley et al., 2002) and the selection of which tree species to extract, retain or add, directly influences species richness (Braga et al., 2019). Thus, land-use history offers different baselines for management interventions to promote both carbon stocks and biodiversity goals: forest-derived agroforests can achieve high ACS if landowners retain a diversity of large-sized native and endemic trees. Maintaining closed canopies would be most favourable for endemic biodiversity (Raveloaritiana et al., 2021) and predation (Schwab et al., 2021). Additionally, increasing canopy cover does not seem to impair yields, so vanilla agroforests can contribute to maintaining ACS and increase canopy cover within the landscape matrix over time, without yield trade-offs (Martin, Wurz, et al., 2021). However, if canopy clearing interventions are necessary, they should target small-statured trees, while maintaining large-diameter trees to limit ACS losses. In contrast, fallow-derived agroforests largely host introduced tree species but contribute to ACS recovery on historically forested fallow land, especially if they allow trees to mature, resulting in large-diameter trees (Ma et al., 2020). To increase benefits for biodiversity in fallow-derived agroforests, the provision of incentives, for example embedded in sustainability certification schemes, might encourage landowners to maintain or plant native or endemic trees species (Tscharntke et al., 2015). Thus, fallow-derived agroforests provide favourable conditions to equally promote ACS, biodiversity, and ecosystem services, if management interventions maximize structural and floristic diversity. 


\section{Conclusion}

This study confirms the unique value of old-growth forests to combine large carbon reservoirs while sheltering associated biodiversity. We also provide empirical support that agroforests can act as carbon reservoirs in a multifunctional landscape, but considering their land-use history and management is important to maximise their benefits: forest-derived agroforests support higher aboveground carbon stocks than fallow-derived agroforests and have the potential to maintain a forest-like structure with native and endemic trees in the landscape, whereas fallow-derived agroforests take land out of the slashand-burn cycle by converting it into permanent tree-dominated land-use systems. Thus, fallow-derived agroforests provide favourable conditions for long-term tree cover rehabilitation with low opportunity costs. If landowners aim to increase carbon stocks in their agroforests, they best retain large-diameter trees or promote their growth. Additionally, the local and biological importance of taxonomic and functional tree diversity calls for strategies that safeguard habitat, biodiversity, and ecosystem services.

\section{Author contribution}

MRS and KO contributed equally to this manuscript and share the first authorship. MRS, KO, AW, DAM, HLTR, ER, and DH conceived the ideas and designed the methodology; MRS and KO collected the tree inventory data; MRS and KO processed the data and MRS analysed the data; AW and KO supported the analysis; MRS and KO led the writing of the manuscript. All authors contributed to the manuscript and gave final approval for publication.

\section{Acknowledgements}

We are thankful to plot owners, chef de fokontany, and the village communities for their friendliness, for providing information, and for giving us access to sites. Special thanks to Thorien Rabemanantsoa for his help and assistance during data collection, to Jean Chrysostome Bevao and Patrice Antilahimena for their help in tree species identification. We acknowledge MNP (Madagascar National Parcs), Ministère de l'Environnement, de l'Écologie et des Forêts (MEEF), and MBG (Missouri Botanical Garden) Antananarivo for the collaboration.

Leaves, twigs, fruits, and flowers were collected for tree species identification, thanks to the research permit $\mathrm{N}^{\circ} 18 / 18 / \mathrm{MEEF} / \mathrm{SG} / \mathrm{DGF} / \mathrm{DSAP} / \mathrm{SCB}$. Re and $\mathrm{N}^{\circ} 254 / 18 / \mathrm{MEEF} / \mathrm{SG} / \mathrm{DGF} / \mathrm{DSAP} / \mathrm{SCB}$.Re issued by MEEF, Antananarivo, Madagascar. 


\section{Synthesis}

The studies within this thesis contribute to refining the conservation evaluation of tropical agroforests and provide data-based evidence to assess the conservation value of vanilla agroforests in the mosaic landscape of north-eastern Madagascar. Furthermore, the studies reveal contemporary patterns of tree diversity and stand structure within and among tree-based land-use types and thereby provide vital information to quantify and understand the consequences of land-use change in this tropical landscape. The purpose of this synthesis chapter is to interconnect the central findings of all studies and embed this new knowledge into the larger conservation context. This knowledge can ultimately feed into the development of biodiversity-friendly land-use practices and management plans, that benefit biodiversity conservation, rural livelihoods, and climate change mitigation and hence contribute to the long-term sustainability of the mosaic landscape.

\section{The importance of land-use history for agroforestry}

The conceptual study in this thesis (chapter 1 ) suggests that land-use history determines biodiversity, ecosystem functions, and services in tropical agroforests and that the differentiation of agroforests based on land-use history might strengthen their conservation potential to mitigate further habitat degradation and species loss.

The case studies in this thesis apply the land-use history concept and thereby demonstrate that land-use history determines stand structure, tree diversity and community composition in vanilla agroforests: The first case study (chapter 2) shows that forest-derived agroforests have the potential to harbor many endemic and native trees species and thereby serve as habitat refugia and biodiversity reservoirs for forest-dependent tree species, whereas fallow-derived agroforests have a limited contribution to maintaining native and endemic tree diversity. Furthermore, forest-derived agroforests can resemble the stand structure of forest fragments, whereas fallow-derived agroforests are structurally simpler. Chapter 3 indicates that both agroforest types show high tree community turnover rates by additive or subtractive heterogenization. Yet, a significantly lower alpha diversity and more introduced species in fallow-derived agroforests suggest that new and potentially introduced generalist species gradually displace less competitive species. Chapter 4 shows that land-use history also has a strong influence on support tree diversity: Forest-derived agroforests harbor many native and endemic support tree species and have four times higher support tree species richness compared to fallow-derived agroforests, which harbor mainly introduced support tree species. Chapter 5 shows that agroforests can act as carbon 
reservoirs in a human-modified landscape, but forest-derived agroforests support higher aboveground carbon stocks than fallow-derived agroforests.

In combination, these case studies allow a more nuanced conservation evaluation of vanilla agroforests: forest-derived agroforests can play an important role in providing habitat for native and endemic tree species and maintain aboveground carbon stocks. Thus, forest-derived agroforests represent an alternative to forest conversion by slash-and-burn shifting cultivation, but they result from forest degradation. In contrast, fallow-derived agroforests play a marginal role for tree species diversity but contribute to the recovery of stand structure and aboveground carbon stocks on historically forested fallow land.

Furthermore, an additional Diversity Turn study in the same research area is closely linked to this thesis. The study is not listed as a chapter in this thesis, but the thesis author KO essentially contributed to the conceptualization of the study and writing of the manuscript. The study addresses the impacts of landuse history and canopy cover on vanilla yields along a chronosequence (Martin, Wurz, et al., 2021). First, the study found that canopy cover was linked to the agroforest age and both forest-derived and fallowderived agroforests gained canopy cover over time. These results indicate that agroforests can contribute to maintain or regain tree cover and canopy cover in the human-modified landscape over time. This strengthens the argument that both agroforest types have a long-term conservation value, but they express this value on different levels: forest-derived agroforests represent a means to retain habitat structure, tree diversity and above-ground carbon stocks, whereas fallow-derived agroforests offer tree cover rehabilitation opportunities and regain above-ground carbon stocks on open but formerly forested land.

In summary, the studies in this thesis disclose patterns how land-use history affects different ecological components of tree diversity in vanilla agroforests and how this influences their conservation value. Thus, these new insights suggest that the differentiation based on land-use history might also be applicable in various tropical agroforestry systems and regions, to better align landscape management with conservation goals.

\section{Trees as structural components benefit endemic biodiversity and support predation}

Trees are the main structural components of forests and tree-based land-use types (Reed et al., 2017). Chapter 2 shows that the transformation of old-growth forest into human-modified land-use types goes along with a decline in stem density, basal area, canopy closure and LAI, thereby causing a simplification 
of habitat structures in the human-modified landscape. The observed habitat simplification is likely caused by different levels of human interference and land-management practices (Allnutt et al., 2013) in combination with natural forces such as cyclones, which frequently hit the study area (de Gouvenain \& Silander, 2003).

In the frame of the Diversity Turn project, several studies used the stand structural data derived in chapter 2, to test how the stand structural components provided by trees affect other taxa and ecosystem functions across the same study plots in the mosaic landscape:

Schwab et al. (2021) conducted a predation experiment to quantify predation rates in the mosaic landscape and used data on stem density, canopy closure, and basal area as proxy elements to quantify the structural complexity of the study plots. They found that predation rates were highest in those landuse types that retained forest structures and their results show that trees and understorey vegetation were strongly related to changes in arthropod predator communities. Their results indicate that predation rates and predator communities differed between vanilla agroforests of contrasting land-use history and they conclude that restoring trees in fallow-derived agroforest and keeping trees in forest-derived agroforests could increase predation rates.

Martin, Andriafanomezantsoa, et al. (2021) studied bird richness and Dröge et al. (2021) studied sound diversity in the mosaic landscape and both used the tree basal area data as a proxy element to quantify the structural complexity of the study plots. They found that tree basal area structured bird community composition and was positively associated with a higher soundscape diversity. This indicates that increasing basal area on the plots and in the landscape might benefit the bird community in the mosaic landscape. Similar results have been reported for bird communities in cacao agroforests in Cameroon: cacao agroforests with a forest-like structure and closed canopies harbored a significantly higher share of forest-specialist birds, compared to structurally simple agroforests (Jarrett et al., 2021).

Raveloaritiana et al. (2021) studied herbaceous plant richness in the mosaic landscape and used the canopy closure data as a proxy for light availability on the study plots. They found that open habitats promoted native and exotic herbaceous plants, which showed a negative response towards dense canopies. In contrast, endemic herbaceous plants were not affected by dense canopies and showed the highest species richness in old-growth forests, forest fragments, and forest-derived vanilla agroforests. This indicates that restoring or maintaining closed canopies in agroforests can contribute to promote endemic herbaceous plants while controlling exotic plants. 
Rakotomalala et al. (2021) studied ant richness in the mosaic landscape and used the canopy closure data as a proxy for light availability on the study plots. They found that higher canopy closure and landscape forest cover were associated with a higher richness of endemic ant species and a lower richness of exotic ant species. Within vanilla agroforests, they conclude that promoting trees in fallow-derived and maintaining trees in forest-derived vanilla agroforests would favor endemic ant species richness.

Wurz et al. (submitted) studied butterfly richness in the mosaic landscape and found that land-use types with woody vegetation hosted a high diversity of endemic and forest butterflies. They suggest that the establishment of vanilla agroforests on fallow land could increase the stand structure and landscape tree cover and thereby favor endemic and forest butterfly species.

Fulgence et al. (2021) studied the reptile and amphibian diversity in the mosaic landscape and found that a high share of amphibian and reptile species exclusively occurred in old-growth forests and forests fragments, indicating a high-forest dependency among these taxa, which is likely linked to stand structural variables that influence microenvironmental conditions.

In a synthesis study, Wurz et al. (submitted) assessed the environmental and management-related drivers of vanilla yields and species richness across taxa and identified the loss of canopy closure as the major driver of species loss and community composition changes across taxa.

In combination, these findings from north-eastern Madagascar are in line with a broad body of literature reporting that many species groups decline along with stand structure simplification in tree-based landuse types in human-modified landscapes (Barrios et al., 2018). However, north-eastern Madagascar harbours a wealth of endemic and microendemic species across most taxa (Vences et al., 2009), with narrow ecological niches and limited adaptability to environmental or biological disruptions (Fordham \& Brook, 2010). Consequently, these endemics are disproportionately vulnerable to land-use change, habitat loss and climate change (Fordham \& Brook, 2010; Pimm et al., 2014). This strengthens the call for land-use options that prevent further human-driven extinction. Our Diversity Turn results, therefore, suggest land-use options that restore or maintain tree cover in the landscape.

\section{Vanilla agroforests offer biodiversity-friendly intensification opportunities}

In the Diversity Turn synthesis study by Wurz et al. (submitted), the authors integrated the stand structural data derived from chapter 2 with vanilla yield data and found that vanilla yields were independent of canopy closure. This finding is consistent with results from Martin et al. (2021), who found that vanilla yields varied independently of canopy cover and land-use history. These findings are in contrast to other 
tropical agroforestry crops such as cacao and coffee, which typically decline under closed canopies and produce higher yields under open canopies (Clough et al., 2009; Harvey et al., 2021; Perfecto et al., 1996). The independence of vanilla yields form canopy cover points towards biodiversity-friendly intensification opportunities in vanilla agroforestry that allow to maintain or rehabilitate tree cover and canopy cover without impairing yields, which would benefit many endemic and native species across taxa.

\section{Trees diversity patterns within the landscape}

Chapters 2, 3 and 4 report patterns of current tree diversity and community structures in vanilla agroforests and tree-based land-use types within the mosaic landscape of north-eastern Madagascar. Overall, the three studies report a high taxonomic diversity in the human-modified landscape, indicating that many tree species can thus far persist in the landscape. Chapter 2 reports that tree species richness differs across land-use types and chapter 3 complements these results and shows that tree communities are transforming both in identity and abundance within and among land-use types. This includes changing patterns of both rare and dominant tree species which can have far-reaching consequences: the loss of rare and endemic species increases their risk of global extinction (Fordham \& Brook, 2010; Pimm et al., 2014). Changes in dominance patterns can directly affect the succession dynamics (Styger et al 2007) or might reduce community resilience to changing biotic and environmental conditions and alter ecosystem functions (Fornoff et al., 2019; Jakovac et al., 2021). Moreover, tree species are long-lived organisms, and even if they temporally survive in altered habitats, they might face time-lagged extinction events (Flinn \& Vellend, 2005). This process might be specifically critical for rare and endemic tree species. Since rare and endemic species mainly occurred in old-growth forests, forest fragments and forest-derived agroforests in our study area, management interventions should protect, retain or restore these habitats, to avoid species loss.

Additionally, chapter 4 shows that agroforest-support trees also contribute to tree diversity in vanilla agroforests. Especially forest-derived agroforests harbor many native and endemic support tree species and have four times higher support tree species richness compared to fallow-derived agroforests. However, many endemic species in forest-derived agroforests occur with low frequencies which means that changing management regimes could risk their survival. Fallow-derived agroforests harbor mainly introduced support tree species, with little conservation value. Therefore, management interventions that favour native and endemic agroforest-support tree species, could contribute promoting tree diversity in the mosaic landscape. 


\section{Trees provide ecosystem services}

Trees are indispensable elements of vanilla agroforests, as the tall trees provide shade and the smallstructured trees act as support structures to the climbing vanilla orchid. Additionally, Malagasy trees provide timber, fuelwood, charcoal and medicines and are therefore important for local livelihoods. Currently, more than half of all endemic tree species (>1500 species) have been reported to have at least one or more uses (Beech, Rivers, et al., 2021).

Chapter 4 reports that a third of agroforest-support tree species is used for medicinal purposes, to provide food products (such as fruits or coffee) or to provide firewood. In an additional Diversity Turn study, Raveloaritiana et al. (submitted) conducted interviews to analyze and quantify the use of natural products by rural households. Within this study, most households reported to habitually consume tree-derived products and reported which species they collect, where they collect them and for which purposes they collect them. The study thus found that trees provide important resources to rural households in the mosaic landscape. The interviewees mentioned construction wood, firewood, charcoal and medicine as the most important tree-derived resources. These resources were mainly collected from woody fallows, forest fragments, as well as vanilla agroforests and the study thus highlights that trees within the mosaic landscape provide important resources to sustain livelihoods.

Both Diversity Turn studies show that the rural population in north-eastern Madagascar uses a mix of endemic, native and introduced tree species to obtain natural products and resources. As long as nonnative species do not displace native and endemic species or alter habitat dynamics, this shows that tree species of all origins can serve as important components in resilient smallholder farming landscapes and form fundamental pillars of daily needs. Promoting the use of native and endemic trees might have the most positive effects on local wildlife but even introduced trees can provide resources for local wildlife (Gérard et al., 2015).

Despite their ecological and economic value, trees are also commonly linked to cultural or spiritual values in the Malagasy culture (Rafidison et al., 2020). These values can either associate certain species with a distinct set of uses or they affect their protection status within the landscape (Rafidison et al., 2020). In this context, trees obtain a certain level of agency beyond being passive elements and therefore act as a connection between the local population and the surrounding biodiversity (Rafidison et al., 2020). This cultural dimension is context-specific and important to consider in the planning and implementation of conservation interventions in north-eastern Madagascar. 
Trees contribute to mitigate climate change in the mosaic landscape and in this context, chapter 5 highlights three findings: first, maintaining existing old-growth forest is by far the most efficient strategy to maximize carbon stocks in the mosaic landscape and should have the maximum conservation priority, as theses habitats also have a high value for biodiversity. Second, vanilla agroforests can contribute to mitigate climate change through carbon storage by either restoring historically forested fallow land or maintaining or increasing tree cover in the landscape. Third, the study shows that trees of all origins can store large amounts of aboveground carbon in their biomass and thereby contribute to mitigate climate change. Here, the geographic origin plays a subordinate role and the most important criterion is the stem diameter. This suggests that a pure focus on the provision of ecosystem services could be critical, as it might maintain and promote high numbers of dominant and potentially introduced species and might disadvantage rare and/or endangered species. To increase benefits for biodiversity and carbon stocks simultaneously, landowners should maintain or plant native or endemic trees species.

\section{The role of trees in the human-modified mosaic landscape}

This thesis shows that trees are important elements in the human-modified landscapes of north-eastern Madagascar, that contribute to biodiversity, provide habitat structure, ecosystem functions and services. At the landscape level, old-growth forests play a special role, as they harbour a substantial share of Madagascar's endemic tree diversity that cannot persist outside these forests, as shown in chapter $2 \& 3$. This does not only apply to endemic trees but also to all other species groups in the Diversity Turn project: a large share of endemic herbaceous plants, ants, reptiles, amphibians, birds and butterflies occurred exclusively in old-growth forests. Furthermore, old-growth forests showed high predation rates (Schwab et al., 2021) and highest aboveground carbon stocks (chapter 5), making their protection the most effective conservation strategy for biodiversity and carbon stocks in the mosaic landscape.

However, the landscape in north-eastern Madagascar inevitably changes and solely and exclusively discussing biodiversity conservation matters in protected areas would miss the conservation value of small forest fragments and agroforests, which also harbour a substantial share of biodiversity while benefitting human livelihoods. Within human-modified landscapes, optimal scenarios that maximize the resilience of natural and human systems aim for a high-quality landscape matrix with at least $40 \%$ forest cover, a large number of smaller forest patches, agroforests, biodiversity-friendly farmland and scattered trees (Arroyo-Rodríguez et al., 2020). Such a biodiversity-friendly agricultural matrix with a high tree cover can increase connectivity, facilitate movement between metacommunities and thereby promote spillover of species and ecosystem services to more intensively cultivated land (Grass et al., 2019). 
In the mosaic landscape of north-eastern Madagascar, vanilla agroforests integrate trees on agricultural land and thereby contribute to provide shade, and store carbon and to increase tree cover, canopy cover and connectivity at the landscape scale. Additionally, the shade and support trees can provide ecosystem services that support the livelihood of the rural population.

Additionally, as shown in this thesis, forest-derived agroforests can maintain a forest-like structure and represent an alternative to forest conversion by slash-and-burn shifting cultivation, but they result from forest degradation. Fallow-derived agroforests, in contrast, contribute to the recovery of stand structure and aboveground carbon stocks on historically forested fallow land. Thus, they play a marginal role for tree species diversity but they can contribute to re-building habitat structure or reconnecting fragmented habitats.

\section{Ecological restoration and tree-based rehabilitation as conservation measures for trees and biodiversity}

As shown in this thesis, old-growth forests have an outstanding value for biodiversity and provide large carbon stocks, therefore their conservation represents the most important and most effective conservation intervention. Additionally, ecological restoration and tree-based rehabilitation interventions could serve as complementary tools to secure overall net gains of biodiversity and a net-positive effect on environmental conditions and ecosystem services (Gann et al., 2019; UN Decade on Ecosystem Restoration 2021-2030). However, it is important that these interventions are carefully tailored to the local conditions and priorities and build on stakeholder-defined objectives (Di Sacco et al., 2021). It is further important that ecological restoration and tree-based rehabilitation interventions consider land rights and do not replace existing natural habitats or displace traditional local uses that are important for food security (Bond et al., 2019).

A suggested point of entry in the mosaic landscape of north-eastern Madagascar would be the establishment of agroforests on formerly forested degraded land, which could increase tree cover at the landscape scale (Martin, Wurz, et al., 2021) while generating revenues for smallholder farmers (Hänke et al., 2018). Given the high turnover rates of tree species communities, interventions that aim to promote biodiversity should aim to consider a maximum diverse number of endemic trees. Alternative interventions might focus on promoting ecosystem services and hence require a different set of strategies because rare species often play a minor role for ecosystem service provision (Grass et al., 2019). However, 
tree-based ecosystem restoration should support and enhance native and endemic biodiversity should not be a driver of species homogenization.

\section{Building on the results of this thesis, how could future research support conservation interventions in the mosaic landscape of north-eastern Madagascar?}

\section{Land-use history:}

As highlighted in a recent review by Jakovac et al. (2021), land-use history strongly influences stand structure dynamics and recovery opportunities in tropical tree-dominated habitats. However, Jakovac et al. (2021) highlight that land-use history is an overarching "umbrella variable" that encompasses a combination of socio-economic and biophysical factors such as: time since initial deforestation, distance to forest remnants, amount of forest cover in proximity, number and frequency of clear-cuts, number and frequency of burning events or cropping cycles, fallow period length, type of previous crop, other management practices such as weeding frequency, soil management and modification. All these land-use history descriptors can have different effects on different ecological components and their importance and their complex interactions are not yet fully understood (Jakovac et al., 2021). Thus, addressing the individual descriptors and their interactions withing the "umbrella variable" of land-use history, would be a promising research path, to improve agroforestry management and to increase the long-term sustainability of this land use option. Building on this, management scenarios could take informed decisions whether to allow natural regeneration, apply assisted regeneration or use tree plantings to restore tree cover and assist landscape restoration (Gann et al., 2019; Jakovac et al., 2021).

\section{Functional diversity:}

Integrating taxonomic diversity patterns with functional diversity patterns would strongly enhance the understanding of tree community changes in the mosaic landscape. Such research could reveal differences in tree functional diversity among land-use types and could identify traits that characterize those tree species that successfully occupy the human-modified landscape. Such insight could inform restoration and rehabilitation interventions to improve the species selection process.

\section{Regeneration and succession dynamics of woody regrowth:}

Integrating natural regeneration into restoration goals and practices can achieve multiple social and environmental benefits and increase resilience and long-term effectiveness of restoration approaches (Chazdon \& Guariguata, 2016). However, regeneration and succession dynamics are complex: eg, previous 
research from Madagascar has shown that natural regeneration can be altered or prevented by persistent invasive species (Styger et al., 2007). Understanding these local dynamics and identifying their drivers would allow to better integrate the natural regeneration potential of woody regrowth into landscape restoration approaches.

\section{Integrating local and scientific knowledge}

The extensive field work in the frame of the Diversity Turn project gave plenty of room for exchange with farmers. This exchange made clear that many farmers obtain an impressive knowledge about local trees and act as stewards of this cultural landscape. Building on their knowledge could be specifically interesting in the case of endemic tree species with very narrow ranges and of which no further botanical information is available. For example, scientists could learn from farmers about species-specific management practices and propagation methods, about fruit and flower phenology, and about local uses and cultural values. Additionally, based on the high level of cooperation shown by the farmers who worked with the Diversity Turn team, future research and conservation projects might consider the approach of Farmer Managed Natural Regeneration (FMNR; Lohbeck et al., 2020) to better integrate farmers into the project and thereby improve the restoration success in vanilla agroforests and towards a biodiversity-friendly and resilient mosaic landscape. 


\section{References}

Abdulai, I., Vaast, P., Hoffmann, M. P., Asare, R., Jassogne, L., Van Asten, P., Rötter, R. P., \& Graefe, S. (2018). Cocoa agroforestry is less resilient to sub-optimal and extreme climate than cocoa in full sun. Global Change Biology, 24(1), 273-286. https://doi.org/10.1111/gcb.13885

Albrecht, A., \& Kandji, S. T. (2003). Carbon sequestration in tropical agroforestry systems. Agriculture, Ecosystems \& Environment, 99(1-3), 15-27. https://doi.org/10.1016/S0167-8809(03)00138-5

Allnutt, T. F., Asner, G. P., Golden, C. D., \& Powell, G. V. N. (2013). Mapping Recent Deforestation and Forest Disturbance in Northeastern Madagascar. Tropical Conservation Science, 6(1), 1-15. https://doi.org/10.1177/194008291300600101

Anderson, M. J., Crist, T. O., Chase, J. M., Vellend, M., Inouye, B. D., Freestone, A. L., Sanders, N. J., Cornell, H. V., Comita, L. S., Davies, K. F., Harrison, S. P., Kraft, N. J. B., Stegen, J. C., \& Swenson, N. G. (2011). Navigating the multiple meanings of $\beta$ diversity: A roadmap for the practicing ecologist. Ecology Letters, 14(1), 19-28. https://doi.org/10.1111/j.1461-0248.2010.01552.x

Anderson, M. J., Ellingsen, K. E., \& McArdle, B. H. (2006). Multivariate dispersion as a measure of beta diversity. Ecology Letters, 9(6), 683-693. https://doi.org/10.1111/j.1461-0248.2006.00926.x

Anderson, M. J., \& Walsh, D. C. I. (2013). PERMANOVA, ANOSIM, and the Mantel test in the face of heterogeneous dispersions: What null hypothesis are you testing? Ecological Monographs, 83(4), 557574. https://doi.org/10.1890/12-2010.1

Anglaaere, L. C. N., Cobbina, J., Sinclair, F. L., \& McDonald, M. A. (2011). The effect of land use systems on tree diversity: Farmer preference and species composition of cocoa-based agroecosystems in Ghana. Agroforestry Systems, 81(3), 249-265. https://doi.org/10.1007/s10457-010-9366-z

Antão, L. H., McGill, B., Magurran, A. E., Soares, A. M. V. M., \& Dornelas, M. (2019). B-diversity scaling patterns are consistent across metrics and taxa. Ecography, 42(5), 1012-1023. https://doi.org/10.1111/ecog.04117

Arroyo-Rodríguez, V., Fahrig, L., Tabarelli, M., Watling, J. I., Tischendorf, L., Benchimol, M., Cazetta, E., Faria, D., Leal, I. R., Melo, F. P. L., Morante-Filho, J. C., Santos, B. A., Arasa-Gisbert, R., Arce-Peña, N., Cervantes-López, M. J., Cudney-Valenzuela, S., Galán-Acedo, C., San-José, M., Vieira, I. C. G., ... Tscharntke, T. (2020). Designing optimal human-modified landscapes for forest biodiversity conservation. Ecology Letters, 23(9), 1404-1420. https://doi.org/10.1111/ele.13535 
Arroyo-Rodríguez, V., Melo, F. P. L., Martínez-Ramos, M., Bongers, F., Chazdon, R. L., Meave, J. A., Norden, N., Santos, B. A., Leal, I. R., \& Tabarelli, M. (2017). Multiple successional pathways in human-modified tropical landscapes: New insights from forest succession, forest fragmentation and landscape ecology research: Multiple successional pathways. Biological Reviews, 92(1), 326-340. https://doi.org/10.1111/brv.12231

Asner, G. P., Clark, J. K., Mascaro, J., Vaudry, R., Chadwick, K. D., Vieilledent, G., Rasamoelina, M., Balaji, A., Kennedy-Bowdoin, T., Maatoug, L., Colgan, M. S., \& Knapp, D. E. (2012). Human and environmental controls over aboveground carbon storage in Madagascar. Carbon Balance and Management, 7(1), 2. https://doi.org/10.1186/1750-0680-7-2

Asner, G. P., Scurlock, J. M. O., \& A. Hicke, J. (2003). Global synthesis of leaf area index observations: Implications for ecological and remote sensing studies: Global leaf area index. Global Ecology and Biogeography, 12(3), 191-205. https://doi.org/10.1046/j.1466-822X.2003.00026.x

Avolio, M. L., Forrestel, E. J., Chang, C. C., La Pierre, K. J., Burghardt, K. T., \& Smith, M. D. (2019). Demystifying dominant species. New Phytologist, 223(3), 1106-1126. https://doi.org/10.1111/nph.15789

Barlow, J., França, F., Gardner, T. A., Hicks, C. C., Lennox, G. D., Berenguer, E., Castello, L., Economo, E. P., Ferreira, J., Guénard, B., Gontijo Leal, C., Isaac, V., Lees, A. C., Parr, C. L., Wilson, S. K., Young, P. J., \& Graham, N. A. J. (2018). The future of hyperdiverse tropical ecosystems. Nature, 559(7715), 517-526. https://doi.org/10.1038/s41586-018-0301-1

Barnes, A. D., Jochum, M., Mumme, S., Haneda, N. F., Farajallah, A., Widarto, T. H., \& Brose, U. (2014). Consequences of tropical land use for multitrophic biodiversity and ecosystem functioning. Nature Communications, 5(1), 5351. https://doi.org/10.1038/ncomms6351

Barrios, E., Valencia, V., Jonsson, M., Brauman, A., Hairiah, K., Mortimer, P. E., \& Okubo, S. (2018). Contribution of trees to the conservation of biodiversity and ecosystem services in agricultural landscapes. International Journal of Biodiversity Science, Ecosystem Services \& Management, 14(1), 1-16. https://doi.org/10.1080/21513732.2017.1399167

Barwell, L. J., Isaac, N. J. B., \& Kunin, W. E. (2015). Measuring $\beta$ - diversity with species abundance data. Journal of Animal Ecology, 84(4), 1112-1122. https://doi.org/10.1111/1365-2656.12362

Baselga, A. (2010). Partitioning the turnover and nestedness components of beta diversity: Partitioning beta diversity. Global Ecology and Biogeography, 19(1), 134-143. https://doi.org/10.1111/j.14668238.2009.00490.x

Baselga, A. (2013). Multiple site dissimilarity quantifies compositional heterogeneity among several sites, while average pairwise dissimilarity may be misleading. Ecography, 36(2), 124-128. https://doi.org/10.1111/j.1600-0587.2012.00124.x 
Baselga, A. (2017). Partitioning abundance-based multiple-site dissimilarity into components: Balanced variation in abundance and abundance gradients. Methods in Ecology and Evolution, 8(7), 799-808. https://doi.org/10.1111/2041-210X.12693

Baselga, A., Orme, D., Villeger, S., De Bortoli, J., Leprieur, F., \& Logez, M. (2021). betapart: Partitioning Beta Diversity into Turnover and Nestedness Components ( $R$ package version 1.5.4) [Computer software]. https://CRAN.R-project.org/package=betapart

Bastin, J.-F., Barbier, N., Réjou-Méchain, M., Fayolle, A., Gourlet-Fleury, S., Maniatis, D., de Haulleville, T., Baya, F., Beeckman, H., Beina, D., Couteron, P., Chuyong, G., Dauby, G., Doucet, J.-L., Droissart, V., Dufrêne, M., Ewango, C., Gillet, J. F., Gonmadje, C. H., ... Bogaert, J. (2015). Seeing Central African forests through their largest trees. Scientific Reports, 5(1), 13156. https://doi.org/10.1038/srep13156

Bates, D., Mächler, M., Bolker, B., \& Walker, S. (2015). Fitting Linear Mixed-Effects Models Using Ime4. Journal of Statistical Software, 67(1). https://doi.org/10.18637/jss.v067.i01

Beckschäfer, P. (2015). Hemispherical_2.0-Batch processing hemispherical and canopy photographs with ImageJ - User Manual. https://doi.org/10.13140/RG.2.1.3059.4088

Beckschäfer, P., Seidel, D., Kleinn, C., \& Xu, J. (2013). On the exposure of hemispherical photographs in forests. IForest - Biogeosciences and Forestry, 6(4), 228-237. https://doi.org/10.3832/ifor0957-006

Beech, E., Hills, R., Rivers, M. C., Oldfield, S. F., \& P.P. Smith. (2021). GlobalTreeSearch [Data set]. Botanic Gardens Conservation International. https://doi.org/10.13140/RG.2.2.33593.90725

Beech, E., Rivers, M., Rabarimanarivo, M., Ravololomanana, N., Manjato, N., Lantoarisoa, F., Andriambololonera, S., Ramandimbisoa, B., Ralimanana, H., Rakotoarisoa, S. E., Razanajatovo, H., Razafiniary, V., Andriamanohera, A., Randrianasolo, V., Rakotonasolo, F., Rakotoarisoa, A., Randriamamonjy, N., Rajaovelona, L., Rakotomalala, N., ... Jeannoda, V. (2021). Red List of Trees of Madagascar. Botanic Gardens Conservation International. https://www.bgci.org/resources/bgci-toolsand-resources/the-red-list-of-trees-of-madagascar/

Beets, P. N., Kimberley, M. O., Oliver, G. R., Pearce, S. H., Graham, J. D., \& Brandon, A. (2012). Allometric Equations for Estimating Carbon Stocks in Natural Forest in New Zealand. Forests, 3(3), 818-839. https://doi.org/10.3390/ $\mathbf{3 0 3 0 8 1 8}$

BGCI. (2021). State of the World's Trees. Botanic Gardens Conservation International. https://www.bgci.org/wp/wp-content/uploads/2021/08/FINAL-GTAReportMedRes-1.pdf

Bhagwat, S. A., Willis, K. J., Birks, H. J. B., \& Whittaker, R. J. (2008). Agroforestry: A refuge for tropical biodiversity? Trends in Ecology \& Evolution, 23(5), 261-267. https://doi.org/10.1016/j.tree.2008.01.005 
Birkinshaw, C., \& Randrianjanahary, M. (2007). The Effects of Cyclone Hudah on the Forest of Masoala Peninsula, Madagascar. Madagascar Conservation \& Development, 2(1). https://doi.org/10.4314/mcd.v2i1.44125

Blaser, W. J., Oppong, J., Hart, S. P., Landolt, J., Yeboah, E., \& Six, J. (2018). Climate-smart sustainable agriculture in low-to-intermediate shade agroforests. Nature Sustainability, 1(5), 234-239. https://doi.org/10.1038/s41893-018-0062-8

Bollen, A., \& Donati, G. (2006). Conservation status of the littoral forest of south-eastern Madagascar: A review. Oryx, 4O(1), 57-66. https://doi.org/10.1017/S0030605306000111

Bond, W. J., Stevens, N., Midgley, G. F., \& Lehmann, C. E. R. (2019). The Trouble with Trees: Afforestation Plans for Africa. Trends in Ecology \& Evolution, 34(11), 963-965. https://doi.org/10.1016/j.tree.2019.08.003

Bordin, K. M., Esquivel-Muelbert, A., Bergamin, R. S., Klipel, J., Picolotto, R. C., Frangipani, M. A., Zanini, K. J., Cianciaruso, M. V., Jarenkow, J. A., Jurinitz, C. F., Molz, M., Higuchi, P., Silva, A. C. da, \& Müller, S. C. (2021). Climate and large-sized trees, but not diversity, drive above-ground biomass in subtropical forests. Forest Ecology and Management, 490, 119126. https://doi.org/10.1016/j.foreco.2021.119126

Bos, M. M., Tylianakis, J. M., Steffan-Dewenter, I., \& Tscharntke, T. (2008). The invasive Yellow Crazy Ant and the decline of forest ant diversity in Indonesian cacao agroforests. Biological Invasions, 10(8), 13991409. https://doi.org/10.1007/s10530-008-9215-4

Braga, D. P. P., Domene, F., \& Gandara, F. B. (2019). Shade trees composition and diversity in cacao agroforestry systems of southern Pará, Brazilian Amazon. Agroforestry Systems, 93(4), 1409-1421. https://doi.org/10.1007/s10457-018-0250-6

Brancalion, P. H. S., Bello, C., Chazdon, R. L., Galetti, M., Jordano, P., Lima, R. A. F., Medina, A., Pizo, M. A., \& Reid, J. L. (2018). Maximizing biodiversity conservation and carbon stocking in restored tropical forests. Conservation Letters, 11(4), e12454. https://doi.org/10.1111/conl.12454

Brancalion, P. H. S., \& Chazdon, R. L. (2017). Beyond hectares: Four principles to guide reforestation in the context of tropical forest and landscape restoration: Forest and landscape restoration principles. Restoration Ecology, 25(4), 491-496. https://doi.org/10.1111/rec.12519

Brancalion, P. H. S., \& Holl, K. D. (2020). Guidance for successful tree planting initiatives. Journal of Applied Ecology, 57(12), 2349-2361. https://doi.org/10.1111/1365-2664.13725 
Brancalion, P. H. S., Niamir, A., Broadbent, E., Crouzeilles, R., Barros, F. S. M., Almeyda Zambrano, A. M., Baccini, A., Aronson, J., Goetz, S., Reid, J. L., Strassburg, B. B. N., Wilson, S., \& Chazdon, R. L. (2019). Global restoration opportunities in tropical rainforest landscapes. Science Advances, 5(7), eaav3223. https://doi.org/10.1126/sciadv.aav3223

Brown, K. A., Parks, K. E., Bethell, C. A., Johnson, S. E., \& Mulligan, M. (2015). Predicting Plant Diversity Patterns in Madagascar: Understanding the Effects of Climate and Land Cover Change in a Biodiversity Hotspot. PLOS ONE, 10(4), e0122721. https://doi.org/10.1371/journal.pone.0122721

Brown, S., \& Lugo, A. E. (1982). The Storage and Production of Organic Matter in Tropical Forests and Their Role in the Global Carbon Cycle. Biotropica, 14(3), 161. https://doi.org/10.2307/2388024

Buerki, S., Devey, D. S., Callmander, M. W., Phillipson, P. B., \& Forest, F. (2013). Spatio-temporal history of the endemic genera of Madagascar: Evolution of the Endemic Madagascan Flora. Botanical Journal of the Linnean Society, 171(2), 304-329. https://doi.org/10.1111/boj.12008

Callmander, M. W., Phillipson, P. B., Schatz, G. E., Andriambololonera, S., Rabarimanarivo, M., Rakotonirina, N., Raharimampionona, J., Chatelain, C., Gautier, L., \& Lowry, P. P. (2011). The endemic and non-endemic vascular flora of Madagascar updated. Plant Ecology and Evolution, 144(2), 121-125.

Cannell, M. G. R., Van Noordwijk, M., \& Ong, C. K. (1996). The central agroforestry hypothesis: The trees must acquire resources that the crop would not otherwise acquire. Agroforestry Systems, 34(1), 27-31. https://doi.org/10.1007/BF00129630

Carrasco, J., Price, V., Tulloch, V., \& Mills, M. (2020). Selecting priority areas for the conservation of endemic trees species and their ecosystems in Madagascar considering both conservation value and vulnerability to human pressure. Biodiversity and Conservation, 29(6), 1841-1854. https://doi.org/10.1007/s10531-020-01947-1

Castle, S. E., Miller, D. C., Ordonez, P. J., Baylis, K., \& Hughes, K. (2021). The impacts of agroforestry interventions on agricultural productivity, ecosystem services, and human well-being in low- and middleincome countries: A systematic review. Campbell Systematic Reviews, 17(2). https://doi.org/10.1002/cl2.1167

Catano, C. P., Dickson, T. L., \& Myers, J. A. (2017). Dispersal and neutral sampling mediate contingent effects of disturbance on plant beta-diversity: A meta-analysis. Ecology Letters, 20(3), 347-356. https://doi.org/10.1111/ele.12733

Chambers, J. Q., Higuchi, N., \& Schimel, J. P. (1998). Ancient trees in Amazonia. Nature, 391(6663), 135136. https://doi.org/10.1038/34325 
Chao, A., Gotelli, N. J., Hsieh, T. C., Sander, E. L., Ma, K. H., Colwell, R. K., \& Ellison, A. M. (2014). Rarefaction and extrapolation with Hill numbers: A framework for sampling and estimation in species diversity studies. Ecological Monographs, 84(1), 45-67. https://doi.org/10.1890/13-0133.1

Chase, J. M., Kraft, N. J. B., Smith, K. G., Vellend, M., \& Inouye, B. D. (2011). Using null models to disentangle variation in community dissimilarity from variation in $\alpha$-diversity. Ecosphere, 2(2), art24. https://doi.org/10.1890/ES10-00117.1

Chave, J., Andalo, C., Brown, S., Cairns, M. A., Chambers, J. Q., Eamus, D., Fölster, H., Fromard, F., Higuchi, N., Kira, T., Lescure, J.-P., Nelson, B. W., Ogawa, H., Puig, H., Riéra, B., \& Yamakura, T. (2005). Tree allometry and improved estimation of carbon stocks and balance in tropical forests. Oecologia, 145(1), 87-99. https://doi.org/10.1007/s00442-005-0100-x

Chave, J., Coomes, D., Jansen, S., Lewis, S. L., Swenson, N. G., \& Zanne, A. E. (2009). Towards a worldwide wood economics spectrum. Ecology Letters, 12(4), 351-366. https://doi.org/10.1111/j.14610248.2009.01285.x

Chave, J., Réjou-Méchain, M., Búrquez, A., Chidumayo, E., Colgan, M. S., Delitti, W. B. C., Duque, A., Eid, T., Fearnside, P. M., Goodman, R. C., Henry, M., Martínez-Yrízar, A., Mugasha, W. A., Muller-Landau, H. C., Mencuccini, M., Nelson, B. W., Ngomanda, A., Nogueira, E. M., Ortiz-Malavassi, E., ... Vieilledent, G. (2014). Improved allometric models to estimate the aboveground biomass of tropical trees. Global Change Biology, 20(10), 3177-3190. https://doi.org/10.1111/gcb.12629

Chazdon, R. L. (2003). Tropical forest recovery: Legacies of human impact and natural disturbances. Perspectives in Plant Ecology, Evolution and Systematics, 6(1-2), 51-71. https://doi.org/10.1078/14338319-00042

Chazdon, R. L., Brancalion, P. H. S., Laestadius, L., Bennett-Curry, A., Buckingham, K., Kumar, C., MollRocek, J., Vieira, I. C. G., \& Wilson, S. J. (2016). When is a forest a forest? Forest concepts and definitions in the era of forest and landscape restoration. Ambio, 45(5), 538-550. https://doi.org/10.1007/s13280016-0772-y

Chazdon, R. L., Brancalion, P. H. S., Lamb, D., Laestadius, L., Calmon, M., \& Kumar, C. (2017). A PolicyDriven Knowledge Agenda for Global Forest and Landscape Restoration. Conservation Letters, 10(1), 125132. https://doi.org/10.1111/conl.12220

Chazdon, R. L., \& Guariguata, M. R. (2016). Natural regeneration as a tool for large-scale forest restoration in the tropics: Prospects and challenges. Biotropica, 48(6), 716-730. https://doi.org/10.1111/btp.12381

Chazdon, R. L., Peres, C. A., Dent, D., Sheil, D., Lugo, A. E., Lamb, D., Stork, N. E., \& Miller, S. E. (2009). The Potential for Species Conservation in Tropical Secondary Forests. Conservation Biology, 23(6), 1406-1417. https://doi.org/10.1111/j.1523-1739.2009.01338.x 
Chen, H. (2018). VennDiagram: Generate high-resolution Venn and Euler plots. R package version 1.6. 20. Website Https://CRAN. R-Project. Org/Package= VennDiagram.

Clark, D. A., Brown, S., Kicklighter, D. W., Chambers, J. Q., Thomlinson, J. R., \& Ni, J. (2001). Measuring net primary production in forests: Concepts and field methods. Ecological Applications, 11(2), 356-370. https://doi.org/10.1890/1051-0761(2001)011[0356:MNPPIF]2.0.CO;2

Clough, Y., Faust, H., \& Tscharntke, T. (2009). Cacao boom and bust: Sustainability of agroforests and opportunities for biodiversity conservation. Conservation Letters, 2(5), 197-205. https://doi.org/10.1111/j.1755-263X.2009.00072.x

Condit, R. (2008). Methods for estimating aboveground biomass of forest and replacement vegetation in the tropics (No. 73; Center for Tropical Forest Science Research Manual). http://136.30.145.206/pdfs/CarbonInventoryMethods.pdf

Cook-Patton, S. C., Leavitt, S. M., Gibbs, D., Harris, N. L., Lister, K., Anderson-Teixeira, K. J., Briggs, R. D., Chazdon, R. L., Crowther, T. W., Ellis, P. W., Griscom, H. P., Herrmann, V., Holl, K. D., Houghton, R. A., Larrosa, C., Lomax, G., Lucas, R., Madsen, P., Malhi, Y., ... Griscom, B. W. (2020). Mapping carbon accumulation potential from global natural forest regrowth. Nature, 585(7826), 545-550. https://doi.org/10.1038/s41586-020-2686-x

Corlett, R. T., \& Primack, R. B. (2008). Tropical Rainforest Conservation: A Global Perspective. Tropical Forest Community Ecology, 442-457.

Danarto, S. A., \& Hapsari, L. (2015). Biomass and Carbon Stock Estimation Inventory of Indonesian Bananas (Musa spp.) and Its Potential Role for Land Rehabilitation. BIOTROPIA - The Southeast Asian Journal of Tropical Biology, 22(2), 102-108. https://doi.org/10.11598/btb.2015.22.2.376

De Beenhouwer, M., Aerts, R., \& Honnay, O. (2013). A global meta-analysis of the biodiversity and ecosystem service benefits of coffee and cacao agroforestry. Agriculture, Ecosystems \& Environment, 175, 1-7. https://doi.org/10.1016/j.agee.2013.05.003

De Beenhouwer, M., Geeraert, L., Mertens, J., Van Geel, M., Aerts, R., Vanderhaegen, K., \& Honnay, O. (2016). Biodiversity and carbon storage co-benefits of coffee agroforestry across a gradient of increasing management intensity in the SW Ethiopian highlands. Agriculture, Ecosystems \& Environment, 222, 193199. https://doi.org/10.1016/j.agee.2016.02.017

de Gouvenain, R. C., \& Silander, J. A. (2003). Do Tropical Storm Regimes Influence the Structure of Tropical Lowland Rain Forests? Biotropica, 35(2), 166-180. https://doi.org/10.1111/j.1744-7429.2003.tb00276.x 
DeFries, R. S., Foley, J. A., \& Asner, G. P. (2004). Land-use choices: Balancing human needs and ecosystem function. Frontiers in Ecology and the Environment, 2(5), 249-257. https://doi.org/10.1890/15409295(2004)002[0249:LCBHNA]2.0.CO;2

Di Marco, M., Harwood, T. D., Hoskins, A. J., Ware, C., Hill, S. L. L., \& Ferrier, S. (2019). Projecting impacts of global climate and land-use scenarios on plant biodiversity using compositional-turnover modelling. Global Change Biology, 25(8), 2763-2778. https://doi.org/10.1111/gcb.14663

Di Sacco, A., Hardwick, K. A., Blakesley, D., Brancalion, P. H. S., Breman, E., Cecilio Rebola, L., Chomba, S., Dixon, K., Elliott, S., Ruyonga, G., Shaw, K., Smith, P., Smith, R. J., \& Antonelli, A. (2021). Ten golden rules for reforestation to optimize carbon sequestration, biodiversity recovery and livelihood benefits. Global Change Biology, 27(7), 1328-1348. https://doi.org/10.1111/gcb.15498

Díaz, S., Fargione, J., Chapin, F. S., \& Tilman, D. (2006). Biodiversity Loss Threatens Human Well-Being. PLoS Biology, 4(8), e277. https://doi.org/10.1371/journal.pbio.0040277

Dransfield, J., \& Beentje, H. (1995). The palms of Madagascar. Royal Botanic Gardens Kew.

Draper, F. C., Asner, G. P., Honorio Coronado, E. N., Baker, T. R., García-Villacorta, R., Pitman, N. C. A., Fine, P. V. A., Phillips, O. L., Zárate Gómez, R., Amasifuén Guerra, C. A., Flores Arévalo, M., Vásquez Martínez, R., Brienen, R. J. W., Monteagudo-Mendoza, A., Torres Montenegro, L. A., Valderrama Sandoval, E., Roucoux, K. H., Ramírez Arévalo, F. R., Mesones Acuy, Í., ... Baraloto, C. (2019). Dominant tree species drive beta diversity patterns in western Amazonia. Ecology, 100(4). https://doi.org/10.1002/ecy.2636

Drever, R. C., Drever, M. C., \& Sleep, D. J. H. (2012). Understanding rarity: A review of recent conceptual advances and implications for conservation of rare species. The Forestry Chronicle, 88(02), 165-175. https://doi.org/10.5558/tfc2012-033

Driscoll, D. A., Banks, S. C., Barton, P. S., Lindenmayer, D. B., \& Smith, A. L. (2013). Conceptual domain of the matrix in fragmented landscapes. Trends in Ecology \& Evolution, 28(10), 605-613. https://doi.org/10.1016/j.tree.2013.06.010

Dröge, S., Martin, D. A., Andriafanomezantsoa, R., Burivalova, Z., Fulgence, T. R., Osen, K., Rakotomalala, E., Schwab, D., Wurz, A., Richter, T., \& Kreft, H. (2021). Listening to a changing landscape: Acoustic indices reflect bird species richness and plot-scale vegetation structure across different land-use types in northeastern Madagascar. Ecological Indicators, 120, 106929. https://doi.org/10.1016/j.ecolind.2020.106929

Du Puy, D., \& Moat, J. (1996). A refined classification of the primary vegetation of Madagascar based on the underlying geology: Using GIS to map its distribution and to assess its conservation status. In Biogéographie de Madagascar (pp. 205-218). http://www1.kew.org/gis/projects/madagascar/download.html 
Dufils, J. M. (2003). Remaining forest cover. In S. Goodman \& J. Benstead (Eds.), The Natural History of Madagascar (pp. 88-96). University of Chicago Press Chicago, IL.

Duriaux Chavarría, J.-Y., Baudron, F., \& Sunderland, T. (2018). Retaining forests within agricultural landscapes as a pathway to sustainable intensification: Evidence from Southern Ethiopia. Agriculture, Ecosystems \& Environment, 263, 41-52. https://doi.org/10.1016/j.agee.2018.04.020

Enquist, B. J., Feng, X., Boyle, B., Maitner, B., Newman, E. A., Jørgensen, P. M., Roehrdanz, P. R., Thiers, B. M., Burger, J. R., Corlett, R. T., Couvreur, T. L. P., Dauby, G., Donoghue, J. C., Foden, W., Lovett, J. C., Marquet, P. A., Merow, C., Midgley, G., Morueta-Holme, N., ... McGill, B. J. (2019). The commonness of rarity: Global and future distribution of rarity across land plants. Science Advances, 5(11), eaaz0414. https://doi.org/10.1126/sciadv.aaz0414

FAO. (2015). Agroforestry. http://www.fao.org/forestry/agroforestry/80338/en/

FAO. (2017). Agroforestry for landscape restoration: Exploring the potential of agroforestry to enhance the sustainability and resilience of degraded landscapes. FAO. https://doi.org/10.4060/i7374e

FAO. (2020). FAOSTAT. Food and Agriculture Organization of the United Nations. http://www.fao.org/faostat/en/\#data/QC

Feliciano, D., Ledo, A., Hillier, J., \& Nayak, D. R. (2018). Which agroforestry options give the greatest soil and above ground carbon benefits in different world regions? Agriculture, Ecosystems \& Environment, 254, 117-129. https://doi.org/10.1016/j.agee.2017.11.032

Ferreira, J., Lennox, G. D., Gardner, T. A., Thomson, J. R., Berenguer, E., Lees, A. C., Mac Nally, R., Aragão, L. E. O. C., Ferraz, S. F. B., Louzada, J., Moura, N. G., Oliveira, V. H. F., Pardini, R., Solar, R. R. C., Vieira, I. C. G., \& Barlow, J. (2018). Carbon-focused conservation may fail to protect the most biodiverse tropical forests. Nature Climate Change, 8(8), 744-749. https://doi.org/10.1038/s41558-018-0225-7

Filgueiras, B. K. C., Peres, C. A., Melo, F. P. L., Leal, I. R., \& Tabarelli, M. (2021). Winner-Loser Species Replacements in Human-Modified Landscapes. Trends in Ecology \& Evolution, 36(6), 545-555. https://doi.org/10.1016/j.tree.2021.02.006

Flinn, K. M., \& Vellend, M. (2005). Recovery of forest plant communities in post-agricultural landscapes. Frontiers in Ecology and the Environment, 3(5), 243-250. https://doi.org/10.1890/15409295(2005)003[0243:ROFPCI]2.0.CO;2

Foley, J. A., DeFries, R., Asner, G. P., Barford, C., Bonan, G., Carpenter, S. R., Chapin, F. S., Coe, M. T., Daily, G. C., Gibbs, H. K., Helkowski, J. H., Holloway, T., Howard, E. A., Kucharik, C. J., Monfreda, C., Patz, J. A., Prentice, I. C., Ramankutty, N., \& Snyder, P. K. (2005). Global Consequences of Land Use. Science, 309(5734), 570-574. https://doi.org/10.1126/science.1111772 
Fordham, D. A., \& Brook, B. W. (2010). Why tropical island endemics are acutely susceptible to global change. Biodiversity and Conservation, 19(2), 329-342. https://doi.org/10.1007/s10531-008-9529-7

Fornoff, F., Klein, A.-M., Blüthgen, N., \& Staab, M. (2019). Tree diversity increases robustness of multitrophic interactions. Proceedings of the Royal Society B: Biological Sciences, 286(1898), 20182399. https://doi.org/10.1098/rspb.2018.2399

Fox, J., \& Weisberg, S. (2018). An R Companion to Applied Regression. Sage publications.

Fulgence, T. R., Martin, D. A., Randriamanantena, R., Botra, R., Befidimanana, E., Osen, K., Wurz, A., Kreft, H., Andrianarimisa, A., \& Ratsoavina, F. M. (2021). Differential responses of amphibians and reptiles to land-use change in the biodiversity hotspot of north-eastern Madagascar. BioRxiv. https://doi.org/10.1101/2021.03.18.435920

Gann, G. D., McDonald, T., Walder, B., Aronson, J., Nelson, C. R., Jonson, J., Hallett, J. G., Eisenberg, C., Guariguata, M. R., Liu, J., Hua, F., Echeverría, C., Gonzales, E., Shaw, N., Decleer, K., \& Dixon, K. W. (2019). International principles and standards for the practice of ecological restoration. Second edition. Restoration Ecology, 27(S1). https://doi.org/10.1111/rec.13035

Ganzhorn, J. U., Lowry, P. P., Schatz, G. E., \& Sommer, S. (2001). The biodiversity of Madagascar: One of the world's hottest hotspots on its way out. Oryx, 35(4), 346-348. https://doi.org/10.1046/j.13653008.2001.00201.x

Ganzhorn, J. U., Malcomber, S., Andrianantoanina, O., \& Goodman, S. M. (1997). Habitat Characteristics and Lemur Species Richness in Madagascar1. Biotropica, 29(3), 331-343. https://doi.org/10.1111/j.17447429.1997.tb00434.x

Ganzhorn, J. U., Wilmé, L., Mercier, J.-L., \& Scales, I. (2014). Explaining Madagascar's biodiversity. In Conservation and Environmental Management in Madagascar (pp. 41-67). Routledge.

Gérard, A., Ganzhorn, J. U., Kull, C. A., \& Carrière, S. M. (2015). Possible roles of introduced plants for native vertebrate conservation: The case of Madagascar: Introduced plants contributing to vertebrate conservation. Restoration Ecology, 23(6), 768-775. https://doi.org/10.1111/rec.12246

Gibbons, P., Lindenmayer, D. B., Fischer, J., Manning, A. D., Weinberg, A., Seddon, J., Ryan, P., \& Barrett, G. (2008). The Future of Scattered Trees in Agricultural Landscapes. Conservation Biology, 22(5), 13091319. https://doi.org/10.1111/j.1523-1739.2008.00997.x

Gibson, L., Lee, T. M., Koh, L. P., Brook, B. W., Gardner, T. A., Barlow, J., Peres, C. A., Bradshaw, C. J. A., Laurance, W. F., Lovejoy, T. E., \& Sodhi, N. S. (2011). Primary forests are irreplaceable for sustaining tropical biodiversity. Nature, 478(7369), 378-381. https://doi.org/10.1038/nature10425 
Giudice Badari, C., Bernardini, L. E., Almeida, D. R. A., Brancalion, P. H. S., César, R. G., Gutierrez, V., Chazdon, R. L., Gomes, H. B., \& Viani, R. A. G. (2020). Ecological outcomes of agroforests and restoration 15 years after planting. Restoration Ecology, 28(5), 1135-1144. https://doi.org/10.1111/rec.13171

Godfray, H. C. J., Beddington, J. R., Crute, I. R., Haddad, L., Lawrence, D., Muir, J. F., Pretty, J., Robinson, S., Thomas, S. M., \& Toulmin, C. (2010). Food Security: The Challenge of Feeding 9 Billion People. Science, 327(5967), 812-818. https://doi.org/10.1126/science.1185383

Gomes, A. C. S., Andrade, A., Barreto-Silva, J. S., Brenes-Arguedas, T., López, D. C., de Freitas, C. C., Lang, C., de Oliveira, A. A., Pérez, A. J., Perez, R., da Silva, J. B., Silveira, A. M. F., Vaz, M. C., Vendrami, J., \& Vicentini, A. (2013). Local plant species delimitation in a highly diverse Amazonian forest: Do we all see the same species? Journal of Vegetation Science, 24(1), 70-79. https://doi.org/10.1111/j.16541103.2012.01441.x

Goodman, R. C., Phillips, O. L., del Castillo Torres, D., Freitas, L., Cortese, S. T., Monteagudo, A., \& Baker, T. R. (2013). Amazon palm biomass and allometry. Forest Ecology and Management, 310, 994-1004. https://doi.org/10.1016/j.foreco.2013.09.045

Goodman, S. M. (2000). Description of the Parc National de Marojejy, Madagascar, and the 1996 biological inventory of the reserve. Fieldiana Zoology, 97, 1-18.

Goodman, S. M., \& Benstead, J. P. (2005). Updated estimates of biotic diversity and endemism for Madagascar. Oryx, 39(1), 73-77. https://doi.org/10.1017/\$0030605305000128

Goodman, S. M., Raherilalao, M. J., \& Wohlhauser, S. (Eds.). (2018). The terrestrial protected areas of Madagascar: Their history, description and biota. Association Vahatra.

Grass, I., Loos, J., Baensch, S., Batáry, P., Librán-Embid, F., Ficiciyan, A., Klaus, F., Riechers, M., Rosa, J., Tiede, J., Udy, K., Westphal, C., Wurz, A., \& Tscharntke, T. (2019). Land-sharing/-sparing connectivity landscapes for ecosystem services and biodiversity conservation. People and Nature, pan3.21. https://doi.org/10.1002/pan3.21

Graves, S., Piepho, H.-P., \& Selzer, L. (2019). multcompView: Visualizations of paired comparisons (0.1-8) [R-package].

Green, R. E., Cornell, S. J., Scharlemann, J. P. W., \& Balmford, A. (2005). Farming and the Fate of Wild Nature. Science, 307(5709), 550-555. https://doi.org/10.1126/science.1106049 
Haddad, N. M., Brudvig, L. A., Clobert, J., Davies, K. F., Gonzalez, A., Holt, R. D., Lovejoy, T. E., Sexton, J. O., Austin, M. P., Collins, C. D., Cook, W. M., Damschen, E. I., Ewers, R. M., Foster, B. L., Jenkins, C. N., King, A. J., Laurance, W. F., Levey, D. J., Margules, C. R., ... Townshend, J. R. (2015). Habitat fragmentation and its lasting impact on Earth's ecosystems. Science Advances, 1(2), e1500052. https://doi.org/10.1126/sciadv.1500052

Hänke, H., Barkmann, J., Blum, L., Franke, Y., Martin, D., Niens, J., Osen, K., Uruena, V., Whiterspoon, S. A., \& Wurz, A. (2018). Socio-economic, land use and value chain perspectives on vanilla farming in the SAVA Region (north-eastern Madagascar): The Diversity Turn Baseline Study (DTBS). July 2019 Edition. Discussion Paper, 1806. https://doi.org/10.13140/RG.2.2.22059.80163

Hansen, M. C., Wang, L., Song, X.-P., Tyukavina, A., Turubanova, S., Potapov, P. V., \& Stehman, S. V. (2020). The fate of tropical forest fragments. Science Advances, 6(11), eaax8574. https://doi.org/10.1126/sciadv.aax8574

Harper, G. J., Steininger, M. K., Tucker, C. J., Juhn, D., \& Hawkins, F. (2007). Fifty years of deforestation and forest fragmentation in Madagascar. Environmental Conservation, 34(04), 325-333. https://doi.org/10.1017/S0376892907004262

Hartig, F. (2021). DHARMa: Residual diagnostics for hierarchical (multi-level/mixed) regression models [Rpackage]. https://cran.r-project.org/web/packages/DHARMa/vignettes/DHARMa.html

Harvey, C. A., Pritts, A. A., Zwetsloot, M. J., Jansen, K., Pulleman, M. M., Armbrecht, I., Avelino, J., Barrera, J. F., Bunn, C., García, J. H., Isaza, C., Munoz-Ucros, J., Pérez-Alemán, C. J., Rahn, E., Robiglio, V., Somarriba, E., \& Valencia, V. (2021). Transformation of coffee-growing landscapes across Latin America. A review. Agronomy for Sustainable Development, 41(5), 62. https://doi.org/10.1007/s13593-021-00712-0

Havkin-Frenkel, D., \& Belanger, F. C. (Eds.). (2018). Handbook of vanilla science and technology (2nd ed.). Wiley-Blackwell.

Hazell, R. J., Chmel, K., Riegert, J., Paul, L., Isua, B., Kaina, G. S., Fibich, P., Molem, K., Stewart, A. J. A., Peck, M. R., Weiblen, G. D., \& Novotny, V. (2021). Spatial scaling of plant and bird diversity from 50 to 10,000 ha in a lowland tropical rainforest. Oecologia, 196(1), 101-113. https://doi.org/10.1007/s00442-02104925-8

Hending, D., Andrianiaina, A., Maxfield, P., Rakotomalala, Z., \& Cotton, S. (2020). Floral species richness, structural diversity and conservation value of vanilla agroecosystems in Madagascar. African Journal of Ecology, 58(1), 100-111. https://doi.org/10.1111/aje.12682 
Hending, D., Andrianiaina, A., Rakotomalala, Z., \& Cotton, S. (2018). The Use of Vanilla Plantations by Lemurs: Encouraging Findings for both Lemur Conservation and Sustainable Agroforestry in the Sava Region, Northeast Madagascar. International Journal of Primatology, 39(1), 141-153. https://doi.org/10.1007/s10764-018-0022-1

Hernandez, J., \& Lubinsky, P. (2011). Cultivation Systems. In E. Odoux \& M. Grisoni (Eds.), Vanilla: Medicinal and Aromatic Plants - Industrial Profiles (pp. 75-96). CRC Press.

Herrera, J. P. (2016). Interactions between plants and primates shape community diversity in a rainforest in Madagascar. Journal of Animal Ecology, 85(4), 982-993. https://doi.org/10.1111/1365-2656.12532

Herrera, J. P., Rabezara, J. Y., Ravelomanantsoa, N. A. F., Metz, M., France, C., Owens, A., Pender, M., Nunn, C. L., \& Kramer, R. A. (2021). Food insecurity related to agricultural practices and household characteristics in rural communities of northeast Madagascar. Food Security. https://doi.org/10.1007/s12571-021-01179-3

Hillebrand, H., Blasius, B., Borer, E. T., Chase, J. M., Downing, J. A., Eriksson, B. K., Filstrup, C. T., Harpole, W. S., Hodapp, D., Larsen, S., Lewandowska, A. M., Seabloom, E. W., Van de Waal, D. B., \& Ryabov, A. B. (2018). Biodiversity change is uncoupled from species richness trends: Consequences for conservation and monitoring. Journal of Applied Ecology, 55(1), 169-184. https://doi.org/10.1111/1365-2664.12959

Hoehn, P., Steffan-Dewenter, I., \& Tscharntke, T. (2010). Relative contribution of agroforestry, rainforest and openland to local and regional bee diversity. Biodiversity and Conservation, 19(8), 2189-2200. https://doi.org/10.1007/s10531-010-9831-z

Hombegowda, H. C., van Straaten, O., Köhler, M., \& Hölscher, D. (2016). On the rebound: Soil organic carbon stocks can bounce back to near forest levels when agroforests replace agriculture in southern India. SOIL, 2(1), 13-23. https://doi.org/10.5194/soil-2-13-2016

Houghton, R. A. (2007). Balancing the Global Carbon Budget. Annual Review of Earth and Planetary Sciences, 35(1), 313-347. https://doi.org/10.1146/annurev.earth.35.031306.140057

Hsieh, T. C., Ma, K. H., \& Chao, A. (2016). iNEXT: An R package for rarefaction and extrapolation of species diversity (Hill numbers). Methods in Ecology and Evolution, 7(12), 1451-1456. https://doi.org/10.1111/2041-210X.12613

Hylander, K., \& Nemomissa, S. (2017). Waiving the extinction debt: Can shade from coffee prevent extinctions of epiphytic plants from isolated trees? Diversity and Distributions, 23(8), 888-897. https://doi.org/10.1111/ddi.12579 
Ibanez, T., Keppel, G., Menkes, C., Gillespie, T. W., Lengaigne, M., Mangeas, M., Rivas-Torres, G., \& Birnbaum, P. (2019). Globally consistent impact of tropical cyclones on the structure of tropical and subtropical forests. Journal of Ecology, 107(1), 279-292. https://doi.org/10.1111/1365-2745.13039

International Trade Centre. (2019). Sustainability Map. International Trade Centre. https://www.sustainabilitymap.org

IPBES. (2019). Global assessment report on biodiversity and ecosystem services of the Intergovernmental Science-Policy Platform on Biodiversity and Ecosystem Services (Version 1). IPBES. https://doi.org/10.5281/ZENODO.3831673

Irwin, M. T., Wright, P. C., Birkinshaw, C., Fisher, B. L., Gardner, C. J., Glos, J., Goodman, S. M., Loiselle, P., Rabeson, P., Raharison, J.-L., Raherilalao, M. J., Rakotondravony, D., Raselimanana, A., Ratsimbazafy, J., Sparks, J. S., Wilmé, L., \& Ganzhorn, J. U. (2010). Patterns of species change in anthropogenically disturbed forests of Madagascar. Biological Conservation, 143(10), 2351-2362. https://doi.org/10.1016/j.biocon.2010.01.023

Isbell, F., Calcagno, V., Hector, A., Connolly, J., Harpole, W. S., Reich, P. B., Scherer-Lorenzen, M., Schmid, B., Tilman, D., van Ruijven, J., Weigelt, A., Wilsey, B. J., Zavaleta, E. S., \& Loreau, M. (2011). High plant diversity is needed to maintain ecosystem services. Nature, 477(7363), 199-202. https://doi.org/10.1038/nature10282

IUCN. (2021). The IUCN Red List of Threatened Species. Version 2021-1. IUCN Red List of Threatened Species. https://www.iucnredlist.org/en

Jackson, S. T., \& Sax, D. F. (2010). Balancing biodiversity in a changing environment: Extinction debt, immigration credit and species turnover. Trends in Ecology \& Evolution, 25(3), 153-160. https://doi.org/10.1016/j.tree.2009.10.001

Jagoret, P., Ngnogue, H. T., Malézieux, E., \& Michel, I. (2018). Trajectories of cocoa agroforests and their drivers over time: Lessons from the Cameroonian experience. European Journal of Agronomy, 101, 183192. https://doi.org/10.1016/j.eja.2018.09.007

Jakovac, C. C., Junqueira, A. B., Crouzeilles, R., Peña-Claros, M., Mesquita, R. C. G., \& Bongers, F. (2021). The role of land-use history in driving successional pathways and its implications for the restoration of tropical forests. Biological Reviews, 96(4), 1114-1134. https://doi.org/10.1111/brv.12694

Jarrett, C., Smith, T. B., Claire, T. T. R., Ferreira, D. F., Tchoumbou, M., Elikwo, M. N. F., Wolfe, J., Brzeski, K., Welch, A. J., Hanna, R., \& Powell, L. L. (2021). Bird communities in African cocoa agroforestry are diverse but lack specialized insectivores. Journal of Applied Ecology, 58(6), 1237-1247. https://doi.org/10.1111/1365-2664.13864 
Jonckheere, I., Fleck, S., Nackaerts, K., Muys, B., Coppin, P., Weiss, M., \& Baret, F. (2004). Review of methods for in situ leaf area index determination. Agricultural and Forest Meteorology, 121(1-2), 19-35. https://doi.org/10.1016/j.agrformet.2003.08.027

Jones, J. P. G., Ratsimbazafy, J., Ratsifandrihamanana, A. N., Watson, J. E. M., Andrianandrasana, H. T., Cabeza, M., Cinner, J. E., Goodman, S. M., Hawkins, F., Mittermeier, R. A., Rabearisoa, A. L., Rakotonarivo, O. S., Razafimanahaka, J. H., Razafimpahanana, A. R., Wilmé, L., \& Wright, P. C. (2019). Last chance for Madagascar's biodiversity. Nature Sustainability, 2(5), 350-352. https://doi.org/10.1038/s41893-0190288-0

Jost, L. (2006). Entropy and diversity. Oikos, 113(2), 363-375. https://doi.org/10.1111/j.2006.00301299.14714.x

Jost, L. (2007). Partitioning diversity into independent alpha and beta components. Ecology, 88(10), 24272439. https://doi.org/10.1890/06-1736.1

Jucker, T., Sanchez, A. C., Lindsell, J. A., Allen, H. D., Amable, G. S., \& Coomes, D. A. (2016). Drivers of aboveground wood production in a lowland tropical forest of West Africa: Teasing apart the roles of tree density, tree diversity, soil phosphorus, and historical logging. Ecology and Evolution, 6(12), 4004-4017. https://doi.org/10.1002/ece3.2175

Karger, D. N., Conrad, O., Böhner, J., Kawohl, T., Kreft, H., Soria-Auza, R. W., Zimmermann, N. E., Linder, H. P., \& Kessler, M. (2017). Climatologies at high resolution for the earth's land surface areas. Scientific Data, 4(1), 170122. https://doi.org/10.1038/sdata.2017.122

Karp, D. S., Frishkoff, L. O., Echeverri, A., Zook, J., Juárez, P., \& Chan, K. M. A. (2018). Agriculture erases climate-driven $\beta$-diversity in Neotropical bird communities. Global Change Biology, 24(1), 338-349. https://doi.org/10.1111/gcb.13821

Karp, D. S., Rominger, A. J., Zook, J., Ranganathan, J., Ehrlich, P. R., \& Daily, G. C. (2012). Intensive agriculture erodes $\beta$-diversity at large scales. Ecology Letters, 15(9), 963-970. https://doi.org/10.1111/j.1461-0248.2012.01815.x

Kay, S., Kühn, E., Albrecht, M., Sutter, L., Szerencsits, E., \& Herzog, F. (2020). Agroforestry can enhance foraging and nesting resources for pollinators with focus on solitary bees at the landscape scale. Agroforestry Systems, 94(2), 379-387. https://doi.org/10.1007/s10457-019-00400-9

Kindt, R., \& Coe, R. (2005). Tree diversity analysis: A manual and software for common statistical methods for ecological and biodiversity studies. World Agrofirestry Centre. 
Klanderud, K., Mbolatiana, H. Z. H., Vololomboahangy, M. N., Radimbison, M. A., Roger, E., Totland, Ø., \& Rajeriarison, C. (2010). Recovery of plant species richness and composition after slash-and-burn agriculture in a tropical rainforest in Madagascar. Biodiversity and Conservation, 19(1), 187-204. https://doi.org/10.1007/s10531-009-9714-3

Komarek, A. M. (2010). Crop diversification decisions: The case of vanilla in Uganda. Quarterly Journal of International Agriculture, 49(892-2016-65217), 227-242.

Kotowska, M. M., Leuschner, C., Triadiati, T., Meriem, S., \& Hertel, D. (2015). Quantifying above- and belowground biomass carbon loss with forest conversion in tropical lowlands of Sumatra (Indonesia). Global Change Biology, 21(10), 3620-3634. https://doi.org/10.1111/gcb.12979

Kull, C. A., Carrière, S. M., Moreau, S., Ramiarantsoa, H. R., Blanc-Pamard, C., \& Tassin, J. (2013). Melting Pots of Biodiversity: Tropical Smallholder Farm Landscapes as Guarantors of Sustainability. Environment: Science and Policy for Sustainable Development, 55(2), 6-16. https://doi.org/10.1080/00139157.2013.765307

Kull, C. A., Tassin, J., \& Carriere, S. M. (2014). Approaching invasive species in Madagascar. Madagascar Conservation \& Development, 9(2), 60. https://doi.org/10.4314/mcd.v9i2.2

Kull, C. A., Tassin, J., Moreau, S., Rakoto Ramiarantsoa, H., Blanc-Pamard, C., \& Carrière, S. M. (2012). The introduced flora of Madagascar. Biological Invasions, 14(4), 875-888. https://doi.org/10.1007/s10530011-0124-6

Kuussaari, M., Bommarco, R., Heikkinen, R. K., Helm, A., Krauss, J., Lindborg, R., Öckinger, E., Pärtel, M., Pino, J., Rodà, F., Stefanescu, C., Teder, T., Zobel, M., \& Steffan-Dewenter, I. (2009). Extinction debt: A challenge for biodiversity conservation. Trends in Ecology \& Evolution, 24(10), 564-571. https://doi.org/10.1016/j.tree.2009.04.011

Labrière, N., Locatelli, B., Laumonier, Y., Freycon, V., \& Bernoux, M. (2015). Soil erosion in the humid tropics: A systematic quantitative review. Agriculture, Ecosystems \& Environment, 203, 127-139. https://doi.org/10.1016/j.agee.2015.01.027

Lamb, D., Erskine, P., \& Parrotta, J. A. (2005). Restoration of Degraded Tropical Forest Landscapes. Science, 310(5754), 1628-1632. https://doi.org/10.1126/science.1111773

Latawiec, A. E., Crouzeilles, R., Brancalion, P. H. S., Rodrigues, R. R., Sansevero, J. B., Santos, J. S. dos, Mills, M., Nave, A. G., \& Strassburg, B. B. (2016). Natural regeneration and biodiversity: A global meta-analysis and implications for spatial planning. Biotropica, 48(6), 844-855. https://doi.org/10.1111/btp.12386 
Le Roux, D. S., Ikin, K., Lindenmayer, D. B., Manning, A. D., \& Gibbons, P. (2015). Single large or several small? Applying biogeographic principles to tree-level conservation and biodiversity offsets. Biological Conservation, 191, 558-566. https://doi.org/10.1016/j.biocon.2015.08.011

Lemon, J., Bolker, B., Oom, S., Klein, E., Rowlingson, B., Wickham, H., Tyagi, A., Eterradossi, O., Grothendieck, G., \& Toews, M. (2021). Package 'plotrix.'

Lenth, R. V. (2016). Least-Squares Means: The R Package Ismeans. Journal of Statistical Software, 69(1). https://doi.org/10.18637/jss.v069.i01

Lewis, S. L., Edwards, D. P., \& Galbraith, D. (2015). Increasing human dominance of tropical forests. Science, 349(6250), 827-832. https://doi.org/10.1126/science.aaa9932

Lewis, S. L., Wheeler, C. E., Mitchard, E. T. A., \& Koch, A. (2019). Restoring natural forests is the best way to remove atmospheric carbon. Nature, 568(7750), 25-28. https://doi.org/10.1038/d41586-019-01026-8

LI-COR Biosciences. (2019). LAI-2200C plant canopy Analyzer instruction manual. LI-COR Biosciences. https://licor.app.boxenterprise.net/s/fqjn5mlu8c1a7zir5qel

Lindenmayer, D. B., Laurance, W. F., \& Franklin, J. F. (2012). Global Decline in Large Old Trees. Science, 338(6112), 1305-1306. https://doi.org/10.1126/science.1231070

Liu, Z., Jia, G., \& Yu, X. (2020). Water uptake and WUE of Apple tree-Corn Agroforestry in the Loess hilly region of China. Agricultural Water Management, 234, 106138. https://doi.org/10.1016/j.agwat.2020.106138

Llopis, J. C., Harimalala, P. C., Bär, R., Heinimann, A., Rabemananjara, Z. H., \& Zaehringer, J. G. (2019). Effects of protected area establishment and cash crop price dynamics on land use transitions 1990-2017 in north-eastern Madagascar. Journal of Land Use Science, 14(1), 52-80. https://doi.org/10.1080/1747423X.2019.1625979

Lohbeck, M., Albers, P., Boels, L. E., Bongers, F., Morel, S., Sinclair, F., Takoutsing, B., Vågen, T.-G., Winowiecki, L. A., \& Smith-Dumont, E. (2020). Drivers of farmer-managed natural regeneration in the Sahel. Lessons for restoration. Scientific Reports, 10(1), 15038. https://doi.org/10.1038/s41598-02070746-z

Ma, Z., Chen, H. Y. H., Bork, E. W., Carlyle, C. N., \& Chang, S. X. (2020). Carbon accumulation in agroforestry systems is affected by tree species diversity, age and regional climate: A global meta-analysis. Global Ecology and Biogeography, 29(10), 1817-1828. https://doi.org/10.1111/geb.13145

Makowski, D., Ben-Shachar, M. S., Patil, I., \& Lüdecke, D. (2020). Automated Results Reporting as a Practical Tool to Improve Reproducibility and Methodological Best Practices Adoption [R-package]. https://github.com/easystats/report 
Manjaribe, C., Frasier, C. L., Rakouth, B., \& Louis, E. E. (2013). Ecological Restoration and Reforestation of Fragmented Forests in Kianjavato, Madagascar. International Journal of Ecology, 2013, 1-12. https://doi.org/10.1155/2013/726275

Mann, H. B., \& Whitney, D. R. (1947). On a test of whether one of two random variables is stochastically larger than the other. The Annals of Mathematical Statistics, 50-60.

Manning, A. D., Fischer, J., \& Lindenmayer, D. B. (2006). Scattered trees are keystone structures Implications for conservation. Biological Conservation, 132(3), 311-321. https://doi.org/10.1016/j.biocon.2006.04.023

Mariel, J., Carrière, S. M., Penot, E., Danthu, P., Rafidison, V., \& Labeyrie, V. (2021). Exploring farmers' agrobiodiversity management practices and knowledge in clove agroforests of Madagascar. People and Nature, 3(4), 914-928. https://doi.org/10.1002/pan3.10238

Martin, D. A., Andriafanomezantsoa, R., Dröge, S., Osen, K., Rakotomalala, E., Wurz, A., Andrianarimisa, A., \& Kreft, H. (2021). Bird diversity and endemism along a land-use gradient in Madagascar: The conservation value of vanilla agroforests. Biotropica, 53(1), 179-190. https://doi.org/10.1111/btp.12859

Martin, D. A., Osen, K., Grass, I., Hölscher, D., Tscharntke, T., Wurz, A., \& Kreft, H. (2020). Land-use history determines ecosystem services and conservation value in tropical agroforestry. Conservation Letters, 13(5). https://doi.org/10.1111/conl.12740

Martin, D. A., Wurz, A., Osen, K., Grass, I., Hölscher, D., Rabemanantsoa, T., Tscharntke, T., \& Kreft, H. (2021). Shade-Tree Rehabilitation in Vanilla Agroforests is Yield Neutral and May Translate into Landscape-Scale Canopy Cover Gains. Ecosystems, 24, 1253-1267. https://doi.org/10.1007/s10021-02000586-5

Martinez Arbizu, P. (2019). pairwiseAdonis: Pairwise multilevel comparison using adonis (0.0.1) [Computer software].

Martinez, B. T., \& Razafindratsima, O. H. (2014). Frugivory and Seed Dispersal Patterns of the Red-Ruffed Lemur, Varecia rubra, at a Forest Restoration Site in Masoala National Park, Madagascar. Folia Primatologica, 85(4), 228-243. https://doi.org/10.1159/000363408

Mascaro, J., Litton, C. M., Hughes, R. F., Uowolo, A., \& Schnitzer, S. A. (2011). Minimizing Bias in Biomass Allometry: Model Selection and Log-Transformation of Data: Model Bias in Tree Allometry. Biotropica, 43(6), 649-653. https://doi.org/10.1111/j.1744-7429.2011.00798.x

McElhinny, C., Gibbons, P., Brack, C., \& Bauhus, J. (2005). Forest and woodland stand structural complexity: Its definition and measurement. Forest Ecology and Management, 218(1-3), 1-24. https://doi.org/10.1016/j.foreco.2005.08.034 
McKinney, M. L., \& Lockwood, J. L. (1999). Biotic homogenization: A few winners replacing many losers in the next mass extinction. Trends in Ecology \& Evolution, 14(11), 450-453. https://doi.org/10.1016/S01695347(99)01679-1

McNicol, I. M., Ryan, C. M., Dexter, K. G., Ball, S. M. J., \& Williams, M. (2018). Aboveground Carbon Storage and Its Links to Stand Structure, Tree Diversity and Floristic Composition in South-Eastern Tanzania. Ecosystems, 21(4), 740-754. https://doi.org/10.1007/s10021-017-0180-6

Melo, F. P. L., Arroyo-Rodríguez, V., Fahrig, L., Martínez-Ramos, M., \& Tabarelli, M. (2013). On the hope for biodiversity-friendly tropical landscapes. Trends in Ecology \& Evolution, 28(8), 462-468. https://doi.org/10.1016/j.tree.2013.01.001

Meyfroidt, P., Carlson, K. M., Fagan, M. E., Gutiérrez-Vélez, V. H., Macedo, M. N., Curran, L. M., DeFries, R. S., Dyer, G. A., Gibbs, H. K., Lambin, E. F., Morton, D. C., \& Robiglio, V. (2014). Multiple pathways of commodity crop expansion in tropical forest landscapes. Environmental Research Letters, 9(7), 074012. https://doi.org/10.1088/1748-9326/9/7/074012

Michel, I., Lobietti, M., Danthu, P., Penot, E., Velonjara, F., Jahiel, M., \& Michels, T. (2021). Agroforestry innovation by smallholders facing uncertainty: The case of clove-based cropping systems in Madagascar. European Journal of Agronomy, 123, 126218. https://doi.org/10.1016/j.eja.2020.126218

Midgley, J. J., Parker, R., Laurie, H., \& Seydack, A. (2002). Competition among canopy trees in indigenous forests: An analysis of the "additive basal area" phenomenon. Austral Ecology, 27(3), 269-272. https://doi.org/10.1046/j.1442-9993.2002.01177.x

Miller, D. C., Ordoñez, P. J., Brown, S. E., Forrest, S., Nava, N. J., Hughes, K., \& Baylis, K. (2020). The impacts of agroforestry on agricultural productivity, ecosystem services, and human well-being in low-and middleincome countries: An evidence and gap map. Campbell Systematic Reviews, 16(1). https://doi.org/10.1002/cl2.1066

Minh, V. T., Mizuno, K., Funakawa, S., Shinjo, H., Tanaka, U., \& An, L. V. (2015). Introduction of Vanilla to Mountainous Villages of Central Vietnam. Tropical Agriculture and Development, 59(4), 199-206. https://doi.org/10.11248/jsta.59.199

Moat, J., \& Smith, P. P. (2007). Atlas of the vegetation of Madagascar [Map]. Royal Botanic Gardens, Kew. Moguel, P., \& Toledo, V. M. (1999). Biodiversity Conservation in Traditional Coffee Systems of Mexico. Conservation Biology, 13(1), 11-21. https://doi.org/10.1046/j.1523-1739.1999.97153.x

Montagnini, F. (2020). The Contribution of Agroforestry to Restoration and Conservation: Biodiversity Islands in Degraded Landscapes. In J. C. Dagar, S. R. Gupta, \& D. Teketay (Eds.), Agroforestry for Degraded Landscapes (pp. 445-479). Springer Singapore. https://doi.org/10.1007/978-981-15-4136-0_15 
Montgomery, R. A., \& Chazdon, R. L. (2001). Forest structure, canopy architecture, and light transmittance in tropical wet forests. Ecology, 82(10), 2707-2718. https://doi.org/10.1890/00129658(2001)082[2707:FSCAAL]2.0.CO;2

Morelli, T. L., Barrows, C. W., Ramirez, A. R., Cartwright, J. M., Ackerly, D. D., Eaves, T. D., Ebersole, J. L., Krawchuk, M. A., Letcher, B. H., Mahalovich, M. F., Meigs, G. W., Michalak, J. L., Millar, C. I., Quiñones, R. M., Stralberg, D., \& Thorne, J. H. (2020). Climate-change refugia: Biodiversity in the slow lane. Frontiers in Ecology and the Environment, 18(5), 228-234. https://doi.org/10.1002/fee.2189

Mori, A. S., Isbell, F., \& Seidl, R. (2018). $\beta$-Diversity, Community Assembly, and Ecosystem Functioning. Trends in Ecology \& Evolution, 33(7), 549-564. https://doi.org/10.1016/j.tree.2018.04.012

Myers, N., Mittermeier, R. A., Mittermeier, C. G., da Fonseca, G. A. B., \& Kent, J. (2000). Biodiversity hotspots for conservation priorities. Nature, 403(6772), 853-858. https://doi.org/10.1038/35002501

Nair, P. K. R., Kumar, B. M., \& Nair, V. D. (2009). Agroforestry as a strategy for carbon sequestration. Journal of Plant Nutrition and Soil Science, 172(1), 10-23. https://doi.org/10.1002/jpln.200800030

Nesper, M., Kueffer, C., Krishnan, S., Kushalappa, C. G., \& Ghazoul, J. (2017). Shade tree diversity enhances coffee production and quality in agroforestry systems in the Western Ghats. Agriculture, Ecosystems \& Environment, 247, 172-181. https://doi.org/10.1016/j.agee.2017.06.024

Newbold, T., Hudson, L. N., Arnell, A. P., Contu, S., Palma, A. D., Ferrier, S., Hill, S. L. L., Hoskins, A. J., Lysenko, I., Phillips, H. R. P., Burton, V. J., Chng, C. W. T., Emerson, S., Gao, D., Pask-Hale, G., Hutton, J., Jung, M., Sanchez-Ortiz, K., Simmons, B. I., ... Purvis, A. (2016). Has land use pushed terrestrial biodiversity beyond the planetary boundary? A global assessment. Science, 353(6296), 288-291. https://doi.org/10.1126/science.aaf2201

Newbold, T., Oppenheimer, P., Etard, A., \& Williams, J. J. (2020). Tropical and Mediterranean biodiversity is disproportionately sensitive to land-use and climate change. Nature Ecology \& Evolution, 4(12), 16301638. https://doi.org/10.1038/s41559-020-01303-0

Nijmeijer, A., Lauri, P.-E., Harmand, J.-M., Freschet, G. T., Essobo Nieboukaho, J.-D., Fogang, P. K., Enock, S., \& Saj, S. (2019). Long-term dynamics of cocoa agroforestry systems established on lands previously occupied by savannah or forests. Agriculture, Ecosystems \& Environment, 275, 100-111. https://doi.org/10.1016/j.agee.2019.02.004

OEC. (2021). Vanilla in Madagascar. OEC - The Observatory of Economic Complexity. https://oec.world/en/profile/bilateral-product/vanilla/reporter/mdg 
Oksanen, J., Blanchet, F. G., Friendly, M., Kindt, R., Legendre, P., McGlinn, D., Minchin, P. R., O'Hara, R. B., Simpson, G. L., Solymos, P., Stevens, M. H. H., Szoecs, E., \& Wagner, H. (2019). vegan: Community Ecology Package (2.5-6) [Computer software]. https://CRAN.R-project.org/package=vegan

Olden, J. D. (2006). Biotic homogenization: A new research agenda for conservation biogeography. Journal of Biogeography, 33(12), 2027-2039. https://doi.org/10.1111/j.1365-2699.2006.01572.x

Oliveira, L. Z., de Gasper, A. L., Lingner, D. V., Sevegnani, L., \& Vibrans, A. C. (2019). Secondary subtropical Atlantic forests shelter a surprising number of rare tree species: Outcomes of an assessment using spatially unbiased data. Biodiversity and Conservation, 28(3), 751-768. https://doi.org/10.1007/s10531018-01690-8

Osen, K., Soazafy, M. R., Martin, D. A., Wurz, A., März, A., Ranarijaona, H. L. T., \& Hölscher, D. (2021). Landuse history determines stand structure and tree diversity in vanilla agroforests of northeastern Madagascar. Applied Vegetation Science, 24(1). https://doi.org/10.1111/avsc.12563

Osterhoudt, S. (2017). Vanilla Landscapes: Meaning, Memory, and the Cultivation of Place in Madagascar. New York Botanical Garden.

Pan, Y., Birdsey, R. A., Fang, J., Houghton, R., Kauppi, P. E., Kurz, W. A., Phillips, O. L., Shvidenko, A., Lewis, S. L., Canadell, J. G., Ciais, P., Jackson, R. B., Pacala, S. W., McGuire, A. D., Piao, S., Rautiainen, A., Sitch, S., \& Hayes, D. (2011). A Large and Persistent Carbon Sink in the World's Forests. Science, 333(6045), 988993. https://doi.org/10.1126/science.1201609

Park, D. S., \& Razafindratsima, O. H. (2019). Anthropogenic threats can have cascading homogenizing effects on the phylogenetic and functional diversity of tropical ecosystems. Ecography, 42(1), 148-161. https://doi.org/10.1111/ecog.03825

Paul, T. S. H., Kimberley, M. O., \& Beets, P. N. (2019). Thinking outside the square: Evidence that plot shape and layout in forest inventories can bias estimates of stand metrics. Methods in Ecology and Evolution, 10(3), 381-388. https://doi.org/10.1111/2041-210X.13113

Perfecto, I., Rice, R. A., Greenberg, R., \& van der Voort, M. E. (1996). Shade Coffee: A Disappearing Refuge for Biodiversity. BioScience, 46(8), 598-608. https://doi.org/10.2307/1312989

Philpott, S. M., Arendt, W. J., Armbrecht, I., Bichier, P., Diestch, T. V., Gordon, C., Greenberg, R., Perfecto, I., Reynoso-Santos, R., Soto-Pinto, L., Tejeda-Cruz, C., Williams-Linera, G., Valenzuela, J., \& Zolotoff, J. M. (2008). Biodiversity Loss in Latin American Coffee Landscapes: Review of the Evidence on Ants, Birds, and Trees. Conservation Biology, 22(5), 1093-1105. https://doi.org/10.1111/j.1523-1739.2008.01029.x 
Philpott, S. M., \& Dietsch, T. (2003). Coffee and Conservation: A Global Context and the Value of Farmer Involvement. Conservation Biology, 17(6), 1844-1846. https://doi.org/10.1111/j.15231739.2003.00150.x

Pimm, S. L. (2021). What we need to know to prevent a mass extinction of plant species. Plants, People, Planet, 3(1), 7-15. https://doi.org/10.1002/ppp3.10160

Pimm, S. L., Jenkins, C. N., Abell, R., Brooks, T. M., Gittleman, J. L., Joppa, L. N., Raven, P. H., Roberts, C. M., \& Sexton, J. O. (2014). The biodiversity of species and their rates of extinction, distribution, and protection. Science, 344(6187), 1246752-1246752. https://doi.org/10.1126/science.1246752

Ponisio, L. C., M'Gonigle, L. K., \& Kremen, C. (2016). On-farm habitat restoration counters biotic homogenization in intensively managed agriculture. Global Change Biology, 22(2), 704-715. https://doi.org/10.1111/gcb.13117

Poorter, L., Rozendaal, D. M. A., Bongers, F., de Almeida-Cortez, J. S., Almeyda Zambrano, A. M., Álvarez, F. S., Andrade, J. L., Villa, L. F. A., Balvanera, P., Becknell, J. M., Bentos, T. V., Bhaskar, R., Boukili, V., Brancalion, P. H. S., Broadbent, E. N., César, R. G., Chave, J., Chazdon, R. L., Colletta, G. D., ... Westoby, M. (2019). Wet and dry tropical forests show opposite successional pathways in wood density but converge over time. Nature Ecology \& Evolution, 3(6), 928-934. https://doi.org/10.1038/s41559-019-0882-6

QGIS Development Team. (2016). QGIS Geographic Information System. Open Source Geospatial Foundation. http://qgis.org/

R Core Team. (2019). R: A language and environment for statistical computing (3.6.3) [Computer software]. R Foundation for Statistical Computing. http://www.R-project.org/

Rafidison, V. M., Rakouth, B., Carrière, S. M., Kjellberg, F., \& Aumeeruddy-Thomas, Y. (2020). Multiple values of isolated and clusters of Ficus tree species protected by Betsileo farmers in rural landscapes in Madagascar: Implications for biodiversity conservation. Biodiversity and Conservation, 29(3), 1027-1058. https://doi.org/10.1007/s10531-019-01924-3

Rakotoarinivo, M., Dransfield, J., Bachman, S. P., Moat, J., \& Baker, W. J. (2014). Comprehensive Red List Assessment Reveals Exceptionally High Extinction Risk to Madagascar Palms. PLoS ONE, 9(7), e103684. https://doi.org/10.1371/journal.pone.0103684

Rakotomalala, A. A. N. A., Wurz, A., Grass, I., Martin, D. A., Osen, K., Schwab, D., Soazafy, M. R., Tscharntke, T., \& Raveloson Ravaomanarivo, L. H. (2021). Tropical land use drives endemic versus exotic ant communities in a global biodiversity hotspot. Biodiversity and Conservation, 30(14), 4417-4434. https://doi.org/10.1007/s10531-021-02314-4 
Ramankutty, N., Mehrabi, Z., Waha, K., Jarvis, L., Kremen, C., Herrero, M., \& Rieseberg, L. H. (2018). Trends in Global Agricultural Land Use: Implications for Environmental Health and Food Security. Annual Review of Plant Biology, 69(1), 789-815. https://doi.org/10.1146/annurev-arplant-042817-040256

Randrianaivo, R. (2014). Rapport sur l'inventaire floristique d' "Antanetiambo Nature Reserve." Missouri Botanical Garden.

Randrianasolo, Z. H., Razafimahatratra, A. R., Razafinarivo, R. N. G., Randrianary, T., Rakotovololonalimanana, H., Rajemison, A. H., Mamitiana, A., Andriamanalina, R. L., Rakotosoa, A., \& Ramananantoandro, T. (2019). Which allometric models are the most appropriate for estimating aboveground biomass in secondary forests of Madagascar with Ravenala madagascariensis? Scientific African, 6, e00147. https://doi.org/10.1016/j.sciaf.2019.e00147

Rappole, J. H., King, D. I., \& Rivera, J. H. V. (2003). Coffee and Conservation. Conservation Biology, 17(1), 334-336. https://doi.org/10.1046/j.1523-1739.2003.01548.x

Rasband, W. S. (2014). ImageJ. U. S. National Institutes of Health. http://imagej.nih.gov/ij/

Raveloaritiana, E., Wurz, A., Grass, I., Osen, K., Soazafy, M. R., Martin, D. A., Faliniaina, L., Rakotomalala, N. H., Vorontsova, M. S., Tscharntke, T., \& Rakouth, B. (2021). Land-use intensification increases richness of native and exotic herbaceous plants, but not endemics, in Malagasy vanilla landscapes. Diversity and Distributions, 27(5), 784-798. https://doi.org/10.1111/ddi.13226

Raveloaritiana, E., Wurz, A., Osen, K., Soazafy, M. R., Grass, I., Martin, D. A., Bemamy, C., Ranarijaona, H. L. T., Borgerson, C., Kreft, H., Hölscher, D., Rakouth, B., \& Tscharntke, T. (submitted). Fallow lands provide multiple ecosystem services to rural households in Madagascar.

Reed, J., van Vianen, J., Foli, S., Clendenning, J., Yang, K., MacDonald, M., Petrokofsky, G., Padoch, C., \& Sunderland, T. (2017). Trees for life: The ecosystem service contribution of trees to food production and livelihoods in the tropics. Forest Policy and Economics, 84, 62-71. https://doi.org/10.1016/j.forpol.2017.01.012

Réjou-Méchain, M., Tanguy, A., Piponiot, C., Chave, J., \& Hérault, B. (2017). BIOMASS: an R-package for estimating above-ground biomass and its uncertainty in tropical forests. Methods in Ecology and Evolution, 8(9), 1163-1167. https://doi.org/10.1111/2041-210X.12753

Rembold, K., Mangopo, H., Tjitrosoedirdjo, S. S., \& Kreft, H. (2017). Plant diversity, forest dependency, and alien plant invasions in tropical agricultural landscapes. Biological Conservation, 213, 234-242. https://doi.org/10.1016/j.biocon.2017.07.020

Rice, R. A., \& Greenberg, R. (2000). Cacao Cultivation and the Conservation of Biological Diversity. AMBIO: A Journal of the Human Environment, 29(3), 167-173. https://doi.org/10.1579/0044-7447-29.3.167 
Rocha-Santos, L., Pessoa, M. S., Cassano, C. R., Talora, D. C., Orihuela, R. L. L., Mariano-Neto, E., MoranteFilho, J. C., Faria, D., \& Cazetta, E. (2016). The shrinkage of a forest: Landscape-scale deforestation leading to overall changes in local forest structure. Biological Conservation, 196, 1-9. https://doi.org/10.1016/j.biocon.2016.01.028

Ruf, F. (2001). Tree crops as deforestation and reforestation agents: The case of cocoa in Côte d'Ivoire and Sulawesi. In A. Angelsen \& D. Kaimowitz (Eds.), Agricultural technologies and tropical deforestation (Vol. 2001, pp. 291-315).

https://www.cifor.org/publications/pdf_files/Books/BAngelsen0101E0.pdf\#page=304

Ruxton, G. D., \& Beauchamp, G. (2008). Time for some a priori thinking about post hoc testing. Behavioral Ecology, 19(3), 690-693. https://doi.org/10.1093/beheco/arn020

Salzman, J., Bennett, G., Carroll, N., Goldstein, A., \& Jenkins, M. (2018). The global status and trends of Payments for Ecosystem Services. Nature Sustainability, 1(3), 136-144. https://doi.org/10.1038/s41893018-0033-0

Scales, I. R. (2014). The drivers of deforestation and the complexity of land use in Madagascar. In I. R. Scales (Ed.), Conservation and environmental management in Madagascar (pp. 129-150). Routledge.

Schatz, G. E. (2005). Generic tree flora of Madagascar (Reprinted 2005). Royal Botanic Gardens \& Missouri Botanical Garden.

Schroeder, P. J., \& Jenkins, D. G. (2018). How robust are popular beta diversity indices to sampling error? Ecosphere, 9(2), e02100. https://doi.org/10.1002/ecs2.2100

Schroth, G. (Ed.). (2004). Agroforestry and biodiversity conservation in tropical landscapes. Island Press.

Schroth, G., Bede, L. C., Paiva, A. O., Cassano, C. R., Amorim, A. M., Faria, D., Mariano-Neto, E., Martini, A. M. Z., Sambuichi, R. H. R., \& Lôbo, R. N. (2015). Contribution of agroforests to landscape carbon storage. Mitigation and Adaptation Strategies for Global Change, 20(7), 1175-1190. https://doi.org/10.1007/s11027-013-9530-7

Schroth, G., Da Fonseca, G. A., Harvey, C. A., Gascon, C., Vasconcelos, H. L., Izac, A.-M. N., Angelsen, A., Finegan, B., Kaimowitz, D., Krauss, U., Laurance, S., Laurance, W., Nasi, R., Naughton-Treves, L., Niesten, E., Richardson, D., Somarriba, E., Tucker, N., Vincent, G., \& Wilkie, D. (2004). Conclusion: Agroforestry and biodiversity conservation in tropical landscapes. In G. Schroth, G. Da Fonseca, C. Harvey, C. Gascon, H. Vasconcelos, \& A. Izac (Eds.), Agroforestry and Biodiversity Conservation in Tropical Landscapes. 
Schuldt, A., Assmann, T., Brezzi, M., Buscot, F., Eichenberg, D., Gutknecht, J., Härdtle, W., He, J.-S., Klein, A.-M., Kühn, P., Liu, X., Ma, K., Niklaus, P. A., Pietsch, K. A., Purahong, W., Scherer-Lorenzen, M., Schmid, B., Scholten, T., Staab, M., ... Bruelheide, H. (2018). Biodiversity across trophic levels drives multifunctionality in highly diverse forests. Nature Communications, 9(1), 2989. https://doi.org/10.1038/s41467-018-05421-z

Schüßler, D., Mantilla-Contreras, J., Stadtmann, R., Ratsimbazafy, J. H., \& Radespiel, U. (2020). Identification of crucial stepping stone habitats for biodiversity conservation in northeastern Madagascar using remote sensing and comparative predictive modeling. Biodiversity and Conservation, 29(7), 21612184. https://doi.org/10.1007/s10531-020-01965-z

Schwab, D., Wurz, A., Grass, I., Rakotomalala, A. A. N. A., Osen, K., Soazafy, M. R., Martin, D. A., \& Tscharntke, T. (2021). Decreasing predation rates and shifting predator compositions along a land-use gradient in Madagascar's vanilla landscapes. Journal of Applied Ecology, 58(2), 360-371. https://doi.org/10.1111/1365-2664.13766

Schwitzer, C., Mittermeier, R. A., Davies, N., Johnson, S., Ratsimbazafy, J., Razafindramanana, J., Louis Jr, E. E., \& Rajaobelina, S. (2013). Lemurs of Madagascar: A strategy for their conservation 2013-2016. IUCN SSC Primate Specialist Group, Bristol Conservation and Science Foundation, and Conservation International. https://portals.iucn.org/library/node/10414

Schwitzer, C., Mittermeier, R. A., Johnson, S. E., Donati, G., Irwin, M., Peacock, H., Ratsimbazafy, J., Razafindramanana, J., Louis, E. E., Chikhi, L., Colquhoun, I. C., Tinsman, J., Dolch, R., LaFleur, M., Nash, S., Patel, E., Randrianambinina, B., Rasolofoharivelo, T., \& Wright, P. C. (2014). Averting Lemur Extinctions amid Madagascar's Political Crisis. Science, 343(6173), 842-843. https://doi.org/10.1126/science.1245783

Shannon, C. E. (1949). Communication Theory of Secrecy Systems*. Bell System Technical Journal, 28(4), 656-715. https://doi.org/10.1002/j.1538-7305.1949.tb00928.x

Shapiro, S. S., \& Wilk, M. B. (1965). An Analysis of Variance Test for Normality (Complete Samples). Biometrika, 52(3/4), 591. https://doi.org/10.2307/2333709

Shumi, G., Schultner, J., Dorresteijn, I., Rodrigues, P., Hanspach, J., Hylander, K., Senbeta, F., \& Fischer, J. (2018). Land use legacy effects on woody vegetation in agricultural landscapes of south-western Ethiopia. Diversity and Distributions, 24(8), 1136-1148. https://doi.org/10.1111/ddi.12754

Si, X., Baselga, A., \& Ding, P. (2015). Revealing Beta-Diversity Patterns of Breeding Bird and Lizard Communities on Inundated Land-Bridge Islands by Separating the Turnover and Nestedness Components. PLOS ONE, 10(5), e0127692. https://doi.org/10.1371/journal.pone.0127692 
Siebert, S. F. (2002). From shade- to sun-grown perennial crops in Sulawesi, Indonesia: Implications for biodiversity conservation and soil fertility. Biodiversity and Conservation, 11(11), 1889-1902. https://doi.org/10.1023/A:1020804611740

Slik, J. W. F., Paoli, G., McGuire, K., Amaral, I., Barroso, J., Bastian, M., Blanc, L., Bongers, F., Boundja, P., Clark, C., Collins, M., Dauby, G., Ding, Y., Doucet, J.-L., Eler, E., Ferreira, L., Forshed, O., Fredriksson, G., Gillet, J.-F., ... Zweifel, N. (2013). Large trees drive forest aboveground biomass variation in moist lowland forests across the tropics: Large trees and tropical forest biomass. Global Ecology and Biogeography, 22(12), 1261-1271. https://doi.org/10.1111/geb.12092

Socolar, J. B., Gilroy, J. J., Kunin, W. E., \& Edwards, D. P. (2016). How Should Beta-Diversity Inform Biodiversity Conservation? Trends in Ecology \& Evolution, 31(1), 67-80. https://doi.org/10.1016/j.tree.2015.11.005

Soininen, J., Heino, J., \& Wang, J. (2018). A meta-analysis of nestedness and turnover components of beta diversity across organisms and ecosystems. Global Ecology and Biogeography, 27(1), 96-109. https://doi.org/10.1111/geb.12660

Solar, R. R. de C., Barlow, J., Ferreira, J., Berenguer, E., Lees, A. C., Thomson, J. R., Louzada, J., Maués, M., Moura, N. G., Oliveira, V. H. F., Chaul, J. C. M., Schoereder, J. H., Vieira, I. C. G., Mac Nally, R., \& Gardner, T. A. (2015). How pervasive is biotic homogenization in human-modified tropical forest landscapes? Ecology Letters, 18(10), 1108-1118. https://doi.org/10.1111/ele.12494

Styger, E., Fernandes, E. C. M., Rakotondramasy, H. M., \& Rajaobelinirina, E. (2009). Degrading uplands in the rainforest region of Madagascar: Fallow biomass, nutrient stocks, and soil nutrient availability. Agroforestry Systems, 77(2), 107-122. https://doi.org/10.1007/s10457-009-9225-y

Styger, E., Rakotondramasy, H. M., Pfeffer, M. J., Fernandes, E. C. M., \& Bates, D. M. (2007). Influence of slash-and-burn farming practices on fallow succession and land degradation in the rainforest region of Madagascar. Agriculture, Ecosystems \& Environment, 119(3-4), 257-269. https://doi.org/10.1016/j.agee.2006.07.012

Tabarelli, M., Peres, C. A., \& Melo, F. P. L. (2012). The 'few winners and many losers' paradigm revisited: Emerging prospects for tropical forest biodiversity. Biological Conservation, 155, 136-140. https://doi.org/10.1016/j.biocon.2012.06.020

Tejeda-Cruz, C., Silva-Rivera, E., Barton, J. R., \& Sutherland, W. J. (2010). Why Shade Coffee Does Not Guarantee Biodiversity Conservation. Ecology and Society, 15(1), art13. https://doi.org/10.5751/ES02870-150113

ter Steege, H., Pitman, N. C. A., Sabatier, D., Baraloto, C., Salomao, R. P., Guevara, J. E., Phillips, O. L., Castilho, C. V., Magnusson, W. E., Molino, J.-F., Monteagudo, A., Nunez Vargas, P., Montero, J. C., 
Feldpausch, T. R., Coronado, E. N. H., Killeen, T. J., Mostacedo, B., Vasquez, R., Assis, R. L., ... Silman, M. R. (2013). Hyperdominance in the Amazonian Tree Flora. Science, 342(6156), 1243092-1243092. https://doi.org/10.1126/science.1243092

Torppa, K. A., Wirta, H., \& Hanski, I. (2020). Unexpectedly diverse forest dung beetle communities in degraded rain forest landscapes in Madagascar. Biotropica, 52(2), 351-365. https://doi.org/10.1111/btp.12767

Tropicos. (2020). Catalogue of the Plants of Madagascar. http://legacy.tropicos.org/Project/Madagascar Tscharntke, T., Clough, Y., Bhagwat, S. A., Buchori, D., Faust, H., Hertel, D., Hölscher, D., Juhrbandt, J., Kessler, M., Perfecto, I., Scherber, C., Schroth, G., Veldkamp, E., \& Wanger, T. C. (2011). Multifunctional shade-tree management in tropical agroforestry landscapes - a review: Multifunctional shade-tree management. Journal of Applied Ecology, 48(3), 619-629. https://doi.org/10.1111/j.13652664.2010.01939.x

Tscharntke, T., Clough, Y., Wanger, T. C., Jackson, L., Motzke, I., Perfecto, I., Vandermeer, J., \& Whitbread, A. (2012). Global food security, biodiversity conservation and the future of agricultural intensification. Biological Conservation, 151(1), 53-59. https://doi.org/10.1016/j.biocon.2012.01.068

Tscharntke, T., Milder, J. C., Schroth, G., Clough, Y., DeClerck, F., Waldron, A., Rice, R., \& Ghazoul, J. (2015). Conserving Biodiversity Through Certification of Tropical Agroforestry Crops at Local and Landscape Scales: Conserving biodiversity by crop certification. Conservation Letters, 8(1), 14-23. https://doi.org/10.1111/conl.12110

Tucker, C. M., Shoemaker, L. G., Davies, K. F., Nemergut, D. R., \& Melbourne, B. A. (2016). Differentiating between niche and neutral assembly in metacommunities using null models of $\beta$-diversity. Oikos, 125(6), 778-789. https://doi.org/10.1111/oik.02803

Tuomisto, H. (2010). A diversity of beta diversities: Straightening up a concept gone awry. Part 1. Defining beta diversity as a function of alpha and gamma diversity. Ecography, 33(1), 2-22. https://doi.org/10.1111/j.1600-0587.2009.05880.x

Ulrich, W., Baselga, A., Kusumoto, B., Shiono, T., Tuomisto, H., \& Kubota, Y. (2017). The tangled link between $\beta$ - and $\gamma$-diversity: $A$ Narcissus effect weakens statistical inferences in null model analyses of diversity patterns: The link between $\beta$ - and $\gamma$-diversity. Global Ecology and Biogeography, 26(1), 1-5. https://doi.org/10.1111/geb.12527

UN Decade on Ecosystem Restoration. (2021). UN Decade on Ecosystem Restoration 2021-2030. http://www.decadeonrestoration.org/node 
Urech, Z. L., \& Zaehringer, J. G. (2015). Understanding deforestation and forest fragmentation from a livelihood perspective. Madagascar Conservation \& Development, 10(2), 67-76.

Valencia, V., Naeem, S., García-Barrios, L., West, P., \& Sterling, E. J. (2016). Conservation of tree species of late succession and conservation concern in coffee agroforestry systems. Agriculture, Ecosystems \& Environment, 219, 32-41. https://doi.org/10.1016/j.agee.2015.12.004

Van der Grijp, P. (1997). Brown gold: Official expectations and local assessment of the tongan vanilla production. Journal de La Société Des Océanistes, 104(1), 93-103.

van der Plas, F., Manning, P., Soliveres, S., Allan, E., Scherer-Lorenzen, M., Verheyen, K., Wirth, C., Zavala, M. A., Ampoorter, E., Baeten, L., Barbaro, L., Bauhus, J., Benavides, R., Benneter, A., Bonal, D., Bouriaud, O., Bruelheide, H., Bussotti, F., Carnol, M., ... Fischer, M. (2016). Biotic homogenization can decrease landscape-scale forest multifunctionality. Proceedings of the National Academy of Sciences, 113(13), 3557-3562. https://doi.org/10.1073/pnas.1517903113

van der Sande, M. T., Poorter, L., Kooistra, L., Balvanera, P., Thonicke, K., Thompson, J., Arets, E. J. M. M., Garcia Alaniz, N., Jones, L., Mora, F., Mwampamba, T. H., Parr, T., \& Peña-Claros, M. (2017). Biodiversity in species, traits, and structure determines carbon stocks and uptake in tropical forests. Biotropica, 49(5), 593-603. https://doi.org/10.1111/btp.12453

van Noordwijk, M., Duguma, L. A., Dewi, S., Leimona, B., Catacutan, D. C., Lusiana, B., Öborn, I., Hairiah, K., \& Minang, P. A. (2018). SDG synergy between agriculture and forestry in the food, energy, water and income nexus: Reinventing agroforestry? Current Opinion in Environmental Sustainability, 34, 33-42. https://doi.org/10.1016/j.cosust.2018.09.003

Vences, M., Wollenberg, K. C., Vieites, D. R., \& Lees, D. C. (2009). Madagascar as a model region of species diversification. Trends in Ecology \& Evolution, 24(8), 456-465. https://doi.org/10.1016/j.tree.2009.03.011

Verdone, M., \& Seidl, A. (2017). Time, space, place, and the Bonn Challenge global forest restoration target. Restoration Ecology, 25(6), 903-911. https://doi.org/10.1111/rec.12512

Vieilledent, G., Gardi, O., Grinand, C., Burren, C., Andriamanjato, M., Camara, C., Gardner, C. J., Glass, L., Rasolohery, A., Rakoto Ratsimba, H., Gond, V., \& Rakotoarijaona, J.-R. (2016). Bioclimatic envelope models predict a decrease in tropical forest carbon stocks with climate change in Madagascar. Journal of Ecology, 104(3), 703-715. https://doi.org/10.1111/1365-2745.12548

Vieilledent, G., Grinand, C., Rakotomalala, F. A., Ranaivosoa, R., Rakotoarijaona, J.-R., Allnutt, T. F., \& Achard, F. (2018). Combining global tree cover loss data with historical national forest cover maps to look at six decades of deforestation and forest fragmentation in Madagascar. Biological Conservation, 222, 189-197. https://doi.org/10.1016/j.biocon.2018.04.008 
Vieilledent, G., Vaudry, R., Andriamanohisoa, S. F. D., Rakotonarivo, O. S., Randrianasolo, H. Z., Razafindrabe, H. N., Rakotoarivony, C. B., Ebeling, J., \& Rasamoelina, M. (2012). A universal approach to estimate biomass and carbon stock in tropical forests using generic allometric models. Ecological Applications, 22(2), 572-583. https://doi.org/10.1890/11-0039.1

Waldron, A., Garrity, D., Malhi, Y., Girardin, C., Miller, D. C., \& Seddon, N. (2017). Agroforestry Can Enhance Food Security While Meeting Other Sustainable Development Goals. Tropical Conservation Science, 10, 194008291772066. https://doi.org/10.1177/1940082917720667

Wanger, T. C., Hölscher, D., Veldkamp, E., \& Tscharntke, T. (2018). Cocoa production: Monocultures are not the solution to climate adaptation-Response to Abdulai et al. 2017. Global Change Biology, 24(2), 561-562. https://doi.org/10.1111/gcb.14005

Watson, J. E. M., Evans, T., Venter, O., Williams, B., Tulloch, A., Stewart, C., Thompson, I., Ray, J. C., Murray, K., Salazar, A., McAlpine, C., Potapov, P., Walston, J., Robinson, J. G., Painter, M., Wilkie, D., Filardi, C., Laurance, W. F., Houghton, R. A., ... Lindenmayer, D. (2018). The exceptional value of intact forest ecosystems. Nature Ecology \& Evolution, 2(4), 599-610. https://doi.org/10.1038/s41559-018-0490-x

Wei, T., Simko, V., Levy, M., Xie, Y., Jin, Y., \& Zemla, J. (2017). Package 'corrplot.' Statistician, 56(316), e24.

Welch, B. L. (1947). The Generalization of 'Student's' Problem when Several Different Population Variances are Involved. Biometrika, 34(1/2), 28. https://doi.org/10.2307/2332510

White, L., O'Connor, N. E., Yang, Q., Emmerson, M. C., \& Donohue, I. (2020). Individual species provide multifaceted contributions to the stability of ecosystems. Nature Ecology \& Evolution, 4(12), 1594-1601. https://doi.org/10.1038/s41559-020-01315-w

Whittaker, R. H. (1960). Vegetation of the Siskiyou Mountains, Oregon and California. Ecological Monographs, 30(3), 279-338. https://doi.org/10.2307/1943563

Wickham, H. (2011). Ggplot2. Wiley Interdisciplinary Reviews: Computational Statistics, 3(2), 180-185. https://doi.org/10.1002/wics.147

Willis, K. J. (2017). State of the World's Plants 2017. Royal Botanic Gardens, Kew.

Winkler, K., Fuchs, R., Rounsevell, M., \& Herold, M. (2021). Global land use changes are four times greater than previously estimated. Nature Communications, 12(1), 2501. https://doi.org/10.1038/s41467-02122702-2

World Agroforestry Centre. (2009). Agroforestree database. http://apps.worldagroforestry.org/treedb/index.php 
Wu, J., Liu, W., \& Chen, C. (2016). Can intercropping with the world's three major beverage plants help improve the water use of rubber trees? Journal of Applied Ecology, 53(6), 1787-1799. https://doi.org/10.1111/1365-2664.12730

Wurz, A., Grass, I., Lees, D., Rakotomalala, A. A. N. A., Sáfián, S., Martin, D. A., Osen, K., Loos, J., Benasoavina, E., Alexis, T., \& Tscharntke, T. (submitted). Land-use change differentially affects endemic, forest and open-land butterflies in Madagascar.

Wurz, A., Tscharntke, T., Martin, D. A., Osen, K., Raveloaritiana, E., Andriafanomezantsoa, R., Andrianisaina, F., Fulgence, T. R., Dröge, S., Rakotomalala, A. A. N. A., Randriamanantena, R., Soazafy, M. R., Andrianarimisa, A., Soavita Babarezoto, F., Barkmann, J., Hänke, H., Hölscher, D., Kreft, H., Rakouth, B., ... Grass, I. (submitted). High crop yields without biodiversity loss in tropical agroforestry.

Yesuf, G., Brown, K. A., \& Walford, N. (2019). Assessing regional-scale variability in deforestation and forest degradation rates in a tropical biodiversity hotspot. Remote Sensing in Ecology and Conservation, 5(4), 346-359. https://doi.org/10.1002/rse2.110

Zaehringer, J. G., Eckert, S., \& Messerli, P. (2015). Revealing Regional Deforestation Dynamics in NorthEastern Madagascar-Insights from Multi-Temporal Land Cover Change Analysis. Land, 4(2), 454-474. https://doi.org/10.3390/land4020454

Zaehringer, J. G., Hett, C., Ramamonjisoa, B., \& Messerli, P. (2016). Beyond deforestation monitoring in conservation hotspots: Analysing landscape mosaic dynamics in north-eastern Madagascar. Applied Geography, 68, 9-19. https://doi.org/10.1016/j.apgeog.2015.12.009

Zaehringer, J. G., Schwilch, G., Andriamihaja, O. R., Ramamonjisoa, B., \& Messerli, P. (2017). Remote sensing combined with social-ecological data: The importance of diverse land uses for ecosystem service provision in north-eastern Madagascar. Ecosystem Services, 25, 140-152. https://doi.org/10.1016/j.ecoser.2017.04.004

Zanne, A. E., Lopez-Gonzalez, G., Coomes, D. A., Ilic, J., Jansen, S., Lewis, S. L., Miller, R. B., Swenson, N. G., Wiemann, M. C., Chave, J., Zanne, A. E., Lopez-Gonzalez, G., Coomes, D. A., Ilic, J., Jansen, S., Lewis, S. L., Miller, R. B., Swenson, N. G., Wiemann, M. C., \& Chave, J. (2009). Global Wood Density Database [Data set]. Dryad Digital Repository. https://doi.org/10.5061/DRYAD.234/1

Zomer, R. J., Neufeldt, H., Xu, J., Ahrends, A., Bossio, D., Trabucco, A., van Noordwijk, M., \& Wang, M. (2016). Global Tree Cover and Biomass Carbon on Agricultural Land: The contribution of agroforestry to global and national carbon budgets. Scientific Reports, 6(1), 29987. https://doi.org/10.1038/srep29987

Zuur, A. F., leno, E. N., \& Elphick, C. S. (2010). A protocol for data exploration to avoid common statistical problems. Methods in Ecology and Evolution, 1(1), 3-14. https://doi.org/10.1111/j.2041210X.2009.00001.x 
Zwartendijk, B. W., van Meerveld, H. J., Ghimire, C. P., Bruijnzeel, L. A., Ravelona, M., \& Jones, J. P. G. (2017). Rebuilding soil hydrological functioning after swidden agriculture in eastern Madagascar. Agriculture, Ecosystems \& Environment, 239, 101-111. https://doi.org/10.1016/j.agee.2017.01.002 


\section{Acknowledgements}

First of all, thanks to my main supervisor Dirk for providing academic support and guiding me through my PhD journey with endless patience. I wonder if there is any supervisor who can read manuscripts thoroughly and give substantial feedback as quickly as you can - you might be a secrete record holder for lightning-fast answers! Also a big thank you to my co-supervisors Holger, Teja, and Ingo for your guidance, support and interest in my work. Jointly, you four PIs promoted and encouraged our ecologist team dynamics from the beginning on and enabled us to put collaborative teamwork into practice and even expand into new projects. I am very grateful for that!

A big thank you to all professors, students and members of the Diversity Turn team in Germany and Madagascar for establishing a positive project spirit. And a special thanks to Hery Lisy for supporting the project and being generous and tolerant with bureaucratic obstacles and shortcomings.

Thanks to our research partners at Missouri Botanical Gardens in Antananarivo, specifically to Patrice, for your excellent support with voucher collection and tree identification. I bet that very few people know as much about Malagasy tree taxonomy and hands-on sample collection as you do, and it was a great honor working with you and learning from your impressive expertise.

I am very grateful to all plot owners, chefs de fokontany and village residents for your interest in our work, your trust, your hospitality, for sharing part of your knowledge and for granting us access to your villages, your land and even your homes. Your openness to cooperate was the core of our project and is the bedrock of this thesis! And knowing that some of you put our joint group photographs into your family photo albums means more to me than any citation record will ever do.

Thanks to the project coordinators Yvonne and Hendrik in Göttingen and Fenohaja in Madagascar for kicking off the project and supporting us in keeping the project running smoothly - both logistically and personally. Also thanks to Guillaume for setting up important contacts and introducing us to key people in the study region. Additionally, thanks to Yvonne, Hendrik and Jessica for many talks and discussions and for sharing your Postdoc experience with us!

Additionally, I am grateful to DAAD for accepting to fund the additional project "Transnational exchange in land use and biodiversity research in Madagascar". Writing the grant and planning and implementing this project was a great learning experience and facilitated invaluable and in-depth collaborative working among our international PhD team members. 
Furthermore, I was supported and accompanied by many people and I feel tremendously grateful for all the direct and indirect elements, that everyone of you contributed to my PhD experience:

Thanks to Eva for guiding me through bureaucratic endeavors, keeping up the positive vibes at Büsgenweg and making sure that the essential office coffee supply never ran dry.

Thanks to Alex for many cheerful chats covering everything from work support to life hacks. Thanks to Medha for sharing relaxing coffee breaks and sparking my interest in the joy of sky gazing.

Thanks to my "office gang" Flo, Joyson, Watit and Hoa Hong for being my welcome committee when I first arrived to Göttingen, for being my campus company and my friends. Our mensa \& coffee ritual was my daily campus highlight! Special thanks to you, Joyson, for sharing amazing homemade food and teaching me fascinating facts about Manipur - I wish I can come to visit one day! Special thanks to you, Flo, for teaching me so many skills from soldering to assembling octocopters and repairing washing machines, for supplying me with spare parts and with sweets and for being my motivation coach and my pilgrimage companion.

Thanks to the extended CRC team for adopting me to the "Indonesian family": Flo, Joyson, Greta, Pierre, Clara, Johannes B., Dirk, Tati, Carina, Rahmi, Joost, Isabelle, Britta - Terima kasih for bringing so much positive spirit to my Göttingen life chapter!

Thanks to the Diversity Turn "Master team" Christina, Stefanie, Adriane, Johannes O., Saskia, Dominik, Vivan and Erika for your great commitment, but also for sharing mountains of rice and unforgettable field work adventures and lots of laughter! Special thanks to Yevgeniya and Johannes $\mathbf{O}$. for your dedicated work on the support tree manuscript.

I am deeply grateful to my strong field work team: Marie Rolande, Thorien, Jean Chrys and Patrice: misaotra betsaka equipe kakazo! Hazo tokana tsy mba ala: a single tree is not a forest and this thesis would not exist without your effort, dedication, and amazing team spirit! It was a pleasure working with you and I am so grateful for all the knowledge on trees, forests and Malagasy cultural wisdom, that you shared with me. Additionally, a special thanks to Evrard and Thorien for supporting the whole Diversity team as outstanding field assistants. You played a key role in representing our project!

Thanks to all people in Madagascar who supported us beyond research, welcomed us and made us feel at home: Fanja and her team in Tana and our extended Sambava network from Elvine and Mama Be to the Royal Sava team and many many more. Misaotra betsaka! 
Thanks to the Diversity Turn PhD team: Annette, Lloyd, Vivi, Janna, Dominic, Annemarie, Marie Rolande, Fulgence, Andry, Estelle and Fanilo: sharing work and life with all of you in Sambava and Göttingen was so enriching and will leave lasting positive marks for the rest of my life. Even though I have lived in many shared flats so far, our house share in Sambava will always be unparalleled! Real teamwork is more than the sum of its parts and I have learned so much from each and everyone of you throughout the last years. You are amazing colleagues AND friends! Misaotra, thanks, danke y gracias!

Marie Rolande: thank you for being my tree-partner in crime in the field and in front of our screens! Dominic and Annemarie: working hand in hand with both of you from day one was invaluable for my personal and academic development. Together we formed the "trio infernale" and achieved so much more than I would have ever achieved alone! Having you two at my side as my colleagues and friends was my lucky strike and I am deeply grateful for this experience!

Becoming a researcher is a process and many teachers and researchers have supported and inspired me with discussions, questions, advice, and their knowledge along my educational pathway. Some have been mentioned already but additionally, I would like to thank Christa Bodisch, Kurt Seilheimer, Dieter Mahsberg, Gerd Vogg, Brigitte Fiala, K. Eduard Linsenmair, Nadine Ruppert, Elke Mannigel, Gerhard Kost, Birgit Ziegenhagen, Papá Leonard and Maafaka Ravelona. You were all pivotal in your own way. To all my close friends, who have not been mentioned yet: Thanks for your patience and for motivating and supporting me, but also thanks for reminding me that a $\mathrm{PhD}$ thesis is only one of many life projects. A very special thanks to Juan Camilo: you and your chispa left the scenery far too early. I will make sure that your imprint stays visible in my future, wherever life takes me - te lo prometo, mano!

Last but most importantly, my deepest gratitude goes to my family for always always always having my back. Thank you for your unconditional support, your optimism and good vibes, your interest in what I do and for always grounding me! I could not wish for more.

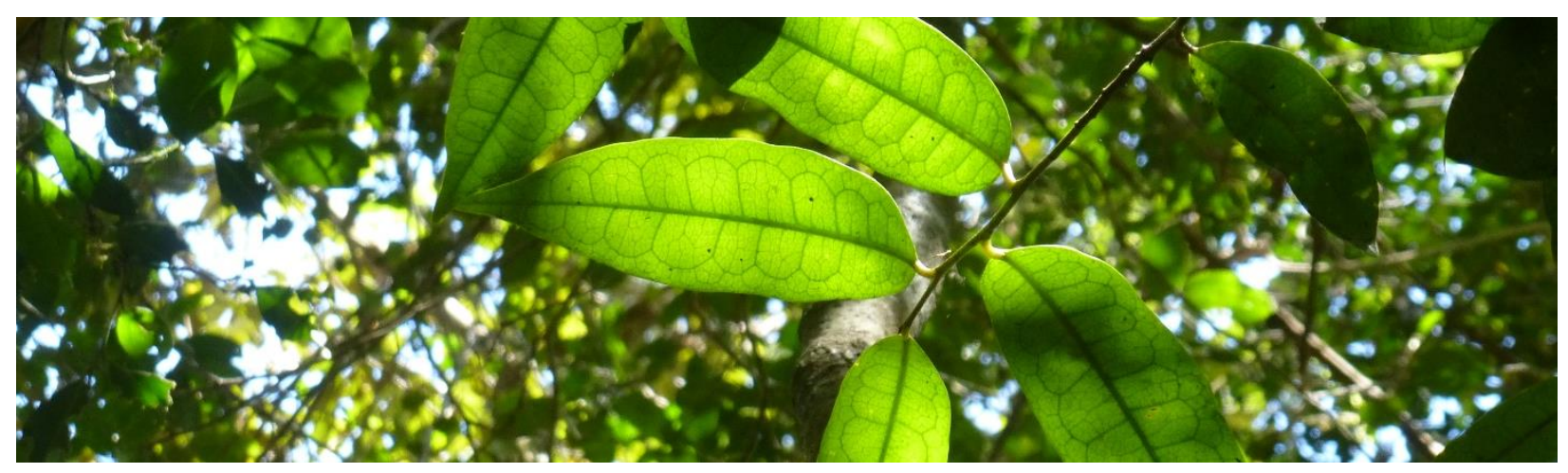




\section{Supporting documents}

\section{List of author affiliations}

$\begin{array}{ll}\text { Last name } & \text { Name } \\ \text { Antilahimena } & \text { Patrice } \\ & \\ \text { Grass } & \text { Ingo }\end{array}$

\section{Affiliation}

- Missouri Botanical Garden, Madagascar Research and Conservation Program, Antananarivo, Madagascar

- Agroecology, University of Goettingen, Göttingen, Germany

- Ecology of Tropical Agricultural Systems, University of Hohenheim, Stuttgart, Germany

Hölscher Dirk

- Tropical Silviculture and Forest Ecology, University of Goettingen, Göttingen, Germany

- Centre for Biodiversity and Sustainable Land Use (CBL), University of Goettingen, Göttingen, Germany

\begin{tabular}{|c|c|c|}
\hline Korol & Yevgeniya & $\begin{array}{l}\text { - Tropical Silviculture \& Forest Ecology, University of Göttingen, } \\
\text { Büsgenweg 1, } 37077 \text { Göttingen, Germany }\end{array}$ \\
\hline Kreft & Holger & $\begin{array}{l}\text { - Biodiversity, Macroecology and Biogeography, University of } \\
\text { Goettingen, Göttingen, Germany } \\
\text { - Centre for Biodiversity and Sustainable Land Use (CBL), } \\
\text { University of Goettingen, Göttingen, Germany }\end{array}$ \\
\hline Martin & Dominic A. & $\begin{array}{l}\text { - Biodiversity, Macroecology and Biogeography, University of } \\
\text { Goettingen, Göttingen, Germany } \\
\text { - Wyss Academy for Nature, University of Bern, Kochergasse 4, } \\
3011 \text { Bern, Switzerland }\end{array}$ \\
\hline März & Adriane & $\begin{array}{l}\text { - Tropical Silviculture \& Forest Ecology, University of Göttingen, } \\
\text { Büsgenweg 1, } 37077 \text { Göttingen, Germany } \\
\text { - Chair of Forestry Economics and Forest Planning, University of } \\
\text { Freiburg, Tennenbacher Str. 4, } 79106 \text { Freiburg, Germany }\end{array}$ \\
\hline
\end{tabular}




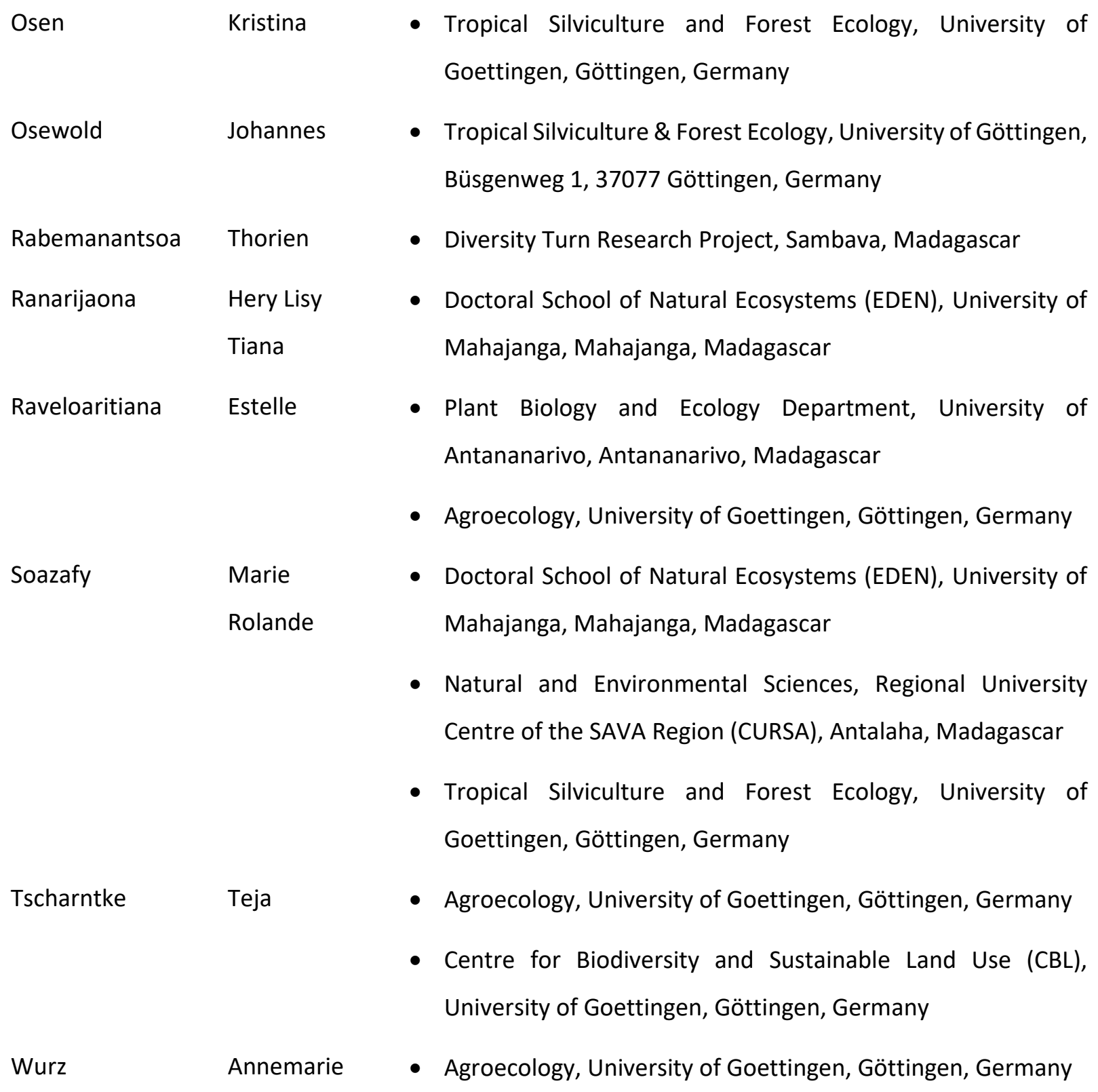




\section{Supplementary information for chapters}

SUPPLEMENTARY INFORMATION FOR CHAPTER 1:

CONCEPTUAL STUDY: LAND-USE HISTORY IN TROPICAL AGROFORESTRY

Appendix S1.1: Table with information about studies from Miller et al. (2020) Supp-001; Filtered for practice type 'Trees integrated with plantation crops' and 'Tropical' OR 'Multiple' ecoregions The supporting information 'conl12740-sup-0001-tableS1.xIsx' for Chapter 1 is available at: https://conbio.onlinelibrary.wiley.com/action/downloadSupplement?doi=10.1111\%2Fconl.12740\&file=c onl12740-sup-0001-tableS1.xlsx

\section{SUPPLEMENTARY INFORMATION FOR CHAPTER 2:}

CASE STUDY: TREE DIVERSITY AND STAND STRUCTURE IN THE MOSAIC LANDSCAPE

Appendix S2.1: Specification on the selection of old-growth forest sites

Our goal was to choose old-growth forest sites that represent the least human-disturbed and presumably demographically most balanced low-altitude forest remnants within the study area. However, continuous low-altitude old-growth forest is scarce within the study area and the only two areas with large forest remnants are located in the two protected areas "Makirovana-Tsihomanaomby Reserve" and "Marojejy National Park". Yet, local expert reported that the low-altitude forest in Makirovana-Tsihomanaomby Reserve is substantially disturbed and frequently used for unauthorized wood extraction and vanilla cultivation, despite the protection status. Therefore, we disregarded the option of sampling at Makirovana-Tsihomanaomby and chose all 10 old-growth forest plots inside Marojejy National Park which experiences lower human disturbance levels.

Marojejy National Park was founded in 1952 as a strict nature reserve and since 1998 it was converted into a National Park, allowing access to the public (Goodman, 2000). The park covers an area of $\sim 55^{\prime} 500$ ha and spans elevation zones from low-altitude rainforest to shrub land above the tree line at the peak of Marojejy at 2132 m.a.s.I. (Goodman, 2000).

We chose all old-growth forest plots within the low-altitude forest at elevations less than 700 m.a.s.l. Five of the plots in Marojejy National Park were located in the Manantenina Valley close to the tourist hiking trails ("Marojejy Tourist"), five further east in the Bangoabe area ("Marojejy East"). Forest plots in the Manantenina valley might have experienced some logging in the past, particularly for precious woods (Patel, 2007), but are now well protected and frequently monitored by National Park staff, as they are 
embedded in the touristic zone of the park. However, some clearings occurred before the park was established in 1952, leading to gaps in the forest cover which are still visible today. We avoided these gaps when we selected the study plots. The second study site, Bangoabe, is further away from the National park office and less frequently monitored by National Park staff, thus illegal selective logging and hunting occasionally occurs (personal communication Jean-Chrysostome Bevao). When selecting the plots, we tried to avoid sites with obvious traces of human disturbance.

The old-growth forest plot centers are a minimum of $250 \mathrm{~m}$ from the forest edge and the minimum distance between old-growth forest plot centers is $260 \mathrm{~m}$.

\section{References}

Goodman, S.M. (2000) Description of the Parc National de Marojejy, Madagascar, and the 1996 biological inventory of the reserve. Fieldiana Zoology, 97, 1-18.

Patel, E.R. (2007) Logging of rare rosewood and palisandre (Dalbergia spp.) within Marojejy National Park, Madagascar. Madagascar Conservation \& Development, 2(1). doi:10.4314/mcd.v2i1.44124.

Appendix S2.2: Data on plot characteristics of 58 study plots with plot coordinates and environmental characteristics (available on OSF: https://doi.org/10.17605/OSF.IO/24Z6P )

Appendix S2.3: Data on tree derived variables such as stem density, basal area, mean canopy closure, mean LAI, species richness and percentage of endemic tree species of 58 study plots (available on OSF: https://doi.org/10.17605/OSF.IO/24Z6P )

Appendix S2.4: Specification of origin and endemism determination for each tree species

The taxonomy of the highly diverse Malagasy tree flora is a dynamic field of research and species identification is a challenging task, specifically for sterile individuals (Callmander et al., 2011). We identified 455 species to the most accurate taxonomic level possible. Of these 455 species, 52\% (237 species) could be classified to species level. 44\% (202 species) belonged to different species but could only be classified to genus level. To treat them as individual morphospecies, we named them in the format of genus sp1, genus sp2, and so forth. 3\% (13 species) belonged to different species but could only be classified to family level. To treat them as individual morphospecies, we named them in the format of 
family_genus no1, family_genus no2, and so forth. $1 \%$ (3 species) belonged to different species but could only be identified with local names. For all names, see Appendix S2.11.

Prior to analysis, we checked spelling validity of genus and species names using the $\mathrm{R}$ package taxize (Chamberlain \& Szöcs, 2013).

Based on information from the Tropicos Madagascar Catalogue (http://www.tropicos.org/Project/Madagascar; accessed January 2020), we classified all species occurring exclusively in the country of Madagascar as endemic and those species occurring naturally in the country of Madagascar but also outside the country as native. We further classified non-native species as introduced and if their origin was missing from the Tropicos Madagascar Catalogue, we classified these species as origin unknown (Appendix S2.11).

For those morphospecies that could only be identified to genus level, we checked whether their specific genus was classified as endemic or native to Madagascar in the Tropicos Madagascar Catalogue and listed them accordingly. Non-native genera-level morphospecies were classified as introduced and if we could not specify their origin, we classified these morphospecies as origin unknown (Appendix S2.11).

We acknowledge that identification ambiguities go along with uncertainties regarding the endemism levels and native versus non-native status of some species. To our knowledge, the Tropicos database is the most up to date source to retrieve information on tree species origins but reassignments go along with new taxonomic research (Callmander et al., 2011).

\section{References}

Callmander, M.W., Phillipson, P.B., Schatz, G.E., Andriambololonera, S., Rabarimanarivo, M., Rakotonirina, N. et al. (2011) The endemic and non-endemic vascular flora of Madagascar updated. Plant Ecology and Evolution, 144(2), 317-321. doi:10.5091/plecevo.2011.513.

Chamberlain, S.A. \& Szöcs, E. (2013) taxize: taxonomic search and retrieval in R. F1000Research, $2,191$. doi:10.12688/f1000research.2-191.v2. 
Appendix S2.5: Numeric test results comparing stem density [stems/ha] across land-use types as displayed with letters in Fig. 2.2a of the main manuscript, based on a Kruskal-Wallis one-way analysis of variance and Dunn's post hoc test. Bold adjusted p-value indicates statistical significance

\begin{tabular}{lccc}
\hline Pairs of land use types & Z & P.unadj & P.adj \\
\hline Forest fragment vs. Old-growth forest & -2.07894 & 0.038 & 0.150 \\
Forest fragment vs. Fallow-derived vanilla agroforest & 2.257199 & 0.024 & 0.120 \\
Old-growth forest vs. Fallow-derived vanilla agroforest & 4.614495 & 0.000 & $\mathbf{0 . 0 0 0}$ \\
Forest fragment vs. Forest-derived vanilla agroforest & 0.900433 & 0.368 & 0.368 \\
Old-growth forest vs. Forest-derived vanilla agroforest & 2.979373 & 0.003 & $\mathbf{0 . 0 2 0}$ \\
Fallow-derived vanilla agroforest vs. Forest-derived vanilla agroforest & -1.2362 & 0.216 & 0.433 \\
Forest fragment vs. Woody fallow & 3.509039 & 0.000 & $\mathbf{0 . 0 0 4}$ \\
Old-growth forest vs. Woody fallow & 5.587979 & 0.000 & $\mathbf{0 . 0 0 0}$ \\
Fallow-derived vanilla agroforest vs. Woody fallow & 1.721677 & 0.085 & 0.255 \\
Forest-derived vanilla agroforest vs. Woody fallow & 2.608606 & 0.009 & 0.055 \\
\hline
\end{tabular}

Appendix S2.6: Numeric test results comparing basal area $\left[\mathrm{m}^{2} / \mathrm{ha}\right]$ across land-use types as displayed with letters in Fig. 2.2b of the main manuscript, based on a Kruskal-Wallis one-way analysis of variance and Dunn's Post hoc test. Bold adjusted p-value indicates statistical significance

\begin{tabular}{lccc}
\hline Pairs of land use types & Z & P.unadj & P.adj \\
\hline Forest fragment vs. Old-growth forest & -2.15836 & 0.031 & 0.124 \\
Forest fragment vs. Fallow-derived vanilla agroforest & 2.265505 & 0.023 & 0.117 \\
Old-growth forest vs. Fallow-derived vanilla agroforest & 4.712852 & 0.000 & $\mathbf{0 . 0 0 0}$ \\
Forest fragment vs. Forest-derived vanilla agroforest & -0.01324 & 0.989 & 0.989 \\
Old-growth forest vs. Forest-derived vanilla agroforest & 2.145115 & 0.032 & 0.096 \\
Fallow-derived vanilla agroforest vs. Forest-derived vanilla agroforest & -2.28052 & 0.023 & 0.135 \\
Forest fragment vs. Woody fallow & 3.720848 & 0.000 & $\mathbf{0 . 0 0 1}$ \\
Old-growth forest vs. Woody fallow & 5.879205 & 0.000 & $\mathbf{0 . 0 0 0}$ \\
Fallow-derived vanilla agroforest vs. Woody fallow & 1.95354 & 0.051 & 0.102 \\
Forest-derived vanilla agroforest vs. Woody fallow & 3.73409 & 0.000 & $\mathbf{0 . 0 0 2}$ \\
\hline
\end{tabular}


Appendix S2.7: Numeric test results comparing mean canopy closure [\%] across land-use types as displayed with letters in Fig. 2.2c of the main manuscript, based on a Kruskal-Wallis one-way analysis of variance and Dunn's Post hoc test. Bold adjusted p-value indicates statistical significance

\begin{tabular}{lccc}
\hline Pairs of land use types & Z & P.unadj & P.adj \\
\hline Forest fragment vs. Old-growth forest & -1.93325 & 0.053 & 0.160 \\
Forest fragment vs. Fallow-derived vanilla agroforest & 3.071278 & 0.002 & $\mathbf{0 . 0 1 5}$ \\
Old-growth forest vs. Fallow-derived vanilla agroforest & 5.26338 & 0.000 & $\mathbf{0 . 0 0 0}$ \\
Forest fragment vs. Forest-derived vanilla agroforest & 0.754763 & 0.450 & 0.450 \\
Old-growth forest vs. Forest-derived vanilla agroforest & 2.688015 & 0.007 & $\mathbf{0 . 0 3 6}$ \\
Fallow-derived vanilla agroforest vs. Forest-derived vanilla agroforest & -2.21546 & 0.027 & 0.107 \\
Forest fragment vs. Woody fallow & 3.522226 & 0.000 & $\mathbf{0 . 0 0 3}$ \\
Old-growth forest vs. Woody fallow & 5.455478 & 0.000 & $\mathbf{0 . 0 0 0}$ \\
Fallow-derived vanilla agroforest vs. Woody fallow & 0.922551 & 0.356 & 0.712 \\
Forest-derived vanilla agroforest vs. Woody fallow & 2.767464 & 0.006 & $\mathbf{0 . 0 3 4}$ \\
\hline
\end{tabular}

Appendix S2.8: Numeric test results comparing mean Leaf Area Index $\left[\mathrm{m}^{2} / \mathrm{m}^{2}\right]$ across land-use types as displayed with letters in Fig. 2.2d of the main manuscript, based on one-way ANOVA and Tukey's HSD post hoc test. Bold adjusted p-value indicates statistical significance

\begin{tabular}{lllll}
\hline Pairs of land use types & diff & Iwr & upr & padj \\
\hline Forest fragment vs. Old-growth forest & -2.706 & -3.625 & -1.787 & $\mathbf{0 . 0 0 0}$ \\
Forest-derived vanilla agroforest vs. Old-growth forest & -3.624 & -4.543 & -2.705 & $\mathbf{0 . 0 0 0}$ \\
Fallow-derived vanilla agroforest vs. Old-growth forest & -3.739 & -4.550 & -2.929 & $\mathbf{0 . 0 0 0}$ \\
Woody fallow vs. Old-growth forest & -3.762 & -4.680 & -2.843 & $\mathbf{0 . 0 0 0}$ \\
Forest-derived vanilla agroforest vs. Forest fragment & -0.918 & -1.837 & 0.001 & 0.050 \\
Fallow-derived vanilla agroforest vs. Forest fragment & -1.033 & -1.844 & -0.223 & $\mathbf{0 . 0 0 6}$ \\
Woody fallow vs. Forest fragment & -1.056 & -1.974 & -0.137 & $\mathbf{0 . 0 1 7}$ \\
Fallow-derived vanilla agroforest vs. Forest-derived vanilla agroforest & -0.115 & -0.926 & 0.695 & 0.994 \\
Woody fallow vs. Forest-derived vanilla agroforest & -0.137 & -1.056 & 0.781 & 0.993 \\
Woody fallow vs. Fallow-derived vanilla agroforest & -0.022 & -0.832 & 0.788 & 1.000 \\
\hline
\end{tabular}

Appendix S2.9: Numeric test results comparing species richness per plot across land-use types as displayed with letters in Fig. 2.2e of the main manuscript, based on a Kruskal-Wallis one-way analysis of variance and Dunn's post hoc test. Bold adjusted p-value indicates statistical significance

\begin{tabular}{lccc}
\hline Pairs of land use types & Z & P.unadj & P.adj \\
\hline Forest fragment vs. Old-growth forest & -1.28664 & 0.198 & 0.595 \\
Forest fragment vs. Fallow-derived vanilla agroforest & 3.597145 & 0.000 & $\mathbf{0 . 0 0 2}$ \\
Old-growth forest vs. Fallow-derived vanilla agroforest & 5.056056 & 0.000 & $\mathbf{0 . 0 0 0}$
\end{tabular}


Forest fragment vs. Forest-derived vanilla agroforest

\begin{tabular}{lll}
0.928502 & 0.353 & 0.706 \\
2.215142 & 0.027 & 0.107 \\
-2.54432 & 0.011 & 0.055 \\
3.879814 & 0.000 & $\mathbf{0 . 0 0 1}$ \\
5.166453 & 0.000 & $\mathbf{0 . 0 0 0}$ \\
0.802151 & 0.422 & 0.422 \\
2.951311 & 0.003 & $\mathbf{0 . 0 1 9}$ \\
\hline
\end{tabular}

Appendix S2.10: Numeric test results comparing percentage of endemic species per plot across land-use types as displayed with letters in Fig. $2.2 f$ of the main manuscript, based on one-way ANOVA and Tukey's HSD post hoc test. Bold adjusted $p$-value indicates statistical significance

\begin{tabular}{lcccc}
\hline Pairs of land use types & diff & Iwr & upr & p adj \\
\hline Forest fragment vs. Old-growth forest & -8.660 & -29.981 & 12.661 & 0.781 \\
Forest-derived vanilla agroforest vs. Old-growth forest & -19.410 & -40.731 & 1.911 & 0.091 \\
Fallow-derived vanilla agroforest vs. Old-growth forest & -54.962 & -73.766 & -36.159 & $\mathbf{0 . 0 0 0}$ \\
Woody fallow vs. Old-growth forest & -45.010 & -66.331 & -23.689 & $\mathbf{0 . 0 0 0}$ \\
Forest-derived vanilla agroforest vs. Forest fragment & -10.750 & -32.071 & 10.571 & 0.615 \\
Fallow-derived vanilla agroforest vs. Forest fragment & -46.302 & -65.106 & -27.499 & $\mathbf{0 . 0 0 0}$ \\
Woody fallow vs. Forest fragment & -36.350 & -57.671 & -15.029 & $\mathbf{0 . 0 0 0}$ \\
Fallow-derived vanilla agroforest vs. Forest-derived vanilla agroforest & -35.552 & -54.356 & -16.749 & $\mathbf{0 . 0 0 0}$ \\
Woody fallow vs. Forest-derived vanilla agroforest & -25.600 & -46.921 & -4.279 & $\mathbf{0 . 0 1 1}$ \\
Woody fallow vs. Fallow-derived vanilla agroforest & 9.952 & -8.851 & 28.756 & 0.570 \\
\hline
\end{tabular}

Appendix S2.11: Data on 455 species and morphospecies, botanic families, geographic origin and occurrence per land-use type (available on OSF: https://doi.org/10.17605/OSF.IO/24Z6P )

Appendix S2.12: Hill numbers $q=0$ (species richness); $q=1$ (Shannon diversity) and $q=2$ (Simpson diversity) and sample coverage per land use type

\begin{tabular}{|c|c|c|c|c|c|}
\hline Land-use type & $\begin{array}{l}\text { Sample size } \\
\text { (Number of } \\
\text { individuals across } 10 \\
\text { plots per land-use } \\
\text { type (18 for fallow- } \\
\text { derived vanilla) }\end{array}$ & $\begin{array}{l}\text { Observed Hill } \\
\text { number for species } \\
\text { richness } \\
q=0\end{array}$ & $\begin{array}{l}\text { Observed Hill } \\
\text { number for } \\
\text { Shannon diversity } \\
q=1\end{array}$ & $\begin{array}{l}\text { Observed Hill } \\
\text { number for } \\
\text { Simpson diversity } \\
q=2\end{array}$ & Sample coverage \\
\hline Old-growth forest & 2078 & 258 & 110.637 & 64.787 & 0.9562 \\
\hline Forest fragment & 1213 & 230 & 102.531 & 52.815 & 0.9250 \\
\hline $\begin{array}{l}\text { Forest-derived vanilla } \\
\text { agroforest }\end{array}$ & 881 & 198 & 89.269 & 45.622 & 0.8911 \\
\hline $\begin{array}{l}\text { Fallow-derived vanilla } \\
\text { agroforest }\end{array}$ & 1010 & 79 & 33.268 & 22.180 & 0.9782 \\
\hline Woody fallow & 302 & 61 & 35.271 & 25.391 & 0.9107 \\
\hline
\end{tabular}


Appendix S2.13: Results of multivariate dispersion test (betadisp) based on a Bray-Curtis dissimilarity matrix and a pairwise permutation test (permutest, 999 permutations) using the betadisp and the permutest function in the vegan R-package

\begin{tabular}{|c|c|c|c|c|c|c|}
\hline & Df & Sums of squares & Mean Sq & $\mathrm{F}$ & $\begin{array}{l}\text { Nr. of per- } \\
\text { mutations }\end{array}$ & $p$-value \\
\hline Groups & 4 & 0.10516 & 0.02629 & 95.686 & 999 & 0.001 \\
\hline Residuals & 53 & 0.14562 & 0.002748 & & & \\
\hline
\end{tabular}

Pairwise comparisons:

(Observed $\mathrm{p}$-value below diagonal, permuted $\mathrm{p}$-value above diagonal)

\begin{tabular}{lccccc}
\hline & $\begin{array}{c}\text { Old-growth } \\
\text { forest }\end{array}$ & Forest fragment & Forest-derived vanilla & $\begin{array}{c}\text { Fallow-derived } \\
\text { vanilla }\end{array}$ & Woody fallow \\
Old-growth forest & & 0.0010 & 0.0010 & 0.0010 & 0.0010 \\
Forest fragment & 0.0011 & & 0.3600 & 0.3920 & 0.3010 \\
$\begin{array}{l}\text { Forest-derived vanilla } \\
\text { Fallow-derived }\end{array}$ & 0.0004 & 0.3836 & & 0.8800 & 0.9890 \\
vanilla & 0.0000 & 0.3984 & 0.8658 & & 0.8120 \\
Woody fallow & 0.0001 & 0.3173 & 0.9859 & 0.8394 & \\
\hline
\end{tabular}

Appendix S2.14: Results of the pairwise permutational multivariate analysis of variance (PERMANOVA, 999 permutations) with a Bonferroni-correction using the pairwise.adonis function in in the pairwiseAdonis package to test for differences in tree species composition between land-use types. Bold adjusted $p$-value indicates statistical significance

\begin{tabular}{lllllll}
\hline Pairs of land use types & Df & Sums of squares & F.Model & $R^{2}$ & p.value & p.adjusted \\
\hline Old-growth forest vs. Forest-derived vanilla & 1 & 0.948 & 27.650 .064 & 0.133157 & 0.001 & $\mathbf{0 . 0 1}$ \\
Old-growth forest vs. Forest fragment & 1 & 0.791 & 24.060 .989 & 0.117911 & 0.001 & $\mathbf{0 . 0 1}$ \\
Old-growth forest vs. Woody fallow & 1 & 1.629 & 47.566 .794 & 0.209023 & 0.001 & $\mathbf{0 . 0 1}$ \\
Old-growth forest vs. Fallow-derived vanilla & 1 & 2.184 & 62.626 .023 & 0.194113 & 0.001 & $\mathbf{0 . 0 1}$ \\
Forest-derived vanilla vs. Forest fragment & 1 & 0.305 & 0.7635895 & 0.040695 & 0.9 & 1 \\
Forest-derived vanilla vs. Woody fallow & 1 & 0.616 & 14.889 .155 & 0.076398 & 0.028 & 0.28 \\
Forest-derived vanilla vs. Fallow-derived vanilla & 1 & 1.009 & 25.355 .344 & 0.088855 & 0.001 & $\mathbf{0 . 0 1}$ \\
Forest fragment vs. Woody fallow & 1 & 0.875 & 21.902 .013 & 0.108478 & 0.001 & $\mathbf{0 . 0 1}$ \\
Forest fragment vs. Fallow-derived vanilla & 1 & 1.486 & 38.277 .366 & 0.128328 & 0.001 & $\mathbf{0 . 0 1}$ \\
Woody fallow vs. Fallow-derived vanilla & 1 & 0.576 & 14.491 .652 & 0.052795 & 0.058 & 0.58 \\
\hline
\end{tabular}




\section{SUPPLEMENTARY INFORMATION FOR CHAPTER 3:}

\section{CASE STUDY: TREE COMPOSITION IN THE MOSAIC LANDSCAPE}

Appendix S3.1: Further remarks on tree species identification

If morphospecies differed from all other species and could be classified to genus level, but not species level, we treated them as individual species and named them in the format of known_genus sp1, known_genus sp2, and so forth. If morphospecies differed from all other species and could be classified to family level, but not genus level, we treated them as individual species, and named them in the format of known_family genus.no1, known_family genus.no2, and so forth. Prior to analysis, we checked spelling validity of family, genus and species names using the R-package 'taxize' (Chamberlain et al., 2020). In spite of all efforts, the taxonomy of the highly diverse Malagasy tree flora is a dynamic field of research and we acknowledge that our tree diversity assessment might underestimate the actual tree species diversity, especially for rare species, due to taxonomic uncertainties (Callmander et al., 2011).

\section{References}

Callmander, M. W., Phillipson, P. B., Schatz, G. E., Andriambololonera, S., Rabarimanarivo, M., Rakotonirina, N., Raharimampionona, J., Chatelain, C., Gautier, L., \& Lowry, P. P. (2011). The endemic and non-endemic vascular flora of Madagascar updated. Plant Ecology and Evolution, 144(2), 121-125.

Chamberlain, S., Szoecs, E., Foster, Z., Arendsee, Z., Boettiger, C., Ram, K., Bartomeus, I., Baumgartner, J., O’Donnell, J., Oksanen, J., Tzovaras, B. G., Marchand, P., Tran, V., Salmon, M., Li, G., \& Grenié, M. (2020). taxize: Taxonomic information from around the web (R package version 0.9.98). https://github.com/ropensci/taxize 
Appendix S3.2: Summary statistics for incidence-based multiple site dissimilarity and abundance-based multiple site dissimilarity within land-use types, derived from five randomly chosen plots per land-use type and 500 replications

\begin{tabular}{|c|c|c|c|c|c|c|c|}
\hline & & & $\begin{array}{l}\text { Old- } \\
\text { growth } \\
\text { forest }\end{array}$ & $\begin{array}{c}\text { Forest } \\
\text { fragment }\end{array}$ & $\begin{array}{c}\text { Forest- } \\
\text { derived } \\
\text { agroforest }\end{array}$ & $\begin{array}{c}\text { Fallow- } \\
\text { derived } \\
\text { agroforest }\end{array}$ & $\begin{array}{l}\text { Woody } \\
\text { fallow }\end{array}$ \\
\hline \multirow{11}{*}{ 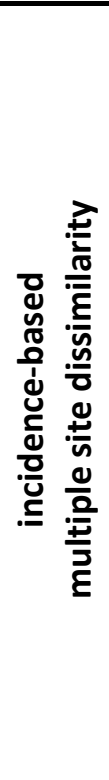 } & \multirow{3}{*}{$\begin{array}{l}\text { Overall } \\
\text { dissimilarity } \\
\text { Jaccard }\end{array}$} & mean & 0.851 & 0.922 & 0.942 & 0.901 & 0.928 \\
\hline & & $s d$ & 0.013 & 0.014 & 0.010 & 0.021 & 0.014 \\
\hline & & median & 0.852 & 0.923 & 0.943 & 0.904 & 0.928 \\
\hline & \multirow{3}{*}{$\begin{array}{l}\text { Turnover } \\
\text { component } \\
\text { Jaccard }\end{array}$} & mean & 0.830 & 0.888 & 0.911 & 0.863 & 0.881 \\
\hline & & sd & 0.013 & 0.027 & 0.015 & 0.031 & 0.025 \\
\hline & & median & 0.831 & 0.886 & 0.912 & 0.865 & 0.883 \\
\hline & \multirow{3}{*}{$\begin{array}{l}\text { Nestedness } \\
\text { component } \\
\text { Jaccard }\end{array}$} & mean & 0.022 & 0.034 & 0.031 & 0.038 & 0.046 \\
\hline & & sd & 0.006 & 0.015 & 0.008 & 0.017 & 0.020 \\
\hline & & median & 0.021 & 0.034 & 0.031 & 0.035 & 0.046 \\
\hline & Beta-ratio & mean & 0.025 & 0.037 & 0.033 & 0.042 & 0.050 \\
\hline & Jaccard & & & & & & \\
\hline \multirow{11}{*}{ 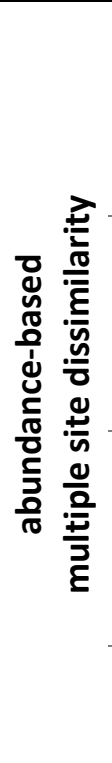 } & \multirow{3}{*}{$\begin{array}{l}\text { Overall } \\
\text { dissimilarity } \\
\text { Bray-Curtis }\end{array}$} & mean & 0.807 & 0.903 & 0.923 & 0.898 & 0.924 \\
\hline & & sd & 0.021 & 0.018 & 0.019 & 0.029 & 0.022 \\
\hline & & median & 0.808 & 0.902 & 0.924 & 0.902 & 0.924 \\
\hline & \multirow{3}{*}{$\begin{array}{l}\text { Turnover } \\
\text { component } \\
\text { Bray-Curtis }\end{array}$} & mean & 0.789 & 0.872 & 0.909 & 0.841 & 0.876 \\
\hline & & sd & 0.023 & 0.026 & 0.024 & 0.044 & 0.038 \\
\hline & & median & 0.788 & 0.872 & 0.912 & 0.846 & 0.881 \\
\hline & \multirow{3}{*}{$\begin{array}{l}\text { Nestedness } \\
\text { component } \\
\text { Bray-Curtis }\end{array}$} & mean & 0.019 & 0.030 & 0.013 & 0.057 & 0.048 \\
\hline & & sd & 0.006 & 0.009 & 0.006 & 0.022 & 0.020 \\
\hline & & median & 0.019 & 0.031 & 0.012 & 0.055 & 0.044 \\
\hline & Beta-ratio & mean & 0.023 & 0.034 & 0.015 & 0.064 & 0.052 \\
\hline & Bray-Curtis & & & & & & \\
\hline
\end{tabular}


Appendix S3.3: Differences in beta-diversity metrics within land-use types based on Kruskal Wallis test and pairwise comparison with Dunn's posthoc test. Land-use types are abbreviated: OGF = Old-growth forest. FF $=$ Forest fragment. VFST $=$ Forest-derived agroforest. VFLW $=$ Fallow-derived agroforest. $\mathrm{WF}=$ Woody fallow. Asterisks indicate significant differences

\begin{tabular}{|l|l|l|l|l|l|l|l|}
\hline & Comparison & Z & P.unadj & P.adj & test & category & sig \\
\hline 1 & FF - OGF & 25.13 & 0 & 0 & K-W_Dunn & betaJAC_all & $* * *$ \\
\hline 2 & FF - VFLW & 10.56 & 0 & 0 & K-W_Dunn & betaJAC_all & $* * *$ \\
\hline 3 & OGF - VFLW & -14.58 & 0 & 0 & K-W_Dunn & betaJAC_all & $* * *$ \\
\hline 4 & FF - VFST & -14.37 & 0 & 0 & K-W_Dunn & betaJAC_all & $* * *$ \\
\hline 5 & OGF - VFST & -39.51 & 0 & 0 & K-W_Dunn & betaJAC_all & $* * *$ \\
\hline 6 & VFLW - VFST & -24.93 & 0 & 0 & K-W_Dunn & betaJAC_all & $* * *$ \\
\hline 7 & FF - WF & -3.9 & 0 & 0 & K-W_Dunn & betaJAC_all & $* * *$ \\
\hline 8 & OGF - WF & -29.03 & 0 & 0 & K-W_Dunn & betaJAC_all & $* * *$ \\
\hline 9 & VFLW - WF & -14.46 & 0 & 0 & K-W_Dunn & betaJAC_all & $* * *$ \\
\hline 10 & VFST - WF & 10.47 & 0 & 0 & K-W_Dunn & betaJAC_all & $* * *$ \\
\hline 11 & FF - OGF & 25.02 & 0 & 0 & K-W_Dunn & betaJAC_turn & $* * *$ \\
\hline 12 & FF - VFLW & 10.83 & 0 & 0 & K-W_Dunn & betaJAC_turn & $* * *$ \\
\hline 13 & OGF - VFLW & -14.19 & 0 & 0 & K-W_Dunn & betaJAC_turn & $* * *$ \\
\hline 14 & FF - VFST & -11.14 & 0 & 0 & K-W_Dunn & betaJAC_turn & $* * *$ \\
\hline 15 & OGF - VFST & -36.16 & 0 & 0 & K-W_Dunn & betaJAC_turn & $* * *$ \\
\hline 16 & VFLW - VFST & -21.97 & 0 & 0 & K-W_Dunn & betaJAC_turn & $* * *$ \\
\hline 17 & FF - WF & 2.99 & 0 & 0 & K-W_Dunn & betaJAC_turn & $* *$ \\
\hline 18 & OGF - WF & -22.04 & 0 & 0 & K-W_Dunn & betaJAC_turn & $* * *$ \\
\hline 19 & VFLW - WF & -7.85 & 0 & 0 & K-W_Dunn & betaJAC_turn & $* * *$ \\
\hline 20 & VFST - WF & 14.13 & 0 & 0 & K-W_Dunn & betaJAC_turn & $* * *$ \\
\hline 21 & FF - OGF & 14.6 & 0 & 0 & K-W_Dunn & betaJAC_nest & $* * *$ \\
\hline 22 & FF - VFLW & -3.04 & 0 & 0 & K-W_Dunn & betaJAC_nest & $* *$ \\
\hline 23 & OGF - VFLW & -17.64 & 0 & 0 & K-W_Dunn & betaJAC_nest & $* * *$ \\
\hline 24 & FF - VFST & 0.99 & 0.32 & 0.32 & K-W_Dunn & betaJAC_nest & \\
\hline 25 & OGF - VFST & -13.61 & 0 & 0 & K-W_Dunn & betaJAC_nest & $* * *$ \\
\hline
\end{tabular}




\begin{tabular}{|c|c|c|c|c|c|c|c|}
\hline & Comparison & $\mathbf{Z}$ & P.unadj & P.adj & test & category & sig \\
\hline 26 & VFLW - VFST & 4.03 & 0 & 0 & K-W_Dunn & betaJAC_nest & $* * *$ \\
\hline 27 & $F F-W F$ & -8.97 & 0 & 0 & K-W_Dunn & betaJAC_nest & $* * *$ \\
\hline 28 & OGF - WF & -23.57 & 0 & 0 & K-W_Dunn & betaJAC_nest & $* * *$ \\
\hline 29 & VFLW - WF & -5.93 & 0 & 0 & K-W_Dunn & betaJAC_nest & $* * *$ \\
\hline 30 & VFST - WF & -9.96 & 0 & 0 & K-W_Dunn & betaJAC_nest & $* * *$ \\
\hline 31 & FF - OGF & 21.45 & 0 & 0 & K-W_Dunn & betaBRAY_all & $* * *$ \\
\hline 32 & FF - VFLW & 0.25 & 0.8 & 1 & K-W_Dunn & betaBRAY_all & \\
\hline 33 & OGF - VFLW & -21.2 & 0 & 0 & K-W_Dunn & betaBRAY_all & $* * *$ \\
\hline 34 & FF - VFST & -11.67 & 0 & 0 & K-W_Dunn & betaBRAY_all & $* * *$ \\
\hline 35 & OGF - VFST & -33.12 & 0 & 0 & K-W_Dunn & betaBRAY_all & $* * *$ \\
\hline 36 & VFLW - VFST & -11.91 & 0 & 0 & K-W_Dunn & betaBRAY_all & $* * *$ \\
\hline 37 & FF - WF & -11.73 & 0 & 0 & K-W_Dunn & betaBRAY_all & $* * *$ \\
\hline 38 & OGF - WF & -33.18 & 0 & 0 & K-W_Dunn & betaBRAY_all & $* * *$ \\
\hline 39 & VFLW - WF & -11.97 & 0 & 0 & K-W_Dunn & betaBRAY_all & $* * *$ \\
\hline 40 & VFST - WF & -0.06 & 0.95 & 0.95 & K-W_Dunn & betaBRAY_all & \\
\hline 41 & FF - OGF & 23.3 & 0 & 0 & K-W_Dunn & betaBRAY_turn & $* * *$ \\
\hline 42 & FF - VFLW & 8.98 & 0 & 0 & K-W_Dunn & betaBRAY_turn & $* * *$ \\
\hline 43 & OGF - VFLW & -14.31 & 0 & 0 & K-W_Dunn & betaBRAY_turn & $* * *$ \\
\hline 44 & FF - VFST & -13.48 & 0 & 0 & K-W_Dunn & betaBRAY_turn & $* * *$ \\
\hline 45 & OGF - VFST & -36.77 & 0 & 0 & K-W_Dunn & betaBRAY_turn & $* * *$ \\
\hline 46 & VFLW - VFST & -22.46 & 0 & 0 & K-W_Dunn & betaBRAY_turn & $* * *$ \\
\hline 47 & $F F-W F$ & -1.91 & 0.06 & 0.06 & K-W_Dunn & betaBRAY_turn & \\
\hline 48 & OGF - WF & -25.2 & 0 & 0 & K-W_Dunn & betaBRAY_turn & $* * *$ \\
\hline 49 & VFLW - WF & -10.89 & 0 & 0 & K-W_Dunn & betaBRAY_turn & $* * *$ \\
\hline 50 & VFST - WF & 11.57 & 0 & 0 & K-W_Dunn & betaBRAY_turn & $* * *$ \\
\hline 51 & $\mathrm{FF}-\mathrm{OGF}$ & 13.09 & 0 & 0 & K-W_Dunn & betaBRAY_nest & $* * *$ \\
\hline 52 & FF - VFLW & -14.42 & 0 & 0 & K-W_Dunn & betaBRAY_nest & $* * *$ \\
\hline 53 & OGF - VFLW & -27.51 & 0 & 0 & K-W_Dunn & betaBRAY_nest & $* * *$ \\
\hline 54 & FF - VFST & 19.57 & 0 & 0 & K-W_Dunn & betaBRAY_nest & $* * *$ \\
\hline 55 & OGF - VFST & 6.48 & 0 & 0 & K-W_Dunn & betaBRAY_nest & $* * *$ \\
\hline
\end{tabular}




\begin{tabular}{|l|l|l|l|l|l|l|l|}
\hline & Comparison & Z & P.unadj & P.adj & test & category & sig \\
\hline 56 & VFLW - VFST & 33.99 & 0 & 0 & K-W_Dunn & betaBRAY_nest & $* * *$ \\
\hline 57 & FF - WF & -9.98 & 0 & 0 & K-W_Dunn & betaBRAY_nest & $* * *$ \\
\hline 58 & OGF - WF & -23.07 & 0 & 0 & K-W_Dunn & betaBRAY_nest & $* * *$ \\
\hline 59 & VFLW - WF & 4.44 & 0 & 0 & K-W_Dunn & betaBRAY_nest & $* * *$ \\
\hline 60 & VFST - WF & -29.55 & 0 & 0 & K-W_Dunn & betaBRAY_nest & $* * *$ \\
\hline
\end{tabular}

Appendix S3.4: Summary statistics for null model z-scores

\begin{tabular}{|l|l|l|l|l|l|l|}
\hline Land-use type & $\begin{array}{l}\text { Mean_null } \\
\text { JAC }\end{array}$ & $\begin{array}{l}\text { Sd_null. } \\
\text { JAC }\end{array}$ & $\begin{array}{l}\text { Median_nul } \\
\text { I.JAC }\end{array}$ & $\begin{array}{l}\text { Mean_null. } \\
\text { BRAY }\end{array}$ & $\begin{array}{l}\text { Sd_null.B } \\
\text { RAY }\end{array}$ & $\begin{array}{l}\text { Median_null. } \\
\text { BRAY }\end{array}$ \\
\hline Old-growth forest & 0 & 1.8 & 0 & 0.7 & 1.7 & 0.6 \\
\hline Forest fragment & -1.2 & 1.7 & -1 & 0.7 & 1.3 & 0.8 \\
\hline $\begin{array}{l}\text { Forest-derived } \\
\text { agroforest }\end{array}$ & -0.1 & 1.6 & 0 & 0.7 & 1.3 & 0.7 \\
\hline $\begin{array}{l}\text { Fallow-derived } \\
\text { agroforest }\end{array}$ & 0 & 1.1 & 0 & 0.3 & 1.1 & 0.4 \\
\hline Woody fallow & -0.1 & 1.1 & 0 & 0 & & 1.1 \\
\hline
\end{tabular}

Appendix S3.5: Results of ANOVA between the mixed model (_M) and the respective reduced model (_R) in which the effect of the land-use types was dropped. Asterisks indicate significant differences

\begin{tabular}{|l|l|l|l|l|l|l|l|}
\hline AIC & BIC & logLik & deviance & Chisq & Df & $\operatorname{Pr}(>$ Chisq) & category \\
\hline-201.8 & -195.6 & 103.9 & -207.8 & NA & NA & NA & overall_jacc_R \\
\hline-212.6 & -198.2 & 113.3 & -226.6 & 18.8 & 4 & $0.0009 * * *$ & overall_jacc_M \\
\hline-158.4 & -152.2 & 82.2 & -164.4 & NA & NA & NA & turnover_jacc_R \\
\hline-163.5 & -149.1 & 88.7 & -177.5 & 13.1 & 4 & $0.0106^{*}$ & turnover_jacc_M \\
\hline-182.8 & -176.6 & 94.4 & -188.8 & NA & NA & NA & nestedness_jacc_R \\
\hline-182.3 & -167.9 & 98.2 & -196.3 & 7.5 & 4 & 0.1 & nestedness_jacc_M \\
\hline-175.1 & -168.9 & 90.5 & -181.1 & NA & NA & NA & overall_bray_R \\
\hline-185.8 & -171.4 & 99.9 & -199.8 & 18.8 & 4 & $0.0009 * * *$ & overall_bray_M \\
\hline-147.8 & -141.6 & 76.9 & -153.8 & NA & NA & NA & turnover_bray_R \\
\hline
\end{tabular}




\begin{tabular}{|l|l|l|l|l|l|l|l|}
\hline-154.4 & -140 & 84.2 & -168.4 & 14.7 & 4 & $0.0054^{* *}$ & turnover_bray_M \\
\hline-175.6 & -169.4 & 90.8 & -181.6 & NA & NA & NA & nestedness_bray_R \\
\hline-183.9 & -169.5 & 98.9 & -197.9 & 16.3 & 4 & $0.0027^{* *}$ & nestedness_bray_M \\
\hline
\end{tabular}

Appendix S3.6: Mixed-effect model fitted values

\begin{tabular}{|c|c|c|c|c|c|}
\hline Land-use type & $\begin{array}{l}\text { Land-use } \\
\text { type_fit }\end{array}$ & $\begin{array}{l}\text { Land-use } \\
\text { type_se }\end{array}$ & $\begin{array}{l}\text { Land-use } \\
\text { type_lower }\end{array}$ & $\begin{array}{l}\text { Land-use } \\
\text { type_upper }\end{array}$ & category \\
\hline $\begin{array}{l}\text { Old-growth } \\
\text { forest }\end{array}$ & 0.521 & 0.017 & 0.487 & 0.555 & overall_jacc \\
\hline $\begin{array}{l}\text { Forest } \\
\text { fragment }\end{array}$ & 0.602 & 0.012 & 0.578 & 0.625 & overall_jacc \\
\hline $\begin{array}{l}\text { Forest-derived } \\
\text { agroforestt }\end{array}$ & 0.628 & 0.012 & 0.604 & 0.652 & overall_jacc \\
\hline $\begin{array}{l}\text { Fallow-derived } \\
\text { agroforest }\end{array}$ & 0.594 & 0.01 & 0.574 & 0.613 & overall_jacc \\
\hline Woody fallow & 0.606 & 0.012 & 0.583 & 0.629 & overall_jacc \\
\hline $\begin{array}{l}\text { Old-growth } \\
\text { forest }\end{array}$ & 0.501 & 0.021 & 0.458 & 0.544 & turnover jacc \\
\hline $\begin{array}{l}\text { Forest } \\
\text { fragment }\end{array}$ & 0.572 & 0.017 & 0.538 & 0.605 & turnover jacc \\
\hline $\begin{array}{l}\text { Forest-derived } \\
\text { agroforestt }\end{array}$ & 0.605 & 0.017 & 0.57 & 0.64 & turnover jacc \\
\hline $\begin{array}{l}\text { Fallow-derived } \\
\text { agroforest }\end{array}$ & 0.551 & 0.014 & 0.524 & 0.578 & turnover jacc \\
\hline Woody fallow & 0.567 & 0.017 & 0.533 & 0.601 & turnover_jacc \\
\hline $\begin{array}{l}\text { Old-growth } \\
\text { forest }\end{array}$ & 0.023 & 0.018 & -0.014 & 0.059 & nestedness_jacc \\
\hline $\begin{array}{l}\text { Forest } \\
\text { fragment }\end{array}$ & 0.032 & 0.014 & 0.003 & 0.061 & nestedness_jacc \\
\hline $\begin{array}{l}\text { Forest-derived } \\
\text { agroforestt }\end{array}$ & 0.021 & 0.015 & -0.009 & 0.051 & nestedness_jacc \\
\hline
\end{tabular}




\begin{tabular}{|c|c|c|c|c|c|}
\hline Land-use type & $\begin{array}{l}\text { Land-use } \\
\text { type_fit }\end{array}$ & $\begin{array}{l}\text { Land-use } \\
\text { type_se }\end{array}$ & $\begin{array}{l}\text { Land-use } \\
\text { type_lower }\end{array}$ & $\begin{array}{l}\text { Land-use } \\
\text { type_upper }\end{array}$ & category \\
\hline $\begin{array}{l}\text { Fallow-derived } \\
\text { agroforest }\end{array}$ & 0.058 & 0.012 & 0.034 & 0.081 & nestedness_jacc \\
\hline Woody fallow & 0.061 & 0.014 & 0.032 & 0.09 & nestedness_jacc \\
\hline $\begin{array}{l}\text { Old-growth } \\
\text { forest }\end{array}$ & 0.492 & 0.017 & 0.458 & 0.526 & overall_bray \\
\hline $\begin{array}{l}\text { Forest } \\
\text { fragment }\end{array}$ & 0.588 & 0.014 & 0.56 & 0.616 & overall_bray \\
\hline $\begin{array}{l}\text { Forest-derived } \\
\text { agroforestt }\end{array}$ & 0.613 & 0.014 & 0.584 & 0.641 & overall_bray \\
\hline $\begin{array}{l}\text { Fallow-derived } \\
\text { agroforest }\end{array}$ & 0.602 & 0.011 & 0.58 & 0.625 & overall_bray \\
\hline Woody fallow & 0.609 & 0.014 & 0.581 & 0.637 & overall_bray \\
\hline $\begin{array}{l}\text { Old-growth } \\
\text { forest }\end{array}$ & 0.476 & 0.021 & 0.433 & 0.519 & turnover_bray \\
\hline $\begin{array}{l}\text { Forest } \\
\text { fragment }\end{array}$ & 0.561 & 0.018 & 0.524 & 0.597 & turnover_bray \\
\hline $\begin{array}{l}\text { Forest-derived } \\
\text { agroforestt }\end{array}$ & 0.601 & 0.019 & 0.563 & 0.638 & turnover_bray \\
\hline $\begin{array}{l}\text { Fallow-derived } \\
\text { agroforest }\end{array}$ & 0.554 & 0.014 & 0.526 & 0.583 & turnover_bray \\
\hline Woody fallow & 0.563 & 0.018 & 0.527 & 0.6 & turnover_bray \\
\hline $\begin{array}{l}\text { Old-growth } \\
\text { forest }\end{array}$ & 0.018 & 0.014 & -0.01 & 0.046 & nestedness_bray \\
\hline $\begin{array}{l}\text { Forest } \\
\text { fragment }\end{array}$ & 0.034 & 0.014 & 0.006 & 0.062 & nestedness_bray \\
\hline $\begin{array}{l}\text { Forest-derived } \\
\text { agroforestt }\end{array}$ & 0.013 & 0.014 & -0.015 & 0.041 & nestedness_bray \\
\hline $\begin{array}{l}\text { Fallow-derived } \\
\text { agroforest }\end{array}$ & 0.071 & 0.01 & 0.051 & 0.092 & nestedness_bray \\
\hline
\end{tabular}




\begin{tabular}{|l|l|l|l|l|l|}
\hline Land-use type & $\begin{array}{l}\text { Land-use } \\
\text { type_fit }\end{array}$ & $\begin{array}{l}\text { Land-use } \\
\text { type_se }\end{array}$ & $\begin{array}{l}\text { Land-use } \\
\text { type_lower }\end{array}$ & $\begin{array}{l}\text { Land-use } \\
\text { type_upper }\end{array}$ & category \\
\hline Woody fallow & 0.067 & 0.014 & 0.04 & 0.095 & nestedness_bray \\
\hline
\end{tabular}

Appendix S3.7: Pairwise comparison of land-use types effects on beta-diversity metrics within each mixed model. Land-use types are abbreviated: OGF $=$ Old-growth forest. FF $=$ Forest fragment. VFST $=$ Forestderived agroforest. VFLW $=$ Fallow-derived agroforest. WF $=$ Woody fallow. Asterisks indicate significant differences

\begin{tabular}{|c|c|c|c|c|c|c|c|}
\hline contrast & estimate & SE & df & t.ratio & p.value & sig & category \\
\hline OGF - FF & -0.081 & 0.023 & 20.557 & -3.578 & 0.014 & $*$ & overall_jacc \\
\hline $\begin{array}{l}\text { OGF - } \\
\text { VFST }\end{array}$ & -0.107 & 0.023 & 20.898 & -4.687 & 0.001 & $* *$ & overall_jacc \\
\hline $\begin{array}{l}\text { OGF - } \\
\text { VFLW }\end{array}$ & -0.073 & 0.022 & 17.055 & -3.358 & 0.027 & $*$ & overall_jacc \\
\hline OGF - WF & -0.085 & 0.023 & 20.557 & -3.788 & 0.009 & $* *$ & overall_jacc \\
\hline FF - VFST & -0.027 & 0.015 & 52.417 & -1.816 & 0.376 & & overall_jacc \\
\hline FF - VFLW & 0.008 & 0.013 & 50.738 & 0.616 & 0.972 & & overall_jacc \\
\hline FF - WF & -0.005 & 0.014 & 48.989 & -0.335 & 0.997 & & overall_jacc \\
\hline $\begin{array}{l}\text { VFST - } \\
\text { VFLW }\end{array}$ & 0.035 & 0.014 & 58.166 & 2.456 & 0.115 & & overall_jacc \\
\hline VFST - WF & 0.022 & 0.015 & 52.417 & 1.494 & 0.571 & & overall_jacc \\
\hline $\begin{array}{l}\text { VFLW - } \\
\text { WF }\end{array}$ & -0.013 & 0.013 & 50.738 & -0.989 & 0.859 & & overall_jacc \\
\hline OGF - FF & -0.07 & 0.03 & 24.798 & -2.377 & 0.155 & & turnover_jacc \\
\hline $\begin{array}{l}\text { OGF - } \\
\text { VFST }\end{array}$ & -0.104 & 0.03 & 23.975 & -3.449 & 0.016 & $*$ & turnover_jacc \\
\hline $\begin{array}{l}\text { OGF - } \\
\text { VFLW }\end{array}$ & -0.05 & 0.028 & 18.418 & -1.796 & 0.405 & & turnover_jacc \\
\hline OGF - WF & -0.066 & 0.03 & 24.798 & -2.214 & 0.207 & & turnover_jacc \\
\hline FF - VFST & -0.034 & 0.023 & 53.997 & -1.442 & 0.604 & & turnover_jacc \\
\hline FF - VFLW & 0.02 & 0.02 & 51.469 & 1.001 & 0.854 & & turnover_jacc \\
\hline
\end{tabular}




\begin{tabular}{|c|c|c|c|c|c|c|c|}
\hline contrast & estimate & SE & df & t.ratio & p.value & sig & category \\
\hline$F F-W F$ & 0.005 & 0.023 & 48.891 & 0.213 & 1 & & turnover_jacc \\
\hline $\begin{array}{l}\text { VFST - } \\
\text { VFLW }\end{array}$ & 0.054 & 0.022 & 61.767 & 2.443 & 0.118 & & turnover_jacc \\
\hline VFST - WF & 0.039 & 0.023 & 53.997 & 1.648 & 0.474 & & turnover_jacc \\
\hline $\begin{array}{l}\text { VFLW - } \\
\text { WF }\end{array}$ & -0.016 & 0.02 & 51.469 & -0.764 & 0.94 & & turnover_jacc \\
\hline OGF - FF & -0.009 & 0.025 & 24.636 & -0.375 & 0.996 & & nestedness_jacc \\
\hline $\begin{array}{l}\text { OGF - } \\
\text { VFST }\end{array}$ & 0.002 & 0.026 & 23.87 & 0.067 & 1 & & nestedness_jacc \\
\hline $\begin{array}{l}\text { OGF - } \\
\text { VFLW }\end{array}$ & -0.035 & 0.024 & 18.366 & -1.477 & 0.589 & & nestedness_jacc \\
\hline OGF - WF & -0.038 & 0.025 & 24.636 & -1.516 & 0.562 & & nestedness_jacc \\
\hline FF - VFST & 0.011 & 0.02 & 53.953 & 0.562 & 0.98 & & nestedness_jacc \\
\hline FF - VFLW & -0.026 & 0.017 & 51.452 & -1.485 & 0.577 & & nestedness_jacc \\
\hline$F F-W F$ & -0.029 & 0.019 & 48.9 & -1.497 & 0.569 & & nestedness_jacc \\
\hline $\begin{array}{l}\text { VFST - } \\
\text { VFLW }\end{array}$ & -0.037 & 0.019 & 61.677 & -1.954 & 0.301 & & nestedness_jacc \\
\hline VFST - WF & -0.04 & 0.02 & 53.953 & -2.007 & 0.276 & & nestedness_jacc \\
\hline $\begin{array}{l}\text { VFLW - } \\
\text { WF }\end{array}$ & -0.003 & 0.017 & 51.452 & -0.184 & 1 & & nestedness_jacc \\
\hline OGF - FF & -0.096 & 0.024 & 25.752 & -4.005 & 0.004 & $* *$ & overall_bray \\
\hline $\begin{array}{l}\text { OGF - } \\
\text { VFST }\end{array}$ & -0.121 & 0.024 & 24.594 & -4.933 & 0 & $* * *$ & overall_bray \\
\hline $\begin{array}{l}\text { OGF - } \\
\text { VFLW }\end{array}$ & -0.111 & 0.022 & 18.753 & -4.922 & 0.001 & $* * *$ & overall_bray \\
\hline OGF - WF & -0.117 & 0.024 & 25.752 & -4.876 & 0 & $* * *$ & overall_bray \\
\hline FF - VFST & -0.025 & 0.019 & 54.198 & -1.27 & 0.71 & & overall_bray \\
\hline FF - VFLW & -0.015 & 0.017 & 51.527 & -0.863 & 0.909 & & overall_bray \\
\hline $\mathrm{FF}-\mathrm{WF}$ & -0.021 & 0.019 & 48.814 & -1.107 & 0.802 & & overall_bray \\
\hline
\end{tabular}




\begin{tabular}{|c|c|c|c|c|c|c|c|}
\hline contrast & estimate & SE & df & t.ratio & p.value & sig & category \\
\hline $\begin{array}{l}\text { VFST - } \\
\text { VFLW }\end{array}$ & 0.01 & 0.018 & 62.205 & 0.553 & 0.981 & & overall_bray \\
\hline VFST - WF & 0.004 & 0.019 & 54.198 & 0.2 & 1 & & overall_bray \\
\hline $\begin{array}{l}\text { VFLW - } \\
\text { WF }\end{array}$ & -0.006 & 0.017 & 51.527 & -0.371 & 0.996 & & overall_bray \\
\hline OGF - FF & -0.085 & 0.03 & 27.166 & -2.779 & 0.068 & . & turnover_bray \\
\hline $\begin{array}{l}\text { OGF - } \\
\text { VFST }\end{array}$ & -0.125 & 0.031 & 25.338 & -4.008 & 0.004 & $* *$ & turnover_bray \\
\hline $\begin{array}{l}\text { OGF - } \\
\text { VFLW }\end{array}$ & -0.078 & 0.028 & 19.098 & -2.765 & 0.081 & . & turnover_bray \\
\hline OGF - WF & -0.087 & 0.03 & 27.166 & -2.873 & 0.055 & . & turnover_bray \\
\hline FF - VFST & -0.04 & 0.026 & 54.69 & -1.551 & 0.534 & & turnover_bray \\
\hline FF - VFLW & 0.006 & 0.022 & 51.772 & 0.28 & 0.999 & & turnover_bray \\
\hline$F F-W F$ & -0.003 & 0.025 & 48.825 & -0.114 & 1 & & turnover_bray \\
\hline $\begin{array}{l}\text { VFST - } \\
\text { VFLW }\end{array}$ & 0.046 & 0.024 & 62.905 & 1.91 & 0.323 & & turnover_bray \\
\hline VFST - WF & 0.037 & 0.026 & 54.69 & 1.441 & 0.604 & & turnover_bray \\
\hline $\begin{array}{l}\text { VFLW - } \\
\text { WF }\end{array}$ & -0.009 & 0.022 & 51.772 & -0.407 & 0.994 & & turnover_bray \\
\hline OGF - FF & -0.016 & 0.021 & 27.437 & -0.781 & 0.934 & & nestedness_bray \\
\hline $\begin{array}{l}\text { OGF - } \\
\text { VFST }\end{array}$ & 0.004 & 0.021 & 22.217 & 0.211 & 1 & & nestedness_bray \\
\hline $\begin{array}{l}\text { OGF - } \\
\text { VFLW }\end{array}$ & -0.054 & 0.018 & 16.126 & -2.939 & 0.063 & . & nestedness_bray \\
\hline OGF - WF & -0.05 & 0.021 & 27.437 & -2.415 & 0.141 & & nestedness_bray \\
\hline FF - VFST & 0.02 & 0.021 & 59.385 & 0.979 & 0.863 & & nestedness_bray \\
\hline FF - VFLW & -0.038 & 0.018 & 55.617 & -2.061 & 0.252 & & nestedness_bray \\
\hline$F F-W F$ & -0.034 & 0.021 & 51.627 & -1.634 & 0.483 & & nestedness_bray \\
\hline $\begin{array}{l}\text { VFST - } \\
\text { VFLW }\end{array}$ & -0.058 & 0.019 & 60.735 & -3.05 & 0.027 & $*$ & nestedness_bray \\
\hline
\end{tabular}




\begin{tabular}{|l|l|l|l|l|l|l|l|}
\hline contrast & estimate & SE & df & t.ratio & p.value & sig & category \\
\hline VFST - WF & -0.054 & 0.021 & 59.385 & -2.587 & 0.086 &. & nestedness_bray \\
\hline $\begin{array}{l}\text { VFLW - } \\
\text { WF }\end{array}$ & 0.004 & 0.018 & 55.617 & 0.222 & 0.999 & & nestedness_bray \\
\hline
\end{tabular}

Appendix S3.8: Summary of singleton species by land-use type and origin

\begin{tabular}{|l|l|}
\hline $\begin{array}{l}\text { Tree singletons in old-growth forest ( } \mathrm{n}=69), \\
\text { representing } 26.7 \% \text { out of } 258 \text { old-growth forest tree species, belonging to } 34 \text { families }\end{array}$ \\
\hline $\begin{array}{l}\text { Tree singletons in forest fragments }(\mathrm{n}=52), \\
\text { representing } 22.6 \% \text { out of } 230 \text { forest fragment tree species, belonging to } 35 \text { families }\end{array}$
\end{tabular}

Geographic origin of tree species

- Endemic tree species - Native tree species - Introduced tree species $\quad$ Tree species of unknown origin

Appendix S3.9: List of 15 common tree species across land-use types

(available on OSF: https://osf.io/wv7yu/?view_only=4a23c4db56e64108964cabf6498528ae)

Appendix S3.10: List of 167 singleton tree species across land-use types

(available on OSF: https://osf.io/wv7yu/?view_only=4a23c4db56e64108964cabf6498528ae)

Appendix S3.11: List of 51 dominance candidate tree species across land-use types

(available on OSF: https://osf.io/wv7yu/?view_only=4a23c4db56e64108964cabf6498528ae)

Appendix S3.12: Full species list of all 455 species and families with geographic origin

(available on OSF: https://osf.io/wv7yu/?view_only=4a23c4db56e64108964cabf6498528ae) 
SUPPLEMENTARY INFORMATION FOR CHAPTER 4:

CASE STUDY: SUPPORT TREE DIVERSITY IN VANILLA AGROFORESTS

After acceptance for publication, the underlying tree data will be uploaded to the Open Science Framework (OSF) database.

SUPPLEMENTARY INFORMATION FOR CHAPTER 5:

CASE STUdY: ABOVEgROUND CARBON STOCKS IN MAdAGASCAR'S VANILLA PRODUCTION LANDSCAPE

Appendix S5.1: Correlations between structural and diversity parameters in vanilla agroforestry systems (Spearman). Threshold $\mathrm{r}=0.7$

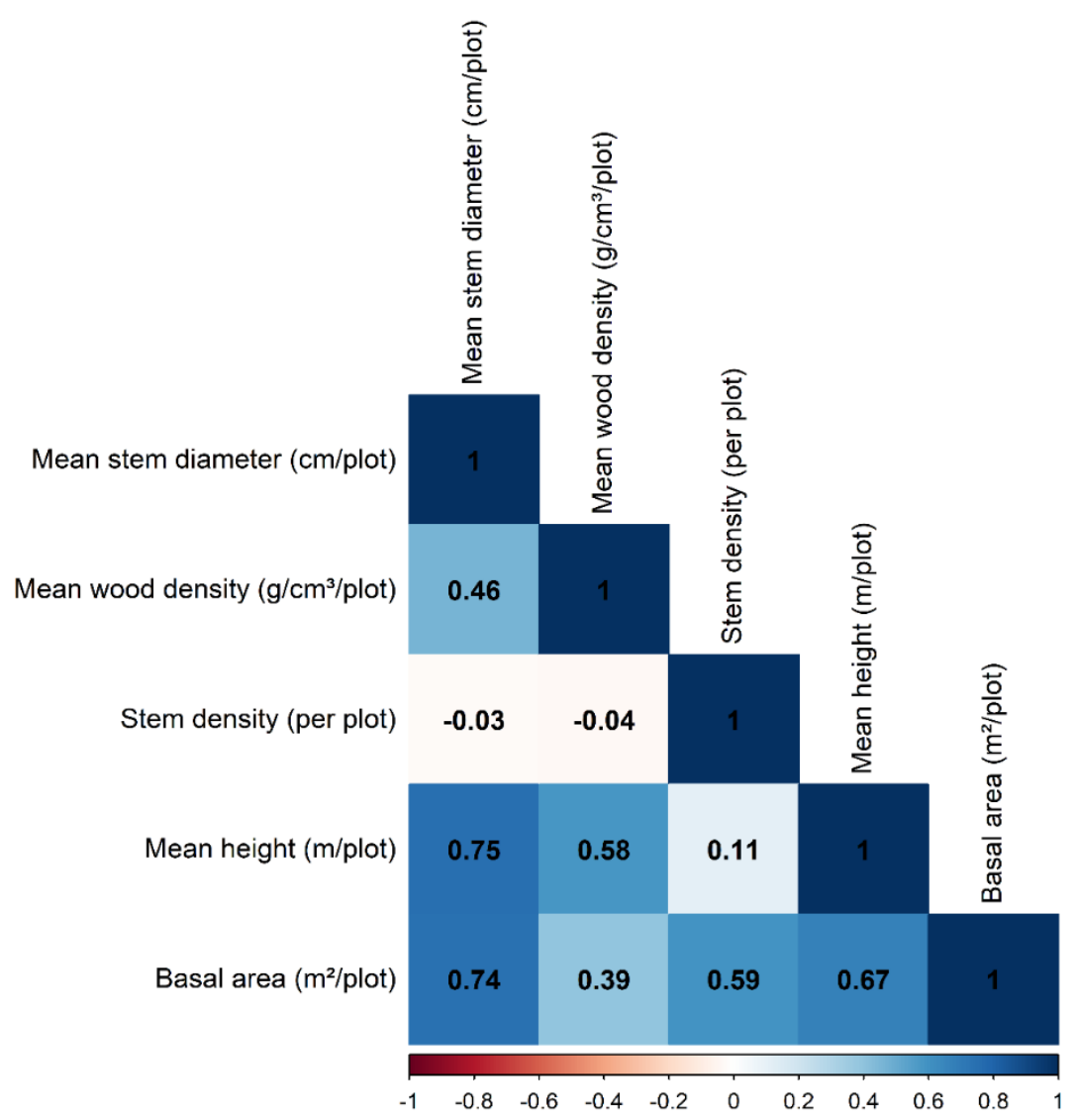


Appendix S5.2: Summary statistics for aboveground carbon stocks (ACS) per land-use type

\begin{tabular}{lllll}
\hline Land-use types & $\begin{array}{l}\text { Median ACS per } \\
\text { hectare }[\mathrm{Mg} / \mathrm{ha}]\end{array}$ & $\begin{array}{l}\text { Mean ACS per } \\
\text { hectare }[\mathrm{Mg} / \mathrm{ha}]\end{array}$ & $\begin{array}{l}\text { Standard } \\
\text { deviation }\end{array}$ & Standard error \\
\hline Old-growth forest & 153 & 178 & 98 & 31 \\
\hline Forest fragment & 54 & 51 & 28 & 9 \\
\hline $\begin{array}{l}\text { Forest-derived } \\
\text { agroforest }\end{array}$ & 50 & 52 & 24 & 8 \\
\hline $\begin{array}{l}\text { Fallow-derived } \\
\text { agroforest }\end{array}$ & 11 & 16 & 15 & 4 \\
\hline Woody fallow & 4 & 5 & 5 & 2
\end{tabular}

Appendix S5.3: Results of one-way ANOVA test and Tukeys's posthoc test on differences in mean aboveground carbon values across land-use types with $95 \%$ family-wise confidence level

\begin{tabular}{|c|c|c|c|c|}
\hline Land-use types & $\begin{array}{l}\text { Mean } \\
\text { differences }\end{array}$ & $\begin{array}{l}\text { Lower limit } \\
\text { (95\% of } \\
\text { confidence } \\
\text { intervalley) }\end{array}$ & $\begin{array}{l}\text { Upper limit } \\
\text { (95\% of } \\
\text { confidence } \\
\text { interval) }\end{array}$ & $\begin{array}{l}\text { Adjusted } \\
\text { p-value }\end{array}$ \\
\hline Forest fragment - Old-growth forest & 1.26726183 & 0.1122703 & 2.42225339 & 0.0248017 \\
\hline Forest-derived vanilla - Old-growth forest & -1.18288587 & -2.3378774 & -0.02789431 & 0.0422254 \\
\hline $\begin{array}{l}\text { Fallow-derived vanilla - Old-growth } \\
\text { forest }\end{array}$ & -2.71812407 & -3.7367309 & -1.69951726 & 0.0000000 \\
\hline Woody fallow - old-growth forest & -3.84632442 & -5.0013160 & -2.69133286 & 0.0000000 \\
\hline Forest-derived vanilla - Forest fragment & 0.08437596 & -1.0706156 & 1.23936752 & 0.9995832 \\
\hline Fallow-derived vanilla - forest fragment & -1.45086225 & -2.4694691 & -0.43225543 & 0.0016597 \\
\hline Woody fallow - Forest fragment & -2.57906259 & -3.7340542 & -1.42407103 & 0.0000006 \\
\hline $\begin{array}{l}\text { Forest-derived vanilla - Fallow-derived } \\
\text { vanilla }\end{array}$ & 1.53523820 & 0.5166314 & 2.55384502 & 0.0007831 \\
\hline Woody fallow - Forest-derived vanilla & -2.66343855 & -3.8184301 & -1.50844699 & 0.0000003 \\
\hline Woody fallow - Fallow-derived vanilla & -1.12820035 & -2.1468072 & -0.10959354 & 0.0229385 \\
\hline
\end{tabular}


Appendix S5.4: Contribution of stem diameter classes of woody species to stem density and aboveground carbon per land-use type. Stem diameter classes (small diameter ranges from $8-20 \mathrm{~cm}$, medium sized-diameter $>20-40 \mathrm{~cm}$, and large trees with DBH $>40 \mathrm{~cm}$ ) were adapted from McNicol et al. (2018).

\begin{tabular}{|c|c|c|c|c|c|c|}
\hline $\begin{array}{l}\text { Proportional contribution } \\
\text { per land-use type }\end{array}$ & $\begin{array}{c}\text { Stem diameter } \\
\text { category }\end{array}$ & $\begin{array}{l}\text { Old-growth } \\
\text { forest }\end{array}$ & $\begin{array}{c}\text { Forest } \\
\text { fragment }\end{array}$ & $\begin{array}{c}\text { Forest-derived } \\
\text { agroforest }\end{array}$ & $\begin{array}{l}\text { Fallow-derived } \\
\text { agroforest }\end{array}$ & $\begin{array}{l}\text { Woody } \\
\text { fallow }\end{array}$ \\
\hline & Small & 74 & 74 & 59 & 83 & 91 \\
\hline \multirow[t]{3}{*}{ Stems (\%) } & Medium & 21 & 24 & 36 & 13 & 8 \\
\hline & Large & 5 & 2 & 5 & 3 & 1 \\
\hline & Small & 15 & 27 & 16 & 24 & 46 \\
\hline \multirow[t]{2}{*}{ Aboveground carbon (\%) } & Medium & 25 & 52 & 55 & 35 & 23 \\
\hline & Large & 61 & 21 & 30 & 42 & 31 \\
\hline
\end{tabular}

\section{References}

McNicol, I.M., Ryan, C.M., Dexter, K.G., Ball, S.M.J. \& Williams, M. (2018) Aboveground carbon storage and its links to stand structure, tree diversity and floristic composition in south-eastern Tanzania. Ecosystems, 21(4), 740-754. https://doi.org/10.1007/s10021-017-0180-6. 
Appendix S5.5: Contribution of geographic origin of woody species to stem density and aboveground carbon per land-use type. Information on origin and endemism for each stem was derived from the Catalogue of the plants of Madagascar

(https://www.tropicos.org/Project/Madagascar; accessed in January 2020) (see Osen et al (2021) for further details)

\begin{tabular}{|c|c|c|c|c|c|c|}
\hline $\begin{array}{l}\text { Proportional contribution } \\
\text { per land-use type }\end{array}$ & $\begin{array}{c}\text { Geographic origin } \\
\text { category }\end{array}$ & $\begin{array}{l}\text { Old-growth } \\
\text { forest }\end{array}$ & $\begin{array}{c}\text { Forest } \\
\text { fragment }\end{array}$ & $\begin{array}{c}\text { Forest-derived } \\
\text { agroforest }\end{array}$ & $\begin{array}{l}\text { Fallow-derived } \\
\text { agroforest }\end{array}$ & $\begin{array}{l}\text { Woody } \\
\text { fallow }\end{array}$ \\
\hline & Endemic & 68 & 68 & 50 & 10 & 31 \\
\hline \multirow{2}{*}{\multicolumn{7}{|c|}{ Stems (\%) }} \\
\hline & & & & & & \\
\hline & Introduced & 2 & 1 & 13 & 63 & 29 \\
\hline & Unknown & 0 & 2 & 4 & 6 & 9 \\
\hline & Endemic & 81 & 70 & 53 & 20 & 22 \\
\hline & Native & 18 & 26 & 41 & 14 & 53 \\
\hline \multicolumn{7}{|l|}{ Aboveground carbon (\%) } \\
\hline & Introduced & 1 & 2 & 5 & 56 & 19 \\
\hline & Unknown & 0 & 3 & 2 & 11 & 6 \\
\hline
\end{tabular}

\section{References}

Osen, K., Soazafy, M.R., Martin, D.A., Wurz, A., März, A., Ranarijaona, H.L.T. \& Hölscher, D. (2021) Land-use history determines stand structure and tree diversity in vanilla agroforests of northeastern Madagascar. Applied Vegetation Science, 24. https://doi.org/10.1111/avsc.12563. 
Appendix S5.6: Effects of mean diameter at breast height, mean stem density, mean wood density and vanilla agroforest on aboveground carbon in vanilla agroforestry systems. The interpretation of the model output was facilitated by the R-package report (Makowski et al., 2020)

\begin{tabular}{|c|c|c|c|}
\hline Predictors & Estimates & $\mathrm{Cl}$ & $p$ \\
\hline (Intercept) & 0.04 & $0.04-0.05$ & $<0.001$ \\
\hline $\begin{array}{l}\text { Mean diameter at breast } \\
\text { height }\end{array}$ & 0.01 & $0.01-0.02$ & $<0.001$ \\
\hline $\begin{array}{l}\text { Land-use history } \\
\text { (fallow-derived vs } \\
\text { forest-derived agroforest) }\end{array}$ & 0.00 & $-0.01-0.01$ & 0.875 \\
\hline Mean stem density & 0.01 & $-0.01-0.01$ & $<0.001$ \\
\hline Mean wood density & 0.00 & $-0.00-0.01$ & 0.431 \\
\hline $\begin{array}{l}\text { Mean diameter at breast } \\
\text { height * land-use history }\end{array}$ & 0.01 & $-0.00-0.02$ & 0.065 \\
\hline $\begin{array}{l}\text { land-use history * mean stem } \\
\text { density }\end{array}$ & 0.01 & $-0.00-0.02$ & 0.063 \\
\hline $\begin{array}{l}\text { Land-use history * mean wood } \\
\text { density }\end{array}$ & -0.00 & $-0.01-0.00$ & 0.191 \\
\hline
\end{tabular}

\begin{tabular}{ll} 
Random Effects & \\
$\sigma^{2}$ & 0.00 \\
$\tau_{00 \text { village }}$ & 0.00 \\
$\mathrm{~N}_{\text {village }}$ & 10 \\
\hline Observations & 28 \\
Marginal $R^{2}$ & 0.906
\end{tabular}

\section{References}

Makowski, D., Ben-Shachar, M.S., Patil, I. \& Lüdecke, D. (2020). Automated reporting as a practical tool to improve reproducibility and methodological best practices adoption. CRAN. https://github.com/easystats/report. 
Appendix S5.7: Wood density calculation of all woody species encountered in this study. It comprises 2 tables: table G1 reports the wood density of all woody species identified until genus and species level, and table G2 which shows the wood density of tree species without pilodyn measures; complemented with database-derived values

(available on OSF: https://osf.io/8vbja/?view_only=60ea04b490f24b8f9d12425595dbd829)

Appendix S5.8: Data on plot characteristics of 58 study plots with plot coordinates and environmental characteristics

(available on OSF: https://osf.io/8vbja/?view_only=60ea04b490f24b8f9d12425595dbd829)

Appendix S5.9: R script for data analysis

(available on OSF: https://osf.io/8vbja/?view_only=60ea04b490f24b8f9d12425595dbd829) 


\section{List of publications}

Osen, K., Soazafy, M. R., Martin, D. A., Wurz, A., März, A., Ranarijaona, H. L. T., \& Hölscher, D. (2021). Land-use history determines stand structure and tree diversity in vanilla agroforests of northeastern Madagascar. Applied Vegetation Science, 24(1). https://doi.org/10.1111/avsc.12563

Fulgence, T. R., Martin, D. A., Randriamanantena, R., Botra, R., Befidimanana, E., Osen, K., Wurz, A., Kreft, H., Andrianarimisa, A., \& Ratsoavina, F. M. (2021). Differential responses of amphibians and reptiles to land-use change in the biodiversity hotspot of north-eastern Madagascar. Animal Conservation, acv.12760. https://doi.org/10.1111/acv.12760

Dröge, S., Martin, D. A., Andriafanomezantsoa, R., Burivalova, Z., Fulgence, T. R., Osen, K., Rakotomalala, E., Schwab, D., Wurz, A., Richter, T., \& Kreft, H. (2021). Listening to a changing landscape: Acoustic indices reflect bird species richness and plot-scale vegetation structure across different land-use types in north-eastern Madagascar. Ecological Indicators, 120, 106929. https://doi.org/10.1016/j.ecolind.2020.106929

Martin, D. A., Osen, K., Grass, I., Hölscher, D., Tscharntke, T., Wurz, A., \& Kreft, H. (2020). Land-use history determines ecosystem services and conservation value in tropical agroforestry. Conservation Letters, 13(5). https://doi.org/10.1111/conl.12740

Martin, D. A., Wurz, A., Osen, K., Grass, I., Hölscher, D., Rabemanantsoa, T., Tscharntke, T., \& Kreft, H. (2021). Shade-Tree Rehabilitation in Vanilla Agroforests is Yield Neutral and May Translate into Landscape-Scale Canopy Cover Gains. Ecosystems, 24, 1253-1267. https://doi.org/10.1007/s10021-020-00586-5 
Martin, D. A., Andriafanomezantsoa, R., Dröge, S., Osen, K., Rakotomalala, E., Wurz, A., Andrianarimisa, A., \& Kreft, H. (2021). Bird diversity and endemism along a land-use gradient in Madagascar: The conservation value of vanilla agroforests. Biotropica, 53(1), 179-190.

https://doi.org/10.1111/btp.12859

Rakotomalala, A. A. N. A., Wurz, A., Grass, I., Martin, D. A., Osen, K., Schwab, D., Soazafy, M. R., Tscharntke, T., \& Raveloson Ravaomanarivo, L. H. (2021). Tropical land use drives endemic versus exotic ant communities in a global biodiversity hotspot. Biodiversity and Conservation, 30(14), 4417-4434. https://doi.org/10.1007/s10531-021-02314-4

Raveloaritiana, E., Wurz, A., Grass, I., Osen, K., Soazafy, M. R., Martin, D. A., Faliniaina, L., Rakotomalala, N. H., Vorontsova, M. S., Tscharntke, T., \& Rakouth, B. (2021). Land-use intensification increases richness of native and exotic herbaceous plants, but not endemics, in Malagasy vanilla landscapes. Diversity and Distributions, 27(5), 784-798. https://doi.org/10.1111/ddi.13226

Schwab, D., Wurz, A., Grass, I., Rakotomalala, A. A. N. A., Osen, K., Soazafy, M. R., Martin, D. A., \& Tscharntke, T. (2021). Decreasing predation rates and shifting predator compositions along a land-use gradient in Madagascar's vanilla landscapes. Journal of Applied Ecology, 58(2), 360371. https://doi.org/10.1111/1365-2664.13766

Soazafy, M. R.\& Osen, K., Wurz, A., Raveloaritiana, E., Martin, D. A., Ranarijaona, H. L. T., \& Hölscher, D. (2021). Aboveground carbon stocks in Madagascar's vanilla production landscape - exploring rehabilitation through agroforestry in the light of land-use history. Global Ecology and Conservation, 31, e01853. https://doi.org/10.1016/j.gecco.2021.e01853

Hänke, H., Barkmann, J., Blum, L., Franke, Y., Martin, D., Niens, J., Osen, K., Uruena, V., Whiterspoon, S. A., \& Wurz, A. (2018). Socio-economic, land use and value chain perspectives on vanilla farming in the SAVA Region (north-eastern Madagascar): The Diversity Turn Baseline Study (DTBS). July 2019 Edition. Discussion Paper, 1806. https://doi.org/10.13140/RG.2.2.22059.80163. 


\section{Publications currently still in review/in preparation}

Osen, K., Soazafy, M. R., Martin, D. A., Wurz, A., Antilahimena, P., Ranarijaona, H. L. T., \& Hölscher, D. (in preparation). High species turnover in tree communities in the mosaic landscape of northeastern Madagascar.

Osewold, J., Korol, Y., Osen, K., Soazafy, M. R., Rabemanantsoa, T., Martin, D. A., Wurz, A., \& Hölscher, D. (submitted). Support trees in vanilla agroforests of Madagascar: Diversity, composition and origin.

Raveloaritiana, E., Wurz, A., Osen, K., Soazafy, M. R., Grass, I., Martin, D. A., Bemamy, C., Ranarijaona, H. L. T., Borgerson, C., Kreft, H., Hölscher, D., Rakouth, B., \& Tscharntke, T. (submitted). Fallow lands provide multiple ecosystem services to rural households in Madagascar.

Martin, D. A., Andrianisaina, F., Fulgence, T. R., Osen, K., Rakotomalala, A. A. N. A., Raveloaritiana, E., Soazafy, M. R., Wurz, A., Andriafanomezantsoa, R., Andriamaniraka, H., Barkmann, J., Dröge, S., Grass, I., Guerrero-Ramírez, N. R., Hänke, H., Hölscher, D., Rakouth, B., Ranarijaona, H. L. T., Randriamanantena, R., ... Kreft, H. (submitted). Identifying leverage points for a sustainable land-use transformation in a global biodiversity hotspot.

Wurz, A., Grass, I., Lees, D., Rakotomalala, A. A. N. A., Sáfián, S., Martin, D. A., Osen, K., Loos, J., Benasoavina, E., Alexis, T., \& Tscharntke, T. (submitted). Land-use change differentially affects endemic, forest and open-land butterflies in Madagascar.

Wurz, A., Tscharntke, T., Martin, D. A., Osen, K., Raveloaritiana, E., Andriafanomezantsoa, R., Andrianisaina, F., Fulgence, T. R., Dröge, S., Rakotomalala, A. A. N. A., Randriamanantena, R., Soazafy, M. R., Andrianarimisa, A., Soavita Babarezoto, F., Barkmann, J., Hänke, H., Hölscher, D., Kreft, H., Rakouth, B., ... Grass, I. (submitted). High crop yields without biodiversity loss in tropical agroforestry. 


\section{Science outreach/Scientific communication}

- Outreach events in Madagascar:

- Stakeholder conferences 2016, 2018, 2019 in Sambava, Madagascar (oral presentation and poster presentation)

- Presentations and workshops for university students in Madagascar

- Scientific conferences (selection):

- Annual conference of the Association for Tropical Ecology and Conservation (ATBC) 2013 in San José, Costa Rica (poster presentation) and 2019 in Antananarivo, Madagascar (poster presentation)

- Student Conference on Conservation Science 2019 in Cambridge, UK (poster presentation)

- Annual conference of the Society for Tropical Ecology (GTÖ): 2017 in Brussels, Belgium (poster presentation) and 2020 in Leipzig, Germany (oral presentation; cancelled short notice due to Covid-19 regulations)

- Planning and organization of a 2-day research symposium in Göttingen on the topic "Tropical agricultural landscapes as an opportunity for nature conservation?" (cancelled short notice due to Covid-19 regulations)

- Public outreach events in Göttingen:

○ Science goes city (poster presentation); Night of Science (poster presentation); Sustainability conference (oral presentation) 


\section{Declaration of Honor}

I hereby declare that I am the sole author of this dissertation entitled Diversity and composition of tree communities in the mosaic landscape of north-eastern Madagascar to attain the doctoral degree "Dr. rer. nat." of the Faculty of Forest Sciences and Forest Ecology at Georg-August-Universität Göttingen within the doctoral program "Diversity Turn in Land Use Science". I further declare that all contributions, references and data sources have been acknowledged as such. Furthermore, this dissertation has not been submitted in any form as part of any other dissertation procedure elsewhere.

Göttingen, (Kristina Osen) 